


\section{Нawa 3ameyatenbhag Россня}

\section{«Город с прекрасной гаванью под названием Нимфей»}
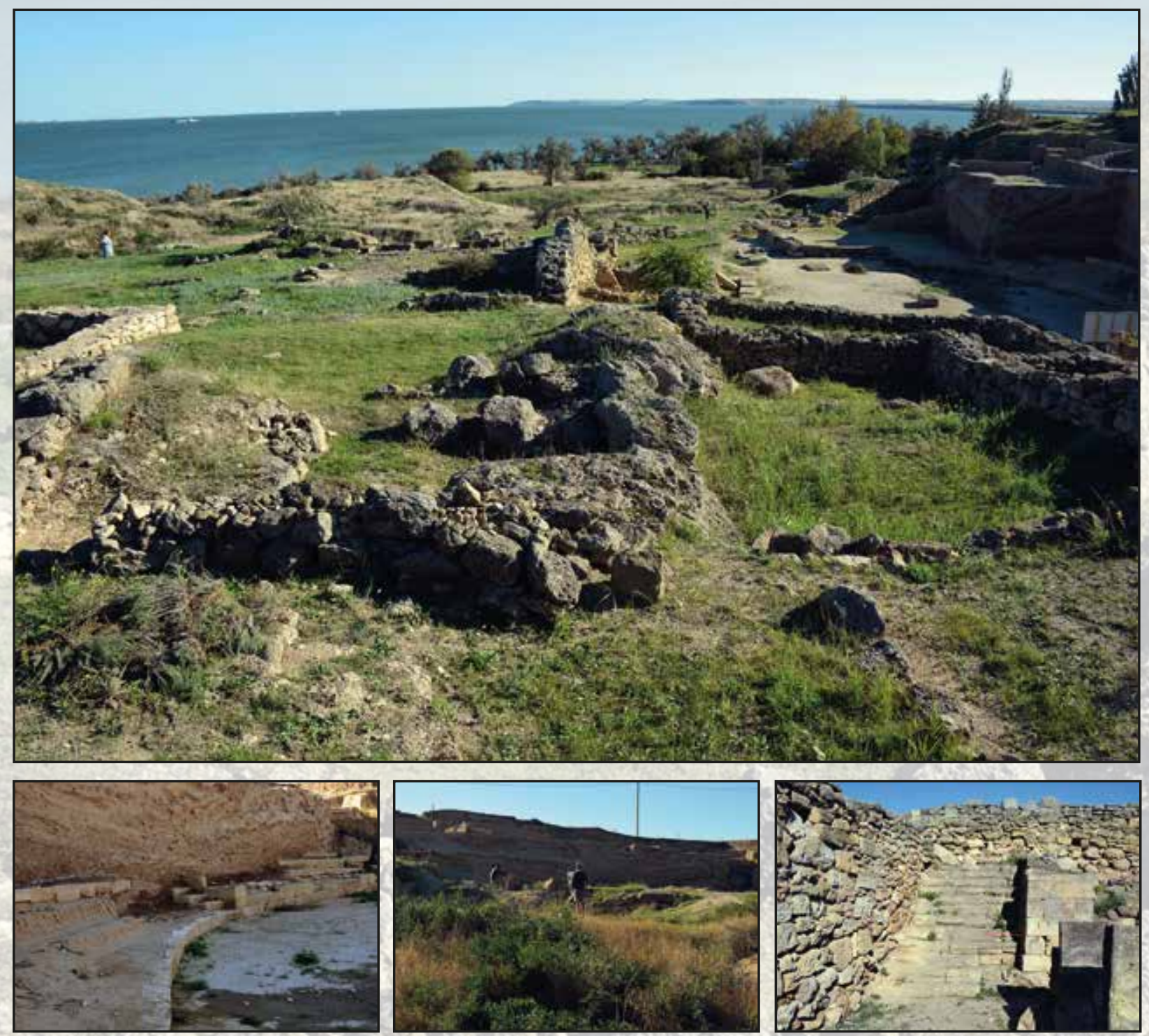

Так описал античный историк и географ Римской Греции Страбон (ок. 64/63 гг. до н.э. - ок. 23/24 г. н.э.) богатый город Нимфей (Храм нимф). Город располагался в 17 км к югу от Пантикапея - современной Керчи. Его современное городище занимает плато на берегу Керченского пролива (в древности Боспора Киммерийского), к западу от которого расположены курганы и грунтовой некрополь. Нимфей основан в 570-560-х гг. до н.э. греческими колонистами из Милета. Население занималось земледелием, особо почитало богиню плодородия Деметру. После завоеваний Александра Македонского Боспорское царство теряет позицию одного из основных поставщиков зерна в Афины из-за поступления туда более дешевого египетского хлеба, в результате происходит переориентация хозяйства боспорских городов на виноделие. За всю свою почти 800 летнюю историю город неоднократно разрушался в ходе ведущихся в Причерноморье войн, но восстанавливался и процветал. После разрушения готами в III в н.э. люди ушли из него, песок и глина скрыли Нимфей от человеческих глаз. И лишь из трудов Страбона, Плиния и Птолемея можно было узнать о его ушедших в вечность богатстве и славе.

На верхней фотографии городище Нимфей. На левой фотографии нижнего ряда - зрительная зона театра, типичная для V- IV вв. до н.э.: круглая арена, к которой примыкали расположенные полукругом зрительские места. Театр полностью еще не раскопан. Фотография в центре - здесь часто можно увидеть художников. Фотография справа - лестница к храму Деметры. Ей более 2400 лет. Обратите внимание на правильность форм плит и их подгонку. 


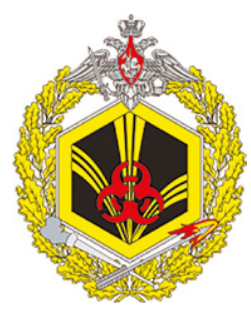

Журнал издается с 2017 года

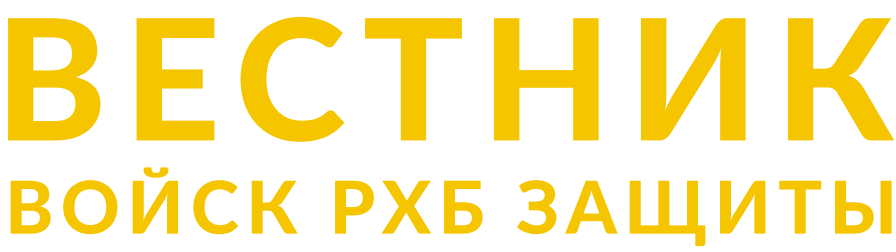

Рецензируемый научно-практический журнал, специализирующийся на освещении химических и биологических угроз Российской Федерации, научных достижений по основным направлениям деятельности и задачам войск РХБ защиты ВС РФ, повышении профессионального уровня специалистов войск РХБ защиты ВС РФ, возрождении интереса к их истории и привлечении молодых ученых к работе в научно-исследовательских организациях войск РХБ защиты ВС РФ
Учредитель и издатель

Федеральное государственное бюджетное

учреждение

"27 Научный центр"

Министерства обороны

Российской Федерации

(27 НЦ МО РФ)

Выходит ежеквартально

Главный редактор

д-р техн. наук, доц. Петров С.В. (Москва)

Заместители главного редактора

канд. биол. наук, снс Супотницкий М.В. (Москва)

канд. техн. наук, доц. Колесников Д.П. (Москва)

\section{Ответственный секретарь}

Шило Н.И. (Москва)

Научный редактор

канд. биол. наук Лебединская Е.В. (Москва)

Редакционная коллегия

член-корреспондент РАН, д-р биол. наук, проф. Аминин Д.Л. (Владивосток)

Аминин Д.Л. (Владивосток)

д-р биол. наук, проф. Ефременко Е.Н. (Москва)

д-р биол. наук, проф. Завьялова Н.В. (Москва)

д-р техн. наук, проф. Мухин В.М.

(Электросталь)

д-р мед. наук, проф. Рембовский В.Р.

(Санкт-Петербург)

д-р хим. наук Родин И.А. (Москва)

д-р хим. наук, проф. Рыбальченко И.В. (Москва)

д-р хим. наук Савельева Е.И. (Санкт-Петербург)

Редакционный совет

Председатель -

канд. воен. наук Кириллов И.А. (Москва)

Заместители председателя: канд. экон. наук Кикоть С.Г. (Москва) канд. хим. наук, доц. Ковтун В.А. (Москва)

Члены редакционного совета:

д-р воен. наук Иноземцев В.А. (Вольск)

д-р техн. наук, проф. Кондратьев В.Б. (Москва)

канд. мед. наук Туманов А.С. (Киров)

д-р хим. наук, проф. Холстов В.И. (Москва)

Дизайн, верстка: Сластилова Л.М. (Москва)

\section{Адрес редакции:}

27 НЦ МО РФ, 105005, г. Москва,

Бригадирский пер., д. 13.

Тел.: 8 (499) 265-42-90, e-mail: 27nc@mil.ru.

Издание зарегистрировано Федеральной

службой по надзору в сфере связи,

информационных технологий и массовых

коммуникаций (Роскомнадзор).

Свидетельство о регистрации средства

массовой информации

ПИ № ФС 77-69472 от 25.04.2017 г.

Все права защищены. При перепечатке

материалов и размещении их на

интернет-ресурсах ссылка на журнал обязательна.

Подписано в печать: 24.06.2021 г. Тираж 500 экз. Отпечатано в типографии:

ФГУП «ЦНИИХМ им. Д.И. Менделеева»,

115487, г. Москва, ул. Нагатинская, д. 16 А.

Тел.: 8 (499) 661-80-46, e-mail: ntrved@cniihm.ru

\section{СОДЕРЖАНИЕ}

Биологическая безопасность и защита от биологических угроз Синтетическая биология - друг или враг? Каких угроз нам следует ожидать?

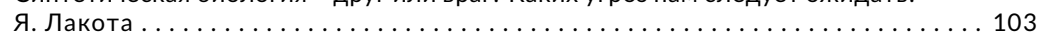

Химическое и биологическое оружие в войнах и конфликтах

Химическое оружие в ирано-иракской войне 1980-1988 годов.

5. Накопленный опыт лечения поражений сернистым ипритом М.В. Супотницкий ...........................

\section{Повседневная деятельность войск РХБ защиты}

О ходе выполнения первоочередных мероприятий по устранению накопленного вреда окружающей среде от деятельности химических предприятий на территории г. Усолье-Сибирское Иркутской области

С.А. Мальцев, Е.В. Вебер, В.А. Иноземцев, М.В. Цапок, П.Е. Беляков,

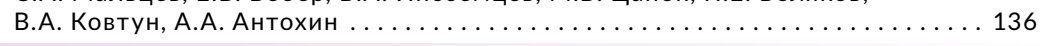

Лекции по ключевым вопросам РХБ безопасности

История развития и применения робототехники при ликвидации последствий аварий на радиационно опасных объектах (лекция)

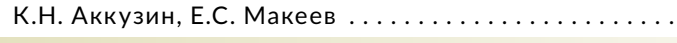

\section{Общие вопросы РХБ защиты войск и населения}

Использование модульности как принципа построения материалов на основе металлорганических каркасных структур с заданными свойствами для создания современных средств защиты

В.В. Завьялов, Н.В. Завьялова, В.И. Холстов, В.А. Ковтун, В.К. Гореленков,

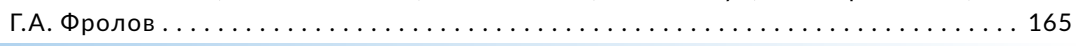

\section{Исторический архив}

Разработка и испытания на людях боевых отравляющих веществ и средств лечения поражений в Германии в 1933-1945 годах

Н.И. Шило . . . . . . . . . . . . . . . . . . . . . . . . . . . . 173

Хроника

Анатолий Васильевич Шатохин (к 70-летию со дня рождения) . . . . . . . . . 199

Все рукописи проверяются программой «Антиплагиат

Журнал включен в научную электронную библиотеку еLIBRARU.RU и Российский индекс научного иитирования (РИНЦ) Журнал включенвнаучнуюэлектронную библиотеку еLRRARU.RU Российский индекснаучного цитирования (РИНЦ). Условия оферты для авторов приведены в п. 11 Правил направления и опубликования нау)
журнале "Вестнник войск РХБ защиты» (Вестник войск РХБ защиты. 2020. № 1. С. 89-97). К публикации принимаются статьи на русском и английском языках, подготовленные в соответствии с Правилами направления и опубликования научных статей в журнале «Вестник войск РХБ защиты». Статьи проходят рецензирование не менее чем двумя рецензентами. Используются модели двойного слепого рецензирования либо открытого рецензирования (по выбору авторов). Плата за публикацию статьи и рецензирование рукописей не взимается, ускоренная публикация не допускается. Труды заочных конференций не публикуются.

Журнал распространяется в органах законодательной и исполнительной власти Российской Федерации, в центральных органах военного управления, в научно-исследовательских организациях и образовательных учреждениях Министерства обороны Российской Федерации, в организациях и на предприятиях учреждениях Министерства обороны Российской Федерации, в организациях и на предприятиях промышленности, работающих в сфере РХБ защиты, а также поступает в Российскую государственную
библиотеку, Российскую национальную библиотеку и другие крупнейшие библиотеки Российской Федерации. Позиция редакции может не совпадать с точкой зрения авторов. 


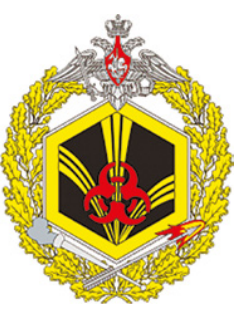

Published since 2017

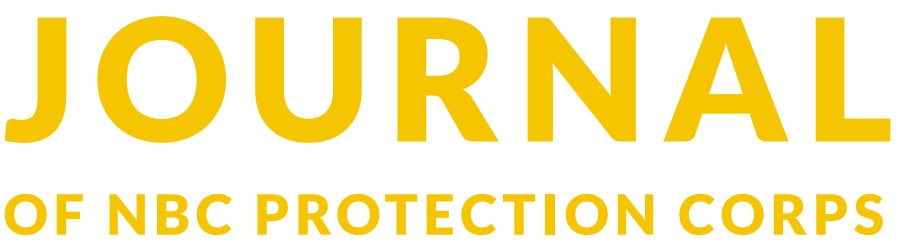

"Journal of NBC Protection Corps» is a peer-reviewed scientific and practical journal, publishing papers in the fields of chemical and biological threats to the Russian Federation. It covers scientific achievements in the main spheres and tasks of the NBC Protection Troops. The objective of the journal is to improve the professional level of specialists of the NBC Protection Troops, to revive the interest in their history and to attract young scientists to the work in scientific research organization of the NBC Protection Troops
Founder and Publisher

Federal State Budgetary Establishment "27 Scientific Centre" of the Ministry of Defence
of the Russian Federation.

Quarterly Edition

Editor-in-Chief
Doctor of Technical Sciences, Associate Professor Doctor of Technical Scienc
Petrov S.V. (Moscow)

Deputy Editors-in-Chief

Candidate of Biological Sciences, Senior Researcher Supotnitskiy M.V. (Moscow)

(Mssociate Professor Kolesnikov D.P. (Moscow)

Executive Secretary

Science Editor

Candidate of Biological Sciences, Senior Researcher Lebedinskaya E.V. (Moscow)

Editorial Board

Corresponding Member of RAS, Doctor of Biological Sciences, Professor Aminin D.L. (Vladivostok)

Doctor of Medical Sciences, Professor

Doctor of Biological Sciences, Professor

Efremenko E.N. (Moscow)

Doctor of Biological Sciences, Professor

Zavyalova N.V. (Moscow)

M. (Elektrostal)

Doctor of Medical Sciences, Professor

Rembovskiy V.R. (St.-Petersburg)

Doctor of Chemical Sciences, Professor

Rybalchenko I.V. (Moscow)

Davelieva E.I. (St.-Petersburg)

Editorial Council

Chairman

Military Sciences Kirillov I.A. (Moscow)

Vice-Chairmen:

Candidate of Economical Sciences Kikot S.G. (Moscow)

Candidate of Chemical Sciences, Associate Professor Kovtun V.A. (Moscow)

Editorial Council Members:

Doctor of Military Sciences

Inozemcev V.A. (Volsk)

Doctor of Technical Sciences, Professo

(Moscow)

(Kirov)

Doctor of Chemical Sciences, Professor

Kholstov V.I. (Moscow)

CRC preparation: Slastilova L.M. (Moscow)

Address of the Editorial Office

Federal State Budgetary Establishment

"27 Scientific Centre» of the Ministry of Defence

of the Russian Federation. Brigadirskii Lane 13,

Moscow 105005, Russian Federation.

el.: 8 (499) 265-42-90, e-mail: 27nc@mil.ru.

Publication is registered by the Federal

Service for Supervision in the Sphere of

Communications.

Certification of the Mass Media

ПИ № ФС 77-69472, April 25, 2017 .

All rights reserved. Links to the journal are

obligatory while citing.

The publication data for the journal is

24 June, 2021.

Circulation: 500 copies.

Published in: Federal State Unitary Establishment "TsNIIKhM» named after D.I. Mendeleev»,

Nagatinskaya Str. 16A, Moscow 115487, Russian Federation Tel.: 8 (499) 661-80-46,

e-mail:ntrved@cniihm.ru

\section{Contents}

Biological Security and Protection against Biological Threats Synthetic Biology - Friend or Foe? What Kind of Threats Should We Expect?

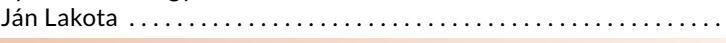

\section{Chemical and Biological Weapons in Wars and Conflicts}

Chemical Weapons in the Iran-Iraq War (1980-1988).

5. Accumulated Experience in the Treatment of Lesions Caused by Sulfur Mustard M.V. Supotnitskiy

\section{NBC Protection Troops Everyday Life}

Implementation of Priority Measures to Eliminate the Accumulated Environmenta Damage Caused by Chemical Enterprises in the City of Usolye-Sibirskoye, Irkutsk Region

S.A. Maltsev, Ye.V. Veber, V.A. Inosemtsev, M.V. Tsapok, P.Ye. Belyakov,

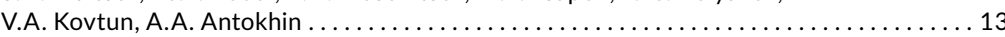

Key Issues of NBC Security. Lectures

The History of the Development and Application of Robotics in the Elimination of

Consequences at Radiation-Hazardous Facilities K.N. Akkuzin, E.S Makeev.

General Issues of NBC Protection of Troops and Civilians

Use of Modularity as a Principle of Design of Metal-organic Framework-based Materials with Specified Properties for Creating Modern Protective Equipment

V.V. Zavyalov, N.V. Zavyalova, V.I. Kholstov, V.K. Gorelenkov, G.A. Frolov

Historical Archive

Development and Human Testing of Chemical Warfare Agents and Means of

Treatment of Lesions in Germany in 1933-1945

N.I. Shilo.

Cronicle

Anatoly Vasilyevich Shatokhin (70th Birth Anniversary).

All the manuscripts are checked by the Antiplagiat program.

The journal is included into the scientific electronic library eLIBRARY.RU and the Russian Science Citation Index. Terms of the offer for the authors are given in the Article 11 of the Rules for the authors (Journal of NBC Protections Corps. 2020. V. 4. No 1. P. 89-97).

Only articles prepared in Russian and English languages and in accordance with the Rules for the Authors of Sending and Publishing of the Articles in the "Journal of NBC Protection Corps", are acceptable for the publication. All research articles are peer reviewed by at least two suitably qualified experts. Double-blind peer review and open peer review are both available by the authors' choice. The journal does not charge article-processing, publication and peer review fees. Accelerated publication is not allowed. The papers from correspondence conferences are not published. The journal is distributed among the bodies of legislative and executive power of the Russian Federation, in the main military headquarters, scientific and research institutions and educational establishments of the Ministry of Defence of the Russian Federation, in engineering, experimental design offices and industrial and manufacturing structures, working in the sphere of NBC Defence. The journal is distributed also among the main manufacturing structures, working in the sphere of NBC Defence. The journal is distributed also
libraries of the Russian Federation, including Russian State Library and Russian National Library

The information and views set out in this publication are those of the author(s) and do not necessarily reflect the official opinion of the Editorial Board. 


\title{
Synthetic Biology - Friend or Foe? What Kind of Threats Should We Expect?
}

\section{Ján Lakota \\ Centre of Experimental Medicine, SAS, Dubravská cesta 9, 84104 Bratislava, Slovakia Faculty of Management Comenius University, Odbojárov 10, 82005 Bratislava, Slovakia}

\begin{abstract}
Received 10 February 2021. Accepted for publication 20 June 2021.
Synthetic biology is a newly emerging branch of dual-use technology. It is a combination of biology and different branches of engineering. The aim of this article is to show the main technological methods of synthetic biology and to give specific examples of its use to create new types of biological agents and methods of biological warfare, previously unthinkable and presented only in science fiction. Basic tools and techniques of synthetic biology are: DNA synthesis and DNA sequencing; «chassis», i.e. host system harboring the genetic toolbox for expression of the desired genes, delivered by suitable vectors, of the engineered biological pathway; engineering of transcription systems that do not deplete the resources of the cell (synthetic promotors and transcription factors); genome modification tools (CRISPR/Cas9 nuclease, zinc finger nucleases, TALE nucleases, meganucleases); computer-aided tools (involved in basic structural design and synthesis; in network design; in prediction of behavior/function/response). Synthetic biology has already demonstrared its capabilities in re-creating known pathogenic viruses and pathogenic bacteria; in making existing pathogenic bacteria and viruses more dangerous for humans; in creating new pathogens; in manufacturing toxic chemicals or biochemicals by exploiting natural and artificial metabolic pathways; in making toxic chemicals and biochemicals via in situ synthesis; in modifying the human microbiome; in modifying the human immune system; in modifying the human genome (through addition, deletion, or modification of genes or through epigenetic changes that modify gene expression and can pass from parent to child during reproduction and thus spread a genetic change through the population over time). The article discusses in detail the possibilities of synthetic biology for the development of new means of biological warfare. The author believes that it is necessary not only to constantly monitor these new dual-use biotechnologies, but also to improve traditional and scientific methods of their monitoring.
\end{abstract}

Keywords: synthetic biology; threat; pathogen; bacteria; virus; human.

For citation: Lakota Ján. Synthetic Biology - Friend or Foe? What Kind of Threats Should We Expect? // Journal of NBC Protection Corps. 2021. V. 5. № 2. P. 103-122. https://doi.org/10.35825/2587-5728-2021-52-103-122

Synthetic biology is a combination of biology and different branches of engineering, such as electrical, mathematical, mechanical, and computer science. It provides a greater ability of understanding and manipulation of the biological systems or creation of novel life forms [1]. Synthetic biology intends to (re)construct novel artificial biological systems, which can maintain the integrative complexity of central dogma of molecular biology $y^{1}$ in a rational and translational manner for the efficient production of desired biomolecules beneficial to the society. Synthetic biology as a scientific direction is based on certain mechanistic ideas about the nature of living organisms. According to these ideas, living organisms can be assembled from blocks of nucleotide sequences encoding certain functions, just like toys are assembled from LEGO bricks. The foundation of synthetic biology was

\footnotetext{
$\overline{1}$ Central dogma of molecular biology. URL: https://en.wikipedia.org/wiki/Central_dogma_of_molecular_biology (date: 20.01.2021).
} 


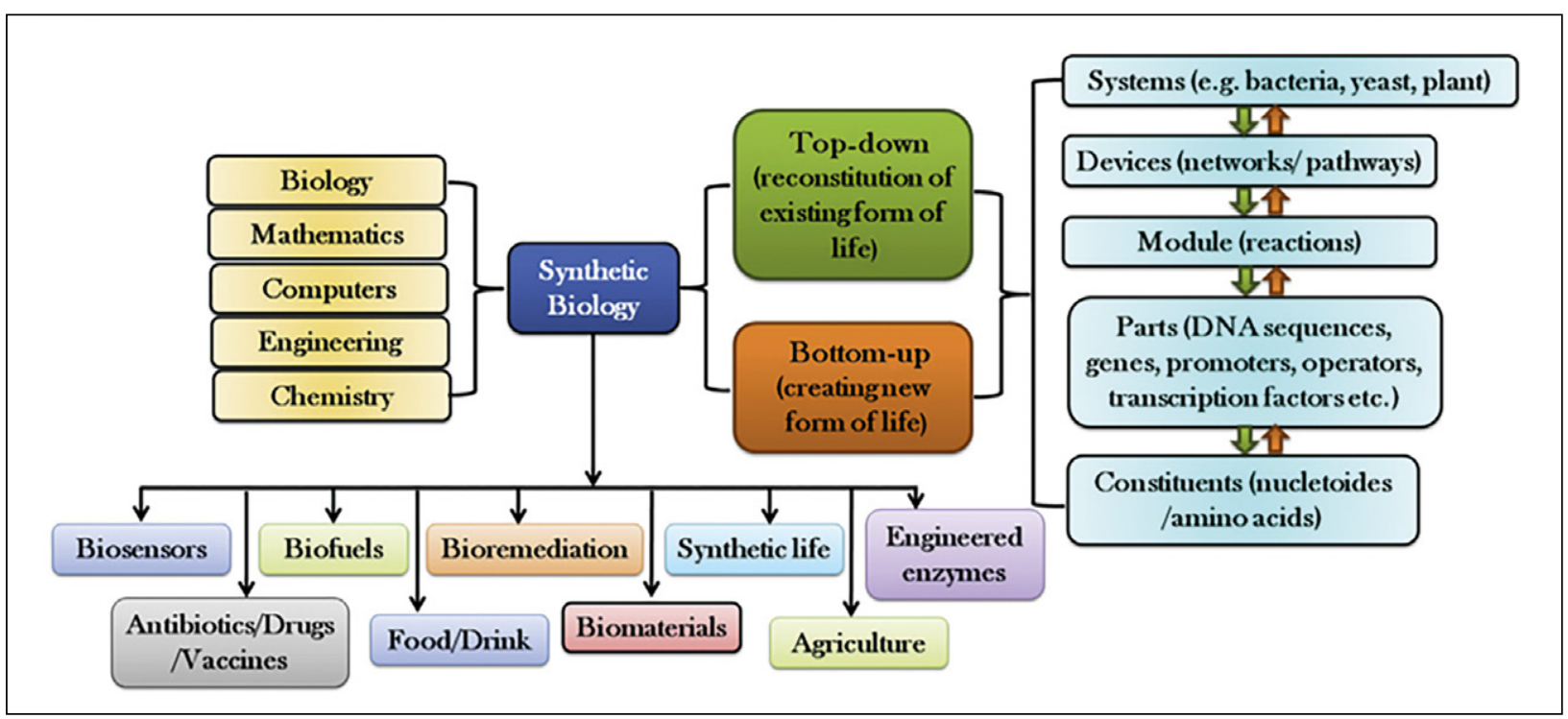

Figure 1 - An overview of synthetic biology showing the combination of different associated fields (copied from [2])

laid by medieval works, dedicated to the attempts to create the homunculus, by Van Helmont's $(1580-1644)^{2}$ recipe for spontaneous generation of mice from dirty laundry, by the O.B. Lepeshinskaya's (1871-1963) theory of «living matter» and by other teachings about the «spontaneous generation of the living» ${ }^{3}$. Attempts to mechanize («synthetize») life ended always with a fiasco and up to date did more harm than good. The aim of this article is to show the main technological methods of synthetic biology and to give specific examples of its use to create new types of biological agents and methods of biological warfare, previously unthinkable and presented only in science fiction.

According to S.P. Singh et al. [2], synthetic biology integrates «the expertise from interdisciplinary fields, synthetic biology approaches are capable of addressing the unpredictable challenges associated with the intricate complexity of cellular systems. Synthetic biology has inspired researches to bioengineer biological systems to perform specific tasks in the area of therapeutics, diagnostics, and biomanufacturing of high-value biomolecules» (Figure 1)

Basic tools and techniques:

DNA synthesis and DNA sequencing.

Organism («chassis»).

Engineering of transcription:

Synthetic promotors;

Transcription factors.

Genome modification tools:

CRISPR/Cas9 nuclease;
Zinc finger nucleases;

TALE nucleases;

Meganucleases.

Computer-aided tools.

Basic tools and techniques of synthetic biology [2]:

DNA synthesis and DNA sequencing

The recent developments in DNA synthesis and DNA sequencing have opened new horizons in genetic modification technologies. Previously this manipulation was difficult because of templatebased DNA synthesis; however, with the advent of de novo DNA synthesis, construction of new genes, control elements, basic building blocks, and even whole genome are possible. Construction of synthetic genome has led to creation of a synthetic version of life in yeast. Since the establishment of the first synthesis by phosphoramidite method ${ }^{4}$, numerous advancements have been made in this field, which ensured a high rate of oligo-synthesis, gene assembly, less error rate, and cost. Mere oligosynthesis and gene-assembly do not ensure the synthesis of the desired sequence as these are prone to errors. Thus, to attain an error-free and verified DNA sequence (gene, promoter, genome, etc.), the assembled sequences are cloned in plasmids and subjected to sequencing. In one method, fluorescent selection marker GFP is fused with the gene sequences in such a way that the addition of the correct sequence will lead to a fluorescence, while error-containing sequence because of frameshift mutation leads to the loss in activity. Application

\footnotetext{
2 Jan Baptist van Helmont. URL: https://en.wikipedia.org/wiki/Jan_Baptist_van_Helmont (date: 20.01.2021).

3 Spontaneous generation. URL: https://en.wikipedia.org/wiki/Spontaneous_generation (date: 20.01.2021).

4 Phosphoramidite Ligands // Phosphorus(III) Ligands in Homogeneous Catalysis: Design and Synthesis / Paul C. J. Kamer and Piet W. N. M.van Leeuwen. John Wiley and Sons. 2012.P. 133-157.https://doi.org/10.1002/9781118299715. ch4
} 
of various polymerases harboring exonucleases and endonuclease activities has also been used to cut heteroduplexes, which on re-amplification can make the sequence error-free. Next-generation sequencing (NGS) approaches promise reduction in error rate by a factor of 500 , when compared with the initial oligo pool. NGS uses different platforms for reading nucleotide sequences which are based on different principles of sequencing but ensure low cost, high speed, and accuracy in sequencing. Another area of DNA synthesis includes the addition of novel synthetic base pairs which would alter the regular codon set and will introduce novel amino acids, and therefore production of novel compounds. Two new bases, one the analog of pyrimidine 6-amino-5-nitro-3-(10-b-D-20deoxyribofuranosyl)-2(1H)-pyridone (dZ) and other its purine analog complement 2 -amino-8-(10b-D-20-deoxyribofuranosyl)-imidazo [1,2-a]-1,3,5triazin- $4(8 \mathrm{H})$-one $(\mathrm{dP})$, exhibited pyDDA:puAAD hydrogen bonding pattern, where "py» indicates a pyrimidine analog and «pu» indicates a purine analog. Here A and D represent acceptor and donor groups in hydrogen bonding. These developments in conglomeration of artificial genetic information systems have enhanced the wide applicability of synthetic biology.

Organism («chassis»)

The host system harboring the genetic toolbox for expression of the desired genes, delivered by suitable vectors, of the engineered biological pathway is termed as chassis. The prerequisite of an efficient chassis is its ability to grow on minimal media so as to lower the production cost, robust growth, and stability in response to the environment or the toxins released by the intermediates during the biosynthesis of macromolecules. Moreover, it should have a strong cell envelope which can tolerate the harsh conditions and at the same time allow secretion and attachment of molecules. The commonly used chassis are Escherichia coli, yeast, and Bacillus subtilis as they have been widely studied, and modification in these microbial systems is easier.

Other microbes have also been considered for chassis, such as Cyanobacteria, which has been used for biofuel production, and Geobacter, which utilizes electricity for carbon dioxide fixation (i.e., electrosynthesis). It is the chassis that provides the raw material and machinery to the synthetic system for performing various cellular, transcriptional, and translational functions. Therefore, correct selection of chassis is essential to achieve the appropriate effectiveness of the synthetic system. The host system has regulatory elements which may suppress the expression of foreign genes or the endogenous gene circuit may compete with the foreign gene system for resources. Therefore, synthetic circuits should be constructed in such a way that it can operate independently of the endogenous circuit or mutated chassis needs to be designed that can utilize less of its resources and provide more to the synthetic system. The remedy to this issue lies in the synthesis of engineered chassis which is based on the concept of the minimal genome. A breakthrough in this area was the development of bacterial cell controlled by the genome which was chemically designed. Moreover, numerous engineered chassis have been attempted, which are designed keeping in mind the compatibility of the synthetic system and the flux of cellular resources directed toward the synthetic system.

\section{Engineering of transcription}

Overexpressing a gene above a threshold level may deplete the resources, which otherwise may be utilized for metabolic function. In addition, accumulation of intermediates may be toxic to final metabolite such that the enzymes work in a coordinated manner, which does not allow accumulation of intermediates above the required level. Therefore, genetic manipulation or engineering of metabolic pathways should be mediated by regulating transcriptional phenomenon.

i) Synthetic promotors

Transcription can be modulated by controlling the behavior of parts of the synthetic circuit, i.e., promoters, transcriptional activators, and repressors. In the microbial system, several promoters (lac promoter, arabinose-inducible promoter, T7 promoter, etc.) are in use to achieve protein expression of the desired gene. However, use of natural promoters often diminishes their utility in achieving intricate gene regulation of the genetic tool. Inducible promoters also have some concerns related to the variable effects in different host systems and additional cost involved in the «inducers». Therefore, it is desirable to decipher the structure of cis elements so that they can be molded by rearranging the cis motifs into the synthetic promoter for the desired fashion of transcriptional control of synthetic toolkit. The synthetic promoter should be preferably short in length but aggressive in transcription. Furthermore, the synthetic promoter is designed to perform constitutive or tissue or cell-type specific or temporal or inducible expression of the gene system. A deep interrogation of the cis-regulatory architecture, which includes motif sequence, position, copy number, and spacer length, governs the strength, temporal, and spatial expression of the promoter. New motifs can be investigated by screening motif libraries or by bioinformatics-based de novo motif discovery tools. Once a suitable motif is isolated, it's copy number and spacing also need to be optimized as they link to promoter strength and arrangement of a transcription factor (TF) to access RNA polymerase complex. The transcriptional activity of a promoter should be examined using combinatorial promoter 
A. Genome Engineering With Cas9 Nuclease
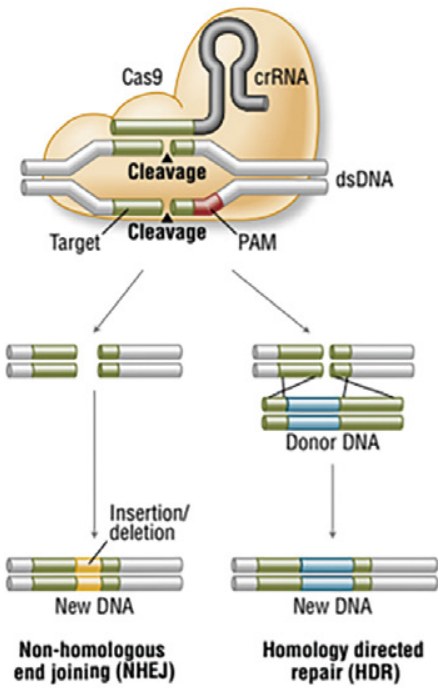

B. Genome Engineering By Double Nicking With Paired Cas9 Nickases

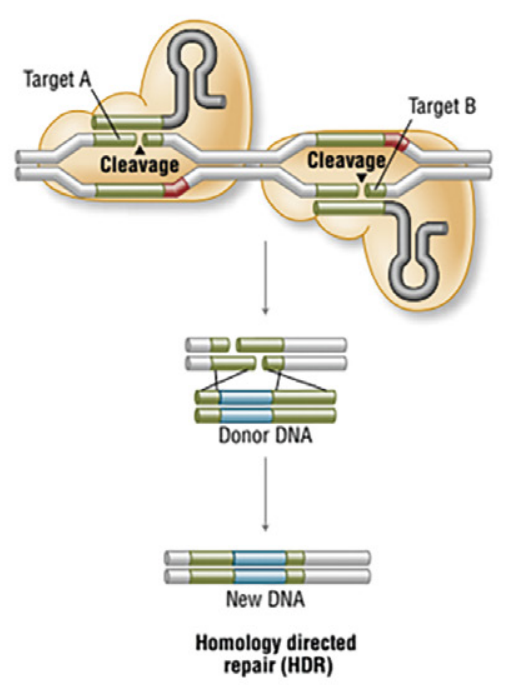

C. Localization With Defective Cas9 Nuclease
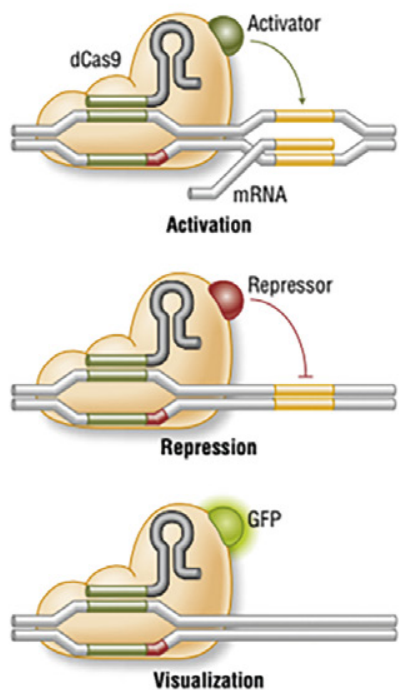

Figure 2 - CRISPR/Cas9 System Applications.

A - Wild-type Cas9 nuclease site specifically cleaves double-stranded DNA activating double-strand break repair machinery. In the absence of a homologous repair template non-homologous end joining can result in indels disrupting the target sequence. Alternatively, precise mutations and knock-ins can be made by providing a homologous repair template and exploiting the homology directed repair pathway. $B$ - Mutated Cas 9 makes a site specific single-strand nick. Two sgRNA can be used to introduce a staggered double-stranded break which can then undergo homology directed repair. C - Nuclease-deficient Cas9 can be fused with various effector domains allowing specific localization. For example, transcriptional activators, repressors, and fluorescent proteins (The whole Figure with text has been taken from [3])

libraries and reporter proteins. Such experiments fine-tune the cis-regulatory architectures for construction of efficient synthetic promoters with desirable regulatory ranges.

ii) Transcription factors

The level of transcription of a gene is dependent on the efficiency of promoter transcription factor (TF) interaction, i.e., quick and potent binding of TF to the cis DNA element. TFs provide regulatory links to the gene circuit, which synthetic biologists intend to create in a biological system. Engineering of TF proteins becomes essential when many genes are to be altered simultaneously to develop a «biofactory». Natural TF's DNA-binding domain (DBD) may recognize multiple cis motifs. TF engineering can be done in the DBD in such a way that it can bind to the defined targets in the promoter sequences for controlled gene expression. Fusion of engineered DBD with effector domain and nuclear localization signal leads to the development of synthetic TF with controlled activity. Several examples of synthetic TFs are available which are being used to regulate the genetic network. An example of synthetic TF is the fusion of tetracycline-dependent repressor (from E. coli) to transactivation domain (from the herpes simplex virus). The synthetic TF regulates transcription by its ability to bind tetracycline responsive element.
Apart from activation, methylation, acetylation, amination, recombination can also be achieved via synthetic TF. Synthetic promoter elements and synthetic transcriptional factors are foremost utensils in rewiring or reconstructing or novel designing of gene expression regulatory networks in the synthetic biological system.

\section{Genome modification tools}

Correction of defective genes or introduction of foreign genes requires efficient editing tools for targeted genome modification. The genome editing tool comprises components for identification of target sites and creation of double-stranded breaks (DSB) in DNA, and the breaks are repaired by homologous recombination or nonhomologous end joining. Various new generation nucleases are available, which are more precise in their catalytic action and can be modified as per the genetic requirements.

\section{i) CRISPR/Cas9 nuclease}

CRISPR (clustered, regularly interspaced, short palindromic repeats) technology is a universal tool for genome engineering and has revolutionized biotechnology. Only recently identified unique CRISPR/Cas (CRISPR associated) systems, as well as re-engineered Cas proteins, have rapidly expanded the functions and applications of CRISPR/Cas systems. The CRISPR/Cas system (Fig. 2) is the 
most popular gene editing tool developed from the indispensable nuclease, Cas9 [3].

Type II CRISPR/Cas system which provides immunity to bacteria against invading viruses, and plasmids led to the foundation of CRISPR/Cas9 system. The Cas 9 component acts as the endonuclease which is guided by a 20 nucleotide guide RNA (gRNA) that has RNA sequence complementary to the DNA of the target site. For genome editing, this gRNA needs to be designed according to the requirement that recognizes the site of cleavage by Cas9, thereby introducing a site for deletions and additions. Apart from gRNA, another prerequisite for cleavage is the presence of a protospacer adjacent motif (PAM), which is a short 2-6 bp long DNA sequence present adjacent to the target site. The absence of PAM restricts the cleavage event. Normally the PAM sequence is 50 -NGG-30 where $\mathrm{N}$ represents any nucleotide base. The aforementioned genome engineering toolboxes have offered several advantages over conventional transgenic approaches by providing opportunities of genetic loci specific gene integration or correction [4].

\section{ii) Zinc finger nucleases}

These are chimeric proteins composed of DNA-binding (ZF) and DNA cleavage domains. The cleavage domain was isolated from Fok 1, a type IIS restriction enzyme that has different binding and cleavage sites. Fok 1 activity requires dimerization of cleavage domain; therefore, two sets of zinc finger nucleases (ZFNs) are required, which recognize the target sites on two DNA strands. Binding of the two finger nucleases, using a short linker, to the recognition sequence increases their concentration, thereby facilitating dimerization followed by cleavage.

\section{iii) TALE nucleases}

These are similar to ZFN as the cleavage site is derived from Fok 1 and requires dimerization of nuclease. However, it shows higher target specificity. The target site is greater than $30 \mathrm{bp}$ because of the incorporation of $15 \mathrm{e} 20$ repeat variable diresidue in the monomer unit. The only limitation associated with TALE nucleases (TALEN) is its large size that makes its entry difficult in the host cell system. ZFN and TALEN have helped in exploring the novel way of sequence-specific genetic correction opportunities in the organism.

\section{iv) Meganucleases}

Meganucleases catalyze cleavage functions at specific loci in the genome. Meganucleases have been reported from a variety of organisms such as archaea, bacteria, phages, fungi, yeast, algae, and some plants. Intron-encoded endonuclease catalyzes DNA cleavage in the intron-lacking alleles. This helps in the movement of introns from introncontaining alleles to intron-less alleles, leading to gene conversion events. Therefore, they are known as homing endonucleases. Based on sequences and motifs, meganucleases are classified into five families. Contrary to the name, meganucleases, these are the smallest nucleases (165 amino acids) which makes their delivery easy. Meganucleases, with potential to generate DNA DSB at targeted loci of interest, are promising enzymatic tools for genome engineering. However, the number of native meganucleases is limited and insufficient to target a large number of desired loci. Because the meganucleases are nonmodular protein, its redesigning is tough as DNA-binding amino acids overlap with the DNA cleavage amino acids, thereby affecting the catalytic activity. However, methods have been developed for custom designing of meganucleases using machine learning approaches.

\section{Computer-aided tools}

As the area of synthetic biology is expanding, novel computational tools need to be developed, aggressively, to understand the current demand of synthetic aspects in biology. Despite the presence of numerous pieces of software, it suffers from certain limitations in terms of their biological counterparts, which sometimes behaves in an unpredictable manner, and due to this, repetition of experiments and analysis is required. Computeraided (CAD) tools are indispensable to synthetic biology as the tools bestowed by it are utilized by biological engineers to understand and ameliorate the properties and functions of synthetic biology parts, devices, networks, etc. CAD tools aid in developing and optimizing parameters based on which synthetic biology devices can be designed and tested. It offers the advantage to judge the feasibility of a model constructed for targeting a specific function. These developments assist in assembling the biological parts to form circuits and networks and simultaneously predict the fate of the assembly. These tools also help in determining the details of the alternates of a design. As the tasks performed by CAD tools are variable, these can be categorized under three sections based on the type of work they are participating in:

i) tools involved in basic structural design and synthesis;

ii) tools involved in network design;

iii) tools involved in prediction of behavior/ function/response.

Another progress could be achieved after employing of artificial intelligence (AI). The progress is exciting however AI is not a universal replacement for the investigations of the natural world. Nevertheless, modern AI will (probably) dominate biological data science for its unpreceded learning capabilities to process complex data [5]. Here we would like to focus on one, recent (press release) example:

«Scientists at the Department of Energy's Lawrence Berkeley National Laboratory have developed a new tool that adapts machine learning 
algorithms to the needs of synthetic biology to guide development systematically. The innovation means scientists will not have to spend years developing a meticulous understanding of each part of a cell and what it does in order to manipulate it; instead, with a limited set of training data, the algorithms are able to predict how changes in a cell's DNA or biochemistry will affect its behavior, then make recommendations for the next engineering cycle along with probabilistic predictions for attaining the desired goal» ${ }^{5}$.

The «desired goal» can be anything... No doubt, that such publications appearing in prestigious journals [6] have a broader reading forum than the civil one. In a study J. Thomsen et al. [7] researchers have developed an AI tool which dramatically speeds up a research of protein dynamics. Interestingly, the used software is freely available and is accessible to all teams in the world rather than be limited to few laboratories with specialist expertise. This are few examples of a great progress in this area.

In the previous article we have put a schema of the division (and the possible (mis)use synthetic biology) as follows [8]:

i) Binary bioweapons (these are twocomponent systems that are relatively safe to handle but become deadly when the two components come together on deployment).

ii) Designer genes (where specific unnatural gene sequences are built into viruses or other life forms to incorporate into the genome of the unsuspecting host, which later becomes the victim).

iii) Gene therapy (today a medical (partial) reality; the technology that allows medicine to repair or replace defective genes in a diseased individual might be subverted to introduce pathogenic sequences into healthy individuals).

iv) Stealth viruses (viruses that could be fashioned by a researcher to infect the host but remain silent until activated by some physiological or environmental trigger).

v) Host-swapping diseases (new zoonotic agents which might be developed specifically for bioweapon purposes by modifying existing pathogens to seek human hosts).

vi) Designer diseases (where the detailed knowledge of biochemical signaling pathways could conceivably be used to create designer diseases).

However, according to ${ }^{6}$ we will now use a slightly different approach: It should be noted that in the era of synthetic biology, the technologies themselves pose no inherent harm, and it would generally take a collection of technologies to create a specific capability that warrants concern. Here we can see how the framework applied to assess capabilities (rather than technologies) that potentially pose a concern because of the harm they might enable. A list of potential capabilities to evaluate was identified by gathering a range of possibilities that have been mentioned in various venues as potential concerns associated with synthetic biology and augmenting that list with additional possibilities that had not been previously raised. These potential capabilities were grouped into categories to ensure a consistent approach to their evaluation using the framework.

i) Re-creating known pathogenic viruses: Constructing a known, naturally occurring pathogenic virus from the starting point of information about its genetic sequence.

ii) Re-creating known pathogenic bacteria: Constructing a known, naturally occurring pathogenic bacterium from the starting point of information about its genetic sequence.

iii) Making existing viruses more dangerous: Creating a modified version of a known virus in which one or more traits have been altered to make the virus more dangerous (such as by enhancing its virulence).

iv) Making existing bacteria more dangerous: Creating a modified version of a known bacterium in which one or more traits have been altered to make the bacterium more dangerous.

v) Creating new pathogens: Constructing a pathogen from the novel combination of multiple parts, which may be derived from various organisms, designed computationally, or created through other strategies.

vi) Manufacturing chemicals or biochemicals by exploiting natural metabolic pathways: Producing a naturally occurring product, such as a toxin by engineering an organism (e.g., bacterium, yeast, or alga) to contain the known biosynthetic or metabolic pathway for the desired product.

vii) Manufacturing chemicals or biochemicals by creating novel metabolic pathways: Creating a new biosynthetic pathway that enables an engineered organism to produce a chemical that is not normally produced biologically.

viii) Making biochemicals via in situ synthesis: Engineering an organism, such as a microorganism that can survive in the human gut, to produce a desired biochemical and delivering this

\footnotetext{
5 Machine learning takes on synthetic biology: algorithms can bioengineer cells for you Scientists develop a tool that could drastically speed up the ability to design new biological systems / Science Daily 2020. September 25. URL: https://www.sciencedaily.com/releases/2020/09/200925113447.htm (date: 14.02.2021).

6 Biodefense in the Age of Synthetic Biology 2018. ISBN 978-0-309-46518-2. https://doi.org/10.17226/24890 (Committee on Strategies for Identifying and Addressing Potential Biodefense Vulnerabilities Posed by Synthetic Biology, Board on Chemical Sciences and Technology, Board on Life Sciences).
} 
microorganism in such a way that it can produce and release this product in situ.

Modifying the human microbiome: Manipulating microorganisms that form part of the population living on and within humans, for example, to perturb normal microbiome functions or for other purposes.

Modifying the human immune system: Manipulating aspects of the human immune system, for example, to upregulate or downregulate how the immune system responds to a particular pathogen or to stimulate autoimmunity.

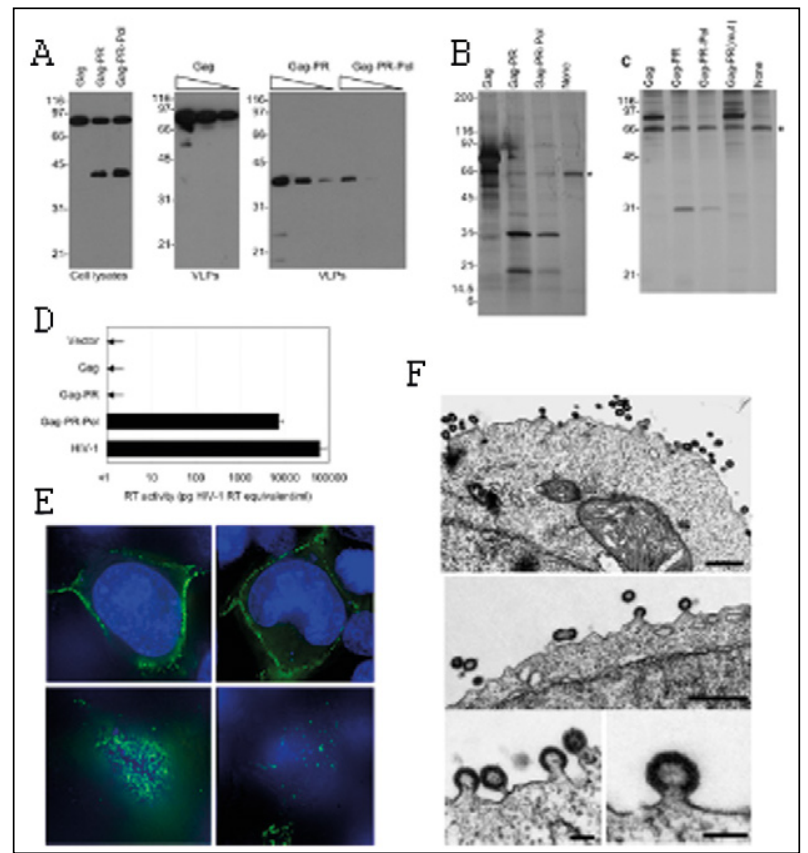

Modifying the human genome: Creating changes to the human genome through addition, deletion, or modification of genes or through epigenetic changes that modify gene expression. A subset of this category is the modification of the human genome through human gene drives, the incorporation of certain types of genetic elements into the human genome that are designed to pass from parent to child during reproduction and that would spread a genetic change through the population over time.

We will follow and only slightly modify the excellent description of potential (mis)use of synthetic biology as it is described in Biodefense in the Age of Synthetic Biology [5].

A ( $\mathrm{i}+\mathrm{ii})$ : RE-CREATING KNOWN PATHOGENS The construction of an organism from scratch requires at least two steps: synthesis of the organism's genome and conversion of that nucleic acid into a viable organism («booting»).

i) Re-creating known pathogenic viruses:

Using today's technology, the genome of almost any mammalian virus can be synthesized, and the sequences of known human viruses are readily available through public databases such as GenBank $^{\oplus}$, an annotated collection of all publicly available whole and partial DNA sequences ${ }^{7}$. The 2002 synthesis of poliovirus by Eckard Wimmer and colleagues was among the first reported syntheses of a viral genome. The team assembled a complementary DNA (cDNA) of the poliovirus genome (approximately 7,500 nucleotides), under the control of the phage T7 promoter, from a series of oligonucleotides with an average size of 69 bases

Figure 3 - Assembly, Processing, and Release of HERV-K Virus-Like Particles. (A-D) 293T cells were transfected with Gag-, Gag-PR-, or Gag-PR-Pol-expressing vectors. (A) Western blot analysis of cell lysates (left) and virions (center and right) using a commercially available antibody to HERV-K Gag. Center shows VLPs from 293T cells transfected with a plasmid-expressing Gag, and right shows VLPs from Gag-PR-and Gag-PR-Pol-expressing $293 T$ cells. Decreasing amounts of virion lysate $(0.1,0.05$, or $0.025 \mu$ l for Gag; 0.4, 0.2 , or $0.1 \mu$ l for Gag-PR and Gag-PR-Pol) were loaded to semiquantitatively estimate relative levels of VLP production. (B) Silver stain analysis of a $4 \%$ to $20 \%$ gradient SDS-PAGE gel loaded with VLPs harvested from $293 T$ cells transfected with plasmids expressing Gag, Gag-PR, Gag-PR-Pol, or empty plasmid control. An asterisk marks a nonspecific 66-kDa protein band, most probably BSA, that is abundant in the culture medium. (C) Silver stain analysis of VLPs harvested from 293 T cells containing Gag, Gag-PR, Gag-PR-Pol, or Gag-PR(mut) encoding an active site mutation (DTG-AAA) in protease. An asterisk marks a nonspecific 66-kDa protein band, most probably BSA, that is abundant in the culture medium. (D) Reverse transcriptase activity in culture supernatants of 293T cells transfected with empty pCRV1 (vector) or vectors expressing HERV-KCON Gag, Gag-PR, or Gag-PR-Pol proteins, as indicated. Enzymatic activity was determined relative to a recombinant HIV-1 reverse transcriptase standard and is representative of three experiments. Supernatants from 293T cells transfected with an HIV-1-based proviral plasmid are included for comparison. (E) Two representative 293T cells transfected with HERV-KCON Gag and Gag-GFP expression plasmids. Cells were fixed $18 \mathrm{~h}$ post-transfection, and nuclei were stained with DAPI (blue) prior to visualization by deconvolution microscopy. Top, Images acquired at the mid-section of the cell to show localization of Gag-GFP proteins; bottom, focused on the bottom of the cell to show accumulated VLPs at the cell-coverslip interface. (F) Gallery of electron micrographs of $293 T$ cells transfected with a Gag-PR-expressing plasmid. Black scale bars in the upper and middle panels represent $500 \mathrm{~nm}$, while scale bars in the lower two panels represent $100 \mathrm{~nm}$. https://doi.org/10.1371/journal.ppat.0030010.g002 [10]

\footnotetext{
NCBI (National Center for Biotechnology Information). 2017. GenBank. URL: https://www.ncbi.nlm.nih.gov/ genbank (date: 20.01.2021).
} 
[9]. In 2007, an infectious form of the ancient endogenous retrovirus HERV-K (HML-2) was obtained [10] (Figure 3).

This cDNA was used to produce viral RNA, which was then used to program an in vitro extract to produce infectious poliovirus virions. Since then, larger and larger viral genomes have been generated, taking advantage of advances in the ability to synthesize longer and longer segments of DNA. Modern assembly methods have greatly expanded the scale at which DNA can be constructed, to the point that building the genome of virtually any virus-either in the form of the genome itself for a DNA virus or as a cDNA of an RNA virus that can be transcribed into the viral genome is now possible [11]. A notable example is the recent report of the construction of the horsepox genome (consisting of more than 200,000 base pairs) as part of an effort to develop a new smallpox vaccine [12] (It should be noted that while the booting of some viruses, e.g., polio, has been performed using cell-free extracts, most viruses must be booted inside cells, and some viruses, including horsepox, require the use of a helper virus in cells) ${ }^{8}$.

\section{ii) Re-creating known pathogenic bacteria:}

The genomes of many existing bacteria have been characterized, and the same types of DNA synthesis and booting approaches used for large viral genomes can, in theory, be applied to re-create known pathogenic bacteria. Indeed, JCVI reported the synthesis and booting of Mycoplasma mycoides in 2010 [13]. Other microbial genome synthesis projects are well under way, such as for Escherichia coli (4 million base pairs) and yeast (11 million base pairs).

B (iii+iv): MAKING EXISTING PATHOGENS MORE DANGEROUS

\section{iii) Making existing viruses more dangerous:}

The following are selected examples of viral traits, presented to give a sense of the range and type of traits that could theoretically be targeted for modification using biotechnology.

Altered Tropism

Tropism is the capacity of a virus to infect or damage specific cells, tissues, or species. While tropism is primarily influenced by the interaction of the viral cell attachment protein(s) with the receptor(s) present on the cell (thus determining viral entry), the larger property of tropism is determined by multiple viral and host cell factors. Altering tropism could be used to expand the host range of an existing virus or otherwise increase a virus's ability to take hold in a targeted population. Several studies have demonstrated the ability to alter the tropism of viruses. The avian influenza H7N9 strain has been causing isolated human infections since the initial outbreak in China in 2013, but sustained human-to-human transition has not been documented. It has been demonstrated that only three mutational changes in the sequence of the hemagglutinin gene are sufficient to switch the virus's tropism from avian to human and support binding to human tracheal epithelial cells [14]. In earlier studies with avian influenza, researchers used sitedirected mutagenesis to introduce mutations into the hemagglutinin gene to allow wild-type $\mathrm{H} 5 \mathrm{~N} 1$ virus to bind to human receptors. Researchers have also used synthetic biology to alter tropism in investigations of the respiratory syndromes SARS (severe acute respiratory syndrome) and MERS (Middle East respiratory syndrome). There is considerable evidence indicating that a SARS-like virus in bats was the origin of the 2003 outbreak of SARS in humans. The bat virus, however, does not grow in cell culture. To help elucidate the steps that may have occurred to convert bat SARS-CoV into a virus infecting humans, scientists substituted the human SARS coronavirus receptor binding domain for the equivalent domain in the bat SARS$\mathrm{CoV}$ virus, making the batSARS virus replication competent in cell culture and mice [15]. Similarly, to develop a small-animal model of MERS-CoV, researchers modified both the mouse, to express a chimeric receptor, and the virus [16].

Enhanced Viral Replication

Enhancing viral replication could help increase the impact and spread of a virus-based bioweapon. In experiments with echovirus 7 researchers demonstrated that decreasing the $\mathrm{CpG}$ and $\mathrm{UpA}$ frequencies in two 1.1- to 1.3-kilobase regions of the viral genome enhanced viral replication in susceptible cells. Conversely, increasing the $\mathrm{CpG}$ and UpA frequencies resulted in decreased viral replication. While it is unknown whether these results would be the same in animals-enhanced replication in cell culture does not necessarily correlate with enhanced replication in vivo, and in fact, the reverse is sometimes the case-an actor with sufficient time and resources may be able to generate variants empirically and passage them in a susceptible host to select a variant with enhanced replication ability.

Enhanced Virulence

Virulence measures the relative capacity of a virus to cause actual disease in a host, rather than just infection. Virulence represents the combined effect of multiple genes and determinants that play specific roles in specific settings in vivo. In the bestknown example of an engineered virus resulting in enhanced virulence researchers engineered

\footnotetext{
8 Kupferschmidt K. How Canadian researchers reconstituted an extinct poxvirus for $\$ 100,000$ using mail-order DNA. Science, News. 2017. July 6. URL: http://www.sciencemag.org/news/2017/07/how-canadian-researchers-reconstituted extinct-poxvirus-100000-using-mail-order-dna (date: 20.01.2021).
} 


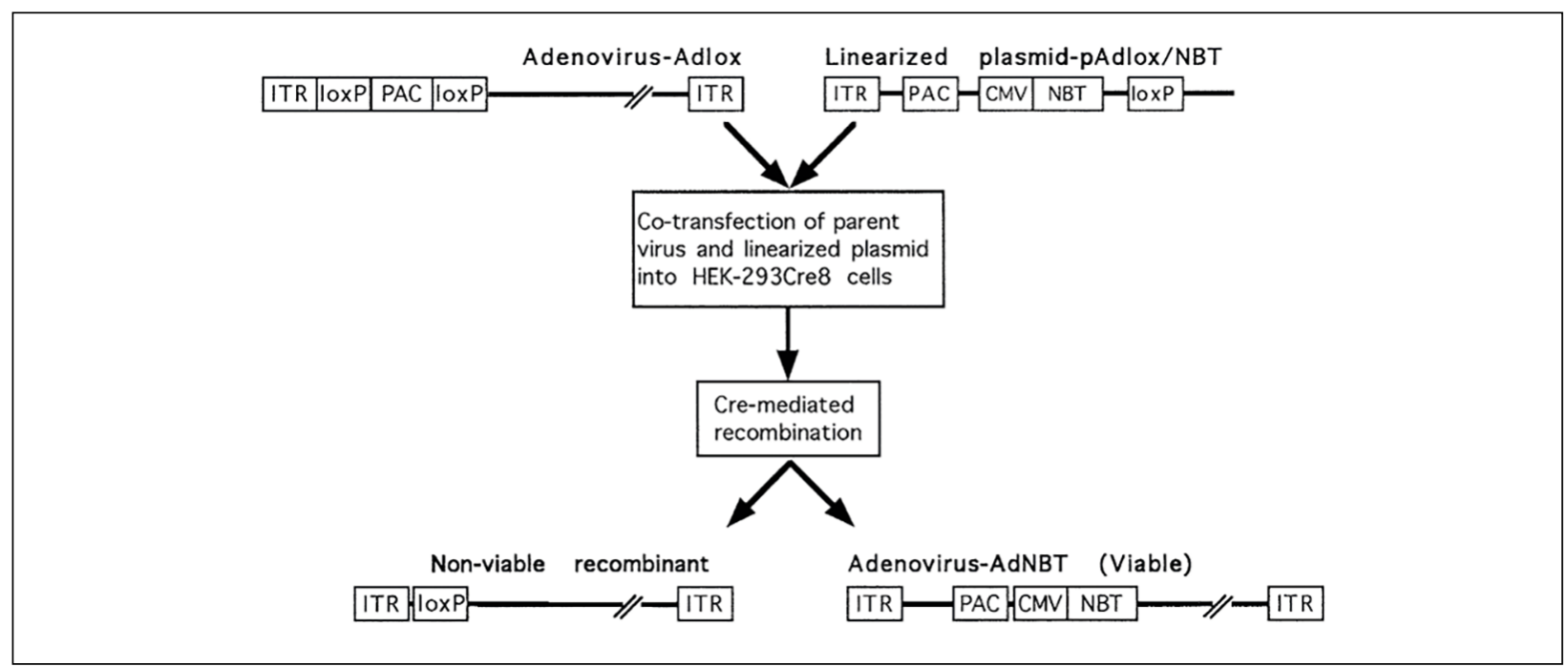

Figure 4 - Construction of recombinant adenovirus encoding neuronal bungarotoxin (Bgt). The schematic shows the Sfil fragment of pAdlox $x$-Bgt that contains, from left to right, the inverted terminal repeat (ITR), packaging signal (Pac), CMV promoter (CMV), K-Bgt CDNA and loxP site. The fragment was cotransfected into a specially created cell line. HEK-293/CRE8 along with a modified adenovirus that contains two loxP sites on either side of the packaging signal. CRE-mediated intramolecular recombination results in unpackagabie viral DNA. Only intermolccular recombination with the plasmid fragment yields functional virus. Hence, proliferation of the correct recombinant is highly favored [19]

ectromelia virus (mousepox), a member of the Orthopoxvirus genus and a natural pathogen of mice, to express mouse interleukin-4 (IL-4), with the goal of producing a contraceptive vaccine to control the mouse overpopulation. In the mouse model, the recombinant virus was shown to suppress primary antiviral cell-mediated immune responses and overcome preexisting immunity [17]. It is also conceivable that actors would seek to manipulate a virus so that it causes disease by different mechanisms than a natural virus might, such as by manipulating neurobiology or altering the host microbiome.

Ability to Evade Immunity

At the root of the increased virulence demonstrated in the mousepox experiments (described under Enhanced Virulence, above) was the recombinant virus's capability to evade immunity. This points to another potential route for actors seeking to produce bioweapons: the development of viruses designed to anticipate and evade the immune response or even to overcome vaccine-based immunity. Detection of viral pathogens by the innate immune system leads to the induction of antiviral mechanisms that are mostly mediated by type-1 interferons. This primary response then leads to the activation of the adaptive immune response that is more directed, antigenspecific, and longer lasting [18].

Many viruses have countermeasures to subvert the innate immune response including interferoninduced antiviral activity. It may be possible to express one or more antagonists of these antiviral activities in a pathogen that does not already have that particular antagonist. In this way, the arsenal of activities that a virus uses to evade the innate immune response would be expanded and virulence may be enhanced. The creation of chimeric viruses developed by genetically substituting capsid genes has been well documented. These viruses have mainly been developed in the context of, for example, improving adenovirus vectors to target specific tissues and as an approach to circumventing preexisting viral immunity that may limit the use of viral gene therapy vectors. It is conceivable that the latter approach could be used to develop a chimeric viral vector expressing a toxin gene targeted to a particular tissue and used in a population with preexisting immunity to the vector virus [19] (Figure 4).

The molecular determinants of targeting are poorly understood, however, and these approaches generally require significant trial and error to be successful.

Ability to Evade Detection

Some modifications could result in a virus that would be difficult to detect using current outbreak response approaches. The most commonly used methods of laboratory identification of viruses are based on real-time polymerase chain reaction assays in which specific primers and fluorescently labeled probes are designed to bind to conserved and unique regions of the viral DNA or cDNA. Nontargeted methods of detection include arraybased assays and next-generation sequencing, but these are not yet in wide use in clinical and commercial laboratories. Cell culture methods 
are rapidly disappearing from use. Mutations that target the primer binding sites could therefore result in a virus that is not recognizable.

Ability to Resist Therapeutics

Actors could seek to develop viruses capable of resisting available therapeutics, though the necessity of this approach would depend on whether effective therapeutics exists [20]. Despite the availability of successful antiviral agents such as those used to counter HIV (human immunodeficiency virus), herpes viruses,

iv) Making existing bacteria more dangerous:

The following are selected examples of bacterial traits, presented to give a sense of the range and type of traits that could theoretically be targeted for modification using biotechnology.

Altered Tropism

Unlike viruses, which are exclusively intracellular pathogens, bacterial pathogens can be either intracellular or extracellular. Generally, extracellular pathogens are relatively environmentally stable and good at adapting to their environment. Even those that are not sporeforming often have the capacity to replicate and cause damage in multiple tissues and cell types and in different locations in the body. Given their environmental stability, they are difficult to eradicate and may not require host-to-host contact for transmission. Intracellular bacteria, like viruses, rely on host cell nutrients and are often able to evade the host immune system. Intracellular pathogens are usually transmitted via direct contact or aerosol transmission. Both intracellular and extracellular pathogens rely on adherins and colonizing factors, which facilitate contact with host target cells, confer resistance to leukocyte attack, and are significant virulence factors [21].

Enhanced Virulence

Many factors influence bacterial virulence and could potentially be targeted for modification. The primary mechanisms of bacterial pathogenesis include host target cell death, whether by cell lysis (resulting either from the multiplication of intracellular pathogens or as a result of the action of bacterial toxins) or by induction of apoptosis (programmed cell death); mechanical perturbations of host physiology (e.g., blockage of circulatory or respiratory passages due to the size or number of invading bacterium or as a result of mucous production); host cell damage resulting from the host immune response to the bacterial infection; and the action of bacterial toxins. The effects of cell death depend upon the host cells involved and are influenced by the bacterial burden introduced, the route of infection, complicating symptoms induced by host immune response, and the rapidity of the infection process. Colonization potential is influenced by the ability of some pathogenic bacteria (e.g., Shigella) to trigger premature or unscheduled apoptosis in the host cells they infect; the initial phase of this process involves the introduction of enzymatically driven damage to host cell DNA followed by massive disturbances in cell integrity and cell death. Another significant virulence factor is the ability of some bacteria (e.g., Bacillus anthracis) to form capsules consisting of polysaccharides and amino acids [22]. Capsules prevent bacteria from being phagocytized by neutrophils and macrophages. Other virulence factors include invasion factors, which are usually encoded chromosomally but may also be plasmidborne, and siderophores, iron-binding factors that allow bacteria to compete with host cells for iron acquisition [23].

Enhanced Toxin Production

Many bacterial pathogens cause damage to host cells and tissues through the production of toxins. These toxins take two forms: exotoxins and endotoxins. Exotoxins are relatively unstable, highly antigenic proteins that are secreted into host body fluids. Some exotoxins are bound to the bacterial cell wall following their synthesis and are released upon lysis of the invading bacterium. Often highly toxic, exotoxins are produced by both Gram-positive and Gram-negative bacteria. Some exotoxins can act only on certain cell types whereas others affect a broad spectrum of cells and tissues. Some bacterial pathogens make only a single toxin (e.g., cholera, diphtheria, tetanus, botulism) whereas others can synthesize two or more distinct toxins (e.g., Staphylococcus, Streptococcus). Antitoxin antibodies to exotoxins are usually made rapidly by the host. The genetic determinants of exotoxins are often found on extrachromosomal elements, usually plasmids or bacteriophages. Endotoxins, on the other hand, are relatively stable, lipopolysaccharide components of the outer membrane of some Gramnegative bacteria that can act as toxins under certain circumstances. Lipid A appears to be the toxic component, which can act while in the intact bacteria expressing it. Endotoxins are generally weakly immunogenic, eliciting fever in the host. They can cause hypotension due to increased vascular permeability accompanied by vasodilation, which can in turn result in shock. The genetic determinants for endotoxins are chromosomal. Actors could potentially seek to modify bacteria to enhance their natural toxin production or introduce toxin production into a bacterium that does not naturally produce toxins.

Ability to Evade Immunity

As with viruses, it is possible to engineer bacteria to anticipate or evade the immune response. Ability to Evade Detection

As with viruses, the most commonly used methods of laboratory identification of bacteria are based on real-time polymerase chain reaction (PCR) assays in which specific primers and fluorescently 
labeled probes are designed to bind to conserved and unique regions of the bacterial chromosomal or extrachromosomal DNA. Another widely used method in clinical microbiology laboratories is MALDI-ToF (matrixassisted laser desorption/ ionization time-of-flight), a method of ionizing large molecules and identifying them by mass spectrometry in comparison to reference standards. Nontargeted methods of detection such as arraybased assays and next-generation sequencing are available but are not yet in wide use in clinical and commercial laboratories. Culture methods are rapidly disappearing from use [24].

Ability to Resist Therapeutics

In contrast to the relatively small number of antivirals, there are many antibacterial agents available that are capable of acting against a wide variety of bacterial pathogens. However, bacteria can be intrinsically resistant to antibiotics, or can acquire resistance via chromosomal mutation and horizontal gene transfer. There are three main mechanisms of antibiotic resistance [25]. First, the bacterium can prevent the antibiotic from accessing its target, either through reduced permeability of the antibiotic through the cell wall or membrane complex or through increased efflux of the antibiotic back out of the organism and away from its target. Second, the antibiotic target can be altered through genetic mutation, causing the target to become modified or protected. Finally, antibiotic resistance can be acquired by direct modification of the antibiotic itself, either by inactivation by antibiotic hydrolysis or by way of inactivation due to a chemical modification. These mechanisms are well studied and could potentially be adapted for the purposeful creation of antibiotic-resistant pathogenic bacteria.

Enhanced Transmissibility

As with viruses, the property of airborne transmission in bacteria is complex and dependent on multiple host and pathogen factors, in particular environmental stability and tissue tropism. Extracellular bacterial pathogens are extremely adaptable to environmental challenges and may not require host-to-host contact for transmission, making these pathogens difficult to eradicate. In addition, many bacterial pathogens that replicate extracellularly are capable of causing damage to different cells and tissue types. On the other hand, many intracellular bacterial pathogens are communicable (i.e., capable of host-to-host transmission), facilitating rapid spread within a community and thus presenting a greater capacity to threaten public health.

Enhanced Stability

The environmental stability of a bacterium depends on its physiology and life cycle. Grampositive bacteria are more environmentally stable than Gram-negative bacteria. In addition, when subjected to harsh environmental conditions such as desiccation, some Gram-positive bacteria form spores capable of remaining viable in the environment for decades, albeit in a metabolically dormant state. For example, spores of Bacillus anthracis can remain viable in the environment for up to a century and constitute the infectious form of this pathogen (with vegetative forms not being infectious) [26]. Actors may find it advantageous to engineer bacterial cell walls to more closely resemble Gram-positive organisms to enhance survival during aerosol dissemination and allow the agent to remain viable and available to infect the target host for extended periods of time.

\section{C (v): CREATING NEW PATHOGENS}

\section{v) Creating new pathogens:}

A major aspiration within the field of synthetic biology is the design and creation of new organisms with beneficial uses. In the context of bioweapons, the possibility that this aspiration may potentially be directed toward producing pathogens that are entirely new was considered. In contrast with the discussion of modifying existing pathogens, the term «new» is used here to describe novel combinations of genetic parts from multiple organisms for which the product is not recognizable as primarily from one source. This can include genetic parts designed computationally with no near relative in the natural world. The resulting range of potential bioweapons in this category is extremely broad but serves to illustrate the more challenging applications that may be possible at some point in the future. One example of a new pathogen would be a virus constructed from parts of many different natural viruses. This mix-and-match approach might be used to combine the replication properties of one virus, the stability of another virus, and the hosttissue tropism of a third, for example. A variety of experimental approaches would be applicable to this goal. Directed-evolution approaches could be used to sample random combinations of viral DNA parts; while each individual combination would have a small chance of success, sampling a very large number of combinations would increase the chances of success. More explicit design approaches might be to develop software to model and predict the properties of specific designs, which would then be built, tested, and improved through multiple iterations of the Design-Build-Test cycle. Even simple changes to existing viruses can produce drastic deficiencies in key viral properties, making any such effort especially difficult. Nonetheless, work involving recomposing the structure of a bacteriophage genome into modular pieces suggests that radical new combinations of viral sequences may be viable, although tools to design viruses with high confidence of success are currently lacking. A different example of a new pathogen would be one based on synthetic "genetic circuits». A major 
pursuit within synthetic biology is the capability to arbitrarily program specific functions using genetic material. These efforts are exemplified by the engineering of DNA-encoded programs, relying heavily on concepts derived from information theory and computer science, such as constructing logic gates from individual switching functions. Importantly, the genetic material encoding those functions can in principle come from anywhere - from any branch of the tree of life or from an entirely new DNA sequence that has never been observed in nature. The designs for genetic circuits have greatly increased in complexity over time through increased reliance on component abstractions and standardization. A number of genetic circuits have been designed to function in human cell lines in culture however, applications using genetic circuits in the human body are still in their infancy. The potential for using such technology to cause harm in the human body is thus a subject of broad speculation. Novel circuits could (in theory) be used to convert a healthy cell into a cancerous one or to provoke an autoimmune response. Such circuits might be designed to act on the host DNA using engineered factors that turn host genes on or off, such as at the level of transcription or translation. A variety of mechanisms have been demonstrated for such general-purpose switching. They include the use of natural or artificial microRNA molecules and the use of CRISPR/dCas9-type programmable gene repression or activation [27]. Importantly, these are examples of mechanisms that have displayed a high degree of programmability in terms of which host DNA sequences can be targeted. In a similar vein, the potential programmability of genetic effectors may also lead to genetic circuits that sense and compute based on the state or type of cell or even specific genetic identity. In some cases, genetic circuits could be delivered to a small number of host cells using nonreplicating delivery mechanisms, which could be either virus-derived, such as those used in some gene therapies or based on nonbiological materials. At the extreme end of difficulty (and feasibility) lies the engineering of life forms that are particularly dissimilar from known life on this planet. "Xenobiology» offers some possibilities - for example, a bacterium employing a different combination of deoxyribonucleotides and ribonucleotides to encode its genetic information [28]. There is a wide range of expert opinion as to the long-term plausibility of such efforts.

$$
\text { D (vi+vii+viii): PRODUCTION OF }
$$

CHEMICALS OR BIOCHEMICALS

vi) Manufacturing chemicals or biochemicals by exploiting natural metabolic pathways:

Biochemical compounds naturally produced by plant and microbial cells have been used for centuries as medicinal compounds. These products have been prepared as both plant extracts, in which the active ingredient is one of numerous chemical structures in the formulation, and as high-purity single compounds, made by cultivating the producing organism in large-scale bioreactors and then purifying the output. Such products have been used to treat diseases ranging from microbial infection to hypertension. The opioids, used as analgesics, are now accessible by microbial fermentation, as well, though optimization of the «home-brewing» process has not been rigorously explored. Each naturally occurring biochemical is the result of a series of chemical reactions that transform simple feedstocks such as glucose into the end products of interest. These transformations are mediated by enzymes encoded by the host organism's DNA. Because biotechnologies allow the DNA encoding the necessary enzymes to be exploited independent of the original host, it is now possible to make such products without relying on the organism that naturally produces them.

vii) Manufacturing chemicals or biochemicals by creating novel metabolic pathways:

While nature has provided a wide array of biochemical compounds that could be exploited for targeted synthesis, enzyme-mediated conversions also can be used to produce chemicals that organisms do not naturally create. Biocatalysis has long been used to produce pharmaceutical intermediates and active ingredients not found in nature. It is not always necessary to use living microbial organisms in these processes; instead, purified enzymes can be used in reaction vessels in a manner analogous to traditional organic synthesis. At its core, designing a new biosynthetic pathway involves specifying a series of enzymatic steps that can convert a set starting substrate to the desired end product. In practice, the starting substrate is often a known primary metabolite (e.g., acetyl-CoA), and the proposed reaction steps are based on known enzymatic chemistry. Engineered metabolic pathways that do not follow an existing natural blueprint have been exploited to commercialize biological production of chemical compounds. The true limits of biological synthesis are unknown, and advances in protein design and engineering are rapidly expanding the repertoire of enzyme-catalyzed reactions ${ }^{9}$. Researchers have also shown that materials typically present in very small amounts in biological systems, such as halogens, can be incorporated into natural products by merging plant and microbial biosynthesis machinery. These examples suggest that the range of molecules that may be accessible by biological synthesis is far larger than what has been demonstrated to date.

NRC. 2015. Industrialization of Biology: A Roadmap to Accelerate the Advanced Manufacturing of Chemicals. Washington, DC: The National Academies Press. 
viii) Making biochemicals via in situ synthesis:

The human microbiome, particularly the gut microbiome, has been a target for metabolic engineering. Gut microbes influence the metabolism of their host and are capable of producing a wide variety of biochemicals. While the extent of the influence of the microbiome on host metabolism remains an active research area, there has already been significant progress toward engineering gut microbes for therapeutic purposes. Engineered microbes are currently being prepared for clinical trials for the treatment of metabolic disorders ${ }^{10}$, although engineering high flux through a metabolic pathway remains undemonstrated. As this research gains steam, it is worth considering whether the human microbiota could be exploited to make biochemicals (within the cells of commensal organisms) and deliver them to human hosts to cause harm. In addition to the gut microbiome, the skin microbiome could be another potential avenue for in situ synthesis of such compounds. Related concepts include the manipulation of the human microbiome to cause dysbioses or as an avenue for horizontal gene transfer. Environmental dispersion of a microorganism capable of producing toxins, antimetabolites, or controlled chemicals may also be considered a potential in situ delivery mechanism, one whose outcome would be difficult to predict. The basic principles of pathway engineering in a microbe are the same whether the intention is to culture the organisms in large vessels followed by purification of the molecules of interest or to introduce the organisms into the environment or a human host for in situ production and release of a biochemical.

\section{E (ix+x+xi): BIOWEAPONS THAT ALTER}

\section{THE HUMAN HOST}

\section{ix) Modifying the human microbiome:}

Human health is highly dependent upon the human microbiome-the microorganisms that live on and within us, especially those associated with the gut, oral cavity, nasopharyngeal space, and skin. These populations of microbes are likely far easier to manipulate than the human host itself, making the microbiome a potentially accessible vector for attack. The human microbiome is the focus of a great deal of academic and commercial research, and microbiome manipulation is an area that is rapidly developing (for more information see also $^{11}$ i.e. Human Microbiome Project).

Delivery of harmful cargo via the microbiome. The microbiome could be used as a vector for other types of harmful cargoes, as well. For example, microbes could be modified to produce functional small RNAs (e.g., microRNAs [miRNAs]) that could be transferred to the host via the gut or skin microbiome to cause a variety of health impacts. Microbes also could potentially be engineered to horizontally transfer a genetic cargo to the native microbiome to, for example, cause a host's own well-established microbes to produce a harmful biochemical. In such a scenario the harmful agent would be manufactured by organisms in the established microbiome, so the engineered microbe would need to infiltrate and persist within the microbiome only long enough to transfer its cargo to a sufficient number of native microbes. Thus, this approach would circumvent the challenges associated with establishing engineered microbes in otherwise occupied niches. It may be possible to harm a population by enhancing the spread of vectors or phage carrying such genetic cargoes [29]. Synthetic biology methods could advance such a capability, for example, through the engineering of toxin:antitoxin couples that would help ensure retention of plasmids. It is also conceivable that microbes could one day be engineered to horizontally transfer genes directly to human cells.

Use of the microbiome to increase the impact of an attack. The microbiome can also potentially be exploited to design a more effective bioweapon or increase the impact of an attack. Knowledge of the human microbiome could be used to modify pathogens or their delivery mechanisms to allow more efficient propagation within or between populations, for example, by taking advantage of the frequent exchange of bacteria between humans and animals. In particular, domestic animals could be used as carriers for engineered agents transmitted via the microbiome. For example, engineered dog or cat microbiomes could be established via adulterated feedstocks or via purposeful contamination of populations in animal shelters or pet stores and then subsequently transmitted to humans. Natural transfers resulting from animal-human contact, such as the transfer of the parasite Toxoplasma gondii from cats to humans and the transfer of Campylobacter from dogs to humans, illustrate the feasibility of this approach. Similarly, research into the role of the microbiome in pathogenesis could provide a roadmap as to how to generate improved pathogens that are better supported by their microbial peers. Studies involving wide-ranging transposon- or CRISPRbased deletion libraries of pathogens have provided many insights into pathogenesis that might have dual-use implications, and such libraries could prove useful in identifying which genes productively or specifically interact with endogenous flora to better establish a pathogen [30]. In addition to using the microbiome to spread toxins and pathogens, manipulating the microbiome might also prove

\footnotetext{
${ }^{10}$ Synlogic. 2017. IND-Enabling Studies. URL: https:/www.synlogictx.com/pipeline/pipeline/ (date: 20.01.2021).

${ }^{11}$ Human Microbiome Project. NIN. 2020. August 20. URL: https://commonfund.nih.gov/hmp (date: 12.01.2021).
} 


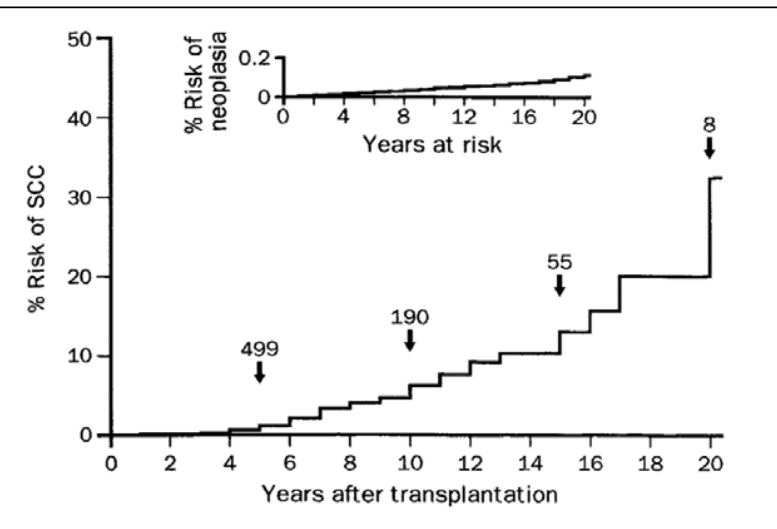

Figure 5 - Cumulative risk of neoplasia after organ transplantation. The risk was $13.6 \%$ after ten years and $40 \%$ after 20 years. Figures above are numbers of recipients at risk for 5-years period [36]

to be a useful adjunct for other biological threats. Recent research shows, for example, that eukaryotic viruses utilize bacteria to improve their chances of infection. It is also conceivable that an actor could introduce an initial agent into a population in order to trigger widespread treatment with broadspectrum antibiotics and then take advantage of the treated population's «clean slate» to introduce or expand an engineered organism via the (now disrupted) microbiome. An actor taking this twostep approach could even incorporate antibiotic or antiviral resistance elements into the initial attack.

Engineered dysbiosis. Our ever-increasing understanding of the human microbiome may lead to opportunities for engineered dysbiosisthat is, the purposeful perturbation of the normally healthy microbiome. This could be accomplished either by causing a known dysbiosis or engineering a new one, and in either case would likely involve introducing otherwise nonpathogenic microorganisms that then lead to diminutions in human health and performance. Since the microbiome likely plays a key role in human dysbioses could also potentially be used to cause longer-term debilitation of a population's ability to defend against disease. Gut, oral, nasal, and skin microbiomes could be targets for such an approach. The degradation of military readiness due to continued operations in harsh climes is an ongoing issue. This situation could be made much worse by targeted additions to or alterations of the skin microbiome that lead to heightened chafing, rashes, windburn, and itchiness. While these are seemingly minor concerns, over time they could degrade military capabilities to the point of impacting readiness.

\section{$\mathrm{x})$ Modifying the human immune system}

Human immunity is the bulwark for protection against infectious disease (For quick review see ref. [31-33]). Two basic systems respond to the vast array of threats in the natural environment. The first is the innate immune system, a collection of nonspecific protective mechanisms triggered by pathogenassociated molecular patterns, such as lipoteichoic acid from Gram-positive bacteria or unmethylated CpG sequences in viral DNA. The second is the adaptive immune system, which generates highly specific antibody and T-cell responses tailored to individual diseases and disease variants. Many natural pathogens manipulate the human immune system, both by suppressing the immune response (e.g., immunodeficiency viruses) and by upregulating certain responses (e.g., respiratory syncytial virus, which induces the immune system to favor a response involving Type $2 \mathrm{~T}$ helper cells [Th2] and subsequently increases the proclivity toward asthma. These examples suggest that it may be feasible to develop a bioweapon capable of manipulating or "engineering» the immune response. Several potential forms for such a bioweapon were considered:

Engineering immunodeficiency. Manipulating a target population to have decreased immunity could increase the impact of a biological attack $[17,34]$. This goal could be pursued either by manipulating a pathogen to simultaneously reduce immunity and cause disease or by separately introducing an immune-suppressing agent and a bioweapon into a target population. Agents used to cause immunodeficiency could be pathogens (e.g., the insidious spread of HIV (human immunodeficiency virus) or chemicals). It is also possible that a disease agent could be tailored to the immune state of a population, either by engineering the agent to avoid extant adaptive or innate immune barriers or by actually taking advantage of those barriers. Chronic (artificial) immunodeficiency as in patients after solid organ transplants can lead to «spontaneous» tumors (Figure 5) which occurs in $40 \%$ recipients in 20 years after surgery $[35,36]$.

Engineering hyperreactivity. The flip side of engineering immune deficiencies would be to attempt to cause immune hyperreactivity. Both pathogens and chemicals have been demonstrated to create a cytokine storm, a dangerous state that results from a positive feedback loop in the immune response. It may be possible to engineer an agent to purposefully trigger such a cascade. For example, some researchers have suggested that the introduction of anthrax lethal toxin into a more benign disease vector could trigger a cytokine storm. There are already widespread responses in the human population to a limited number of well-known allergens and that may provide a means of engineering biological threats that would trigger life-threatening IgE-mediated immune responses. The development and testing of new immunotherapies could also provide a roadmap for potentially engineering threats; for example, actors 
could learn from clinical studies in which antiCD28 antibodies caused life-threatening cytokine storms.

Engineering autoimmunity. Natural autoimmune diseases cause significant disability and death. It may be possible to engineer a disease that causes the body to turn on itself. Mouse models for the stimulation of autoimmunity now exist. For example, Experimental Autoimmune Encephalomyelitis, which mimics the symptoms of the human malady multiple sclerosis, has been induced in mice by immunization with antigens that cause an immune response [37]. Normally, such self-immunization is prevented by the mechanisms that ensure exclusion of antibodies and T-cells that are self-reactive, but some pathogens may present antigens that are similar enough to the body's own proteins that the original immune response spreads from the pathogen to the new human target. Research into checkpoint inhibitors, compounds designed to unleash the human immune system to eradicate tumors, could also potentially inform efforts to purposely engineer autoimmunity. By overstimulating the immune system, checkpoint inhibitors have been shown to lead to autoimmunity, often in the form of colitis. In addition, particular compounds have been shown to lead to an autoimmune disease of the liver. One potential route of attack could be to introduce such compounds via the microbiome.

\section{xi) Modifying the human genome:}

In addition to using synthetic genes to impact human physiology through pathogens or modifications to the microbiome, it may also be possible to insert engineered genes directly into the human genome via horizontal transfer, in other words, to use «genes as weapons». Recent improvements in the ability to deliver genetic information via horizontal transfer, for example, through tools such as CRISPR/Cas9, potentially opened the way for synthetic or cross-species transfer of genetic information into human hosts. In addition to protein-encoding genes, genes that encode RNA products such as short hairpin RNAs (shRNAs) or miRNAs could potentiallybe exploited as weapons in their own right. In combination with technologies for the modification of genes or their expression, deepening insights into systems biology could open new opportunities for causing diseases that are outside the rubric of the types of threats typically focused on in biodefense. Several ways in which synthetic biology approaches could be used to horizontally transfer genetic information to a human target to cause harm were considered:

Deletions or additions of genes. If researchers can create mouse models of particular disease states based on the deletion or addition of particular genes, it follows that if the genomes of human beings could be similarly modified, such modifications could potentially cause a wide variety of noninfectious diseases. In particular, decades of research on genes associated with oncogenesis - oncogenes - have yielded many examples of gene changes that lead to cancer, including via infection by viruses and bacteria. Oncogenes could potentially be horizontally transferred to human cells via unnatural means. In this vein, CRISPR/Cas9 has been used to create point mutations, deletions, and complex chromosomal rearrangements in germline and somatic cells to develop mouse models for cancer [38].

Epigenetic modifications. Just as programmed genetic modifications are possible, it may also prove possible to use horizontal transfer to alter the epigenetic state of an organism in a way that causes harm. Epigenetic modifications are clearly of immense importance in gene expression and are implicated in disease states and pathogenicity. For example, it is possible to predict the course of oncogenesis based on the epigenetic state of a tumor. Sequence-specific epigenetic modifications can be carried out by small RNAs in other species, such as plants, but are not extensive in humans. However, the sequence-specific binding capabilities of Cas9 and other CRISPR elements may allow fusion proteins to carry out sequence-specific epigenetic modifications [39]. There are also chemicals that yield relatively nonspecific epigenetic changes [40].

Small RNAs. Small RNAs are another example of functional genetic information that could be horizontally transferred. Small RNAs, although not a genome modification per se, are important because they may prove capable of modifying gene expression and bringing about phenotypic change. The large number of small interfering RNA (siRNA), short hairpin RNA (shRNA), micro RNA (miRNA) and other small-RNA library studies in a variety of species and cells from different species, including human, provides a potential roadmap of what sequences may lead to what disease states or to modulation of defenses against disease (for review see [41]). Similarly, there are already numerous viral and other vectors that can encode and express small RNAs. The known fact that, many viral pathogens already seem to encode small RNAs that aid in their pathogenicity further underlines this possibility [42]. For example, the oncogenic gamma herpesviruses Epstein-Barr virus (EBV) and Kaposi's sarcoma-associated herpesvirus (KSHV) encode miRNAs that clearly act as mediators of immune suppression [43]. While most gene delivery mechanisms would likely be facilitated by CRISPR elements, direct delivery of small RNAs via liposomes or other vehicles has proven possible in many cell types. More recently the delivery of entire messenger RNAs (mRNAs) has proven useful for vaccination and cellular reprogramming [44]. Naked RNA is generally considered to be fragile 
due its susceptibility to ribonuclease in the cell, and its delivery is largely confined to laboratory settings, but there are approaches for stabilizing RNAs (e.g., using liposomes, nanoparticles, synthetic polymers, cyclodextrins, ribonucleoproteins, and viral capsids. RNA can be expressed from genes delivered as simple expression vectors, as low fitness-burden cargoes on viral pathogens, or via CRISPR element insertion. One reason that RNA delivery is potentially a viable biological threat is that even a small initial skew in gene expression (such as the changes in gene expression normally caused by miRNAs) could greatly alter the probability of an initial cellular alteration. Even small amounts of a targeted RNA would not modify the genome per se but might allow or encourage cells to begin the process of selftransformation to tumors, as evidenced by the fact that a large number of pro-oncogenic miRNAs have already been discovered [45]. In addition to RNAs produced by viruses, bacteria produce numerous small regulatory RNAs; introduction of these into the endogenous microbiome could lead to dysbiosis. Larger mRNAs can also be delivered via liposomes and nanoparticles or by RNA replication strategies being developed for vaccine production; these methods could potentially be used to express deleterious cargo such as toxins or oncogenes, similar to threats related to DNA vectors.

CRISPR/Cas9. CRISPR elements can be harnessed for site-specific cleavage of genes, followed by homologous recombination via doublestrand break repair or other mechanisms. This technology has revolutionized genome engineering. The fact that DNA recognition can be programmed by simple modification of an RNA element makes precision targeting of genome change much easier than previous technologies such as zinc finger endonucleases and TAL effector nuclease (TALEN)-mediated sequence specific recognition of DNA. Another advantage of CRISPR technology is its broad host range; CRISPR elements are able to recognize and bind to DNA sequences in species other than those in which they originally evolved. Thus, the fact that gene editing technologies such as CRISPR make possible genomic changes in animal models that directly impact health and pathogenesis further implies that it may be possible to manipulate either germline or somatic cells to make such changes in humans. Significantly, the sequence specificity of CRISPR elements might also make possible ethno specific targeting of genebased weapons depending on the distributions of alleles. In terms of delivery, CRISPR elements could potentially be loaded onto a pathogen or delivered via the microbiome to modify human genomes in a way that would pose harm to individuals or populations.

Human gene drives. Because of the ability of CRISPR elements to modify genomes, they can be repurposed as selfish genetic elements in their own right, wherein their introduction into a naïve genome leads to their site-specific establishment. In sexually reproducing organisms, an appropriately modified CRISPR element or other homing endonuclease gene, when used as a gene drive, can spread throughout a population. Gene drives are well known in nature, such as the Drosophila $\mathrm{P}$ element, which moves nonspecifically through naïve populations based on sexual (vertical) transfer. Gene drives have recently proven to be extremely useful for engineering mosquito populations for infertility [46]. They have been proposed for the attenuation of fitness in other undesirable species, as well ${ }^{12}$.

It should be noted that exome sequence data are being generated at an exponential rate, the introduction of CRISPR elements in humans or other higher organisms would likely be identified quickly and immediately recognized as cause for alarm. The presence of previously unknown oncogenes in viruses not normally known to harbor oncogenes would also be an immediate cause for alarm. However, the surreptitious spread of an oncogenic small-RNA sequence, especially if it is embedded within a protein-encoding gene, might be less noticeable and thus evade detection. In addition, threats related to horizontal gene transfer in synergy with the threats posed by pathogens may lead to new modes of attack. Just as clinical trials of immunotherapies are increasingly a roadmap for engineering cytokine storms, the increasing knowledge on gene deletions, gene additions, and small-RNA modifications of human cells may provide a roadmap for the induction of noninfectious disease states that could be abetted by pathogen engineering (and, conversely, that could abet the spread of the pathogens themselves, such as via immunodeficiency viruses).

Finally, let us fully cite from the book Biodefense in the Age of Synthetic Biology p. 92, printed in 2018: ${ }^{13}$

«More insidiously, it is possible that some diseases could be engineered not only to target but to actively take advantage of known immune prevalences, in particular

\footnotetext{
12 National Academies of Sciences, Engineering, and Medicine. Gene Drives on the Horizon: Advancing Science, Navigating Uncertainty, and Aligning Research with Public Values. Washington, DC: The National Academies Press. 2016.

${ }^{13}$ Biodefense in the Age of Synthetic Biology 2018. ISBN 978-0-309-46518-2. https://doi.org/10.17226/24890 (Committee on Strategies for Identifying and Addressing Potential Biodefense Vulnerabilities Posed by Synthetic Biology, Board on Chemical Sciences and Technology, Board on Life Sciences).
} 
those related to vaccination. An extremely sophisticated adversary, knowing in advance the likely fitness landscape of a given pathogen, could release an engineered pathogen that is "designed to evolve» in particular ways upon encountering the most likely human immune response. For example, if an immunodominant epitope is known, and if previous modeling or experimentation had indicated the range of likely sequence substitutions in response to the antibodies already present due to vaccination, and if some of these sequence substitutions lead to increased engagement with a cell surface receptor, then the sequence of the pathogen could be poised in advance to evolve greater lethality or transmissibility. The advantage of this approach, from a malicious actor's perspective, is that a milder form of a disease could spread broadly and then «self-activate» as a result of «designed evolution» to become a pandemic».

It is not very much that one can add to this prophetic paragraph.

\section{Author Contribution}

Elaboration of the concept of the paper; collection, analysis, and systematization of scientific literature; writing and edition of paper.

\section{Conflict of interest statement}

I am declaring that I prepared the article from sources freely available on the Internet and free available publications, figures and other possible legal sources. I, as a sole author declare that the research was conducted in the absence of any commercial or financial relationship that could be construed as a potential conflict of interest.

\section{Peer review information}

The article has been peer reviewed by two experts in the respective field. Peer reviews are available from the Editorial Board and from Russian Science Citation Index database.

\section{References:}

1. Young E., Alper H. Synthetic biology: tools to design, build, and optimize cellular processes // Journal of Biomedicine and Biotechnology. 2010. https://doi. org/10.1155/2010/130781

2. Singh S.P., Bansal S., Pandey A. Basics and Roots of Synthetic Biology (In book: Current Developments in Biotechnology and Bioengineering Synthetic Biology, Cell Engineering and Bioprocessing Technologies (P. 3-22). Publisher: Elsevier. https://www.researchgate. net/publication/334646804_Basics_and_Roots_of_ Synthetic_Biology

3. Reis A. CRISPR/Cas9 and Targeted Genome Editing: A New Era in Molecular Biology / In CRISPR/ Cas9 and Targeted Genome Editing: A New Era in Molecular Biology. 2015. https://international.neb. com/tools-and-resources/feature-articles/crispr-cas9and-targeted-genome-editing-a-new-era-in-molecularbiology

4. Liu R., Liang L., Freed E.F. et al. Directed Evolution of CRISPR/Cas Systems for Precise Gene Editing // Trends Biotechnol. 2021. V. 39(3). P. 262-273. https://doi.org/10.1016/j.tibtech.2020.07.005

5. Ching T., Himmelstein D.S., Beaulieu-Jones B.K. et al. Opportunities and obstacles for deep learning in biology and medicine // J. R. Soc. Interface. 2018. V. 15(141). 20170387.https://doi.org/10.1098/rsif.2017.0387

6. Zhang J., Petersen S.D., Radivojevic T. et al. Combining mechanistic and machine learning models for predictive engineering and optimization of tryptophan metabolism // Nat. Commun. 2020. V. 11(1). 4880. https://doi.org/10.1038/s41467-020-17910-1
7. Thomsen J., Sletfjerding M.B., Jensen S.B. et al. DeepFRET, a software for rapid and automated singlemolecule FRET data classification using deep learning // Elife. 2020. V. 9. e60404. https://doi.org/10.7554/ eLife.60404

8. Lakota Ján. Today`s Biothreats - Where the Past Predictions Meet the Future // Journal of NBC Protection Corps. 2020. V. 4. № 4. P. 421-440. https:// doi.org/10.35825/2587-5728-2020-4-4-421-430

9. Cello J., Paul A.V., Wimmer E. Chemical synthesis of poliovirus cDNA: Generation of infectious virus in the absence of natural template // Science. 2002. V. 297(5583):. P. 1016-1018. https://doi.org/10.1126/ science. 1072266

10. Lee Y.N., Bieniasz P. Reconstitution of an infectious human endogenous retrovirus // PLoS Pathog. 2007. V. 3(1): e10. P. 0119-0130. https://doi.org/10.1371/ journal.ppat.0030010

11. Wimmer E., Paul A.V. Synthetic poliovirus and other designer viruses: What have we learned from them? // Annual Review of Microbiology. 2011. V. 65. P. 583-609. https://doi.org/10.1146/annurevmicro-090110-102957

12. Noyce R.S., Lederman S., Evans D.H. Construction of an infectious horsepox virus vaccine from chemically synthesized DNA fragments // PLoS ONE. 2018. V. 13(1). e0188453. https://doi.org/10.1371/ journal.pone. 0188453

13. Gibson, D.G., Glass J.I., Lartigue C. et al. Creation of a bacterial cell controlled by a chemically synthesized genome // Science. 2010. V. 329(5987. P. 52- 
56. https://doi.org/10.1126/science.1190719

14. de Vries R.P., Peng W., Grant O.C. et al. Three mutations switch H7N9 influenza to humantype receptor specificity // PLoS Pathogens. 2017. V. 13(6):e1006390. https://doi.org/10.1371/journal. ppat.1006390

15. Becker M.M., Graham R.L., Donaldson E.F. et al. Synthetic recombinant bat SARS-like coronavirus is infectious in cultured cells and in mice // Proc. Natl. Acad. Sci. USA. 2008. V. 105(50). P. 19944-19949. https:// doi.org/10.1073/pnas.0808116105

16. Cockrell A.S., Yount B.L., Scobey T. et al. A mouse model for MERS coronavirus induced acute respiratory distress syndrome // Nature Microbiology. 2016. V. 2. 16226. https://doi.org/10.1038/ nmicrobiol.2016.226

17. Jackson P.J., Ramsay A. J., Christensen C.D. et al. Expression of mouse interleukin- 4 by a recombinant ectromelia virus suppresses cytolytic lymphocyte responses and overcomes genetic resistance to mousepox // J. Virol. 2001. V. 75, № 3. P. 1205-1210. https://doi.org/: 10.1128/JVI.75.3.1205-1210.2001

18. Iwasaki A., Medzhitov R. Innate responses to viral infection / in Field's Virology, 6th Ed., D.M. Knipe and P.M. Howley, eds. Philadelphia, PA: 2013. P. 189-213.

19. Gorman S., Viseshakul N., Cohen B. et al A recombinant adenovirus that directs secretion of biologically active $\kappa$-bungarotoxin from mammalian cells // Molecular Brain Research. 1997. V. 44, № 1. P. 143146. https://doi.org/10.1016/S0169-328X(96)00250-1

20. Coen D.M., Richman D.D. Antiviral agents / in Field's Virology, 6th Ed., D.M. Knipe and P.M. Howley, eds. Philadelphia, PA: 2013. P. 338-373.

21. Ribet D., Cossart P. How bacterial pathogens colonize their hosts and invade deeper tissues // Microbes and Infection. 2015. V. 15(3). P. 173-183. https://doi.org/10.1016/j.micinf.2015.01.004

22. Cress B.F., Englaender J.A., He W. et al. Masquerading microbial pathogens: Capsular polysaccharides mimic host-tissue molecules // FEMS Microbiology Reviews. 2014. V. 38(4). P. 660-697. https://doi.org/10.1111/1574-6976.12056

23. Quenee L.E., Hermanas T.M., Ciletti N. et al. Hereditary hemochromatosis restores the virulence of plague vaccine strains // Journal of Infectious Diseases. 2012. V. 206(7). P. 1050-1058. https://doi.org/10.1093/ infdis/jis433

24. Carleton H.A., Gerner-Smidt P. Wholegenome sequencing is taking over foodborne disease surveillance // Microbe. 2016. V. 11(7). P. 311-317.

25. Blair J.M., Webber M.A., Baylay A.J. et al. Molecular mechanisms of antibiotic resistance // Nature Reviews Microbiology. 2015. V. 13. P. 41-51. https://doi. org/10.1038/nrmicro3380

26. Revich B.A., Podolnaya M.A. Thawing of permafrost may disturb historic cattle burial grounds in East Siberia // Global Health Action. 2011. V. 4(1). 8482. https://doi.org/10.3402/gha.v4i0.8482

27. Luo M.L., Mullis A.S., Leenay R.T. et al.
Repurposing endogenous type I CRISPR-Cas systems for programmable gene repression // Nucleic Acids Research. 2015. V 43(1). P. 674-681. https://doi. org/10.1093/nar/gku971

28. Zhang Y., Ptacin J.L., Fischer E.C. et al. A semisynthetic organism that stores and retrieves increased genetic information // Nature. 2017. V. 551(7682). P. 644-647. https://doi.org/10.1038/nature24659

29. Krishnamurthy M., Moore R.T., Rajamani S. et al. Bacterial genome engineering and synthetic biology: Combating pathogens // BMC Microbiology. 2016. V. 16. 258. https://doi.org/10.1186/s12866-016-0876-3

30. Barquist L., Boinett C.J., Cain A.K. Approaches to querying bacterial genomes with transposoninsertion sequencing // RNA Biology. 2013. V. 10(7). P. 1161-1169. https://doi.org/10.4161/rna.24765

31. Simon A.K., Hollander G.A., McMichael A. Evolution of the immune system in humans from infancy to old age // Proc. Biol. Sci. 2015. V. 282(1821). P. 20143085. https://doi.org/10.1098/rspb.2014.3085

32. Delves P.J. Overview of the Immune System // MSD Manual for the Consumer. 2020 Apr. https://www. msdmanuals.com/home/immune-disorders/biologyof-the-immune-system/overview-of-the-immunesystem (дата обращения: 21.12.2020)

33. Brodin P., Davis M.M. Human immune system variation // Nat. Rev. Immunol. 2017. V. 1. P. 21-29. https://doi.org/10.1038/nri.2016.125

34. Koch L., Lopes A., Maiguy A. et al. Natural outbreaks and bioterrorism: How to deal with the two sides of the same coin? // J. Glob. Health. 2020. V. 10(2). 020317. https://doi.org/10.7189/jogh.10.020317

35. Dantal J., Soulillou J.P. Immunosuppressive drugs and the risk of cancer after organ transplantation // N. Engl. J. Med. 2005. V. 352(13). P. 1371-1373. https:// doi.org/10.1056/NEJMe058018

36. London N.J., Farmery S.M., Will E.J. et al. Risk of neoplasia in renal transplant patients // Lancet. 1995. V. 346(8972). P. 403-406. https://doi.org/10.1016/ s0140-6736(95)92780-8. Erratum in: Lancet. 1995. Sep 9; V. 346(8976). P. 714. PMID: 7623570.

37. Constantinescu C.S., Farooqi N., O'Brien K. et al. Experimental autoimmune encephalomyelitis (EAE) as a model for multiple sclerosis (MS) // Br. J. Pharmacol. 2011. V. 64(4). P. 1079-1106. https://doi.org/10.1111/ j.1476-5381.2011.01302.x

38. Mou H., Kennedy Z., Anderson D.G. et al. Precision cancer mouse models through genome editing with CRISPR-Cas9 // Genome Medicine. 2015. V. 7. 53. https://doi.org/10.1186/s13073-015-0178-7

39. Brocken D.J.W., Tark-Dame M., Dame R.T. dCas9: A versatile tool for epigenome editing // Current Issues in Molecular Biology. 2017. V. 26. P. 15-32. https:// doi.org/10.21775/cimb.026.015

40. Bennett R.L., Licht J.D. Targeting epigenetics in cancer // Annual Reviews of Pharmacology and Toxicology. 2018. V. 58. P. 187-207. https://doi. org/10.1146/annurev-pharmtox-010716-105106

41. RNA-Based Regulation in Human Health and 
Disease / Ed. Rajesh Pandey, 2020. V. 19, Translational Epigenetics. Academic Press; 1st edition (19 Aug. 2020). 42. Vojtechova Z., Tachezy R. The Role of miRNAs in Virus-Mediated Oncogenesis // Int. J. Mol. Sci. 2018. V. 19(4). P. 1217. https://doi.org/10.3390/ijms19041217

.43. Cullen B.R. MicroRNAs as mediators of viral evasion of the immune system // Nature Immunology. 2013. V. 14(3). P. 205-210. https://doi.org/10.1038/ ni. 2537

44. Steinle H., Behring A., Schlensak C. et al. Concise review: Application of in vitro transcribed messenger RNA for cellular engineering and reprogramming: Progress and challenges // Stem Cells. 2017. V. 35(1). P. 68-79. https://doi.org/10.1002/ stem. 2402

45. O’Bryan S., Dong S., Mathis J.M. et al. The roles of oncogenic miRNAs and their therapeutic importance in breast cancer // European Journal of Cancer. 2017. V. 72. P. 1-11. https://doi.org/10.1016/j.ejca.2016.11.004

46. Hammond A., Galizi R., Kyrou K. et al. A CRISPR-Cas9 gene drive system targeting female reproduction in the malaria mosquito vector Anopheles gambiae // Nature Biotechnology. 2016. V. 34(1). P. 78-83. https://doi.org/10.1038/nbt.3439

Author

Centre of Experimental Medicine, SAS, Dubravska cesta 9, 84104 Bratislava, Slovakia Faculty of Management Comenius University, Odbojárov 10, 82005 Bratislava, Slovakia

Ján Lakota. MD, PhD

\title{
Синтетическая биология - друг или враг? Каких угроз нам следует ожидать?
}

\author{
Ян Лакота \\ Центр экспериментальной медицины, Академия наук Словакии, Дубравская \\ 9, 841 04, Братислава; Факультет менеджмента, Университет им. Я.А. Коменского, \\ ул. Бойцы Сопротивления 10, 820 05, Братислава, Словакия
}

\begin{abstract}
Поступила 10.02.2021 г. Принята к публикации 20.06.2021 г.
Синтетическая биология - недавно появившаяся ветвь технологий двойного назначения, новая область применения инженерных принципов в биологии. Цель работь - показать основные технологические приемы этой технологии и привести конкретные примеры ее использования для создания новых видов биологических поражающих агентов и приемов ведения биологической войны, ранее немыслимых и представленных только в научно-фантастических книгах. Основные инструменты и методические приемы синтетической биологии: синтез и секвенирование больших фрагментов ДНК; разработка «платформы» («шасси») - т.е. системы-хозяина, несущей генетический набор инструментов для экспрессии желаемых генов сконструированного биологического пути, доставляемых подходящими векторами; разработка систем транскрипции, не истощающих ресурсы клетки (синтетические промоторы и факторы транскрипции); инструменты модификации генома (нуклеаза CRISPR/Cas9, нуклеазы цинковых пальцев, TALE нуклеазы, мегануклеазы); и компьютерные инструменты (участвующие в базовом структурном проектировании и синтезе; в проектировании сети; в прогнозировании поведения/функции/реакции). Синтетическая биология уже показала большие возможности в воссоздании известных патогенных вирусов и патогенных бактерий; в повышении опасности для людей существующих патогенных бактерий и вирусов (например, путем повышения их вирулентности или способности преодолевать иммунитет); создании патогенов, ранее не существовавших в природе; производства токсичных химикатов или биохимических веществ с использованием естественных и искусственных метаболических путей; изготовлении токсических веществ посредством синтеза in situ; изменение микробиома человека; изменения иммунной системы человека; модификации генома человека путем добавления, удаления или модификации генов или посредством эпигенетических изменений, которые изменяют экспрессию генов и могут передаваться от родителя к ребенку во время репродукции, распространяя генетические изменения в популяции. В работе подробно рассмотрены возможности синтетической биологии для разработки новых средств и способов ведения биологической войны. Например, введение в геном вируса эктромелии (оспы
\end{abstract}


мышей) гена интерлейкина-4 значительно повысило его вирулентность для мышей. Он подавлял первичные иммунные ответы и преодолевал ранее существовавший иммунитет к исходному вирусу. Аналогичный результат был получен с рекомбинантным аденовирусом, кодирующим нейрональный токсин индийской змеи бунгаруса - бунгаротоксин. Путем введения в составе инъекционных препаратов антигенов, похожих на собственные белки человека, можно за короткий срок вызвать аутоиммунное состояние у тысяч людей, которое проявится у них через годы рассеянным склерозом и другими энцефалопатиями. Приводится работа, опубликованная в 2018 г., в которой утверждается, что современные технологии синтетической биологии и математического моделирования эпидемий, если уже известен иммунодоминантный эпитоп патогена, позволяют сконструировать такой его вариант, который при «столкновении» с наиболее вероятным иммунным ответом человека будет эволюционировать в сторону большей контагиозности и способности преодолевать иммунитет, сформировавшийся в результате уже перенесенной болезни или вакцинации. Автор считает, что необходимо не только постоянно отслеживать эти новые биотехнологии двойного назначения, но и совершенствовать традиционные и научные методы мониторинга их использования.

Ключевые слова: синтетическая биология; угроза; возбудитель; бактерии; вирус; человек.

Библиографическое описание: Лакота Ян. Синтетическая биология - друг или враг? Каких угроз нам следует ожидать? // Вестник войск РХБ защитыл. 2021. Т. 5. № 2. С. 103-122. https://doi.org/10.35825/2587-5728-2021-5-2-103-122

Вклад автора

Разработка концепции статьи; сбор, анализ и систематизация научной литературы; написание и издание статьи.

\section{Заявление о конфликте интересов}

Я заявляю, что подготовил статью на основании источников, свободно доступных в Интернете, бесплатных публикаций, рисунков и других легальных источников. Я, как единственный автор, заявляю, что исследование проводилось при отсутствии каких-либо коммерческих или финансовых отношений, которые могут быть истолкованы как потенциальный конфликт интересов.

\section{Сведения о рецензировании}

Статья прошла открытое рецензирование двумя рецензентами, специалистами в данной области. Рецензии находятся в редакции журнала и в РИНЦе.

\section{Список источников:}

Cmp. 119-121.

Об авторе

Центр экспериментальной медицины, Академия наук Словакии, Дубравская дорога 9, 841 04, Братислава, Словакия.

Факультет менеджмента, Университет им. Я.А. Коменского, ул. Бойцы Сопротивления 10, 820 05, Братислава, Словакия.

Ян Лакота. $\mathrm{MD}, \mathrm{PhD}$

Контактное лицо: Ян Лакота; jan.lakota@savba.sk 


\section{М.В. Супотницкий Федеральное государственное бюджетное учреждение
"27 Научный чентр» Министерства обороны Российской Федерации,
105005, Российская Федерация, г. Москва, Бригадирский переулок, д. 13}

Поступила 23.04.2021 г. Принята к публикации 20.06.2021 г.

Сернистый иприт широко использовался в ходе ирано-иранской войны (1980-1988 гг.) и в других конфликтах на Ближнем Востоке. Благодаря своей доступности он может быть применен террористическими организациями на территории Российской Федерации. Иран единственная страна, против которой иприт применялся в условиях современной войны. Цель работы - анализ и обобщение опыта лечения массовых поражений военнослужащих сернистым ипритом, накопленного иранскими специалистами в ходе ирано-иракской войны 1980-1988 гг. Для подготовки статьи использовались официальные документы ООН, ЦРУ США, иранские работы и другие открытые источники. Установлено, что иракская армия применяла иприт в двух агрегатных состояниях - капельножидком и сухом. Сухой иприт новинка той войны. Он представляет собой тонко измельченный кремнезем, пропитанный ипритом, размер частиц - менее 5 мкм. Первые клинически выраженные признаки поражения появлялись через 15 мин, в то время как действие иприта в капельножидком и парообразном состоянии могло начаться через несколько часов. Причиной тяжелых ипритных поражений иранских военнослужащих было отсутствие средств индивидуальной защиты, несвоевременная эвакуация из зоны заражения ипритом, отсутствие в боевых порядках мобильных запасов чистой воды и дегазационных установок, неправильная сортировка пораженных. Наиболее эффективным дегазирующим раствором для кожи, который можно применить при массовом поступлении пораженных ипритом, иранские специалисты считают $0,5 \%$ раствор гипохлорита натрия. Единственным безопасным антидотом в реалиях войны остается тиосульфат натрия, но если его ввести отравленному в течение 60 мин после воздействия иприта. При эвакуации пострадавших и лечении в госпиталях в тяжелых случаях необходимо устанавливать внутривенный катетер, проводить трахеотомию с установлением трахеотомической трубки, как можно раньше использовать бронхоскопию для промывания бронхов. Лечение поражений кожи и глаз - консервативное. При перфорации роговицы, если ее диаметр составляет более 2 мм - кератопластика, менее - цианоакрилатный клей. Лечение поражений органов дыхания направлено на облегчение симптомов и уменьшение тяжести осложнений. Для этого применяют бронходилататоры, противокашлевые средства, муколитики и, при необходимости, антибиотики. Применение кортикостероидов должно быть ограничено лечением тех пациентов с бронхоспазмом, которым не помогают бронходилататоры. Из перспективных методов лечения ипритных поражений легких иранские врачи рассматривают генную терапию и лечение мезенхимальными стволовыми клетками.

Ключевые слова: генная терапия; дегазация; зоны контроля; ирано-иракская война; мезенхимальные стволовые клетки; отложенные осложнения; сернистый иприт; сухой иприт; тиосульбат натрия; химическое оружие.

Библиографическое описание: Супотницикй М.В. Химическое оружие в ирано-иракской войне 1980-1988 годов. 5. Накопленный опыт лечения поражений сернистым ипритом // Вестник войск РХБ защииты. 2021. Т. 5. № 2. C. 123-135. https://doi.org/10.35825/2587-5728-2021-5-2-123135 
Применение иракской армией химического оружия в ходе ирано-иракской войны 1980-1988 гг. привело к большим потерям среди иранских военнослужащих и изменило ход войны в пользу Ирака при несопоставимых с Ираном людских ресурсах. Основными отравляющими веществами (OB) на ирано-иракском фронте были сернистый иприт, табун, зарин и циклозарин. Анализ эффективности применения химического оружия показал, что благодаря массированности и многократности его применения авиацией, реактивными системами залпового огня (РСЗО), а также использованию OB второго поколения (табун, зарин, циклозарин), смертоносность химического оружия по сравнению с Первой мировой войной (ПМВ) возросла в десятки раз. В ходе всей ираноиракской войны и в послевоенный период иранскими врачами велась кропотливая работа по накоплению опыта лечения поражений ОВ на фронте, а также сведений о последствиях, проявляющихся уже в мирное время. Такого опыта нет ни у одной страны мира. Однако в российской научной литературе мы не нашли каких-либо обобщающих работ по данной проблеме. А изучать есть что. По данным Комиссии ООН по наблюдению, контролю и инспекциям (United Nations Monitoring Verification \& Inspection Commission, UNMOVIC), за время войны по иранским войскам было применено 2,54 тыс. т ОВ (1,8 тыс. т сернистого иприта, 140 т табуна, около 600 т зарина/циклозарина). Иракская армия провела не менее 387 крупных химических атак на иранские войска $[1,2]$.

Цель работы - анализ и обобщение опыта лечения массовых поражений военнослужащих сернистым ипритом в ходе ирано-иракской войны, накопленного иранскими специалистами 1980-1988 гг.

Статья представляет собой пятое исследование, посвященное применению химического оружия в ирано-иракской войне ${ }^{1}$. Для ее подготовки использовались официальные документы и материалы ООН, ЦРУ США, иранские и западные научные работы, а также другие открытые источники. При описании лечения поражений сернистым ипритом основное внимание уделялось публикациям иранских медицинских специалистов, имевших клинический опыт ведения нескольких тысяч пациентов с поражениями ОВ во время ирано-иранской войны и наблюдавших за ними более трех десятилетий - это S.A. Foroutan, L. Etemad, M. Moshiri, M. Balali-Mood, M. Tabarestani,

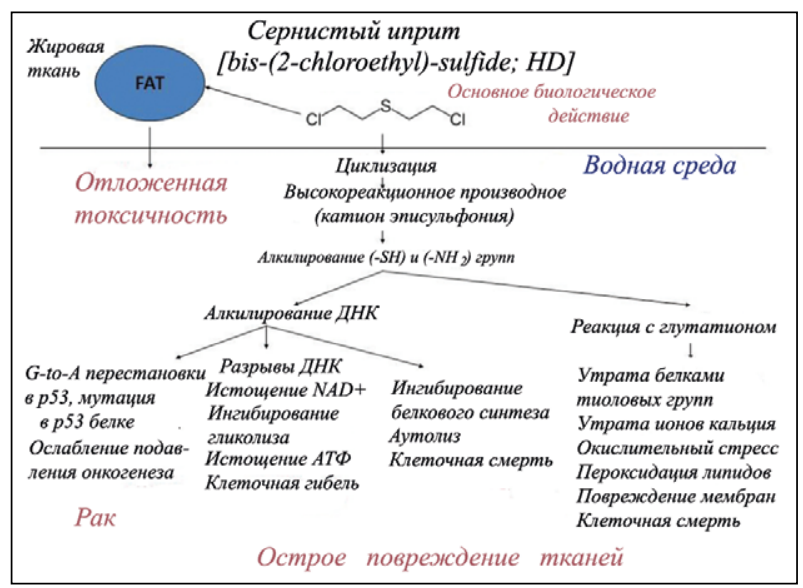

Рисунок 1 - Механизм действия сернистого иприта. Это жирорастворимая молекула с потенциальной способностью длительно сохраняться в жировой ткани. При попадании в водную среду нежировой ткани человека он циклизуется с образованием высокореактивного катиона эписульфония, который алкилирует ДНК и инактивирует глутатион (основной клеточный антиоксидант). Алкилирование ДНК приводит к заменам нуклеотидов, чаще всего к переходу G в А. Такая мутация может инактивировать гены-супрессоры опухолей ( $p 53$ ) и вызвать у отравленного рак легких, как это было замечено у рабочих японского завода по производству иприта. Инактивация глутатиона вызывает дисбаланс окислительно-восстановительной активности клеток и нарушает регуляцию воспалительных реакций. Высокий уровень воспалительных цитокинов ингибируem anonтоз полиморфно-ядерных лейкоцитов, особенно нейтрофилов, таким образом продлевая их активное состояние и усиливая повреждение тканей [8]

I. Freitag, N. Firusian, E. Darchini-Maragheh и др. Обобщению опыта лечения поражений ОВ нервно-паралитического действия будет посвящена отдельная статья.

Новое в применении сернистого иприта ${ }^{2}$. Механизм токсического действия иприта точно не установлен. Одна из схем, показывающая такой механизм, приведена на рисунке 1. Иракцы применяли иприт в двух агрегатных состояниях - капельножидком и сухом. Если боевая эффективность первого известна еще с ПМВ и подробно описана в научной литературе [7], то сухой иприт оказался новинкой этой войны. Он представлял собой тонко измельченный (от 0,1 до 10,0 мкм) кремнезем, пропитанный ипритом.

\footnotetext{
В первой работе рассматривалась подготовка Ирака к химической войне [3], во второй - применение химического оружия в боевых действиях [4], в третьей - медицинские последствия применения химического оружия [5], в четвертой показано, каким образом происходила ликвидация химического оружия в Ираке [6].

2 Подробно поражения сернистым ипритом, полученные в ходе войны иранскими военнослужащими, обобщены в нашей работе [5].
} 
В основном размер частиц был менее 5 мкм, что позволяло им проникать и задерживаться в глубоких отделах легких человека. Латентный период при поражении таким ипритом значительно сокращался. Первые клинически выраженные признаки поражения появлялись через 15 мин, в то время как иприт в парообразном состоянии мог не подействовать на бойца в течение четырех-шести часов. Сухой иприт не обнаруживался газоанализаторами воздуха, рассчитанными на ОВ в состоянии пара, и проникал через костюмы химической защиты $[9,10]$. Первое применения иракцами авиабомб, снаряженных сухим ипритом, произошло в начале 1985 г. при отражении иранского наступления на нефтяные месторождения на островах Маджнун на южном участке реки Тигр. Иранские военнослужащие, получившие поражение таким ипритом, описывали его как белую пыль (... white dust were observed), появившуюся после разрыва бомбы [11].

После ПМВ значительно возросли возможности средств и способов ведения химической войны. Если в конце ПМВ основным средством применения ОВ стала ствольная артиллерия, то в ходе ирано-иракской войны широко использовались авиация и реактивные системы залпового огня, позволившие иракским войскам применять ОВ с невиданной в ПМВ массированностью. До 75 \% произведенных иракцами ОВ сброшено на иранцев авиабомбами․․ Авиация перенесла применение ОВ с тактической на oneративную глубину. Сернистый иприт в основном применялся 155-мм снарядами и авиабомбами [3]. Невозвратные потери воинских подразделений от иприта могли достигать 30 \%, что было невозможно в ПМВ [5]. Общая структура иранских потерь от химического оружия приведена в работе E. Darchini-Maragheh с соавт. [12] и в наших публикациях $[5,6]$.

Предотвращение поражений сернистым ипритом. Иранские медицинские специалисты выделяют ранние, хронические и отсроченные последствия воздействия сернистого иприта на человека. К «ранним поражениям» относятся полученные на поле боя. К «поздним» или «отсроченным» относятся те, которые обнаружились в послевоенное время у считавшихся вылеченными ветеранов войны, получивших поражения сернистым ипритом на фронте (в данной работе не рассматривается). Как оказалось, ранние и поздние поражения составляют единый процесс. «Хроническое осложнение» следствие постоянного профессионального контакта с ОВ в течение относительно длительного периода времени (в данной работе не рассматривается) [12-18].

Предотвращцение ранних поражений ипритом непосредственно в зоне боевых действий. Осуществляется на основе мер первичной и вторичной профилактики поражений ипритом. При планировании таких мероприятий исходят из того, что иприт может оставаться в жидкой фазе на загрязненной одежде, оружии, средствах защиты, личных вещах, коже военнослужащего в течение многих часов или даже дней.

Первичная профилактика направлена на снижение количества пораженных и уменьшение тяжести поражения, если не удалось избежать контакта с ипритом. Она включает немедленное удаление пострадавших от иприта из зоны заражения (горячая зона) ${ }^{4}$, снятие и удаление контаминированной одежды, оружия, снаряжения и личных вещей. Пострадавшие как можно скорее должны пройти сортировку (рисунок 2) и полную помывку 0,5 \% раствором гипохлорита натрия $(\mathrm{NaOCl})^{5}$ или большим количеством чистой воды с нейтральным мылом (что менее эффектно) [19].

Сортировка пораженных - это динамический процесс, который следует проводить непрерывно как в загрязненных (горячая зона), так и в чистых (теплая) зонах. Программы сортировки включают выявление следующих групп пораженных: Т 1 (немедленная или срочная): пострадавшие, которым требуется медицинская помощь и усиленное жизнеобеспечение в течение короткого времени на месте получения поражения ипритом и в стационаре. Т 2 (отсроченная): пострадавшие с поражениями ипритом, которые нуждаются в длительном лечении и госпитализации, но

\footnotetext{
The Chemical Weapons Programme. United Nations Monitoring, Verification and Inspection Commission (UNMOVIC) Compendium. N.Y., 2001.

4 В настоящее время иранцы используют деление зон заражения ипритом на зоны контроля (Control Zones), предложенные Национальным институтом охраны труда и здоровья США. См. National Institute for Occupational Safety and Health (NIOSH). 2015. Sulfur Mustard: Blister Agent. Доступно: https://www.cdc.gov/niosh/ershdb/ emergencyresponsecard_29750008.html (дата обращения: 08.05.2021). Зона контроля - это зона, в которой произошел инцидент с опасными материалами, которые определяются в зависимости от безопасности и степени опасности. Зона разделена на горячую, теплую и холодную. Горячая зона - это область, где существует прямая и непосредственная угроза. Теплая зона относится к зоне уменьшения риска загрязнения и устанавливается вокруг горячей зоны, чтобы обеспечить буфер между горячей и холодной зонами. А холодная зона - это территория, где не ожидается существенной угрозы, и могут быть задействованы дополнительные медицинские/ транспортные ресурсы [19].
}

5 Гипохлорит натрия - сильный окислитель, содержит 95,2 \% активного хлора. 


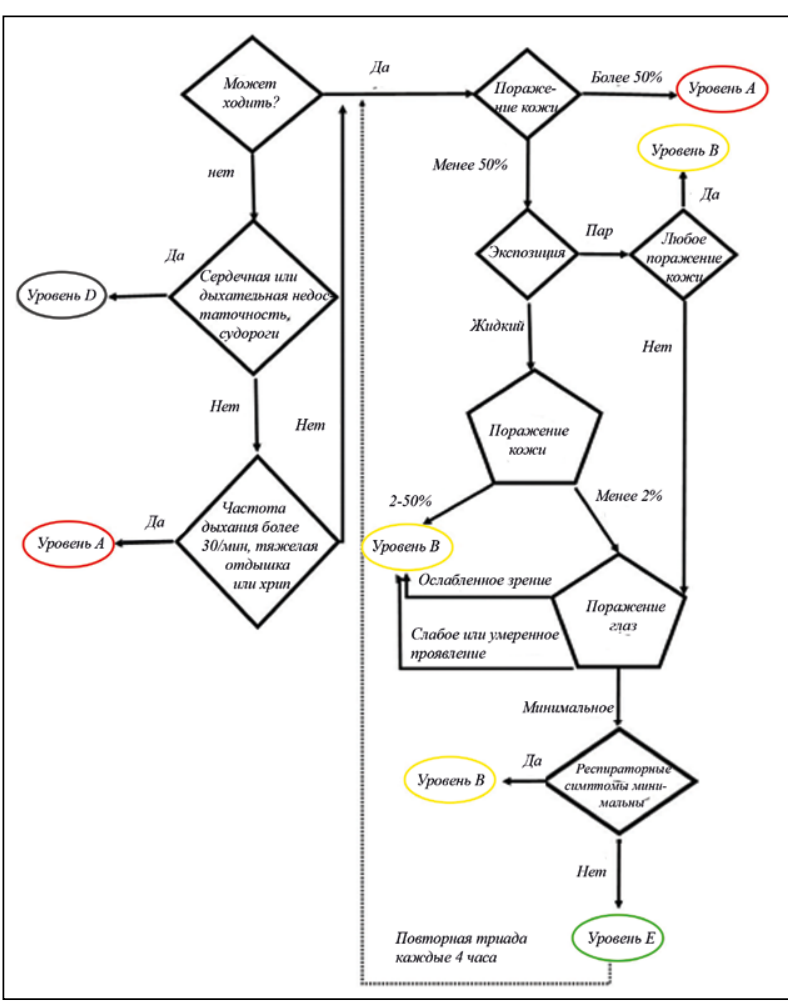

отсрочка оказания этой помощи не влияет на прогноз события. Т 3 (минимальная): пострадавшие с легкими пораженими ипритом, которые не будут эвакуированы и смогут вернуться в строй в короткие сроки. Т 4 (выжидающая): жертвы со смертельными пораженими, которые, вероятно, не выживут при доступной медицинской помощи. По цветам и серьезности воздействия на военнослужащего на поле боя, красный, желтый, зеленый и черный цвета были установлены для немедленных или срочных, отсроченных, минимальных и выжидаемых групп пораженных (см. рисунок 2).

Промывание кожи недостаточным количеством воды увлажняет ее и снижает защитный эпидермальный барьер, облегчая иприту проникновение в организм [20].

Во время химических атак иранцы столкнулись с тем, что воды для смывания иприта не хватало, поэтому военнослужащие пытались отмыть лицо и руки водой с грунта (из луж), но она оказалась загрязненной ипритом. В результате они получали поражения кожи рук, лица и глаз ${ }^{6}$. Таким образом, в зоне возможного химического нападения противника должны быть сосредоточены защищенные от контаминации запасы чистой воды в транспортных средствах с душевыми установками. Кроме того, вокруг района боевых
Рисунок 2 - Сортировка пораженных ипритом. Уровень А - наиболее тяжелые и нуждающиеся в немедленном проведении реанимачионных мероприятий. Им необходимо обеспечить проходимость дыхательных путей и размещение внутривенного катетера, а затем провести дегазацию. Уровень В - тяжелые, но не имеющие опасных для жизни проблем, они могут перенести дегазацию. Уровень С - в настоящее время не имеют симптомов после воздействия иприта, но симптомы появятся позже. Повести дегазацию и наблюдать не менее 24-48 ч, а также повторно обследовать и отсортировать их. Если у пострадавших со статусом уровня C симnтомы отсутствуют (респираторные, глазные и кожные), они могут быть выписаны. В течение периода наблюдения эти пациенты должны получать антиоксидантные препараты, такие как HAK (N-Acetyl cysteine) no 600 мг 3 раза/сут или витамин Е. Уровень D - умирающие (остановка сердиа, остановка дыхания, неослабевающие судороги). В случае большого количества пораженных усилия врачей следует переориентировать на пострадавших со статусом $A, B$ и $C$, имеющих более высокие шансы на выздоровление [19]

действий на этапах медицинской эвакуации должны быть созданы полевые центры с недоступными для контаминации ОВ запасами чистой воды $[11,19]$.

Складчатые и влажные участки тела (ягодицы, пах, подмышки, шея, спина, колени, локти и т.д.), которые могут задерживать иприт, при дегазации следует мыть с большой осторожностью. Волосы на голове целесообразно состричь [20]. Глаза необходимо начать промывать как можно быстрее после контакта с ипритом в течение 5-15 мин, используя обильное количество чистой воды. Рекомендуются для промывания глаз: физиологический раствор, раствор бикарбоната натрия 1,5\%; дихлорамин Т 0,5 \%; сульфат натрия или сульфат магния. Разбавленный детский шампунь также оказался полезным для удаления иприта. Для дегазации кожи можно использовать 0,5 \% водный раствор бытового отбеливателя. Повязки на глаза накладывать не следует, так как токсическое действие иприта может усилиться из-за повышения температуры. В случае попадания иприта на кожу на открытых участках тела можно использовать порошок хлорида кальция или оксида магния с последующим промыванием водой с мылом. В случае поражения желудочно-кишечного тракта рвоту не следует вызывать, надо дать отравленному от 100 до 200 мл молока, затем осторожно

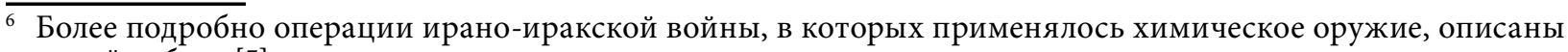
в нашей работе [5]. 
Таблица 1 - Составы для дегазации сернистого иприта [19]

\begin{tabular}{|c|l|}
\hline Обрабатываемая поверхность & \multicolumn{1}{|c|}{ Состав } \\
\hline Кожа & $\begin{array}{l}\text { 0,5 \% водный раствор гипохлорита натрия; } \\
\text { комплект RSDL - содержит Dekon 139 и калиевую соль 2,3-бутандиона монооксма } \\
\text { (DAM) в растворителе, состоящем из монометилового эфира полиэтиленгликоля } \\
\text { (MPEG) и воды; } \\
\text { фуллерова земля (стандарт BPC) - непластичная слабосцементированная природная } \\
\text { глина (обычно состоит из алюмосиликата магния и бентонита); } \\
\text { мазь М5 - хлорамин в водной среде (используется в армии США); } \\
\text { вода и щелочное мыло; } \\
\text { вода }\end{array}$ \\
\hline Глаза & $\begin{array}{l}\text { физиологический раствор; } \\
\text { вода }\end{array}$ \\
\hline Поверхности & $\begin{array}{l}\text { \% в водный раствор гипохлорита натрия; } \\
\text { фуллерова земля (стандарт ВРС); } \\
\text { DF200 - пенящийся состав на основе хлорсодержащего компонента, } \\
\text { предназначен для дегазации и дезинфекции (компоненты не раскрываются), } \\
\text { используется армией США; } \\
\text { перекись водорода (3 \% раствор) }\end{array}$ \\
\hline
\end{tabular}

провести промывание желудка через зонд [13, 19]. Составы для дегазации иприта в рекомендуемом порядке приведены в таблице 1.

Введение антидота. Поиски соединений, обладающих антидотным действием в отношении сернистого иприта, ведутся с ПМВ. В конце 1950-х гг. была показана нетоксичность и эффективность при лечении ипритных поражений тиосульфата натрия [23, 24]. Его антидотное действие сохраняется всего в течение 60 мин после воздействия иприта. Рекомендуемая доза составляет 200-500 мл $10 \%$ раствора, который следует вводить внутривенно в течение 30-60 мин [21, 22, 25]. Отсроченное на 4-24 ч введение препарата не показало антидотных эффектов [26], однако он используется для лечения ипритных поражений в госпитальных условиях [11].

Вторичная профилактика включает поддержку дыхания, обезболивание, повторную дегазацию (при необходимости), профилактику инфекций [21].

Лечение поражений сернистым ипритом. Общая схема лечения по зонам контроля и в госпитале представлена на рисунке 3.

Кожа. По сравнению с ожоговыми ранами сопоставимого размера, заживление ипритных ран происходило гораздо медленнее [11]. Волдыри размером менее 2 см следует оставить нетронутыми, за исключением случаев, когда они уже разорвались. Из волдырей диаметром более 2 см рекомендуется аспирировать шприцом жидкость, а затем очистить их от некротизированной ткани. Ее удаление уменьшает воспаление, улучшает заживление ран и уменьшает площадь поражения. Поверхностное поражение кожи с эритемой и небольшими волдырями не требует хирургической обработки $[19,21]$, однако такие поражения вы- зывают более выраженное раздражение кожи и интенсивные боли, чем глубокие поражения [27]. При сильной боли - сульфат морфина.

A. Ghorani-Azam и M. Balali-Mood [28], основываясь на своем опыте, полученном во время войны, считают, что пораженную ипритом кожу со вскрытыми или лопнувшими волдырями после обработки следует покрыть кремом сульфадиазина серебра толщиной 2 мм. Применение местных препаратов, способных контролировать и замедлять высвобождение нанокристаллического серебра в область раны, в настоящее время рассматривается как ценное средство при лечении ипритных поражений кожи [19].

При ипритных поражениях кожи половых органов рекомендуется сидячая ванна с раствором перманганата калия 1:5000 и последующим покрытием кремом или растворами антибиотиков местного действия. Из-за высокого риска загрязнения генитальной повязки мочой, повязка на рану в этой части тела не рекомендуется [19].

Глаза. Лечение острых ипритных поражений глаза в основном консервативное. Начинается с закапывания антибиотиков местного действия, препаратов для увлажнения роговицы (лубриканты), кортикостероидов и продолжается ежедневной смазкой искусственными слезами и местными антибиотиками [30]. Местные кортикостероиды полезны для уменьшения отека и воспаления роговицы и снижения риска поздней неоваскуляризации. Противовоспалительное лечение будет эффективно в течение короткого периода времени после воздействия серного иприта (особенно в начале первого часа). При неоваскуляризации роговицы его можно продолжить в течение недели. Использование дексамицина (дексаметазон + неомицин) в качестве противовоспалительного средства уменьшает симптомы ипритного 


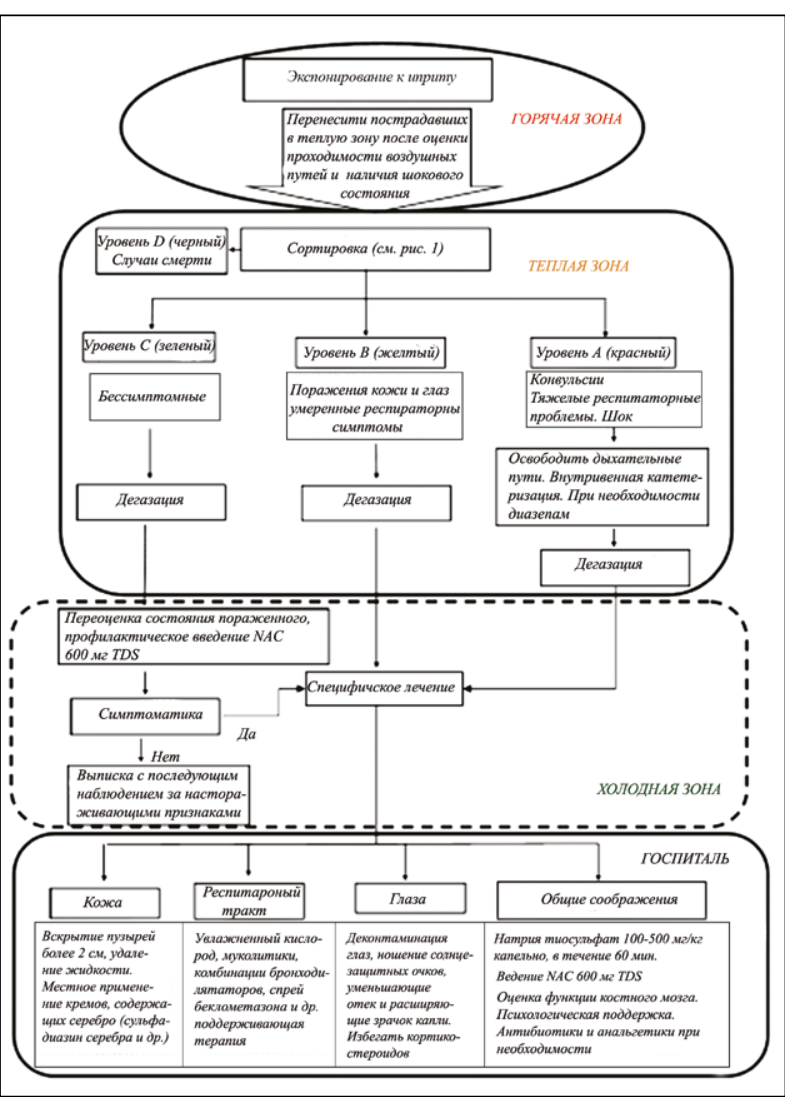

Рисунок 3 - Медичинские мероприятия для пораженных ипритом по зонам контроля и $в$ госпитале. Аббревиатуры: NAC (N-Acetyl cysteine) ацетилцистеин (муколитик); TDS (Total Dissolved Solids) - растворенные твердые вещества [19]

поражения со стороны века, конъюнктивы и роговицы. Из-за высокого риска инфекции роговицы кортикостероиды следует применять с осторожностью, особенно при наличии признаков дефектов эпителия роговицы. Для контроля внутриглазного давления и ослабления боли следует назначать мидриатические и/или противоглаукомные глазные капли. Мидриатики (например циклопентолат и атропин) уменьшают спазм цилиарной мышцы и предотвращают образование задних иридолентикулярных спаек. Оральные анальгетики предпочтительнее местных анальгетиков, потому что местные средства могут повредить роговицу и замедлить заживление [21, 30].

При тяжелой форме поражения глаз ${ }^{7}$ глазные капли антибиотиков применять каждые 6 ч в течение недели, при отсутствии инфекции конъюнктивы и роговицы - использовать глазные капли кортикостероидов (одна капля каждые 4-6 ч в течение недели и затем уменьшить дозу по мере необходимости). Глазная смазка каждые 2-4 ч. При наличии большого дефекта эпителия роговицы и отсутствия сухости глаз, тяжелой ишемии и инфекции роговицы или конъюнктивы, возможно ношение мягких контактных линз. Доксициклин - в капсулах (100 мг каждый 12 ч в течение 2 нед., а затем - по мере необходимости) [15].

При ипритной перфорации роговицы, если ее диаметр равен или менее 2 мм, при отсутствии инфекции роговицы и выпадения радужной оболочки, для закрытия перфорации целесообразно применять цианоакрилатный клей ${ }^{8}$. После затвердевания сгустка поверхность глаза промывается физиологическим раствором, закапывается раствор антибиотика и надевается мягкая контактная линза с бандажной целью. Если диаметр перфорации больше 2 мм или при наличии выпадения радужной оболочки, существует риск попадания клея в переднюю камеру глаза, его токсического влияния на эндотелий и хрусталик при непосредственном контакте с этими структурами, формирования задних и передних синехий. В этом случае проводится кератопластика [15].

Дыхательная система. При вдыхании пара иприта в основном поражаются гортань, глотка и слизистая оболочка трахеобронхов. Пар в более высокой концентрации может достигать нижних отделов дыхательных путей. Признаки поражения дыхательной системы возникают до появления поражений кожи. Опыт лечения ипритных повреждений легких, накопленный иранскими врачами, говорит о том, что оно должно быть направлено на облегчение симптомов и уменьшение тяжести осложнений $[13,19,28]$.

Поддерживающее и симптоматическое лечение включает увлажненный воздух или кислород, средства от кашля, бронходилататоры и респираторную физиотерапию [13]. Более эффективна, чем любые другие бронходилататоры, комбинация бета-агонистов (например, сальбутамол, торговое название; альбутерол, вентолин) и антихолинергических средств (например, ипротропия бромид, торговое название атровент). По клиническим показаниям для контроля осложнений может потребоваться введение противовоспалительных средств (кортикостероидов), антиоксидантов, муколитиков и антибиотиков (препочтительны макролиды, так как они обладают противовоспалительным и иммуномодулирующим действием) [25]. Профилактическая антибиотикотерапия с осторожностью из-за риска появления резистентных микроорганизмов и возможных

\footnotetext{
Клиника различных форм поражения глаз ипритом и диагностические критерии приведены в нашей работе [5] и работе Z. Rajavi с соавт. [15].

8 О применении цианокрилатного клея при лечении дефектов роговицы см. в работе С.В. Труфанова [31].
} 
межлекарственных взаимодействий [13]. Применение кортикостероидов должно быть ограничено лечением тех пациентов с бронхоспазмом, которым не помогают бронходилататоры. Для улучшения проходимости дыхательных путей возможна комбинация ингаляционных кортикостероидов и агонистов $\beta-2$ длительного действия. Пациентам, плохо реагирующим на бронходилататоры, может быть назначен $\mathrm{N}$-ацетилцистеин (NAC) - перорально в максимальной дозе 1200 мг/сут или 1800 мг/сут. Ингаляционные кортикостероиды относительно безопасны, но системные кортикостероиды имеют серьезные побочные эффекты и должны применяться с осторожностью и только у пациентов в очень тяжелом состоянии интоксикации, но надо помнить, что их эффективность остается под вопросом [19].

В тяжелых случаях требуется интубация трахеи и искусственная вентиляция легких, особенно при наличии охриплости или стридора, что свидетельствует об обструкции дыхательных путей из-за ларингоспазма, отека гортани или образование псевдомембран. При суженнии дыхательных путей рекомендуется смесь Heliox: гелий - кислород (79:21) с неинвазивной вентиляцией с положительным давлением. Этот метод вентиляции легких положительно влиял на систолическое, диастолическое и среднее артериальное давление, частоту пульca, частоту дыхания и одышку, а также повышал уровень кислорода в артериальной крови.

У пациентов с тяжелой ипритной интоксикацией, прежде, чем у них ухудшится состояние и возникнет надгортанная или гортанная непроходимость, рекомендуется выполнить эндотрахеальную интубацию или даже раннюю трахеотомию [13]. Некоторые авторы в послевоенных работах рекомендовали уже на ранней стадии промывать бронхи изотоническим солевым раствором для удаления трахеобронхиального дебриса, вызванного некрозом и шелушением эпителиальной ткани [32].

Подавление функиии костного мозга. Это звено патогенеза отравления ипритом установлено еще в ПМВ. Отравленных ипритом выделяли из общей массы газоотравленных, контуженных и инфекционных больных по выраженной лейкопении. Количество лейкоцитов начинает снижаться на 3-й и 4-й сутки после воздействия иприта и достигает минимального уровня примерно на 9-й день. В 1918 г. Е.В Krumbhaar и H.D. Krumbhaar [33] обнаружили, что если снижение количества лейкоцитов через трое суток после поражения ипритом проходит за планку
5 тыс. кл./мм³, выздоровление военнослужащего становится маловероятным, ниже 520 кл./ мм $^{3}$ - признак близкого смертельного исхода. В то же время лейкоцитоз, сменивший период лейкопении, означает, что у отравленного ипритом появился шанс на временное выздоровление.

M. Tabarestani с соавт. в 1990 г. сообщили о тяжелой лейкопении, обнаруженной у военнослужащих через 1-3 нед. после воздействия иприта. Биопсия костного мозга трех жертв смертельного воздействия иприта показала выраженную гипоцеллюлярность и дизеритропоэтические изменения [34]. В качестве экспериментального средства, ускоряющего регенерацию костного мозга, в настоящее время рассматривается колониестимулирующий фактор гранулоцитов (G-CSF) или его пегилированная форма с более продолжительным действием (pegGCSF), используемые при миелосупрессии, вызванной химиотерапией ${ }^{9}$ [19].

Опыт лечения иранских военнослужащих, пораженных сернистым ипритом, накопленный немецкими врачами из мюнхенских клиник ${ }^{\mathbf{1 0}}$. Лечение проходили 12 иранских военнослужащих. В клиники они поступали в течение 1984 г. и 1985 г. Из 12 пациентов 11 прибыли в Мюнхен через 6-8 сут после воздействия иприта, в одном случае - до прибытия прошло 17 сут. Средний возраст пациентов при поступлении составлял 22,5 года. Ипритные поражения они получили в результате применения иракцами химических бомб в боях за острова Маджнун. Средств индивидуальной защиты у них не было. Ниже приведено краткое обобщение их историй болезни [11].

Появление симптомов: симптомы со стороны глаз проявились первыми и затронули 44 \% пациентов уже через 10 мин после воздействия иприта. В течение 2 ч - у 88 \% пациентов наблюдались глазные симптомы, тогда как симптомы со стороны верхних дыхательных путей (22 \%), легких (56 \%) или желудочно-кишечного тракта (22 \%) встречались реже, и только у 10 \% пациентов наблюдалась эритема без образования волдырей. Образование волдырей началось у 30 \% пациентов через 4 ч после первого контакта с ипритом.

Глаза: почти все пациенты описали боль в глазах, слезотечение и жжение век. Веки были сильно отечны, блефароспазм привел к временной слепоте. 75 \% пациентов имели тяжелый (гнойный) конъюнктивит. Наиболее серьезными осложнениями были эрозии и помутнение роговицы (50 \%).

\footnotetext{
9 Стоимость 2 мкг 6100 рублей (производитель PAN-Biotech), цена указана на конец июня 2021 г.

10 Bundeswehr Institute of Pharmacology and Toxicology, Munich, Germany и Department of Toxicology, Klinikum rechts der Isar, Technical University of Munich, Germany.
} 


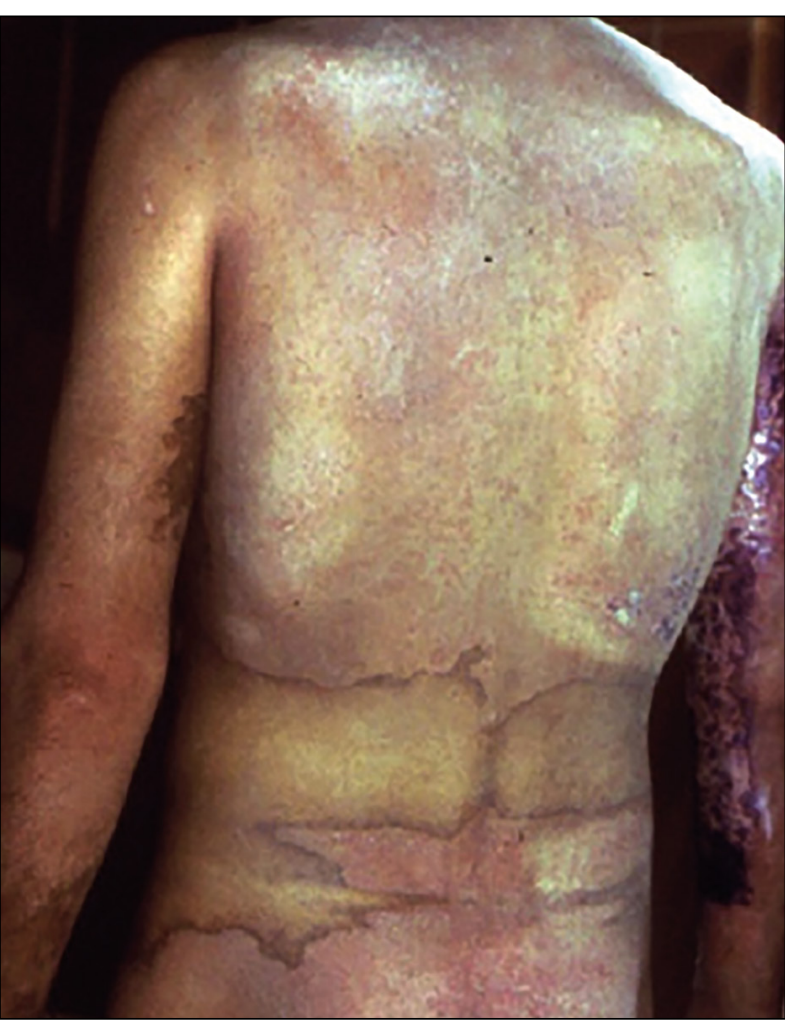

Рисунок 4 - Иранский военнослужащий после воздействия пара сернистого сернистого иприта. Типичные гипо- и гиперпигментированные участки на спине. В области пояса кожа была защищена ремнем [11]

Кожа: эритема, гипо- и гиперпигментированные участки, волдыри, язвы и отеки. На рисунке 4 показана спина одного из пациентов, получившего поражение паром сернистого иприта, Обнаруживаются эритема, гипо- и гиперпигментированные участки. Область, которая была покрыта поясом, была частично защищена, поэтому симптомы в этой области менее очевидны. На рисунке 5 показана рука пациента, получившего тяжелое поражение ипритом. Образовались волдыри, язвы и отеки. Остальные участки кожи гиперпигментированы.

Верхние дыхательные пути: у всех пациентов - охриплость голоса и боль в горле. Наиболее пораженные пациенты не могли глотать (25\%). Отек гортани наблюдался у 45 \% пациентов, воспаление - у $27 \%$, облитерирующий некроз - у $27 \%$.

Бронхиальный тракт и легкие: кашель (92 \%), мокрота (67 \%), кровянистая мокрота (42\%). Газы крови не изменились у 33 \% пациентов. Остальные 67 \% страдали алкалозом (33 \%), гипоксией (50 \%) или ацидозом (17 \%). Аускуль- тация была нормальной у 84 \% пациентов, но у 8 \% отмечено бронхиальное дыхание. Изменения на рентгенограмме - у 17 \% пациентов.

Симптомы со стороны ЦНС: у всех пациентов наблюдались признаки апатии и депрессии. В течение первых 2 недель пациенты сохраняли сонливость.

Бронхоскопия выполнена у 58 \% пациентов. Воспалительные процессы в бронхах - у каждого исследованного, у 57 \% - признаки кровотечения и некротизированная слизистая.

Трахеотомия потребовалась 25 \% пациентов, она была проведена через 7 или 12 суток после поступления в госпиталь, трахеотомическая трубка устанавливалас на 1-2 недели. У 2 из 11 пациентов развился стеноз трахеи, окклюзия которого составляла 10 и $60 \%$ просвета соответственно.

Электроэниефалографии (ЭЭГ): легкие или умеренные изменения на ЭЭГ были обнаружены у 73 \% пациентов в виде несинхронизированных и медленных волн (тета). Через 6 недель все ЭЭГ были нормальными.

Температура: 50 \% пациентов имели повышенную температуру $\left(38-40{ }^{\circ} \mathrm{C}\right)$ при поступлении, и у $91 \%$ она возникла в какой-то момент во время лечения. Температура нормализовалась у 27 \% через 3 нед. и у $45 \%$ через 4 нед.

Анализ крови: лейкоциты были повышены у 10 из 12 пациентов и колебались от 11200 до 20700/л (в норме 4-11×103/л). У 2 пациентов было нормальное количество лейкоцитов. 10 из 12 пациентов страдали анемией. Тромбоциты в норме у 8 \%, повышенные - у 67 \% и пониженные - у 25 \% пациентов.

\section{Лечение в Иране}

Глаза промывали раствором лактата Рингера. Мидриатики (например, циклопентолат) и сульфонамидные антибиотики (например, сульфацетамид) применялись местно. Пациентам рекомендовалось держать глаза закрытыми в течение 24-48 ч.

Кожа: волдыри вскрывали и дренировали в стерильных условиях. Крыша волдыря не снималась. Пациентов ежедневно мыли водопроводной водой, а пораженные участки кожи промывали раствором лактата Рингера ${ }^{11}$. Крем Furamid TM (фуразолидон, метронидазол) или сульфадиазин серебра (Sulfadiazini Argentum, 10 мг/1 г) наносили для предотвращения инфицирования ран. Инфицированные участки кожи обрабатывали нитрофуразоном.

Дьхательные пути: использовались ингаляции влажного воздуха и муколитиков (например, бромгексина). Кодеин был назначен

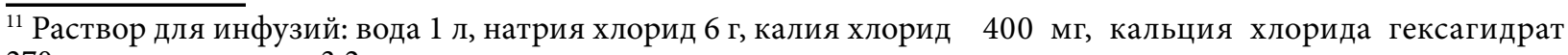
270 мг, натрия лактат 3,2 г. 
для облегчения постоянного кашля. Инфекции лечили гентамицином или карбенициллином. Сильную одышку лечили вспомогательной вентиляцией легких и положительным давлением в конце выдоха.

\section{Лечение в Мюнхене, Германия}

По прибытии все пациенты были помещены в отделения интенсивной терапии.

Детоксикация: 7 пациентов получали гемодиализ в течение 5 сут. Плазмаферез проведен двум пациентам. Тиосульфат натрия (10\%) начинали с 500 мл/сут, а затем продолжали с 250 мл/сут в течение 5-7 сут. Древесный уголь и лактулоза принимались перорально в течение 3 сут. $\mathrm{N}$-ацетилцистеин вводили не менее 11 сут.

Кожа: повязки на рану меняли два раза в день. Влажные участки покрывали парафиновой марлевой повязкой, серебряными повязками (например, Actisorb ${ }^{\mathrm{TM}}$ ), декспантенолом, а сухие участки - флуметазоном (например, Locacorten $^{\mathrm{TM}}$ ).

Подмышечные впадины и мочонка: поскольку эти участки кожи были сильно поражены, пациенты получали дополнительное лечение смесью клиохинола и триамцинолона, а также раствором пиоктанина или раствором Кастеллани.

Глаза: использовались глазные капли мидриатиков (например, атропин) и антибиотиков (неомицин, гентамицин, ацидамфеникол, полимиксин-В-сульфат).

Дьхательные пути: муколитики (например, амброксол), кодеин, дексаметазон использовались в сочетании с вдыханием влажного воздуха. Трахеотомия была необходима для лечения тяжелых случаев и обеспечения легкого бронхиального туалета ${ }^{12}$.

Общее лечение: все пациенты получали профилактику тромбоза (низкие дозы гепарина, 10 тыс. МЕ/сут). Для профилактики язвы желудка назначали ранитидин и дополнительно в 2 случаях пирензепин. Фитоменадион назначался при снижении факторов свертывания крови. Некоторые пациенты получали тестостерон в качестве анаболического лечения.

В целом лечение в мюнхенских клиниках оказалось эффективным, умер один пациент из 12. Причиной смерти стали сепсис из-за угнетения костного мозга и обструкции дыхательных путей. Для выздоровления пациентов потребовалось 4-6 нед., однако отложенные последствия поражения ипритом будут сопровождать их весь остаток жизни [12-18].

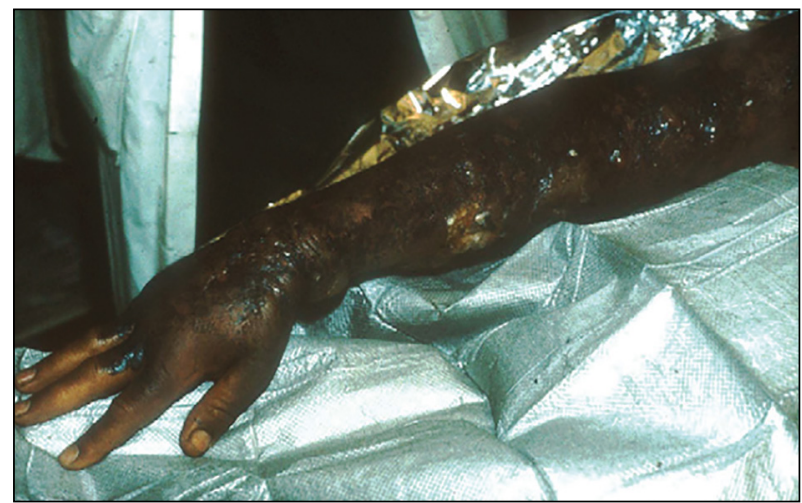

Рисунок 5 - Рука иранского военнослужащего, получившего поражение сернистым ипритом. Кожа гиперпигментирована. Образование волдырей и язв являются признаками сильного местного воздействия. Пораженные участки отечны [11]

Германские врачи, как и иранские, обратили внимание на необходимость в тяжелых случаях проводить трахеотомию и устанавливать трахеотомические трубки, использовать бронхоскопию для промывания бронхов. Быстро проведенная бронхоскопия с промыванием может в большинстве случаев оказаться достаточной мерой для предотвращения тяжелых осложнений со стороны дыхательных путей. Лечение бронходилататорами, противокашлевыми средствами, муколитиками и (при необходимости) антибиотиками было аналогично лечению, рекомендованному иранскими врачами и оказалось эффективным. Пневмонии удалось избежать у всех пациентов, инфекционные процессы ограничивались бронхиальной системой [11].

Принципиально новые подходы к лечению ипритных поражений. Таких направлений два

Генная терапия. Для обоснования разработки методов лечения на основе данной технологии проводится аналогия между отсроченными ипритными поражениями легких и хронической обструктивной болезнью легких (ХОБЛ) [35], для лечения которой методы генной терапии разрабатываются в настоящее время [36].

Мезенхимальные стволовые клетки (МСК) - класс мультипотентных стволовых клеток с пролиферативной и самообновляющейся способностью, которые могут дифференцироваться в различные клеточные линии, такие как эпителиальные клетки легких, что делает их хорошим кандидатом для регенерации бронхиол у пациентов, подвергшихся воздействию иприта. МСК рассматриваются как

\footnotetext{
12 Туалет бронхиального дерева включает тщательную последовательную аспирацию содержимого из долевых и сегментарных ветвей, промывание их индифферентным или антисептическим раствором, введение лекарственных веществ. Аспирацию содержимого бронхов при лечебной бронхофиброскопии производят через инструментальный канал бронхофиброскопа.
} 
новая стратегия лечения пациентов глубокими ипритными поражениями кожи и с отсроченными легочными осложнениями [37].

Если сравнивать с методами медицинского лечения поражений сернистым ипритом, использованными в ПМВ, то надо признать, что принципиальных отличий того опыта с опытом, накопленным во время ирано-иракской войны, нет. В основе снижения количества пораженных по-прежнему находится быстро проведенная деипритизация и сортировка пораженных на группы, нуждающиеся в разных объемах медицинской помощи. Лечение по-прежнему остается консервативным и восстановительным. Его ценность - в том, что оно более эффективно при массовом поступлении пораженных, чем применявшиеся в ПМВ (введение недорого и нетоксичного тиосульфата натрия в качестве антидота и терапевтического средства), усовершенствованная тактика лечения поражений кожи (новые антисептики), глаз (антибиотики, лубриканты, местные кортикостероиды, мидриатики, пластика роговицы и др.), поражений легких (при тяжелых поражениях ранние трахеотомия и промывание бронхов с помощью бронхоскопа, антибиотики, муколитики, бронходилятаторы, ингаляционные кортикостероиды). Однако проблема лечения тяжелых поражений ипритом, особенно в связи с возможностью его многодневного массированного применения авиацией и использования в сухом виде, остается. О лечении поражений сухим ипритом в иранской литературе упоминаний нет. Видимо, не случайно. Здесь нужно накапливать собственный опыт лечения на экспериментальных животных. О том, что иранские врачи использовали все имеющиеся варианты лечения в рамках прежних консервативных методов, говорит их переход к принципиально новым технологиям - генной терапии и лечению мезенхимальными стволовыми клетками ипритных поражений легких. Такие технологии будут использованы и для лечения ипритных поражений кожи и глаз. Это очень важный сигнал изменения подходов в лечении ипритных поражений, который не стоит игнорировать. Опыт Ирана, накопленный в ходе ирано-иракской войны, показывает и то, что создание и применение химического оружия враждебной стороной не является проблемой. Всегда найдутся те, кто этому поспособствует из геополитических и иных соображений, оставаясь в стороне. А иранский опыт обращения в международные структуры $(\mathrm{OOH}$, Красный крест) показывает, что государство, объявленное мировым сообществом «изгоем», может не рассчитывать на их поддержку. Поэтому готовность к отражению химической войны должна быть постоянной.

\section{Вклад автора/ Autor Contribution}

Идея и концепция статьи, поиск и анализ литературы, написание статьи цифровая обработка изображений / Idea and concept of an article, search and analysis of literature, writing an article, digital image processing.

\section{Информация о конфликте интересов}

Автор заявляет, что исследования проводились при отсутствии любых коммерческих или финансовых отношений, которые могли бы быть истолкованы как потенциальный конфликт интересов.

\section{Сведения о рецензировании}

Статья прошла открытое рецензирование двумя рецензентами, специалистами в данной области. Рецензии находятся в редакции журнала и в РИНЦе.

Список источников

1. Karami Ali. Long Legacy // CBRNe WORLD. 2012. August. P. 30-40.

2. Hashemian A., Khoshnood K., Desai M.M. et al. Anxiety, depression, and posttraumatic stress in Iranian survivors of chemical warfare // JAMA. 2006. V. 296. № 5. P. 560-566.

3. Супотницкий М.В., Шило Н.И., Ковтун В.А. Химическое оружие в ирано-иракской войне 19801988 годов. 1. Подготовка Ирака к химической войне // Вестник войск РХБ защиты. 2019. Т. 3. № 1. С. 4064. https://doi.org/10.35825/2587-5728-2019-3-1-40-64

Supotnitskiy M.V., Shilo N.I., Kovtun V.A. Chemical Weapons in the Iran-Iraq War (1980-
1988). 1. Iraq Preparing for Chemical War // Journal of NBC Protection Corps. 2019. V. 3. № 1. P. 40-64. https://doi.org/10.35825/2587-5728-2019-3-1-40-64 (in Russian).

4. Супотницкий М.В., Шило Н.И., Ковтун В.А. Химическое оружие в ирано-иракской войне 19801988 годов. 2. Применение химического оружия в боевых действиях // Вестник войск РХБ защиты. 2019. T. 3. № 2. C. 150-174. https://doi.org/10.35825/25875728-2019-3-2-150-174

Supotnitskiy M.V., Shilo N.I., Kovtun V.A. Chemical Weapons in the Iran-Iraq War (1980-1988). 2. Combat Use of Chemical Weapons // Journal of NBC 
Protection Corps. 2019. V. 3. № 2. P. 150-174. https://doi. org/10.35825/2587-5728-2019-3-2-150-174 (in Russian).

5. Супотницкий М.В., Шило Н.И., Ковтун В.А. Применение химического оружия в ирано-иракской войне 1980-1988 годов. 3. Медицинские последствия химической войны // Вестник войск РХБ защиты. 2019. Т. 3. № 3. С. 255-289. https://doi. org/10.35825/2587-5728-2019-3-3-255-289

Supotnitskiy M.V., Shilo N.I., Kovtun V.A. Chemical Weapons in the Iran-Iraq War (1980-1988). 3. Medical Consequences of Chemical Warfare // Journal of NBC Protection Corps. 2019. V. 3. № 3. P. 255-289. https:// doi.org/10.35825/2587-5728-2019-3-3-255-289 (in Russian).

6. Супотницкий М.В., Шило Н.И., Ковтун В.А. Применение химического оружия в ирано-иракской войне 1980-1988 годов. 4. Ликвидация химического оружия Ирака // Вестник войск РХБ защиты. 2020. T. 4. № 2. С. 131-159. https://doi.org/10.35825/25875728-2020-4-2-131-159

Supotnitskiy M.V., Shilo N.I., Kovtun V.A. Chemical Weapons in the Iran-Iraq War (1980-1988). 4. The Destruction of Iraqi Chemical Weapons // Journal of NBC Protection Corps. 2020. V. 4. № 2. P. 131-159. https://doi.org/10.35825/2587-5728-2020-4-2-131-159 (in Russian).

7. Franke S. Lehrbuch der Militärchemie. Band 1. Deutscher Militärverlag. Berlin, 1967.

8. Haines D.D., Fox S.C. Acute and long-term impact of chemical weapons: Lessons from the Iran-Iraq war // Forensic Sci. Rev. 2014. V. 26. P. 98-114.

9. Impact and implication of chemical weapons use in the Iran-Iraq war. Director Central Intelligence. Interagency Intelligence Memorandum. NI IIM 8810004C. Top Secret. April 1988. Approved for release 08.10.2010.

10. Javed Ali. Chemical Weapons and the IranIraq War: A Case Study in Noncompliance // The Nonproliferation Review/Spring. 2001. P. 43-58.

11. Kehe K., Thiermann F., Balszuweit F. et al. Acute effects of sulfur mustard injury Munich experiences // Toxicology. 2009. V. 263. P. 3-8. doi: 10.1016/j. tox.2009.04.060

12. Darchini-Maragheh E., Balali-Mood M. Delayed Complications and Long-term Management of Sulfur Mustard Poisoning: Recent Advances by Iranian Researchers (Part I of II)// Iran. J. Med. Sci. 2018. V. 43, № 2. P. 103-124.

13. Razavi S.M., Karbakhsh M., Salamati P. Preventive measures against the mustard gas: a review // Medical Journal of the Islamic Republic of Iran. 2013. Vol. 27, № 2. P. 83-90. https://doi.org/10.22088/ cjim.10.3.241

14. Eghtedardoost M., Mohammad Z.H., Askari N. et al. The delayed effect of mustard gas on housekeeping gene expression in lung biopsy of chemical injuries // Biochemistry and Biophysics Reports. 2017. Vol. 11. P. 27-32.

15. Rajavi Z., Safi S., Javadi M.A. et al. Clinical
Practice Guidelines for Prevention, Diagnosis and Management of Early and Delayed-onset Ocular Injuries Due to Mustard Gas Exposure // J. Ophthalmic. Vis. Res. 2017. V. 12, № 1. P. 65-80. https://doi.org/10.4103/jovr. jovr_253_16

16. Hefazi M., Maleki M., Mahmoudi M., Tabatabaee A., Balali-Mood M. Delayed complications of sulfur mustard poisoning in the skin and the immune system of Iranian veterans 16-20 years after exposure // Int. J. Dermatol. 2006. V. 45. P. 1025-1031.

17. Foroutan S.A. Medical notes on chemical warfare, part II // Kowsar. Med. J. 1997. V. 1. P. 159-177. [in Persian].

18. Balali-Mood M., Hefazi M. Comparison of Early and Late Toxic Effects of Sulfur Mustard in Iranian Veterans // Basic \& Clinical Pharmacology \& Toxicology. 2006. V. 99. P. 273-282

19. Etemad L., Moshiri M.. Balali-Mood M. Advances in treatment of acute sulfur mustard poisoning a critical review // Critical reviews in toxicology. 2019. V. 49, № 3. P. 191-214. https://doi.org/10.1080/10408444.2 019.1579779

20. Chilcott R.P. Toxicity of sulphur mustard // Toxicol. Appl. Pharmacol. 2005. V. 204. P. 99-100. https://doi.org/10.1016/j.taap.2004.09.016

21. Balali-Mood M., Hefazi M. The pharmacology, toxicology, and medical treatment of sulphur mustard poisoning // Fundam Clin Pharmacol. 2005. V. 19. P. 297315. https://doi.org/10.1111/j.1472-8206.2005.00325.x

22. Graham J.S, Schoneboom B.A. Historical perspective on effects and treatment of sulfur mustard injuries // Chem. Biol. Interact. 2013. V. 206. P. 512-522. https://doi.org/10.1016/j.cbi.2013.06.013

23. Callaway S., Pearce K.A. Protection against systemic poisoning by mustard gas, di(2-chloroethyl) sulphide, by sodium thiosulphate and thiocit in the albino rat // Br. J. Pharmacol. Chemother. 1958. V. 13(4). P. 395-398. https://doi.org/10.1111/j.1476-5381.1958. tb00227.x

24. Hatiboglu I., Mihich E., Moore GE, Nichol CA. Use of sodium thiosulfate as a neutralizing agent during regional administration of nitrogen mustard: an experimental study // Ann Surg. 1962. V. 156. P. 994. https://doi.org/10.1097/00000658-196212000-00022

25. Poursaleh Z, Harandi AA, Vahedi E, Ghanei M. Treatment for sulfur mustard lung injuries; new therapeutic approaches from acute to chronic phase // Daru. 2012. V. 20(1). P. 27. https://doi.org/10.1186/20082231-20-27

26. Dorr R.T., Soble M., Alberts D.S. Efficacy of sodium thiosulfate as a local antidote to mechlorethamine skin toxicity in the mouse // Cancer Chemother Pharmacol. 1988. V. 22. P. 299-302. https:// doi.org/10.1007/BF00254235.

27. Graham J.S., Chilcott R.P., Rice P. et al. Wound healing of cutaneous sulfur mustard injuries: strategies for the development of improved therapies // J. Burns. Wounds. 2005. V. 4. el. https://www.ncbi.nlm.nih.gov/ pmc/articles/PMC1501116/ 
28. Ghorani-Azam A., Balali-Mood M. Clinical pharmacology and toxicology of mustard compounds / In: Balali-Mood M., Abdollahi M., editors. Basic and clinical toxicology of mustard compounds. New York (NY): Springer, 2015. P. 63-101.

29. Gu T.Y. Mechanism and treatment of sulfur mustard-induced cutaneous injury // Chin. J. Traumatol. 2014. V. 17. P. 345-350. https://doi.org/10.3760/cma.j.is sn.1008-1275.2014.06.010

30. Baradaran-Rafii A., Eslani M., Tseng S.C. Sulfur mustard-induced ocular surface disorders // Ocul Surf. 2011. V. 9. P. 163-178. https://doi.org/10.1016/ S1542-0124(11)70026-X

31. Труфанов С.В. Применение цианоакрилатного клея в хирургическом лечении перфорации роговицы (клиническое наблюдение) // Вестник офтальмологии. 2020. Т. 136(5). C. 232-236. https://doi. org/10.17116/oftalma2020136052232

Trufanov S.V. The use of cyanoacrylate glue in the surgical treatment of corneal perforation (clinical case) // Bulletin of Ophthalmology. 2020. V. 136 (5), P. 232 236. https://doi.org/10.17116/oftalma2020136052232 (in Russian).

32. Freitag L., Firusian N., Stamatis G., Greschuchna D. The role of bronchoscopy in pulmonary complications due to mustard gas inhalation // Chest.

\section{V. 100. P. 1436-1441.}

33. Krumbhaar E.B., Krumbhaar H.D. The blood and bone marrow in yellow cross gas (mustard gas) poisoning. Changes produced in the bone marrow of fatal cases // J. Med. Res. 1919. V. 40(3). P. 497-508.

34. Tabarestani M., Balau-Mood M., Farhoodi M. Hematological findings of sulphur mustard poisoning in Iranian combatants // Med. J. Islamic Republic Iran (MJIRI). 1990. V. 4. P. 185-190.

35. Arabipoura I., Amani J.. Ali S. et al. The study of genes and signal transduction pathways involved in mustard lung injury: A gene therapy approach // Gene. 2019. V. 714. P. 143968. https://doi.org/10.1016/j. gene. 2019.143968

36. Wu D-D., Song J., Bartel S. et al. The potential for targeted rewriting of epigenetic marks in COPD as a new therapeutic approach // Pharmacology and Therapeutics. 2018. V. 183. P. 1-14. https://doi. org/10.1016/j.pharmthera.2017.08.007

37. Nejad-Moghaddam A., Tahmasbpour T., Sohrabiyan M. et al. Stem cells therapy: a review on approaches that can be used for treatment of respiratory failures in sulfur mustard-injured patients // Immunopharmacology and Immunotoxicology. 2018. V. 40. № 5. P. 359-367. https://doi.org/10.1080/08923973. 2018.1510961

Об авторе

Федеральное государственное бюджетное учреждение «27 Научный центр» Министерства обороны Российской Федерации, 105005, Российская Федерация, г. Москва, Бригадирский переулок, д. 13.

Супотницкий Михаил Васильевич. Главный специалист, канд. биол. наук, ст. науч. сотр.

Контактная информация: 27nc_1@mil.ru Контактное лицо: Супотницкий Михаил Васильевич; 27nc_1@mil.ru

\title{
Chemical Weapons in the Iran-Iraq War (1980-1988) 5. Accumulated Experience in the Treatment of Lesions Caused by Sulfur Mustard
}

\author{
M.V. Supotnitskiy
}

\section{Federal State Budgetary Establishment "27 Scientific Centre» of the Ministry of Defence of the Russian Federation. Brigadirskii Lane 13, Moscow 105005, Russian Federation}

Received 23 April 2021. Accepted for publication 20 June 2021

Sulfur mustard was widely used during the Iran-Iraq war (1980-1988) and in other conflicts in the Middle East. Due to its availability, it can be used by terrorist organizations on the territory of the Russian Federation. Iran is the only country, against which mustard gas was used in modern warfare. The aim of this work is to analyze and summarize the experience of treating of sulfur mustard exposure, accumulated by Iranian specialists during the Iran-Iraq war (1980-1988). The UN official documents and materials, declassified CIA documents, articles of Iranian authors as well as other open sources have been used during its preparation. The Iraqi army used mustard gas 
in two aggregate states: liquid and dry. Dry mustard gas was a novelty of that war. It was a powdered silica steeped in mustard gas, with a particle size of less than $5 \mu \mathrm{m}$. The first signs and symptoms of poisoning could appear after 15 minutes, while acute poisoning effects of exposure to mustard gas vapour or liquid were typically delayed for several hours. The reasons for the severe mustard lesions of the servicemen were the lack of personal protective equipment, untimely evacuation from the mustard gas contamination zone, and the absence of mobile reserves of clean water and degassing installations in battle formations. Iranian experts consider $0.5 \%$ sodium hypochlorite solution to be the most effective decontaminant. The only safe antidote is sodium thiosulfate, administered within 60 minutes after exposure to mustard gas. During the evacuation of victims and their treatment in hospitals it is necessary, in severe cases, to insert an intravenous catheter, carry out a tracheotomy with the installation of a tracheotomy tube, and use bronchoscopy as early as possible to flush the bronchi. The treatment of skin and eye lesions should be conservative. In case of a corneal perforation, if its diameter is more than $2 \mathrm{~mm}$ - keratoplasty, if it is less - cyanoacrylate glue. Treatment of respiratory lesions aims to relieve symptoms and reduce the severity of complications. For this, bronchodilators, antitussives, mucolytics and, if necessary, antibiotics are used. The use of corticosteroids should be limited to the treatment of those patients with bronchospasm, who can not be treated by bronchodilators. The Iranians also consider gene therapy and treatment with mesenchymal stem cells to be the promising method used in the treatment of lung lesions.

Keywords: gene therapy; degassing; control zones; Iran-Iraq war; mesenchymal stem cells; delayed complications; sulfur mustard; dry mustard gas; sodium thiosulfate; chemical weapons

For citation: Supotnitskiy M.V. Chemical Weapons in the Iran-Iraq War (1980-1988). 5. Accumulated Experience in the Treatment of Lesions Caused by Sulfur Mustard // Journal of NBC Protection Corps. 2021. V. 5. № 2. P. 123-135. https://doi.org/10.35825/2587-5728-2021-5-2-123-135

\section{Conflict of interest statement}

The author declares that the research was conducted in the absence of any commercial or financial relationship that could be construed as a potential conflict of interest.

Peer review information

The article has been peer reviewed by two experts in the respective field. Peer reviews are available from the Editorial Board and from Russian Science Citation Index database.

References

See P. 132-134.

Author

Federal State Budgetary Establishment «27 Scientific Centre» of the Ministry of Defence of the Russian Federation. Brigadirskii Lane 13, Moscow 105005, Russian Federation.

Mikhail Vasilyevich Supotnitskiy. Senior Researcher. Chief Specialist. Candidate of Biological Sciences.

Contact information: 27nc_1@mil.ru

Contact person: Supotnitskiy Mikhail Vasilyevich; 27nc_1@mil.ru 


\title{
вреда окружающей среде от деятельности
}

химических предприятий на территории

г. Усолье-Сибирское Иркутской области

\author{
С.А. Мальцев ${ }^{1}$, Е.В. Вебер ${ }^{1}$, В.А. Иноземцев ${ }^{2}$ М.В. Цапок ${ }^{2}$, П.Е. Беляков ${ }^{2}$,
}

\author{
B.A. Ковтун ${ }^{3}$, А.А. Антохин ${ }^{3}$
}

1 Управление начальника войск радиационной, химической и биологической защиты Вооруженных Сил Российской Федерации, 119160,

Российская Федерация, г. Москва, Фрунзенская наб., д. 22/2

2 Федеральное государственное бюджетное учреждение «33 Центральный научно-исследовательский испытательный институт» Министерства обороны Российской Федерации, 412918, Российская Федерация, Саратовская обл., г. Вольск-18, ул. Краснознаменная, д. 1

${ }^{3}$ Федеральное государственное бюджетное учреждение "27 Научный иентр» Министерства обороны Российской Федерации, 105005, Российская Федерация, г. Москва, Бригадирский переулок, д. 13

Поступила 23.03.2021 г. Исправленный вариант 09.06.2021 г. Принята к публикации 20.06.2021 г. Сложная обстановка, близкая к экологической катастрофе, в г. Усолье-Сибирском Иркутской области складывалась, начиная с 90-х годов прошлого века. В 2020 г. проблема накопленного вреда от химических предприятий, расположенных в экологической зоне озера Байкал, являющейся особо охраняемой природной территорией, вышла на федеральный уровень и 30 июля 2020 г. Президентом Российской Федерации поставлена задача по ликвидации химического заражения на территории бывшего предприятия ООО «Усольехимпром». Цель pаботы - обобщить опыт войск РХБ защиты, накопленный в ходе мероприятий по устранению накопленного вреда окружающей среде от деятельности химических предприятий на территории г. Усолье-Сибирское Иркутской области. На основании тщательного мониторинга промышленной площадки ООО «Усольехимпром» был составлен план первоочередных мероприятий по устранению имевшихся на объекте химических угроз. Для выполнения поставленной задачи была сформирована группировка войск (сил) и средств, принимающая участие в мероприятиях по ликвидации, основу которой составил сводный отряд войск радиационной, химической и биологической защиты (далее - войска РХБ защиты). Также в состав группировки вошли подразделения Госкорпорации «Росатом», МЧС России, Росгвардии и Федерального медико-биологического агентства. Группировкой войск (сил) и средств на тренировках были отработаны все вопросы, касающиеся безопасного проведения работ, осуществлена организация взаимодействия между ведомствами, распределены функциональные обязанности. После завершения подготовительного этапа приступили к ликвидационным мероприятиям, в ходе которых приведены в безопасное состояние и фрагментированы 17 аварийных железнодорожных емкостей, содержащих 104,3 т токсичных химикатов, проведен демонтаж надземной части цеха ртутного электролиза, в котором было разлито более 600 т. ртути, ликвидированы наиболее опасные скважины Р-2Х и Р-5, из которых откачано 107 тыс. л отходов производства эпихлоргидрина. В ходе работ сводным отрядом войск РХБ защиты проводился непрерывный мониторинг химической обстановки на территории промышленной площадки ООО «Усольехимпром» и прилегающей территории, отбор и проведение химических исследований проб почвы, воды и воздуха на наличие в них токсичных химикатов, а также специальная обработка техники, участков местности и дорог и санитарная обработка личного состава после выполнения задач. При выполнении ликвидационных мероприятий личный состав сводного отряда войск РХБ защиты столкнулся с рядом про- 
блемных вопросов, связанных с обеспечением химической безопасности при выполнении работ. Своевременное решение этих вопросов посредством разработки технических решений и их применения позволило выполнить все мероприятия в установленные сроки, при этом задача сводного отряда по обеспечению химической безопасности личного состава и населения выполнена на высоком профессиональном уровне. Все работы проведены в период с 8 августа по 24 ноября 2020 г.

Ключевые слова: аварийные железнодорожные иистерны; ООО «Усольехимпром»; отходы производства эпихлоргидрина; химическая безопасность; химическое заражение; хлорсилан; чрезвычайная ситуация.

Библиографическое описание: Мальцев С.А., Вебер Е.В., Иноземиев В.А., Цапок М.В., Беляков П.Е., Ковтун В.А., Антохин А.А. О ходе выполнения первоочередных мероприятий по устранению накопленного вреда окружающей среде от деятельности химических предприятий на территории г. Усолье-Сибирское Иркутской области // Вестник РХБ защиты. 2021. T. 5. № 2. C. 136-148. https://doi.org/10.35825/2587-5728-2020-5-2-136-148

С ростом крупных химических производств появляются новые опасности и угрозы, приводящие к возможности возникновения крупномасштабных чрезвычайных ситуаций (ЧС) техногенного характера. Для оперативного реагирования на них был определен порядок привлечения Вооруженных Сил Российской Федерации и других воинских формирований к ликвидации ЧС, который регламентируется Федеральным законом от 1994 г. № 68-Ф3¹, a также: Конституцией Российской Федерации ${ }^{2}$ Федеральным конституционным законом «О чрезвычайном положении» ${ }^{3}$, федеральными законами Российской Федерации «О безопасности» ${ }^{4}$ "Об обороне» ${ }^{5}$ и другими; указами Президента Российской Федерации. В 2020 г. такой угрозой стало бывшее предприятие ООО «Усольехимпром» (г. Усолье-Сибирское Иркутской области), расположенное в экологической зоне озера Байкал, являющейся особо охраняемой природной территорией ${ }^{6}$. Согласно полученным результатам расчета заблаговременного прогнозирования масштабов возможного химического заражения, при возникновении ЧС в зоне возможного химического заражения могли оказаться какжители г. УсольеСибирское с численностью населения 76 тыс. чел., так и г. Ангарска с численностью населения 224 тыс. чел. ${ }^{7}$ По масштабам катастрофы руководитель Росприроднадзора Светлана Радионова оценила сложившуюся ситуацию как «экологический Чернобыль» ${ }^{6}$ В 2018 г. в близлежащем городе Усолье-Сибирское введен режим ЧС, который действует и по сей день ${ }^{8}$.

На «Совещании об экологической ситуации в г. Усолье-Сибирском» 30 июля 2020 г. Президентом Российской Федерации было принято решение сформировать группировку войск (сил) и средств для проведения мероприятий по ликвидации накопленного экологического вреда окружающей среде от деятельности химических предприятий на территории промышленной площадки ООО «Усольехимпром»9.

Цель работь - обобщить опыт войск РХБ защиты, накопленный в ходе мероприятий по

\footnotetext{
1 Федеральный закон от 21.12.1994 г. № 68-Ф3 «О защите населения и территорий от чрезвычайных ситуаций природного и техногенного характера» // «Российская газета». № 250. 24.12.1994.

2 Конституция Российской Федерации // Собрание законодательства РФ, 01.07.2020, № 31, ст. 4398.

3 Федеральный конституционный закон от 30.05.2001 г. № 3-ФК3 «О чрезвычайном положении» // «Российская газета». № 105. 2.06.2001.

4 Федеральный закон от 28.12.2010 г. № 390-ФЗ «О безопасности» // «Российская газета». № 295. 29.12.2010.

Федеральный закон от 31.05.1996 г. № 61-Ф3 «Об обороне» // «Российская газета». № 106. 6.06.1996.

6 Степанова А.Н. Сибирский «Чернобыль» из офшора: как разорялся «Усольехимпром» // Новости России, СНГ и мира. 2020. URL: https://regnum.ru/news/economy/3024813.html (дата обращения: 28.02.2021).

7 Свод правил СП 165.1325800.2014. Инженерно-технические мероприятия по гражданской обороне: утв. Министерством строительства и жилищно-коммунального хозяйства Российской Федерации от 12.11.2014 г. № 705/пр.: ввод. в действие с 12.11.2014. М.: Госстрой, 2014. 88 с.

8 Постановление Мэра города Усолье-Сибирское. О введении режима функционирования «Чрезвычайная ситуация» для городского звена областной территориальной подсистемы единой государственной системы предупреждения и ликвидации чрезвычайной ситуации: постановление: утверждено Мэром города от 6 ноября 2018 г. № 157. Усолье-Сибирское: муниципальное образование «город Усолье-Сибирское», 2018. 5 с.
}

9 Ситуация в Усолье-Сибирском // Природно-ресурсные ведомости. 2020. № 7(478). С. 1-3. 


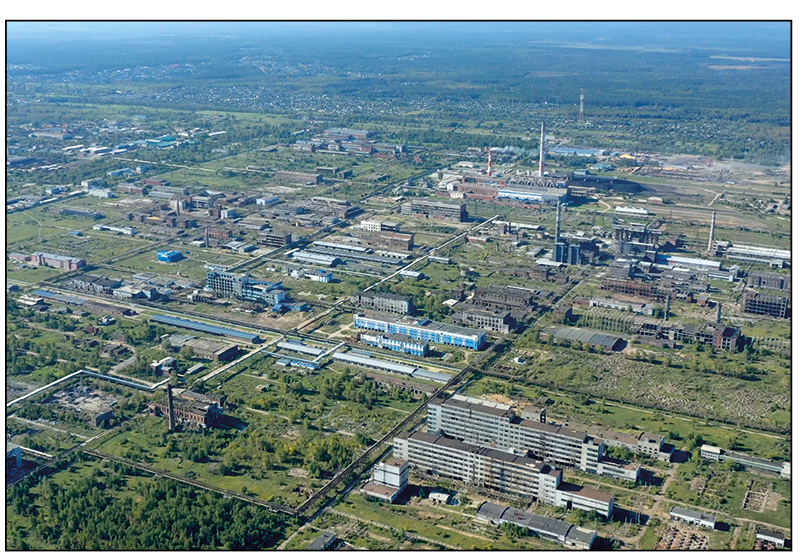

Рисунок 1 - Промышленная площадка бывшего предприятия

ООО «Усольехимпром». Фотография

c caŭma: https://rosinform.press/na-usolehimpromeproizoshlo-samovozgoranie-himicheskih-veshhestv (дата обращения: 10.02.2021)

устранению накопленного вреда окружающей среде от деятельности химических предприятий на территории г. Усолье-Сибирское Иркутской области.

К августу 2020 г. на территории промышленной площадки площадью 610 га были расположены 439 полуразрушенных объектов недвижимости, в том числе таковым являлся цех ртутного электролиза, в котором было разлито более 600 т. ртути. По всей территории промышленной площадки были размещены 17 наземных (закопанных) аварийных железнодорожных емкостей с химически опасными веществами. Также на территории бывшего предприятия ООО «Усольехимпром» находились 12 скважин глубинного захоронения с токсичными веществами, шламонакопитель и линза нефтепродуктов на берегу реки Ангара (рисунки 1 и 2).

Во исполнение указаний начальника Генерального штаба Вооруженных Сил Российской Федерации в целях выполнения мероприятий по ликвидации химического заражения на территории г. Усолье-Сибирское начальником войск РХБ защиты генерал-лейтенантом И.А. Кирилловым был сформирован сводный отряд войск РХБ защиты.

Основная цель сводного отряда - обеспечение химической безопасности при проведении первоочередных мероприятий. На сводный отряд возлагалось решение следующих задач:

- постановка щелочных завес вокруг расснаряжаемых емкостей в случае возникновения аварийных ситуаций;

- мониторинг химической обстановки на территории промышленной площадки ООО «Усольехимпром»;

- отбор проб и проведение экспресс-анализа почвы, воды и воздуха;
- участие в подготовке технических решений по выполнению задач.

Сводный отряд войск РХБ защиты вошел в сформированную в соответствии с решением Президента Российской Федерации группировку войск (сил) и средств, принимающих участие в мероприятиях по ликвидации накопленного экологического вреда окружающей среде от деятельности химических предприятий на территории промышленной площадки ООО «Усольехимпром». Также в состав группировки вошли подразделения Госкорпорации «Росатом», МЧС России, Росгвардии и ФМБА.

В подготовительном периоде перед началом выполнения работ с личным составом сводного отряда проводились ежедневные тренировки по отработке практических навыков. 31 августа 2020 г., в соответствии с постановлением администрации г. Усолье-Сибирское, на территории города были организованы и проведены штабные учения (рисунок 3).

В ходе проведения тренировок и межведомственных учений было организовано взаимодействие между подразделениями, входящими в состав группировки, уточнены задачи каждого подразделения, отработаны их совместные практические действия. Личным составом сводного отряда войск РХБ защиты на практике была показана целесообразность использования универсальной тепловой машины УТМ-80М для постановки жидкостных завес. Высота такой завесы в полной мере обеспечивает химическую безопсность.

При практическом применении УТМ-80М были выявлены следующие замечания:

не предусмотрено самостоятельное приготовление (перемешивание) рецептуры;

нагрев до рабочей температуры занимает продолжительное время.

Для устранения замечаний группой научно-технической поддержки сводного отряда войск РХБ защиты было принято следующее техническое решение: дополнительно привлекались два расчета АРС-14КМ - для приготовления и заправки УТМ-80М горячими щелочными растворами.

Опыт, приобретенный в ходе ежегодных межведомственных учений на химических предприятиях и последующих тренировках сил и средств группировки на промышленной площадке ООО «Усольехимпром» показал, что при разгерметизации железнодорожной цистерны время на устранение аварийной течи составляет от 15 до 30 мин. Исходя из этого, нормативное время постановки непрерывной локализационной завесы должно составлять не менее 30 мин.

В ходе обследования аварийных железнодорожных цистерн проведено просвечивание с помощью тепловизора каждой емкости и опре- 
О ходе выполнения первоочередных мероприятий по устранению накопленного вреда...

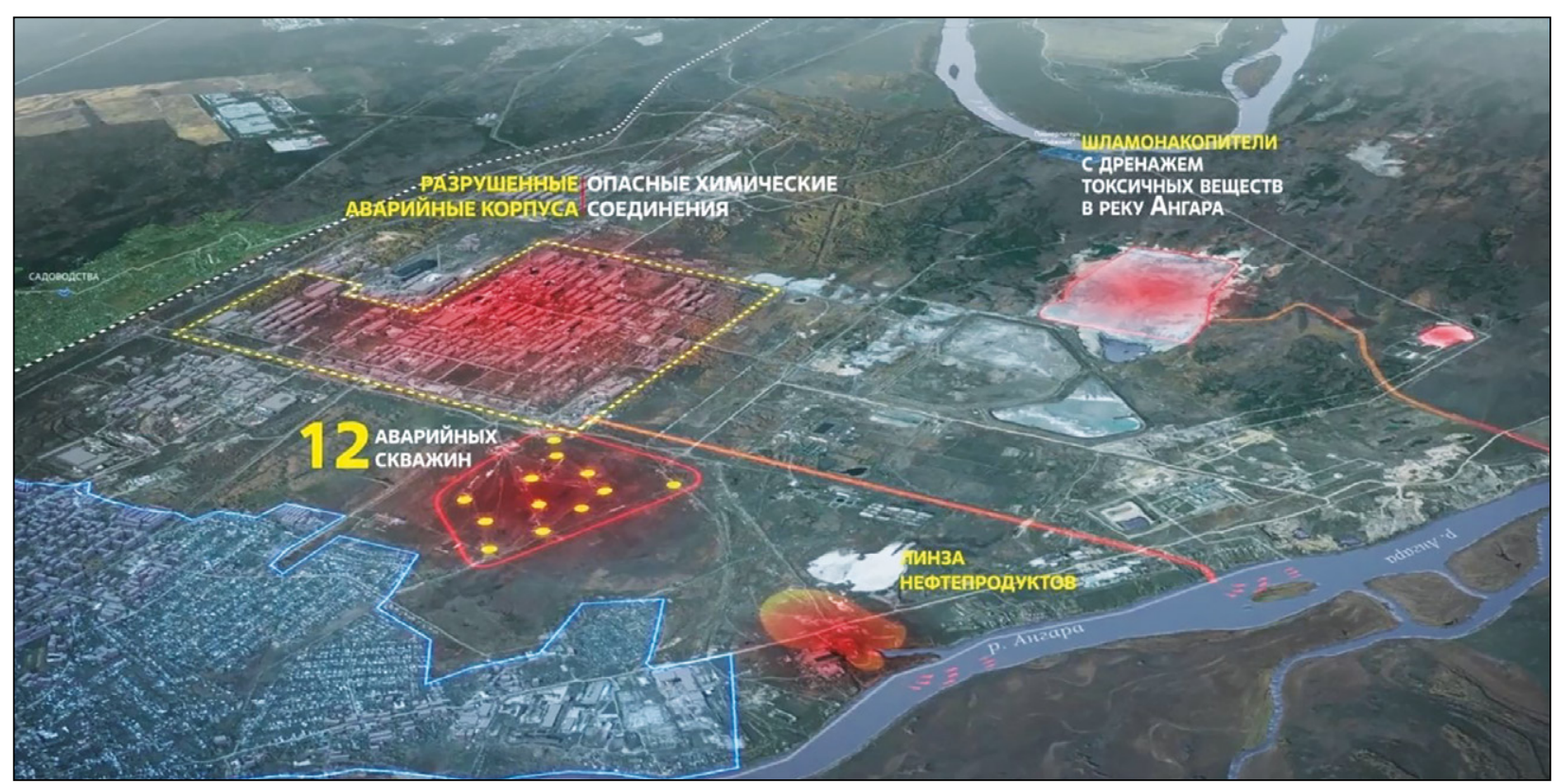

Рисунок 2 - Источники возможного химического заражения на территории бывшего предприятия ООО «Усольехимпром». Фотография из видео с сайта:

https://www.youtube.com/watch?v=m3vHOkrZ4iw (дата обращения: 10.02.2021)

делены объемы содержимых в них токсичных химикатов. На основании полученных данных были рассчитаны объемы работ по инженерной подготовке территории: организация планировки грунта, расчистка рабочих площадок от мусора и растительности, приведение цистерн в рабочие положения (их выкапывание, переворачивание горловиной вверх). В зависимости от объемов токсичных веществ для каждой емкости рассчитаны высота обваловок и конфигурации ловушек в местах возможного разлива токсичных химикатов на грунт.

После завершения подготовительных мероприятий силами «Научно-исследовательского института технологий органической, неорганической химии и биотехнологии» и сводного отряда войск РХБ защиты были начаты работы

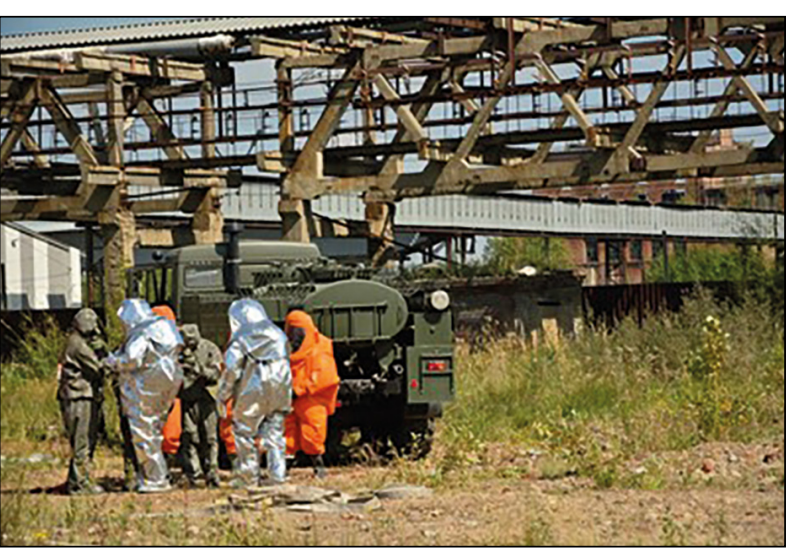

по вскрытию аварийных емкостей и их дальнейшему перетариванию в «еврокубы».

Защита личного состава сводного отряда войск РХБ защиты, находящегося на рабочих площадках, обеспечивалась их пребыванием в средствах индивидуальной защиты кожи изолирующего типа - Л-1, в средствах индивидуальной защиты органов дыхания - противогазах ПМК-4 с фильтрующей поглощающей коробкой ГП-9кБ-Оптима от паров ртути и хлороранических веществ, а также - изолирующих противогазах ИП-4.

Вскрытие емкостей осуществлялось согласно требованиям проекта производства работ.

Первым этапом являлось вскрытие 17 аварийных цистерн, выравнивание давления в емкостях с атмосферным, взятие на анализ проб

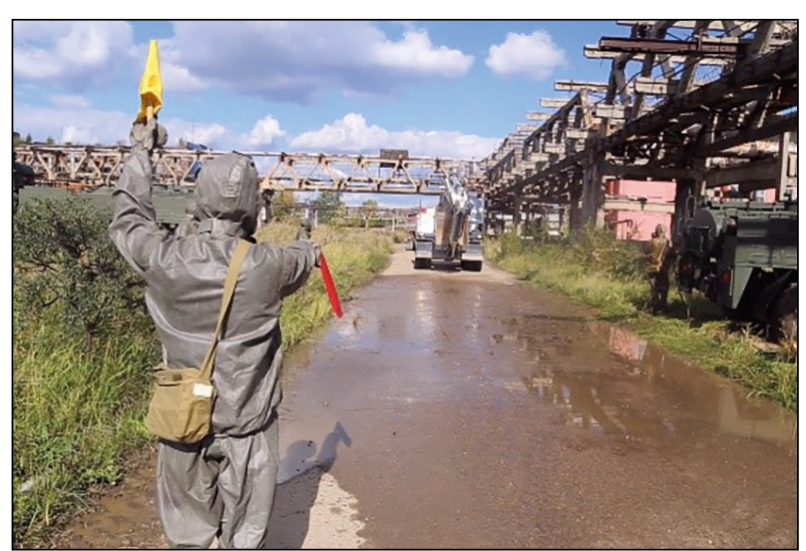

Рисунок 3 - Организация и проведение штабных учений на территории промышленной площадки ООО «Усольехимпром» (август 2020 г., фотографии авторов) 

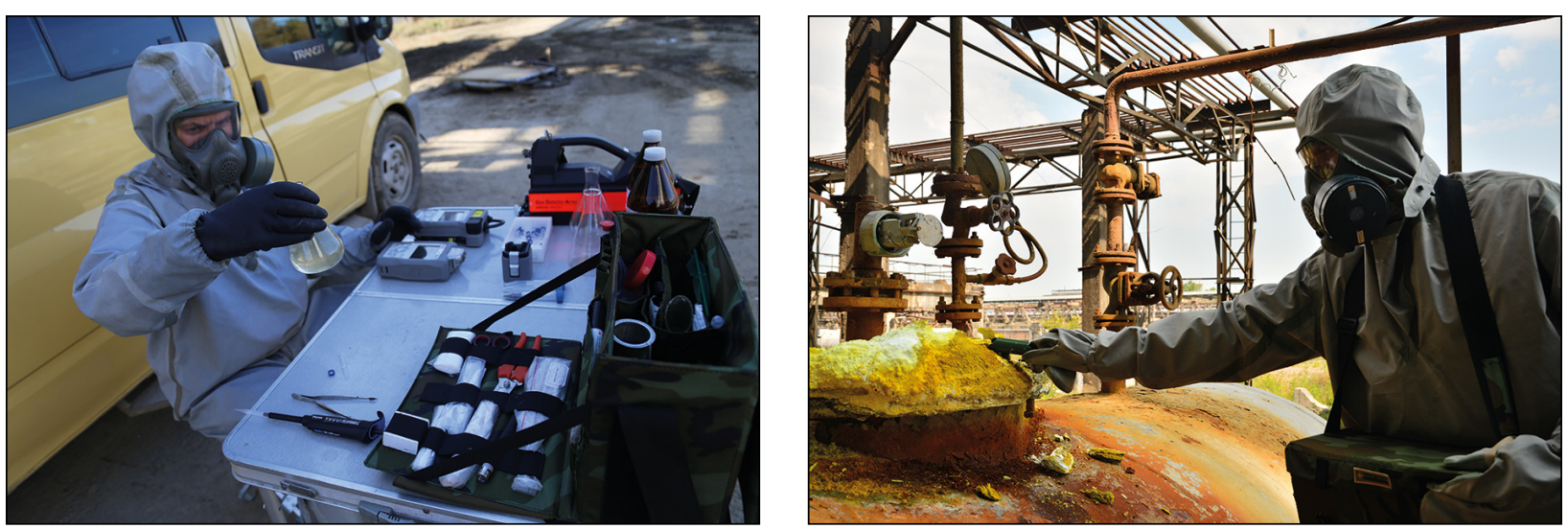

Рисунок 4 - Отбор и анализ проб содержимого аварийных железнодорожных иистерн (сентябрь 2020 г., фотографии авторов)

содержимого, герметизация горловин (рисунок 4).

Вторым этапом осуществлялось непосредственное перетаривание содержимого из аварийных емкостей в «еврокубы» и металлические толстостенные бочки объемом 270 л.

До поставки Госкорпорацией «Росатом» специализированных насосов, в целях недопущения простоя группировки в решении поставленных задач, перетаривание осуществлялось

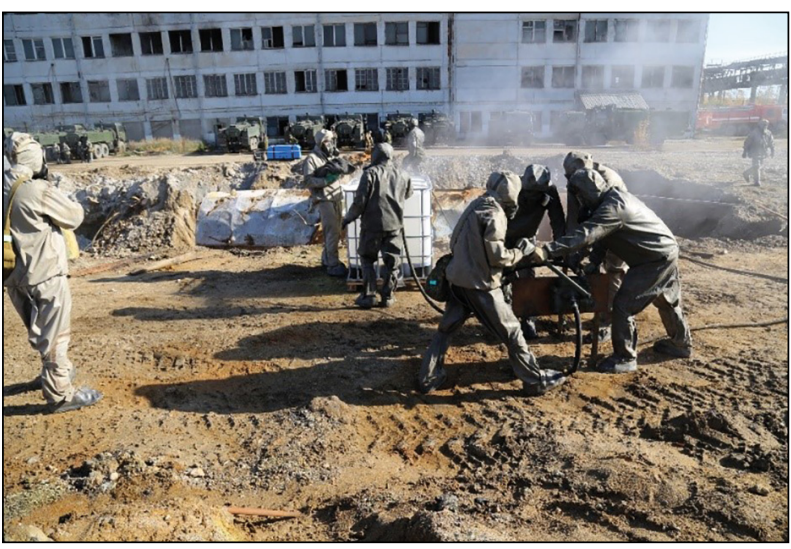

двумя насосами БКФ на специальных станинах (рисунок 5).

Однако содержащиеся в аварийных емкостях токсичные вещества (смеси хлорсиланов с органическими растворителями) в процессе перетаривания активно реагировали с кислородом и влагой воздуха, образуя при этом соляную кислоту [1], которая разрушала резинотехнические изделия насосов. В результате насосы приходили в непригодное состояние (рисунок 6).

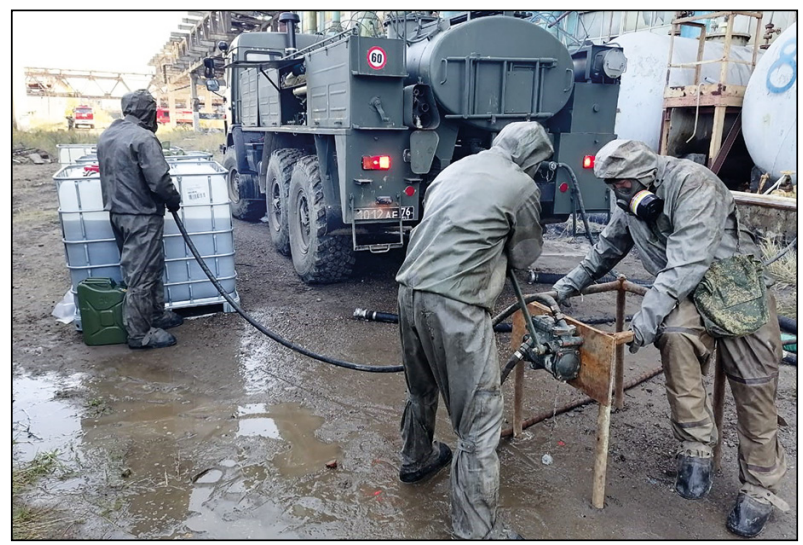

Рисунок 5 - Перетаривание специалистами войск РХБ защиты токсичных веществ насосами БКФ, расположенными на специальных станинах (октябрь 2020 г., фотографии авторов)
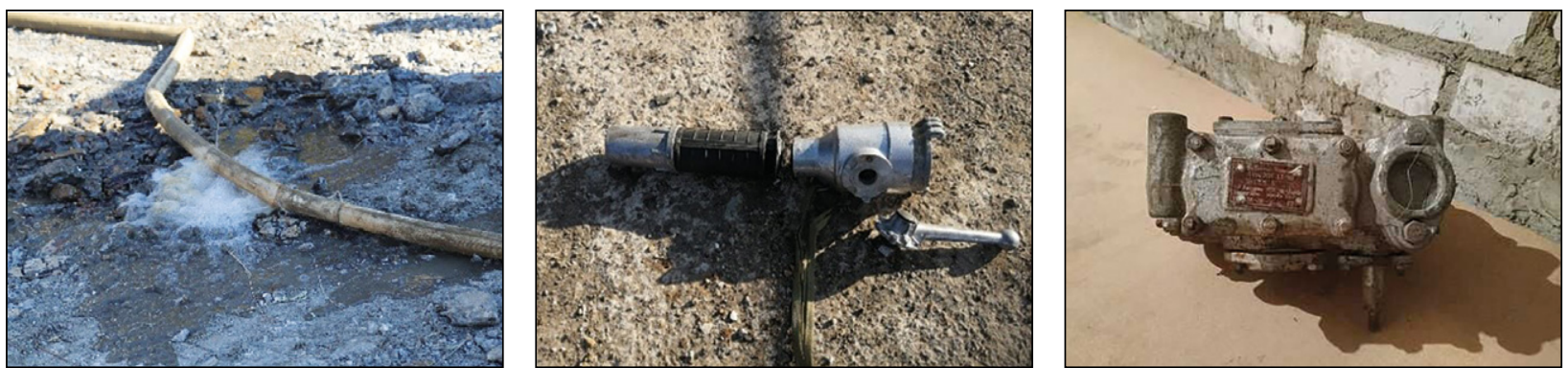

Рисунок 6 - Повреждения рукавов, насосов и других металлических и резинотехнических изделий, используемых при перекачке хлорсиланов (октябрь 2020 г., фотографии авторов) 


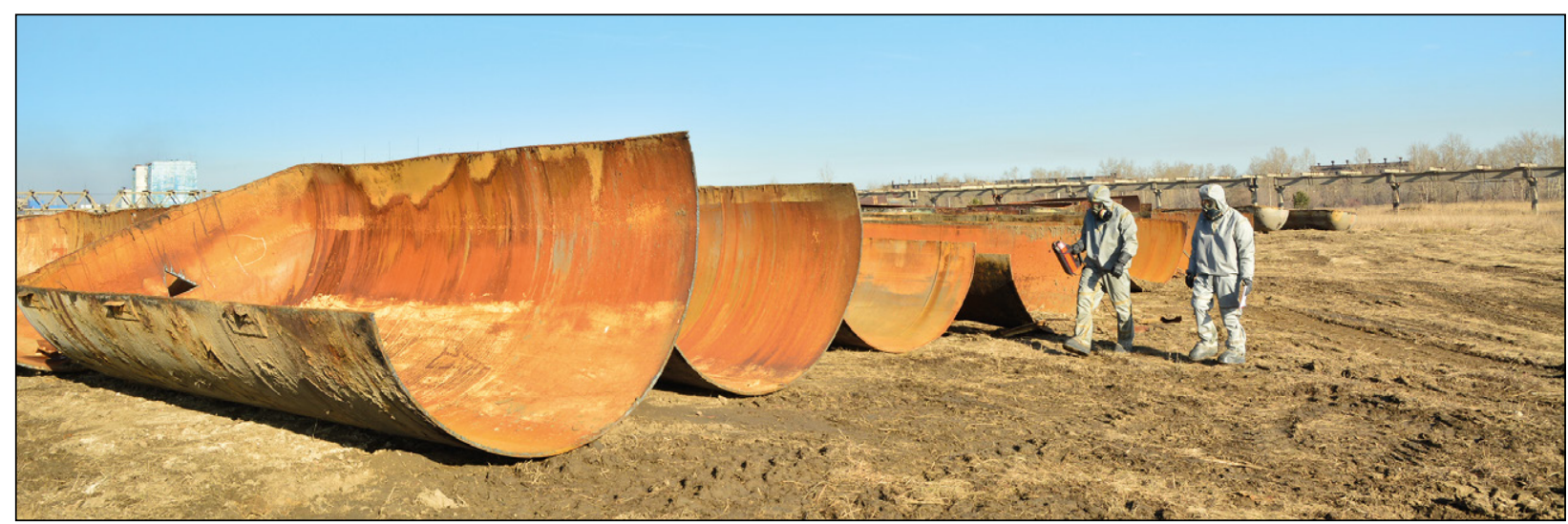

\section{Рисунок 7 - Фрагментированные железнодорожные емкости, расположенные на специально подготовленной площадке (октябрь 2020 2., фотографии авторов)}

По результатам работы был сделан вывод, что для перетаривания агрессивных жидкостей (таких, как хлорсиланы) насосы, входящие в состав АРС-14KМ, не пригодны, и данное положение необходимо учитывать при модернизации существующих и разработке новых образцов машин по специальной обработке, принимаемых на снабжение войск РХБ защиты.

После перетаривания аварийные емкости были промыты $10 \%$ раствором едкого натра [2] и фрагментированы (кислородно-ацетиленовая резка металла) (рисунок 7).

«Еврокубы» и бочки с токсичными веществами вывезены на предварительно подготовленный склад временного хранения, расположенный на рабочей площадке № 4. Вскрытие и перетаривание аварийных емкостей осуществлялось на соответствующих рабочих площадках, оборудованных с учетом специфики выполняемых задач. Каждая площадка условно делилась на «чистую» и «грязную» половины [3]. Типовая схема площадки обезвреживания аварийных емкостей представлена на рисунке 8.

«Чистая» зона площадки располагалась на наветренной стороне. В ней размещались:

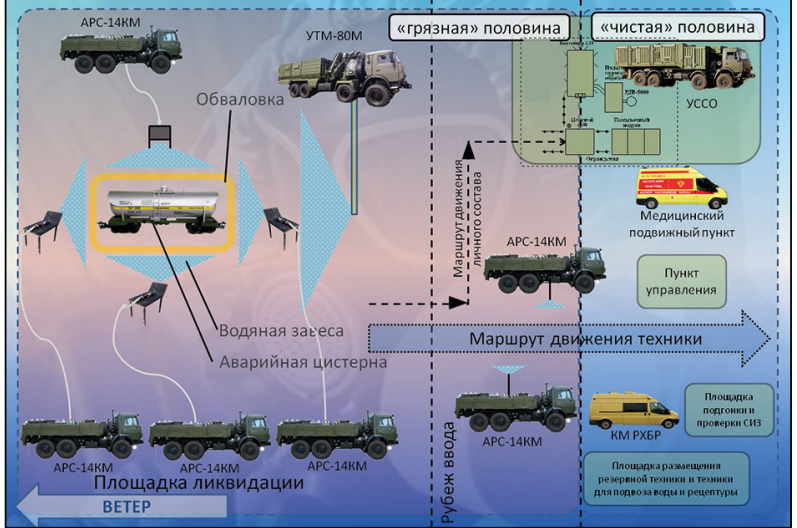

Рисунок 8 - Типовая схема площадки обезвреживания аварийных емкостей (схема авторов)

пункт управления (РАГ-2М), площадка проверки и подгонки средств индивидуальной защиты, медицинский подвижный пункт, мобильная лаборатория КМ РХБР, площадка размещения резервной техники, пункт специальной обработки техники и личного состава.

Специальная обработка техники осуществлялась двумя расчетами

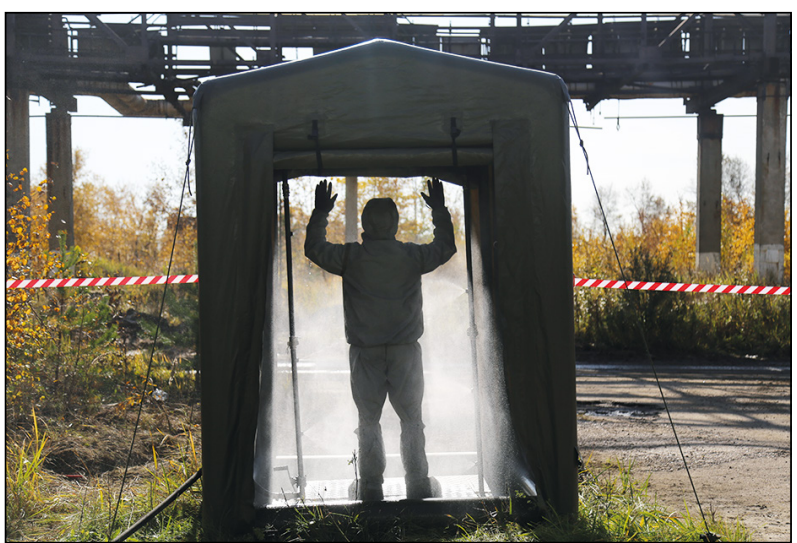

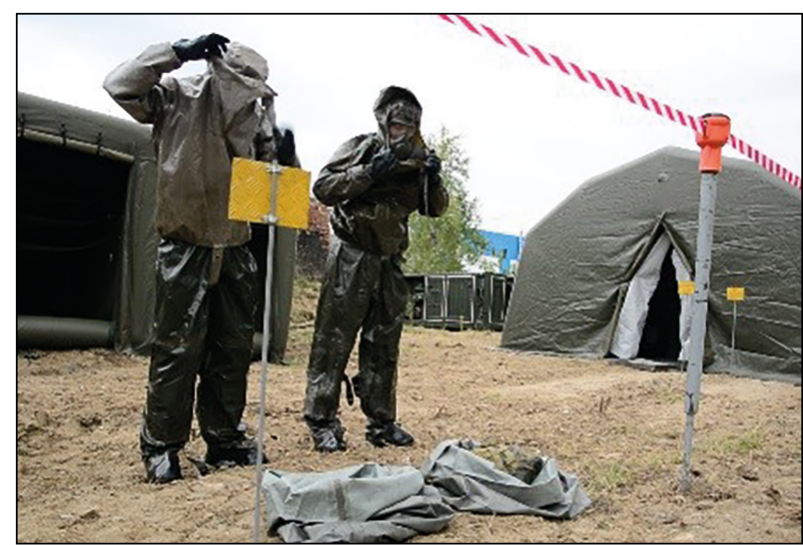

Рисунок 9 - Проведение специальной обработки средств индивидуальной защиты (октябрь 2020 г., фотографии авторов) 

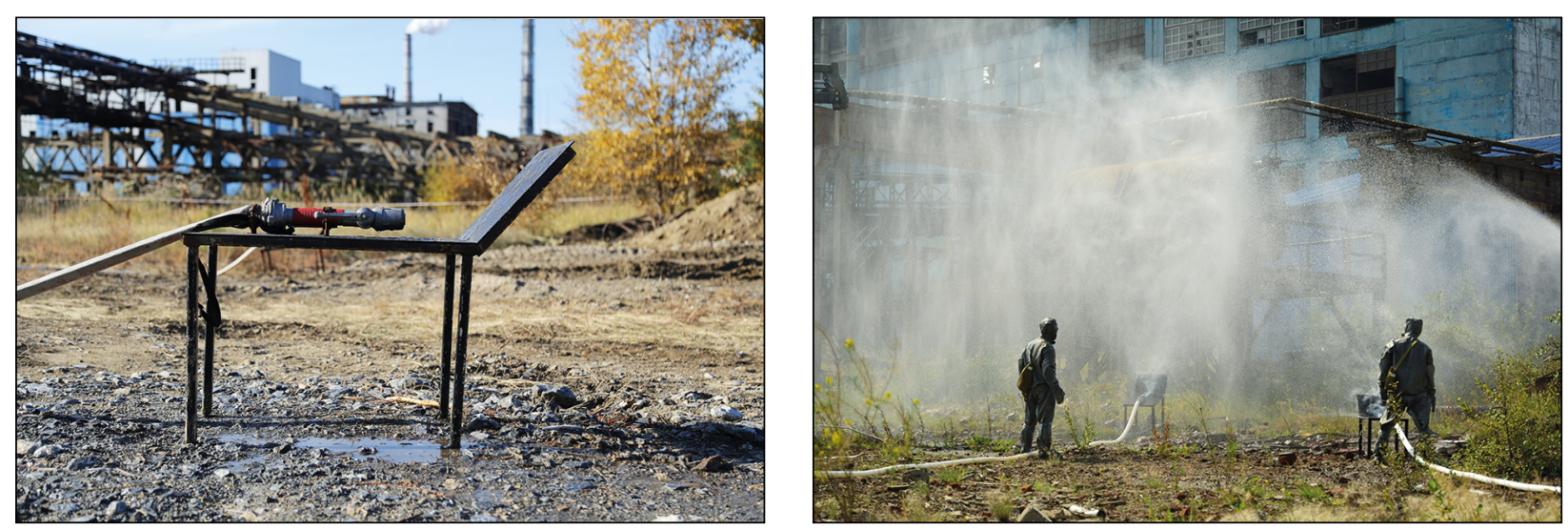

Рисунок 10 - Вспомогательный стол и выставляемая с его помощью щелочная завеса (октябрь 2020 г., фотографии авторов)

АРС-14КМ, а санитарная обработка личного состава и дегазация средств индивидуальной защиты - расчетом универсальной станции специальной обработки УССО (рисунок 9).

В «грязной» зоне осуществлялось непосредственное выполнение работ по вскрытию и перетариванию токсичных веществ. Химическая безопасность обеспечивалась четырьмя расчетами APC-14КМ и одним расчетом УТМ$80 \mathrm{M}$ с горячей дегазирующей рецептурой.

Для нейтрализации паров соляной кислоты, образующейся в процессе взаимодействия хлорсиланов с влагой воздуха, в качестве дегазирующей рецептуры использовали приготовленный и нагретый до 50-70 ${ }^{\circ} \mathrm{C} 10$ \% водный раствор карбоната натрия [4]. Для данных целей на начальном этапе использовали кальцинированную соду с территории промышленной площадки, склад с которой был обнаружен в процессе мониторинга.

В последующем для приготовления дегазатора при работах с аварийными емкостями использовали гидроксид натрия [2], поставленный Госкорпорацией «Росатом».

На практике было выявлено, что для полной локализации распространяющегося облака

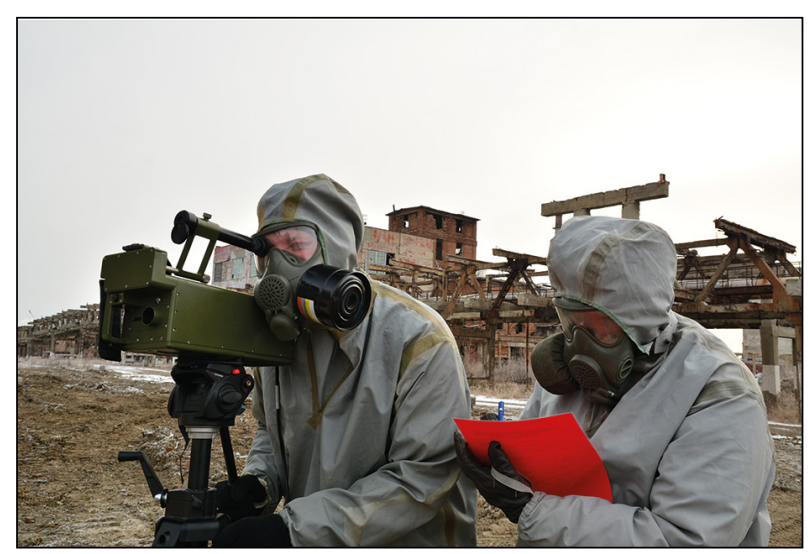

зараженного воздуха при перетаривании токсичных веществ из железнодорожных емкостей целесообразно использовать специальные вспомогательные столы совместно с пожарными рукавами. Использование вспомогательного стола при постановке жидкостной завесы с помощью одного расчета AРС-14КМ в полной мере обеспечивает химическую безопасность (рисунок 10).

При организации постановки непрерывной жидкостной завесы предварительно осуществлялся расчет времени, сил и средств на заправку, доставку, приготовление и нагрев рецептуры.

При постановке щелочных завес личный состав расчетов АРС-14КМ выставлял вспомогательные столы по периметру аварийной емкости, обеспечивая эффективность локализации облака зараженного воздуха (при любом направлении ветра) в случае аварийной ситуации.

Вместе с тем при постановке завесы, из-за малого угла наклонной площадки вспомогательного стола $-60^{\circ}$, а также при сильном ветре дегазирующий раствор попадал на горловину

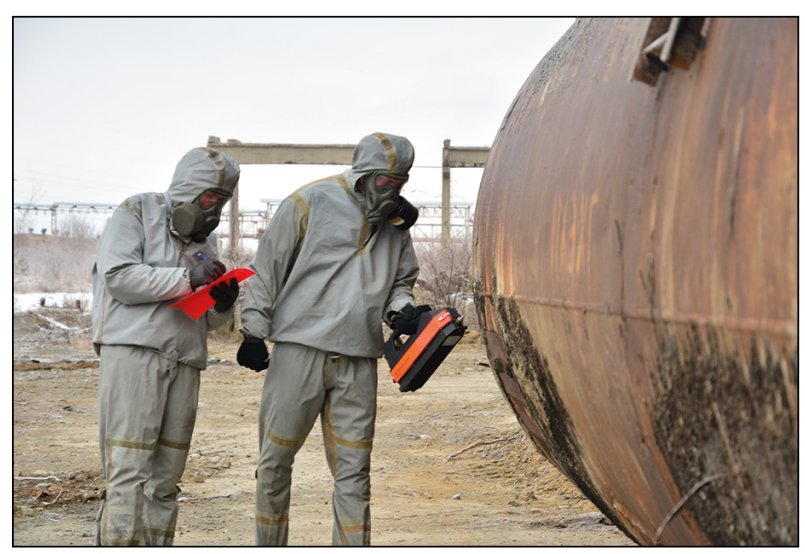

Рисунок 11 - Проведение мониторинга химической обстановки расчетом КМ РХБР (октябрь 2020 г., фотографии авторов) 


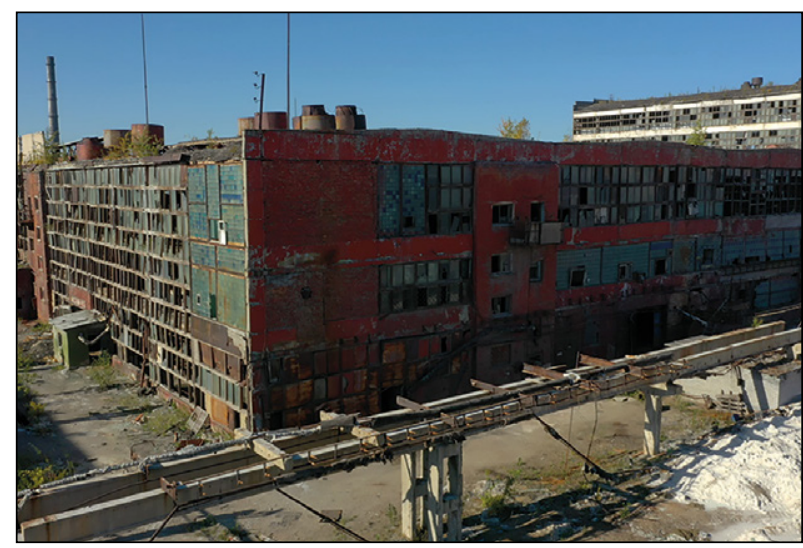

A

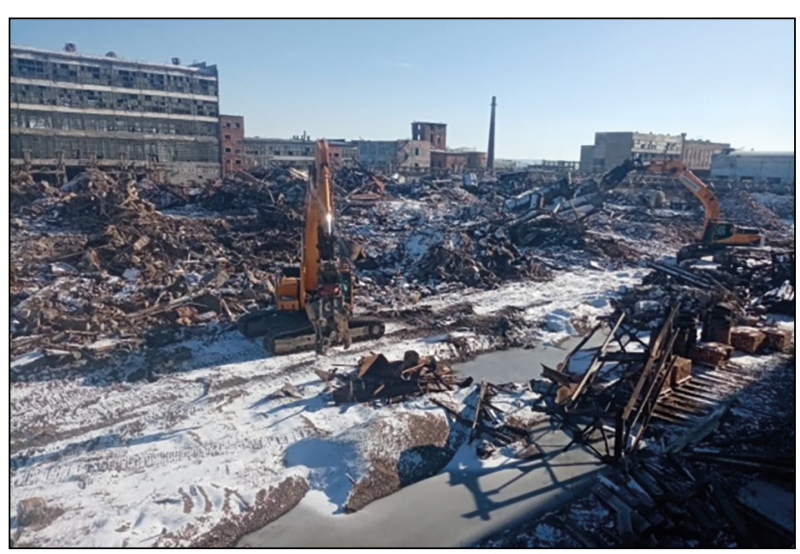

Б

Рисунок 12 - Цех ртутного электролиза на момент начала работ (A) и по окончании работ по демонтажу надземной части (Б) (октябрь 2020 г., фотографии авторов)

цистерны и бурно взаимодействовал с хлорсиланами с выделением тепла и кислых паров [5].

С целью исключения контакта дегазирующего раствора с содержимым емкости на ее поверхности, угол наклонной площадки вспомогательного стола был увеличен до $70^{\circ}-75^{\circ}$ (подъем передних ножек вспомогательного стола). Данное положение также обеспечило максимальную высоту завесы и сократило минимально допустимое расстояние от аварийной емкости до вспомогательного стола (при условии непопадания дегазирующей рецептуры на поверхность емкости, особенно на горловину).

Мониторинг химической обстановки, пробоотбор различных сред и химический анализ проб осуществлялись двумя расчетами мобильного комплекса РХБ разведки (рисунок 11).

Заложенные тактико-технические характеристики в мобильном комплексе РХБ разведки в полном объеме обеспечивали проведение экспресс анализов парогазовых сред с использованием газоанализатора GDA-2,5, жидких и твердых проб - TruDefender, FirstDefender. Углубленный химический анализ проводили на GC/MC Griffin-460. Непрерывную химическую разведку местности осуществляли при помощи прибора химической разведки дистанционного действия ПХРДД-3.

В ходе отработки практических задач выявлен и решен ряд проблемных вопросов:

1. Штатный комплект пробоотбора КПО-1М не предназначен для отбора проб агрессивных сред (отходы производства эпихлоргидрина и хлорсиланы). Входящие в его состав приспособления и инструменты разрушаются при взаимодействии с агрессивными средами. Для решения вопроса необходимо ввести в состав комплекта пробоотбора химически стойкие приспособления, инструменты и лабораторную посуду.

2. В мобильных комплексах не предусмотрено наличие запасного комплекта расходных материалов и растворителей для пробоотбора и проведения специфических анализов. В связи с этим комплектование комплексов необходимо производить заблаговременно и с учетом поставленных специальных задач.

Одним из наиболее опасных источников химического заражения являлся цех ртутного электролиза, в котором было разлито более 600 т. ртути (рисунок 12).

Для обеспечения химической безопасности при демонтаже надземной части цеха специалистами 33 института, 27 Центра и 9-го полка осуществлялся ежедневный мониторинг окружающей среды с использованием анализатора ртути РА-915М (рисунок 13).

В результате проведенного мониторинга в районе расположения цеха ртутного электролиза выявлены значительные превышения предельно допустимых концентраций паров ртути. В целях недопущения поражения личного состава и населения токсичными парами, сводным отрядом войск РХБ защиты производилось пылеподавление при выполнении работ. Кроме того, определены маршруты движения техники, обеспечивающие максимальную безопасность и оперативность доставки рецептуры, при этом обоснована необходимость специальной обработки шасси при выезде с площадки с использованием демеркуризационной ванны (рисунок 14) ${ }^{10}$.

На практике было показано, что минимально необходимое количество специальной

\footnotetext{
10 Ртуть в биосфере: эколого-геохимические аспекты. Материалы Международного симпозиума (Москва, 7-9 сентября 2010 г.). М.: ГЕОХИ РАН, 2010. 477 с.
} 

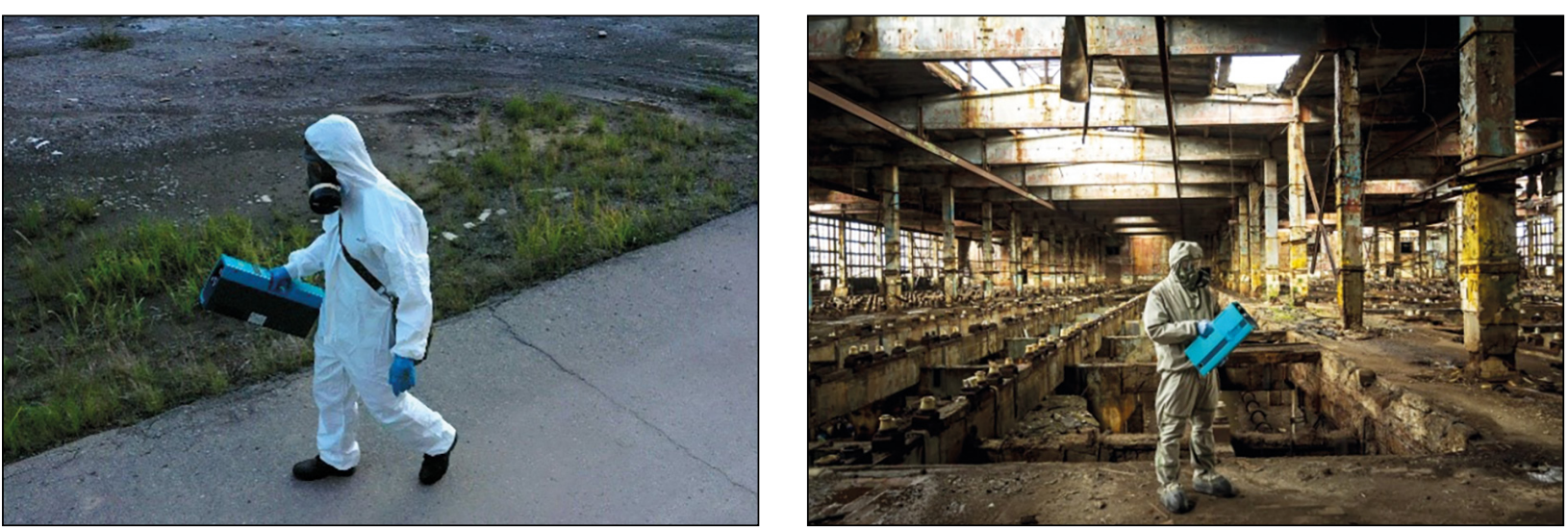

Рисунок 13 - Проведение специалистами войск РХБ защиты ежедневного мониторинга окружающей среды с использованием анализатора ртути РА-915М (октябрь 2020 г., фотографии авторов)

техники сводного отряда при проведении мероприятий в районе расположения цеха ртутного электролиза составляет:

УТМ-80М - 1 ед. (непосредственная дегазация конструкций здания);

АРС-14КМ - 5 ед. (подвоз и заправка УТМ$80 \mathrm{M}$ подогретой дегазационной рецептурой, дегазация дорог и участков местности, специальная обработка техники);

УССО - 1 ед. (санитарная обработка личного состава);

КМ РХБР - 2 ед. (химический мониторинг в районе проведения работ и на территории промышленной площадки ООО «Усольехимпром»).

Следующими химическими опасными объектами, на которых сводным отрядом войск РХБ защиты обеспечивалась химическая безопасность при выполнении ликвидационных мероприятий, являлись скважины Р-2x и Р-5, расположенные на территории рассолопромысла (рисунок 15).

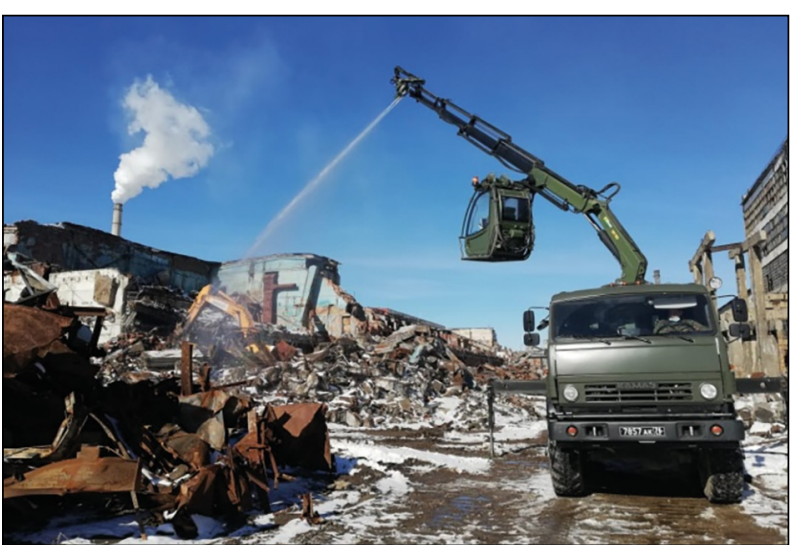

Рисунок 14 - Пылеподавление с использованием УТМ-80М при демонтаже надземной части иеха ртутного электролиза (октябрь 2020 г., фотография авторов)
До 24 ноября 2020 г. сводный отряд обеспечивал химическую безопасность при проведении Госкорпорацией «Росатом» комплекса мероприятий по установке над скважинами противовыбросного оборудования, подъему рабочих и обсадных колонн, установлению цементных мостов и заполнению стволов скважин буровым раствором.

После проведения работ проведен демонтаж оборудования и организована рекультивация земель.

По результатам выполненных первоочередных мероприятий по устранению накопленного вреда окружающей среде от деятельности химических предприятий на территории г. Усолье-Сибирское Иркутской области необходимо проработать следующие вопросы, заблаговременное решение которых позволит более оперативно и качественно выполнять поставленные задачи.

При постановке непрерывных жидкостных завес выявлена проблема по заправке спец-

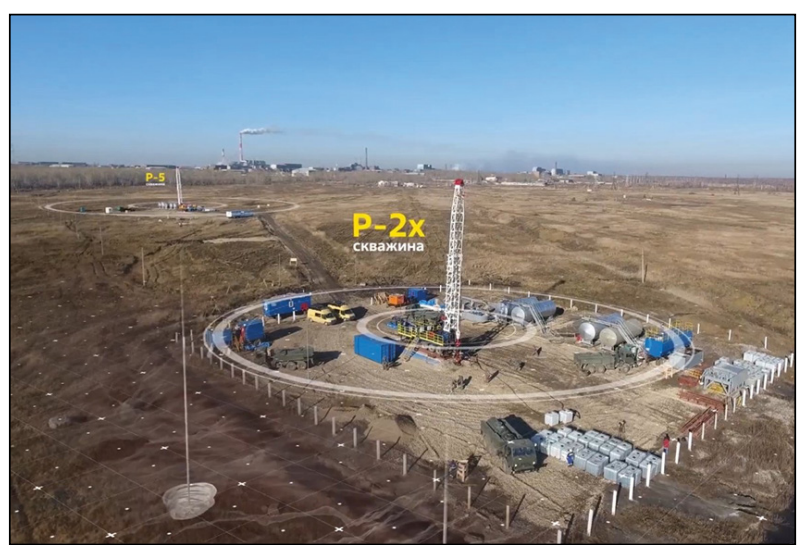

Рисунок 15 - Скважины P-2x и P-5, расположенные на территории рассолопромысла. Фотография из видео с сайта:

https://www.youtube.com/watch?v=m3vHOkrZ4iw (дата обращения: 10.02.2021) 
техники войск РХБ защиты водой, т.к. на весь завод был исправен только один пожарный гидрант и один переходник (на 51 мм) для пожарных рукавов АРС-14КМ и при этом отсутствовали природные источники воды.

На начальных этапах работ ограничение возможностей группировки было связано с запретом въезда на частные территории коммерческих предприятий, расположенных на территории промышленной площадки ООО «Усольехимпром».

Отдельно целесообразно провести анализ организации взаимодействия ведомств и федеральных органов исполнительной власти, входящих в состав группировки, требуется разработка Регламента взаимодействия и управления межведомственной группировкой.

При проведении межведомственных тренировок и учений необходимо более качественно отрабатывать вопросы взаимодействия и уточнения задач между ведомствами. Несогласованность действий группировки при выполнении задач может поставить под угрозу срыва план совместных работ группировки. Кроме того, орган управления группировкой должен четко понимать потребности и задачи каждого ведомства в отдельности и прорабатывать заранее вопросы обеспечения дегазаторами, средствами индивидуальной защиты, техническими средствами перетаривания, средствами связи между ведомствами группировки на месте. А каждое ведомство в отдельности должно знать общий замысел всех выполняемых работ в соответствии с утвержденным проектом выполнения работ.
Так, отсутствие общего утвержденного проекта выполнения работ вызывало недопонимание у представителей ведомств в плане распределения функциональных обязанностей и на фоне общей подготовленности сил и средств группировки снижало эффективность и оперативность выполняемых задач. Привлекаемые структуры, как государственные, так и коммерческие выполняли узкие специфичные задачи, при этом понимание общего замысла, порядка и алгоритма ликвидации ЧС выработалось лишь на завершающих этапах проводимых работ.

В связи с тем, что в компетенцию войск РХБ защиты входила установка требований и правил по обеспечению химической безопасности, контроль их исполнения для всех участников межвидовой группировки, а также участие в разработке технических решений по наиболее сложным и проблемным вопросам ликвидации химического заражения, можно сделать вывод о том, что войскам РХБ защиты как на современном этапе, так и в будущем предстоит выполнять ведущую роль при ликвидации ЧС химического характера. Данное положение обязывает и в дальнейшем наращивать усилия, направленные на разработку перспективных вооружений и средств РХБ защиты, модернизацию систем управления, связи и передачи информации. Необходима детальная проработка всех проблемных вопросов с последующей корректировкой соответствующих руководящих документов и учебного процесса для выпускников учебных заведений войск РХБ защиты.

\section{Вклад авторов / Autors Contributions}

Все авторы внесли существенный вклад в проведении мероприятий по устранению накопленного вреда окружающей среде от деятельности химических предприятий на территории г. Усолье-Сибирское Иркутской области и подготовку статьи, прочли и одобрили финальную версию до публикации / All the authors played an importaint role in the elimination of the environmental damage, caused by the activities of chemical enterprises in the city of Usolye-Sibirskoye, Irkutsk region.

Информация о конфликте интересов

Авторы заявляют, что исследования проводились при отсутствии любых коммерческих или финансовых отношений, которые могли бы быть истолкованы как потенциальный конфликт интересов.

\section{Сведения о рецензировании}

Статья прошла открытое рецензирование двумя рецензентами, специалистами в данной области. Рецензии находятся в редакции журнала и в РИНЦ.

Список источников / References

1. Копылов B.М., Хананашвили Л.М., Школьник О.В., Иванов А.Г. Гидролитическая поликонденсация органохлорсиланов // Высокомолекулярные соединения. 1995. Т 37. № 3. С. 394-416.

Kopylov V.M., Khananashvili L.M., Shkolnik O.V., Ivanov A.G. Hydrolytic Polycondensation of
Organochlorosilanes (Review) // High-Molecular Compounds. 1995. V. 37. № 3. P. 394-416.

2. Петров В.Г., Липанов А.М., Трубачев А.В., Чичерина А.А. Обезвреживание опасных веществ на перепрофилированном объекте по уничтожению люизита // Химическая физика и мезоскопия. 
2009. T 11. № 1. C. 54-58.

Petrov V.G., Lipanov A.M., Trubachev A.V., Chicherina A.A. Neutralization of hazardous substances at a converted lewisite destruction facility // Chemical Physics and Mesoscopy. 2009. V. 11.No. 1. P. 54-58.

3. Багрий А.К., Галкин Г.П., Гуськов Н.С. и др. Защита от атомного, химического и бактериологического оружия М.: Воениздат, 1957. 198 с.

Bagriy A.K., Galkin G.P., Guskov N.S. et al. Protection against Atomic, Chemical and Bacteriological Weapons. Moscow: Military Publishing, 1957. 198 p.
4. Патент РФ 2535218. Заявл. 05.07.2013; опубл. 10.12.2014

Patent RF (2535218) 2014.

5. Гаврилова А.В., Кирилин А.Д., Белова Л.О., Коробова Е.А. Алкоксисиланы - синтез и применение // Химия и технология органических веществ. 2008. T. 3. № 1 . C. 50-58.

Gavrilova A.V., Kirilin A.D., Belova L.O., Korobova E.A. Alkoxysilanes - Synthesis and Application // Chemistry and Technology of Organic Substances. 2008. V. 3. No. 1. P. 50-58.

Об авторах

Управление начальника войск радиационной, химической и биологической защиты Вооруженных Сил Российской Федерации, 119160, Российская Федерация, г. Москва, Фрунзенская наб., д. 22/2.

Мальцев Сергей Александрович. Начальник отдела, кандидат технических наук;

Вебер Евгений Владимирович. Старший офицер отдела, кандидат технических наук.

Федеральное государственное бюджетное учреждение «33 Центральный научно-исследовательский испытательный институт» Министерства обороны Российской Федерации, 412918, Российская Федерация, Саратовская обл., г. Вольск-18, ул. Краснознаменная, д. 1.

Иноземцев Валерий Александрович. Начальник «33 Центрального научно-исследовательского испытательного института» Министерства обороны Российской Федерации, доктор военных наук;

Цапок Максим Владимирович. Заместитель начальника отдела, кандидат технических наук, доцент; Беляков Павел Евгеньевич. Старший научный сотрудник.

Федеральное государственное бюджетное учреждение «27 Научный центр» Министерства обороны Российской Федерации, 105005, Российская Федерация, г. Москва, Бригадирский переулок, д. 13.

Ковтун Виктор Александрович. Начальник «27 Научного центра» Министерства обороны Российской Федерации, кандидат химических наук, доцент;

Антохин Антон Андреевич. Научный сотрудник отдела, кандидат химических наук.

Контактная информация для всех авторов: 27nc_1@mil.ru Контактное лицо: Ковтун Виктор Александрович, 27nc_1@mil.ru 


\title{
Implementation of Priority Measures to Eliminate the Accumulated Environmental Damage Caused by Chemical Enterprises in the City of Usolye-Sibirskoye, Irkutsk Region
}

\author{
S.A. Maltsev ${ }^{1}$, Ye.V. Veber ${ }^{1}$, V.A. Inosemtsev², M.V. Tsapok ${ }^{2}$, P.Ye. Belyakov², \\ V.A. Kovtun ${ }^{3}$, A.A. Antokhin ${ }^{3}$ \\ ${ }^{1}$ Directorate of the Chief of the Radiation, Chemical and Biological Defence Troops \\ of the Armed Forces of the Russian Federation. \\ Frunzenskaya Embankment 22, 119160, Russian Federation \\ ${ }^{2}$ Federal State Budgetary Establishment "33 Central Scientific Research Test Institute» \\ of the Ministry of Defence of the Russian Federation. Krasnoznamennaya Street 1, \\ Volsk-18, Saratov Region 412918, Russian Federation \\ ${ }^{3}$ Federal State Budgetary Establishment "27 Scientific Centre» of the Ministry of Defence \\ of the Russian Federation, Brigadirskii Lane 13, Moscow 105005, Russian Federation
}

Received 23 March 2021. Corrected variant 09 June 2021. Accepted for publication 20 June 2021

A difficult situation, close to an environmental disaster, had been developing in the town of UsolyeSibirskoye, Irkutsk Region, since the 90s of the XX century. In 2020, the problem of accumulated environmental damage caused by chemical enterprises of the ecological zone of Lake Baikal, reached the federal level. On July 30, 2020, the President of the Russian Federation set the task of eliminating chemical contamination on the territory of the former enterprise LLC «Usoliekhimprom». The aim of this work is to summarize the experience of the Russian NBC Protection Troops, accumulated in course of eliminating the environmental damage, caused by the activities of chemical enterprises in the city of Usolye-Sibirskoye, Irkutsk region. The plan on priority measures was drawn up on the basis of careful monitoring of the "Usoliekhimprom» LLC industrial site in order to eliminate the chemical threats, existed at the facility. The special group of troops (forces) was formed to take part in liquidation activities. This group was formed from NBC Protection Troops, the State Atomic Energy Corporation «Rosatom», the Russian Emergencies Ministry, the Russian Guard and the Federal Biomedical Agency. In course of the training, the special group of troops (forces) worked out all the issues related to the safe conduct of the work, organized interaction between departments, and distributed the functional responsibilities. After the completion of the preparatory stage, the group began to work. 17 emergency railway tanks containing 104, 3 tons of toxic chemicals were fragmented, the above-ground part of the mercury electrolysis workshop with more than 600 tons of mercury was dismantled, the most dangerous wells P-2X and P-5 with 107 thousand liters of epichlorohydrin production wastes were pumped out. In course of work, the detachment of the NBC Protection Troops carried out continuous monitoring of the chemical situation on the territory of the industrial site of «Usoliekhimprom LLC» and the adjacent territory. When carrying out liquidation measures, the personnel of the detachment of the NBC Protection Troops faced a number of problematic issues related to ensuring chemical safety. The solution of these problems made it possible to complete all the work in time and at a high professional level. All the work was carried out from August 8 to November 24, 2020.

Keywords: hazardous railway tank-car; LLC «Usoliekhimprom»; waste from epichlorohydrin production; chemical safety; chemical contamination; chlorosilane; emergency.

For citation: Maltsev S.A., Veber Ye.V., Inosemtsev V.A., Tsapok M.V., Belyakov P.Ye., Kovtun V.A., Antokhin A.A. Implementation of Priority Measures to Eliminate the Accumulated Environmental Damage Caused by Chemical Enterprises in the City of Usolye-Sibirskoye, Irkutsk Region // Journal of NBC Protection Corps. 2021. V. 5. № 2. P. 136-148. https://doi.org/10.35825/2587-5728-2021-5-2$136-148$ 
Conflict of interest statement

The authors declare that the research was conducted in the absence of any commercial or financial relationship that could be construed as a potential conflict of interest.

\section{Peer review information}

The article has been peer reviewed by two experts in the respective field. Peer reviews are available from the Editorial Board and from Russian Science Citation Index database.

References

See P. 145-146.

\section{Authors}

Directorate of the Chief of the Radiation, Chemical, and Biological Defence Troops of the Armed Forces of the Russian Federation. Frunzenskaya Embankment 22, 119160, Russian Federation.

Sergey Aleksandrovich Maltsev. Head of the Department. Candidate of Technical Sciences.

Eugeny Vladimirovih Veber. Senior Officer of the Department. Candidate of Technical Sciences.

Federal State Budgetary Establishment «33 Central Scientific Research Test Institute» of the Ministry of Defence of the Russian Federation. Krasnoznamennaya Street 1, Volsk-18, Saratov Region 412918, Russian Federation.

Valeriy Alexandrovich Inozemtsev. Head of Institute, Doctor of Military Sciences.

Maxim Vladimirovich Tsapok. Deputy Head of the Department. Candidate of Technical Sciences, Associate Professor.

Pavel Yevgenievich Belyakov. Senior Researcher.

Federal State Budgetary Establishment «27 Scientific Centre» of the Ministry of Defence of the Russian Federation. Brigadirskii Lane 13, Moscow 105005, Russian Federation.

Viktor Aleksandrovich Kovtun. Head of the Centre. Candidate of Chemical Sciences, Associate Professor.

Anton Andreyevich Antokhin. Researcher. Candidate of Chemical Sciences.

Contact information for all authors: 27nc_1@mil.ru Contact person: Viktor Aleksandrovich Kovtun,27nc_1@mil.ru 
Федеральное государственное казенное военное образовательное учреждение высшего образования «Военная академия радиационной, химической и биологической защиты имени Маршала Советского Союза С.К. Тимошенко" Министерства обороны Российской Федерации, 156015, Российская Федерация, г. Кострома, ул. Горького, д. 16

\begin{abstract}
Поступила 02.03.2021 г. Принята к публикации 20.06.2021 г.
Лекция предназначена для подготовки специалистов в высших военных учебных заведениях по Федеральному государственному стандарту «Робототехника военного и специального назначения», а также для подготовки операторов робототехнических комплексов (средств) военного назначения в учебных центрах и воинских частях.

В лекции рассмотрены два учебных вопроса:

1) Ретроспективный анализ радиационных аварий и их последствий.

2) Анализ применения роботизированной техники и робототехнических комплексов для ликвидации последствий радиационных аварий.

Вывод: материал, представленный в лекции, направлен на расширение знаний обучающихся в области истории развития радиационных аварий (катастроф) и применения роботизированной техники и робототехнических комплексов для ликвидации последствий таких аварий. Анализ применения робототехники в условиях повышенного радиационного фона показывает незаменимость робототехнических комплексов при решении задач в несопоставимых для жизни человека условиях. Вместе с тем, актуализируются проблемные вопросы развития и применения экстремальной робототехники.
\end{abstract}

Ключевые слова: радиационно-опасные объекты; радиационные аварии; радиационная разведка и контроль; ликвидация последствий аварий; робототехнические комплексы.

Библиографическое описание: Аккузин К.Н., Макеев Е.С. История развития и применения робототехники при тиквидации последствии аварий на радиационно опасных объектах (лекция) // Вестник войск РХБ защичты. 2021. Т. 5. № 2. C. 149-164. https://doi.org/10.35825/25875728-2021-5-2-149-164

В настоящее время развитие отечественной робототехники (в том числе и экстремальной) обусловлено появлением в последнее десятилетие потока открытой информации в области разработок, испытаний и эксплуатации робототехнических комплексов. Последнее также позволило российским военным специалистам значительно продвинуться в сфере военной робототехники.

Ключевым фактором, обуславливающим производство и совершенствование робототехнических комплексов (РТК) военного и специального назначения, является возмож- ность их применения в опасных и смертельно опасных для человека условиях. В нашей стране такая необходимость возникла при ликвидации последствий радиационной аварии на Чернобыльской АЭС. Огромные дозы гамма-излучения делали нахождение ликвидаторов в очаге заражения несопоставимым с жизнью.

Опыт применения РТК, полученный в результате ликвидации последствий аварии на Чернобыльской АЭС, стал мощным толчком в сфере разработок экстремальных РТК, в том числе и для войск РХБ защиты. 


\section{1. Ретроспективный анализ радиацион- ных аварий и их последствий.}

Атомные технологии нашли свое применение на транспорте, в оборонной промышленности, энергетике и других сферах человеческой деятельности. Манипуляции по транспортировке, хранению, использованию и утилизации радиоактивных веществ (PB) производятся на радиационно опасных объектах.

Радиационно опасный объект (POO) объект, на котором хранят, перерабатывают, используют или транспортируют радиоактивные вещества, и где в случае аварии или при разрушении может произойти облучение ионизирующим излучением или радиоактивное загрязнение людей, сельскохозяйственных животных и растений, объектов народного хозяйства, а также окружающей природной среды ${ }^{1}$.

К типовым РОО относятся:

- атомные станции;

- предприятия по переработке отработанного ядерного топлива и захоронению радиоактивных отходов;

- предприятия по изготовлению ядерного топлива;

- научно-исследовательские и проектные организации, имеющие ядерные установки и стенды;
- транспортные ядерные энергетические установки;

- военные объекты ${ }^{1}$.

Вместе с широкими возможностями, обеспечиваемыми эксплуатацией POО, подобные объекты являются источником огромных рисков для окружающей среды и населения. Возможность выхода радиоактивных продуктов или ионизирующего излучения в окружающую среду в размерах, превышающих допустимые нормы, может привести к авариям катастрофических масштабов.

Радиационная авария - это нарушение правил безопасной эксплуатации ядерноэнергетической установки, оборудования или устройства, при котором произошел выход радиоактивных продуктов или ионизирующего излучения за предусмотренные проектом пределы их безопасной эксплуатации, приводящий к облучению населения и загрязнению окружающей среды [1].

Аварии с выходом РВ в окружающую среду принято классифицировать по границе распространения и количеству вышедших при аварии радиоактивных веществ. Для классификации аварий в России используется предложенная Международным агентством по атомной энергии (МАГАТЭ) международная шкала ядерных событий (INES) [2].

Таблица 1 - Международная шкала ядерных событий (INES) с примерами

\begin{tabular}{|c|c|}
\hline Класс, название, пример аварии & Ожидаемые последствия \\
\hline $\begin{array}{l}7 \text { класс - глобальная авария } \\
\text { (Чернобыль, СССР, } 1986 \text { г.) }\end{array}$ & $\begin{array}{c}\text { Большой выброс. Значительный ущерб здоровью людей и } \\
\text { окружающей среде. Величина выброса по J }{ }_{131}^{-} \\
\text {более } 1016 \text { Бк. }\end{array}$ \\
\hline $\begin{array}{c}6 \text { класс - тяжелая авария } \\
\text { (Виндскейл, Англия, } 1957 \text { г.) }\end{array}$ & $\begin{array}{c}\text { Значительный выброс. Полная реализация внешнего } \\
\text { противоаварийного плана на ограниченной территории. } \\
\text { Величина выброса J }\end{array}$ \\
\hline $\begin{array}{c}5 \text { класс - авария с риском для окружающей среды } \\
\text { (Три-Майл-Айленд, США, } 1979 \text { г.) }\end{array}$ & $\begin{array}{c}\text { Значительное повреждение активной зоны ядерного реактора. } \\
\text { Ограниченный выброс. Частичная реализация внешнего } \\
\text { противоаварийного плана на ограниченной территории. } \\
\text { Величина выброса Ј }{ }_{131} \text { - от } 1014 \text { до } 1015 \text { Бк. }\end{array}$ \\
\hline $\begin{array}{l}4 \text { класс - авария в пределах АЭС } \\
\text { (Сант-Лоурент, Франция, } 1980 \text { г.) }\end{array}$ & $\begin{array}{c}\text { Частичное повреждение активной зоны. Острые последствия } \\
\text { для здоровья персонала. За пределами АЭС - небольшой } \\
\text { выброс. Облучение лиц из населения - порядка нескольких мЗв. }\end{array}$ \\
\hline $\begin{array}{c}3 \text { класс - серьезное происшествие } \\
\text { (Ленинградская АЭС, } 1975 \text { г.) }\end{array}$ & $\begin{array}{c}\text { Большое загрязнение. Переоблучение персонала АЭС. За } \\
\text { пределами АЭС - очень небольшой выброс. Облучение } \\
\text { населения - ниже доли от установленного предела дозы, } \\
\text { порядка десятых долей мЗв. }\end{array}$ \\
\hline 2 класс - происшествия средней тяжести & События с потенциальным последствием для безопасности. \\
\hline 1 класс - незначительное происшествие & Отклонения от разрешенных границ функционирования. \\
\hline 0 класс - инцидент ниже 1 класса шкалы & Отклонения, не влияющие на безопасность \\
\hline
\end{tabular}

ГОСТ P22.0.05-94: Безопасность в чрезвычайных ситуациях. Техногенные чрезвычайные ситуации. Термины и определения. М.: ВНИИ ГОЧС, 1994. 17 с. 
Шкала разделена на две большие части. Нижние три класса (1-3) относятся к происшествиям (инцидентам), а верхние классы (4-7) - к авариям. Примеры разделения ядерных событий по классам представлены в таблице 1 [2].

В зависимости от границ зон распространения радиоактивных веществ и радиационных последствий, потенциальные аварии на АЭС делятся на 6 типов [2].

Локальная авария. Радиационные последствия аварии ограничиваются пределами объекта. При этом возможно облучение персонала и загрязнение зданий и сооружений, находящихся на территории АЭС, выше уровней, установленных для нормальной эксплуатации.

Местная авария. Радиационные последствия аварии ограничиваются пределами пристанционного поселка и населенных пунктов в районе расположения АЭС. При этом возможно облучение персонала и населения выше уровней, установленных для нормальной эксплуатации.

Территориальная авария. Радиационные последствия аварии ограничиваются пределами субъекта Российской Федерации, на территории которого расположена АЭС, и включают, как правило, две и более административно-территориальные единицы субъекта. При этом возможно облучение персонала и населения нескольких административно-территориальных единиц субъекта Российской Федерации выше уровней, установленных для нормальной эксплуатации.

Региональная авария. Радиационные последствия аварии ограничиваются пределами двух и более субъектов Российской Федерации и приводят к облучению населения и загрязнению окружающей среды выше уровней, установленных для нормальной эксплуатации. Если при региональной аварии количество людей, получивших дозу облучения выше уровней, установленных для нормальной эксплуатации, может превысить 500 человек или количество людей, у которых могут быть нарушены условия жизнедеятельности, превысит 1 тыс. человек, или материальный ущерб от аварии превысит 5 млн. минимальных размеров оплаты труда, то такая авария будет федеральной.

Трансграничная авария. Радиационные последствия аварии выходят за территорию Российской Федерации, либо данная авария произошла за рубежом и затрагивает территорию Российской Федерации.

Число радиационных аварий и происшествий в мире исчисляется не одним десятком. Приведем их краткий ретроспективный анализ.

1 сентября 1944 г. США, штат Теннеси. В Ок-Риджской национальной лаборатории при попытке прочистить трубу в лабораторном устройстве по обогащению урана произошел взрыв гексафторида урана, что привело к образованию опасного вещества - гидрофтористой кислоты. Пять человек, находившихся в это время в лаборатории, пострадали от кислотных ожогов и вдыхания смеси радиоактивных и кислотных паров. Двое из них погибли, а остальные получили серьезные травмы [3].

19 июня 1948 2. Объект «А» комбината «Маяк» в Челябинской области СССР.

В СССР первая тяжелая радиационная авария произошла 19 июня 1948 года, на следующий же день после выхода атомного реактора по наработке оружейного плутония (объект «А» комбината «Маяк» в Челябинской области) на проектную мощность. В результате недостаточного охлаждения нескольких урановых блоков произошло их локальное сплавление с окружающим графитом. В ходе ликвидации аварии облучению подвергся весь мужской персонал реактора, а также солдаты строительных батальонов, привлеченные к ликвидации аварии [4].

3 марта 1949 2. в результате массового сброса комбинатом «Маяк» в реку Теча высокоактивных жидких радиоактивных отходов облучению подверглись около 124 тыс. человек в 41 населенном пункте. Наибольшую дозу облучения получили 28,1 тыс. человек, проживавших в прибрежных населенных пунктах по реке Теча (средняя индивидуальная доза - 210 м3в). У части из них были зарегистрированы случаи хронической лучевой болезни [3].

12 декабря 1952 г. - авария в Чок-Риверской лаборатории, Канада, 5 уровень INES.

Чок-Риверская лаборатория - место крупных исследований и разработок для поддержки и развития ядерных технологий, в частности, реакторной техники CANDU. 12 декабря 1952 года разрушение стержня затвора реактоpa, в сочетании с несколькими ошибками оператора, привело к большому выходу мощности (более чем в два раза выше номинальной) реактора NRX AECL. Радиоактивные продукты деления попали во внешнюю среду, а около 3800 кубических метров радиоактивно загрязненной воды было сброшено прямо на землю, в мелкие траншеи неподалеку от реки Оттавы [4].

1 марта 1954 г. США были проведены ядерные испытания на атолле Бикини (Маршалловы острова) под кодовым название Castle Bravo.

В начале 1950-х гг. гонка ядерных вооружений была в самом разгаре, причем США в ней отставали от СССР. У советских военных в 1953 г. уже была готовая термоядерная бомба, пригодная к сбрасыванию с самолета, в то время как у Соединенных Штатов - еще нет.

1 марта 1954 г. на атолле Бикини (Маршалловы острова) был взорван собранный накануне двухступенчатый заряд на основе 


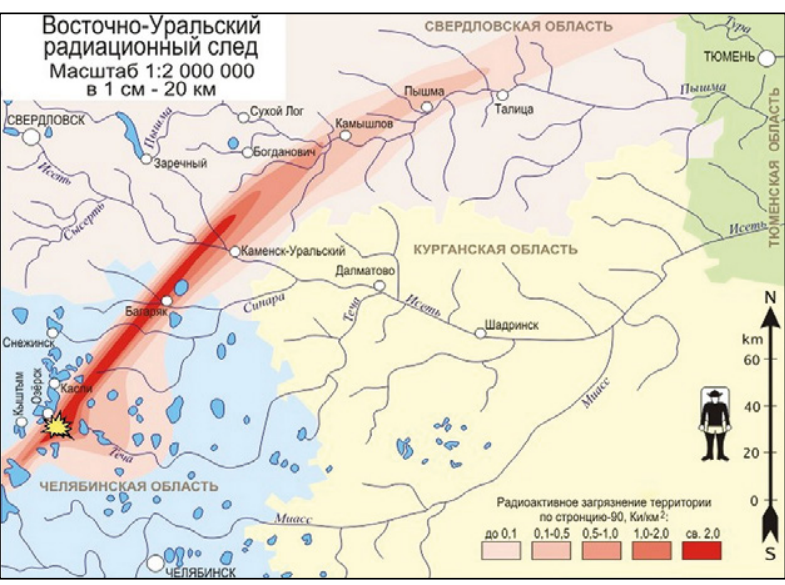

Рисунок 1 - Восточно-Уральский радиационный след при «Кыштымской» аварии (http://souzchernobylnsk.ru/uploads/news/ nuclearcronics/nuclear_chronics_31.jpg. Дата обращения: 14.02.2021)

дейтерида лития-6. При этом выделился объем энергии, эквивалентный 15 мегатоннам. Это было самое мощное из всех ядерных испытаний, когда-либо проводившихся Соединенными Штатами. Результатом взрыва стало масштабное радиационное загрязнение окружающей среды [5].

29 ноября 1955 г. «человеческий фактор» привел к аварии на американском экспериментальном реакторе EBR-1 (штат Айдахо, США), 4 уровень INES. B процессе эксперимента с плутонием, в результате неверных действий оператора, реактор саморазрушился, выгорело 40\% его активной зоны [3].

29 сентября 1957 г. - Кыштымская авария, CCCP (6 уровень INES).

В хранилище радиоактивных отходов комбината «Маяк» в Челябинской области взорвалась емкость, содержавшая радиоактивные вещества. Специалисты оценили мощность взрыва в 70-100 т в тротиловом эквиваленте.

Радиоактивное облако от взрыва прошло над Челябинской, Свердловской и Тюменской областями, образовав так называемый Восточно-Уральский радиоактивный след площадью свыше 20 тысяч кв. км. По оценкам специалистов, в первые часы после взрыва, до эвакуации с промплощадки комбината, подверглись разовому облучению до 100 рентген более пяти тысяч человек (рисунок 1) [4].

В ликвидации последствий аварии в период с 1957 г. по 1959 г. участвовали от 25 тыс. до 30 тыс. военнослужащих. В советское время катастрофа была засекречена [4].

10 октября 1957 2. в Уиндскейле, Великобритания, произошла крупная авария (5 уровень INES) на одном из двух реакторов по наработке оружейного плутония (рисунок 2).

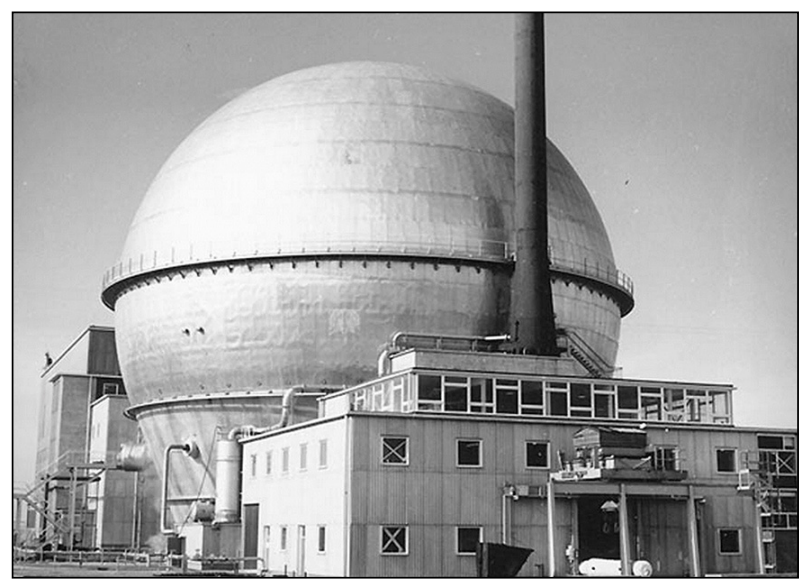

Рисунок 2 - Комплекс в Уиндскейле, построенный для производства плутония (https://i2.wp.com/ souzchernobylnsk.ru/uploads/news/nuclearcronics/ nuclear_chronics_20.jpg.

Дата обращения: 11.02.2021)

Вследствие ошибки, допущенной при эксплуатации, температура топлива в реакторе резко возросла, в активной зоне возник пожар, продолжавшийся в течение 4 суток. Получили повреждения 150 технологических каналов, что повлекло за собой выброс радионуклидов. Всего сгорело около 11 т урана. Радиоактивные осадки загрязнили обширные области Англии и Ирландии, радиоактивное облако достигло Бельгии, Дании, Германии и Норвегии [3].

3 января 1961 г. - авария в Айдахо-Фоллз, штат Айдахо, США (5 уровень INES). На Национальной станции испытания реакторов произошла тяжелая авария на экспериментальной АЭС, введенной в эксплуатацию в 1958 г. Стационарный реактор малой мощности номер 1, или SL-1, взорвался, убив троих рабочих и вызвав расплавление топливных элементов. Причиной послужил неправильно извлеченный стержень регулирования мощности реактора (рисунок 3 ).

Хотя реактор и выбросил в атмосферу 3 ТБк радиоактивного йода, его удаленное местоположение позволило минимизировать урон, нанесенный населению $[4,6]$.

4 июля 1961 2. на советской атомной подводной лодке К-19, находившейся в северной части Атлантического океана, была выявлена неисправность ядерного реактора. Все восемь членов экипажа, которые устраняли неисправность реактора, умерли в течение 3 недель с момента аварии. Радиационному заражению также подвергся остальной экипаж и рабочие дока, ремонтировавшие лодку. В последующие несколько лет еще 20 членов экипажа скончались от лучевой болезни [4].

17 января 1966 г. с авиабазы Сеймур-Джонсон (США) на очередное патрулирование вылетела пара стратегических бомбардировщиков 


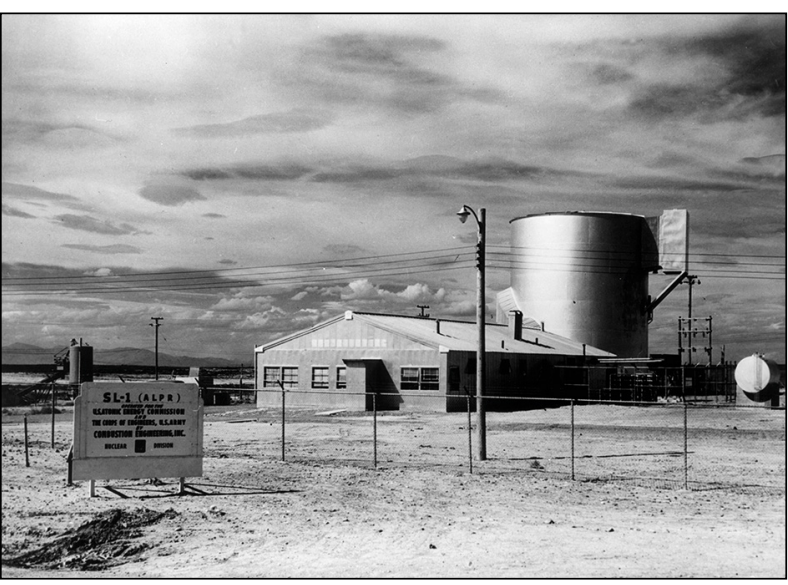

Рисунок 3 - АЭС в Айдахо-Фоллз, umam Aŭdaxo, США

(https://miro.medium.com/max/6400/1 ${ }^{*}$ Rny4przjMBb 23a4BYNMe2A.jpeg.

Дата обращения: 14.02.2021)

В-52 «Стратофортресс». На борту каждого самолета находились четыре термоядерные бомбы B28RI мощностью 1,45 Мт тротилового эквивалента. Американский стратегический бомбардировщик B-52G с термоядерным оружием на борту столкнулся с танкером КС-135 во время дозаправки в полете.

В результате катастрофы погибли 7 человек и были потеряны четыре термоядерные бомбы. Три из них были найдены сразу, четвертая, упавшая в море - лишь после двухмесячных поисков. Две бомбы, упавшие неподалеку от Паломареса, разрушились, вызвав радиационное заражение местности [7].

В апреле 1967 2. на комбинате «Маяк» произошел очередной радиационный инцидент. Озеро Карачай, которое «Маяк» использовал для сброса жидких радиоактивных отходов, сильно обмелело; при этом оголилось 2-3 гектара прибрежной полосы и 2-3 гектара дна озера. В результате ветрового подъема донных отложений с оголившихся участков дна водоема была вынесена радиоактивная пыль. Была загрязнена территория в 1,8 тыс. квадратных километров, на которой проживало около 40 тыс. человек (рисунок 4) [3].

21 января 1968 г. над базой ВВС США «Туле» в Гренландии произошла авиакатастрофа. После возникновения пожара на борту стратегического бомбардировщика В-52 экипаж был вынужден экстренно покинуть самолет. Неуправляемая машина потерпела крушение вблизи базы. Бомбардировщик выполнял боевое патрулирование в рамках операции «Хромированный купол» и нес четыре термоя-

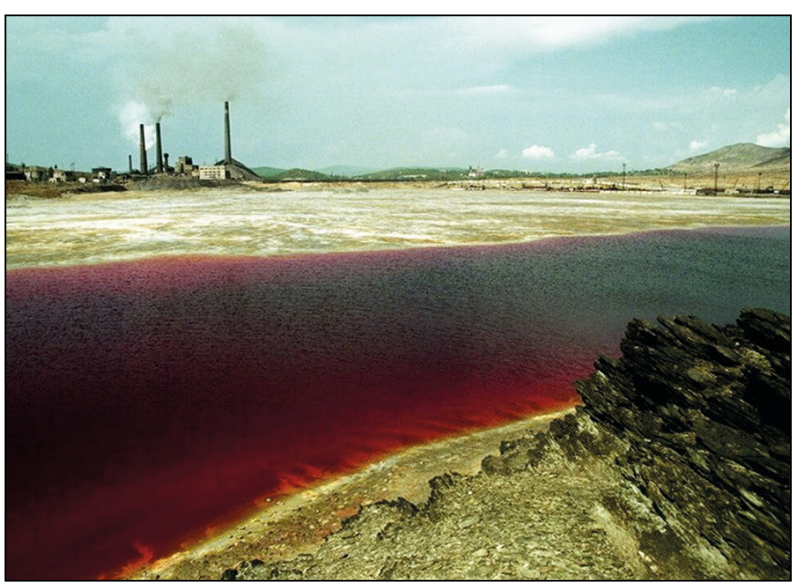

Рисунок 4 - Озеро Карачай, СССР (https://wp.com/souzchernobylnsk.ru/ uploads/news/nuclearcronics/ nuclear_chronics_08.jpg. Дата обращения: 13.02.2021)

дерные бомбы B28FI. В результате падения самолета, оставленного экипажем, термоядерные боеприпасы разрушились, вызвав радиационное заражение местности ${ }^{2}$.

В 1969 2. имела место авария подземного ядерного реактора в Люценсе (Швейцария), 5 уровень INES (рисунок 5). Пещеру, где находился реактор, зараженную радиоактивными выбросами, пришлось навсегда замуровать.

В том же 1969 2. произошла авария во Франции - на АЭС «Святой Лаврентий» взорвался запущенный реактор мощностью 500 мВт. Оказалось, что во время ночной смены оператор по невнимательности неправиль-

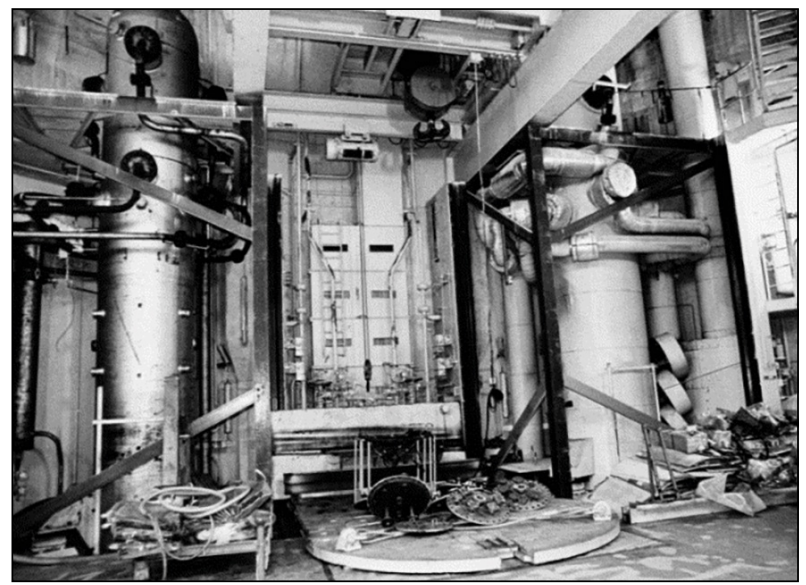

Рисунок 5 - Опытная АЭС в Люченсе (Швейцария), 1989 г

(https://nashagazeta.ch/sites/default/files/ styles/article/public/bez_imeni.jpg?itok=NTZl8Sjc. Дата обращения: 13.02.2021)

\footnotetext{
2 Википедия. Свободная энциклопедия. URL: https://ru.wikipedia.org/wiki/Список_радиационных_аварий (дата обращения: 14.03.2021).
} 


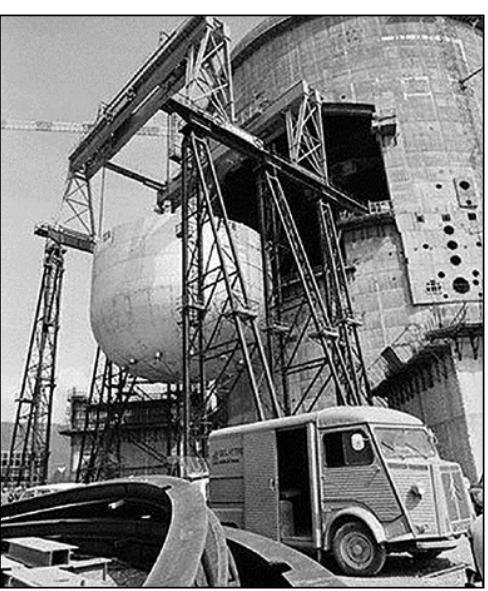

Рисунок 6 - АЭС «Святой Лаврентий» (https:// www.topnews.ru/upload/ photo/0f21c685/05e54.jpg. Дата обращения: 13.02.2021)

но загрузил топливный канал. В результате часть элементов перегрелась и расплавилась, вытекло около 50 кг жидкого ядерного топлива [3] (рисунок 6).

18 января 1970 г. произошла радиационная авария на заводе «Красное Сормово», СССР. При строительстве атомной подводной лодки К-320 произошел неразрешенный запуск реактора, который отработал на запредельной мощности около 15 секунд. При этом произошло радиоактивное заражение зоны цеха, в котором строилось судно (рисунок 7).

В цехе находилось около 1 тыс. рабочих. Радиоактивного заражения местности удалось избежать из-за закрытости цеха. Основные работы по ликвидации аварии продолжались до 24 апреля 1970 г. В них приняло участие более

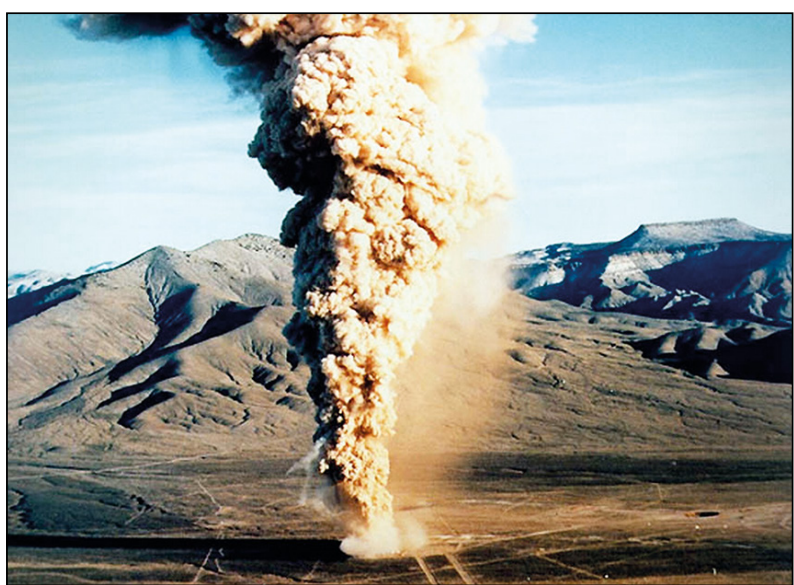

Рисунок 8 - Взрыв на одной площадок для ядерных испытаний Юкка-Флэт.

(http://souzchernobylnsk.ru/uploads/news/ nuclearcronics/nuclear_chronics_30.jpg. Дата обращения: 13.02.2021) тысячи человек. К январю 2005 г. в живых из них осталось 380 человек [4].

18 декабря 1970 г. - Юкка-Флэт, штат Невада, США. Юкка-Флэт является одной из площадок для ядерных испытаний в США (рисунок 8). 18 декабря 1970 г. при детонации 10 кт атомной бомбы, закопанной на глубине в 275 м под землей, плита, удерживавшая взрыв, треснула, и в воздух поднялся столб радиоактивных осадков, в результате чего было облучено 86 человек, принимавших участие в испытаниях. Радиационные осадки выпали в округе. Кроме того, их также отнесло на север Невады, в штаты Айдахо и Калифорнию, а также в восточные части штатов Орегон и Вашингтон. В 1974 г. два специалиста, которые присутствовали при взрыве, умерли от лейкемии [4].

30 ноября 1975 2. - авария на Ленинградской АЭС, СССР (3 уровень INES). Данная авария по внешним признакам очень похожа на чернобыльскую. В результате прекращения теплосъема из технологического канала разрушилась тепловыделяющая сборка и продукты деления урана (Cs137, Cs134, Ce144, Sr90 и т.д.), а также трансурановые элементы (Pu238, $\mathrm{Pu} 239$, Am241 и др.) оказались в графитовой кладке реактора. Аварийный выброс радиоактивности в атмосферу продолжался в течение месяца. По разным оценкам, в окружающую среду попало от 137 тыс. до 1,5 млн Кu радиоактивных веществ. Тонны жидких радиоактивных отходов были сброшены в Балтийское море [4].

22 февраля 1977 2. - авария на АЭС в Богунице, Чехословакия, 4 уровень INES. Реактор КС-150 был экспериментальной разработкой для работы на уране, добываемом в Чехословакии. Несмотря на это, на первом в своем роде комплексе было множество аварий, поэтому за- 
крыть его должны были более 30 раз. В 1976 г. погибло двое рабочих, но самая ужасная авария произошла 22 февраля 1977 г., когда один из рабочих во время обычной смены топлива неверно вытащил стержень регулирования мощности реактора. Эта ошибка вызвала масштабную утечку радиоактивных веществ из реактора [4].

24 января 1978 г. советский спутник морской космической системы разведки и целеуказания Космос-954 с ядерной энергетической установкой на борту упал на территорию Канады, вызвав радиоактивное заражение части $\mathrm{Ce}$ веро-Западных территорий [6].

28 марта 1979 г. произошла авария на АЭС «Три-Майл-Айленд» в штате Пенсильвания, США (5 уровень INES), которая стала одним из самых серьезных инцидентов в атомной энергетике США.

В результате серии сбоев в работе оборудования и грубых ошибок операторов на втором энергоблоке АЭС произошло расплавление 53\% активной зоны реактора. В атмосферу были выброшены инертные радиоактивные газы - ксенон и йод. Кроме того, в реку Сукуахана было сброшено $185 \mathrm{~m}^{3}$ слаборадиоактивной воды. Из района, подвергшегося радиационному воздействию, было эвакуировано 200 тыс. человек [3].

13 марта 1980 г. - авария на АЭС Сен-Лоран-дез-O, Франция (4 уровень INES). Авария на АЭС Сен-Лоран-дез-О - самый тяжелый радиационный инцидент на ядерных объектах Франции.

Инцидент произошел на втором блоке (SLA-2), оснащенном графито-газовым реактором UNGG (Uranium Naturel Graphite Gaz) мощностью 500 МВт, работающем на природном уране и охлаждаемым углекислым газом. В 17 ч. 40 мин. реактор был автоматически заглушен из-за резкого повышения активности. Было выяснено, что произошло частичное расплавление активной зоны, вызванное коррозией конструкционных элементов топливных каналов. В течение 29 месяцев проводились работы по очистке реактора от расплавленного топлива, в которых участвовало около 500 человек. В процессе ликвидации аварии был произведен вынужденный контролируемый выброс радиоактивного йода в атмосферу (в объеме 0,37 ГБк). Блок SLA-2 окончательно вернулся в строй только в 1983 г., но его мощность была ограничена 450 МВт. Блок был закрыт в 1992 г.[4].

В 1982 г. в Мурманской области произошла крупнейшая по своим масштабам радиационная авария на 569-й береговой технической базе в губе Андреева, где располагалось хранилище отработанного ядерного топлива, расположенное в 55 км северо-западнее Мурманска и в 60 км от границы Норвегии на берегу залива Западная лица (Кольский полуостров).
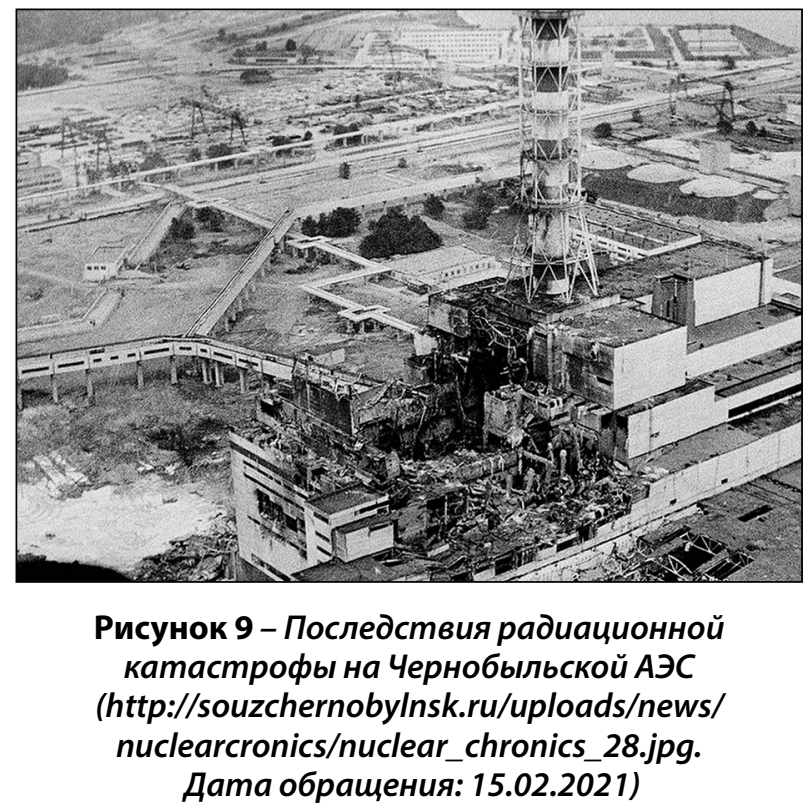

На хранилище произошла утечка радиоактивной воды из бассейна здания № 5. Ликвидация аварии шла с 1983 г. по 1989 г.. За этот период в воды Баренцева моря вытекло около 700 тыс. т. высокорадиоактивной воды. В ликвидации аварии участвовало около 1 тыс. человек [4].

7 бевраля 1983 г. спутник Космос-1402 после завершения задачи не смог выйти на орбиту захоронения. Реактор разрушился над Атлантическим океаном, рассеяв в атмосферу 44 кг урана [6].

10 августа 1985 г. - авария в бухте Чажма, CCCP (5 уровень INES).

Авария произошла на атомной подводной лодке К-431 проекта 675, которая находилась у пирса для перезарядки активных зон реакторов. При подъеме крышки реактора плавучий кран, удерживавший крышку реактора, поднял ее слишком высоко, и реактор вышел на пусковой режим, что вызвало тепловой взрыв. Мгновенно погибли 11 офицеров и матросов, осуществлявших операцию. Их тела были практически полностью испарены взрывом. В центре взрыва уровень радиации, определенный впоследствии по уцелевшему золотому кольцу одного из погибших офицеров, составлял 90 тыс. рентген/ час. На подводной лодке начался пожар, который сопровождался мощными выбросами радиоактивной пыли и пара. Известно, что всего в результате аварии пострадали 290 человек. Из них 10 погибли в момент аварии, у 10 зафиксирована острая лучевая болезнь, у 39 - лучевая реакция [4].

26 апреля 1986 г. - радиационная катастрофа на Чернобыльской АЭС, СССР (7 уровень INES). В ночь с 25 на 26 апреля 1986 г. на четвертом блоке Чернобыльской АЭС произошла крупнейшая в мире ядерная авария с ча- 
стичным разрушением активной зоны реактора и выходом осколков деления за пределы зоны (рисунок 9).

В результате катастрофы в атмосферу было выброшено около 190 т радиоактивных веществ. 8 из 140 т радиоактивного топлива реактора оказались в воздухе. Население в Чернобыле подверглось облучению в 90 раз большему, чем при падении бомбы на Хиросиму. В результате аварии произошло радиоактивное заражение местности в радиусе 30 км. Загрязнена территория площадью 160 тыс. км². Пострадали северная часть Украины, Беларусь и запад России. Радиационному загрязнению подверглись 19 российских регионов с территорией почти 60 тыс. км ${ }^{2}$ и с населением 2,6 млн человек [3].

13 сентября 1987 2. в городе Гояния, Бразилия, произошел один из самых страшных случаев радиационного заражения местности, 5 уровень INES. Институт радиотерапии переехал, оставив в старом помещении установку для радиотерапии, в которой все еще находился хлорид цезия.

Мародеры, нашедшие установку, вывезли ее с территории больницы и продали на свалку. Владелец свалки пригласил родственников и друзей посмотреть на светящееся голубым светом вещество. Все они потом разошлись по городу и начали заражать радиацией своих друзей и родственников. Общее число зараженных составило 245 человек, четверо из них умерли [4].

6 апреля 1993 2. на радиохимическом заводе Сибирского химического комбината произошел взрыв. В результате взрыва был разрушен один из аппаратов по экстракции урана и плутония, содержавший раствор нитрата уранила. При взрыве значительная часть плутония и других радиоактивных веществ была выброшена в атмосферу.

После аварии на расстоянии 8 км к северо-востоку от места аварии радиационный фон составил до 300 микрорентген/час. В результате аварии подверглись радиоактивному облучению 1946 человек. Жертв при взрыве и ликвидации аварии не было. Индекс по международной шкале ядерных событий INES-4 [4].

17 июня 1997 2. в лаборатории Всероссийского Научно-исследовательского института экспериментальной физики (ВНИИЭФ) при монтаже оборудования на экспериментальной установке вследствие нарушения регламента работ создались условия для возникновения самопроизвольной цепной ядерной реакции. Произошла ядерная вспышка с резким повышением температуры и одновременным образованием мощного нейтронного излучения. Мощный поток нейтронов инициировал возникновение наведенного жесткого гамма-излучения. В результате реакции возник постоянный источник тепла и нейтронов. Сотрудник ядерного центра, проводивший эксперимент, получил смертельную дозу облучения. Повышение температуры могло привести к тепловому взрыву и возгоранию радиоактивных материалов с образованием аэрозоля, который при выбросе из помещения лаборатории вызвал бы сильное радиоактивное загрязнение воздуха и местности [8].

30 сентября 1999 2. произошла авария на ядерном объекте Токаймура, Япония (4 уровень INES). На заводе по изготовлению топлива для АЭС в научном городке Токаймура (префектура Ибараки) из-за ошибки персонала началась неуправляемая цепная реакция, которая продолжалась в течение 17 ч. Облучению подверглись 439 человек, 119 из них получили дозу, превышающую ежегодно допустимый уровень. Трое рабочих получили критические дозы облучения. Двое из них скончались [3].

11 марта 2011 года произошла авария на АЭС Фукусима-1, Япония (7 уровень INES). Причиной аварии стало разрушительное землетрясение магнитудой более 9 баллов, которое было признано самым сильным землетрясением в истории Японии. Толчки на глубине более 32 км парализовали работу пятой части всех энергоблоков в Японии, которые находились под управлением автоматики и предусматривали такую ситуацию. Цунами, которое накрыло Японию спустя полчаса после землетрясения, вывело из строя систему аварийного питания охлаждения реактора.

Персонал АЭС приложил все усилия, чтобы дать охлаждение на раскаленные реакторы, однако трагедии избежать не удалось. Водород, скопившийся в контурах первого, второго и третьего реакторов, создал такое давление в системе, что конструкция не выдержала и раздалась серия взрывов, вызвавшая обрушение энергоблоков. В воздух поднялись радиоактивные металлы и газы, которые распространились по близлежащей территории и попали в воды океана. После катастрофы на атомной станции «Фукусима-1» было эвакуировано более 120 тыс. жителей близлежащих территорий [4].

8 августа 2019 2. в районе ракетного полигона ВМФ России «Ненокс» в Архангельской области произошла нештатная ситуация в ходе испытаний военной техники (рисунок 10).

В результате инцидента пять человек погибли на месте, двое скончались от травм в больнице и еще четверо пострадавших получили высокие дозы облучения. Инцидент привел к кратковременному повышению радиационного фона в Северодвинске. По сообщению Министерства обороны РФ, причиной инцидента явился взрыв жидкостного ракетного двигателя. Позже государственная корпорация «Рос- 
атом» сообщила, что в двигателе использовался радиоизотопный источник питания [4].

2. Анализ применения роботизированной техники и робототехнических комплексов для ликвидации последствий радиационных аварий.

Воздействие высоких уровней радиации на человеческий организм в результате радиационных аварий обуславливает необходимость совершенствования имеющихся и разработки новых современных технических средств и тактики их применения для ликвидации последствий таких аварий.

Поэтому актуальность применения роботизированной техники для радиационной разведки местности и ликвидации последствий аварий на радиационно опасных объектах не вызывает сомнений.

Применение дистанционно управляемой и роботизированной техники в ядерной промышленности не является инновацией. Одним из первых роботов, предназначенных для практического применения, был разработанный в 1958 г. компанией Хьюз Эйркрафт робот для обращения с радиоактивными материалами на ядерных установках США [9].

Использование подобной роботизированной техники обеспечивало доступ к таким зонам на ядерной установке, в которых тепловая или радиационная обстановка делала невозможным или ограничивала пребывание человека.

Впервые робототехника применялась при ликвидации последствий радиационной аварии на АЭС «Три-Майл-Айленд» в марте 1979 г., которая стала одним из самых серьезных инцидентов в атомной энергетике США. Большая часть активной зоны реактора была разрушена и многие технологические помещения стали недоступны для человека.

Наиболее широкомасштабной попыткой использования роботов при ликвидации последствий на АЭС «Три-Майл-Айленд» стало применение робота дистанционной рекогносцировки (RRV), названного «скитальцем», для обследования подвальных помещений защитной оболочки реактора [10].

На станции использовались три таких робота, два из которых действовали в наиболее загрязненных помещениях и осуществляли замеры радиации (достигавшей 10-30 Зв/ч) и других параметров, передачу видеоизображения от трех телекамер, сбор образцов, снятие и удаление радиоактивно загрязненного слоя бетона с пола контейнмента и некоторые демонтажные работы.

Робот Louie, две усовершенствованные модификации которого работали на АЭС «ТриМайл-Айленд», был создан ранее Westinghouse

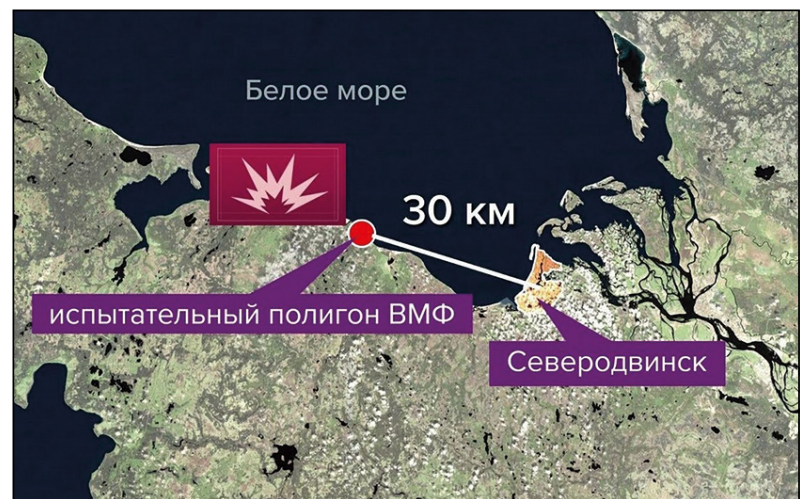

Рисунок 9 - Расположение испытательного полигона под Северодвинском (https://i1.wp.com/ souzchernobylnsk.ru/uploads/news/nuclearcronics/ nuclear_chronics_13.jpg.

Дата обращения: 15.02.2021)

для площадки ядерно-оружейного комплекса в Хэнфорде, штат Вашингтон. Это был многоцелевой манипулятор с громоздкими камерами и освещением, установленный на гусеничную платформу. Один из этих роботов использовался для замера радиации в местах, недоступных для RRV; второй применялся для очистительных работ [10].

Робот Fred весом около 200 кг представлял собой удаленно управляемый манипулятор, способный поднять груз весом с человека на двухметровую высоту. Он был установлен на шестиколесную полноприводную платформу, оснащен мойкой высокого давления и использовался для дезактивации помещений и оборудования во вспомогательных зданиях [10].

В августе 1982 г. для фотографирования и получения данных об уровнях радиации на этой АЭС был применен робот SISI, представляющий собой гусеничную платформу массой 12 кг с навесным оборудованием [9].

Под влиянием аварии на АЭС «Три-МайлАленд» в 1980-х гг. был разработан целый ряд новых роботов для атомной отрасли, таких как IRIS, ODEX, Kluge, Rocomp, Surbot, Surveyor (тезка современной разработки GE Hitachi). Особенно революционным для того времени казался ODEX, созданный компанией Odetics (позже Iteris) и доработанный американским Исследовательским институтом электроэнергетики (EPRI). Этот «шестилапый» шагающий робот-паук при весе 170 кг мог приподнять легковой автомобиль и нести до 400 кг груза (рисунок 11).

Он обладал автономной энергетической установкой и невиданной по тем временам ловкостью движений благодаря координации с помощью нескольких микропроцессоров и участию удаленного оператора или компьютера [10].

Еще более серьезным полигоном для испытаний робототехники стала авария на Черно- 


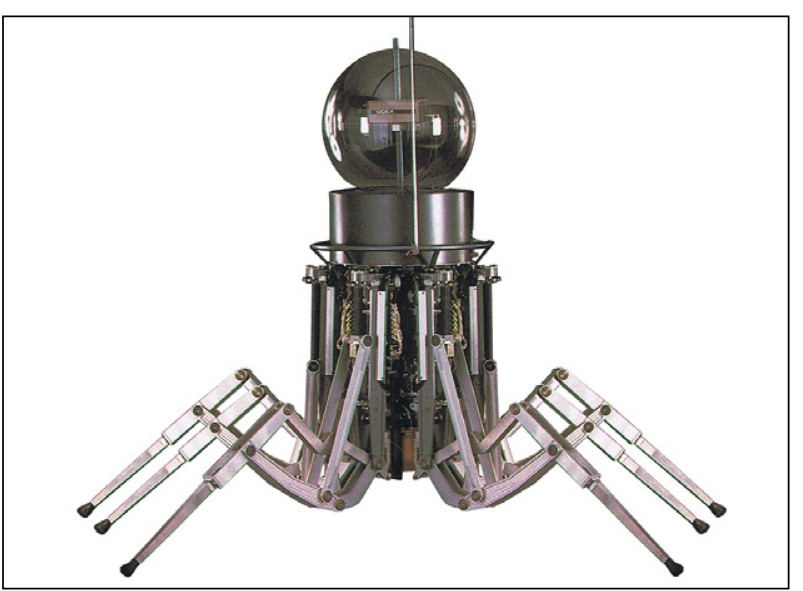

Рисунок 11 - Шагающий робот универсального действия ODEX, США

(https://theoldrobots.com/images30/robot53.JPG. Дата обращения: 15.02.2021)

быльской АЭС. Необходимость в применении роботизированной техники при ликвидации последствий аварии на Чернобыльской АЭС стала своеобразным толчком к развитию отечественной экстремальной робототехники. Именно эта трагедия впервые остро поставила вопрос о необходимости иметь технику для выполнения работ в подобных чрезвычайных ситуациях.

Начиная с первых месяцев после катастрофы роботы и роботизированная техника с разной степенью успешности применялись для визуального осмотра и измерения радиации (машины радиационной разведки типа РP, РР-Г, РКК, РДК, РДГ), разбора завалов, тяжелых земляных работ в районе станции, захоронения PAO (машины разграждения и тяжелые бульдозеры: советский «Клин-1», финский Tamrock, японский Kamatsu D-155, немецкий Liebherr PR751 и др.); расчистки, снятия и удаления радиоактивно загрязненного слоя на станции, в том числе на крышах зданий (СТР-1, МОБОТ, TP-A, ТР-Б, ТР-Г, ДДК-Р1, немецкие MF2, и MF3); погрузки радиационно опасных отходов (ПДП, финский манипулятор Foresteri); дезактивации и сбора отдельных радиоактивных фрагментов («Урал», «Крот», РПБ, «Белоярец») и т.д. [10].

Остальные РТК, использовавшиеся на Чернобыльской АЭС, выполняли работы по радиационной разведке в помещениях и на территории, регулярному контролю уровней излучения и состава аэрозольной фракции газа над аварийным реактором, очистке от высокоактивных отходов кровель знергоблоков, расчистке завалов, сбору и контейнированию высокоактивных отходов, дезактивации помещений энергоблоков, резке металлических элементов и закрытию задвижек на аварийном оборудовании [11].
Оснащенные радиометрической, телевизионной аппаратурой и другим оборудованием, наземные РТК выполняли технологические операции в чрезвычайно опасных, недоступных для человека аварийных зонах с высокими уровнями радиации, что сохранило жизнь и здоровье многих людей.

В целом, по оценкам разных специалистов, эффективность применения РТК в первой, самой тяжелой фазе ликвидации последствий аварии в Чернобыле оказалась невысокой. Многие РТК и роботизированная техника оказались неэффективными или неспособными работать в условиях сильных радиационных полей (сотни и тысячи рентген/час). Среди РТК, вызвавших наименьшие нарекания и принесших ощутимую пользу, были, в частности, РТК МОБОТ, СТР-1, «Клин-1», ДДК-Р-1, ТР-Г, РКК-1, ПДП [10].

МОБОТ, разработанный МГТУ им. Н.Э. Баумана, в усовершенствованной модификации МОБОТ Ч-ХВ-2 представлял собой компактную гусеничную машину весом порядка полутонны, оснащенную фронтальным погрузчиком с бульдозерным ковшом, отбойным молотком, манипулятором с грейфером (клещевым хватом для обломков и сыпучих грузов). Робот был оснащен электромеханическими приводами, управлялся и получал энергию по кабелю, оборудованному кабелеукладчиком, и мог передавать операторам визуальную (от двух телекамер), акустическую и дозиметрическую информацию $[10,13]$.

CTP-1 (специализированный транспортный робот), в котором были соединены разработки ВНИИТрансмаша, ГосИФТП, ВНИИ АЭС, НПО «Энергия» и других организаций, представлял собой легкий $(1,1 \mathrm{~T})$ радиоуправляемый бульдозер с регулируемым ковшом, телекамерами, автономным электропитанием и шасси, созданным на основе конструкций луноходов и концептуального марсохода. «Клин-1», разработку которого возглавлял ВНИИТрансмаш, был тяжелой многоцелевой машиной - роботизированной версией ИМР (инженерной машины разграждения), созданной на основе танка Т-72 для расчистки завалов и обеспечения прохода войск. «Клин-1» оснащался бульдозерным отвалом, мощным манипулятором, грейфером, телекамерами, дозиметрическими приборами. Роботизированная машина действовала в полях повышенной радиации и управлялась по радиоканалу из располагавшейся поодаль машины управления. «Клин-1», наряду с другой тяжелой техникой, снимал слой почвы вокруг станции, валил погибший, радиоактивно загрязненный лес, расчищал наиболее серьезные завалы, осуществлял радиационную разведку [10].

На радиоуправляемые РТК возлагались большие надежды, однако, несмотря на достигнутые положительные результаты, опыт 
показал техническое несовершенство применяемых РТК.

Ограниченные технологические возможности (недостаточная управляемость, надежность, радиационная стойкость элементов систем управления и контроля) РТК, использовавшихся для выполнения работ по ликвидации аварии на Чернобыльской АЭС, обусловили необходимость создания РТК различных классов и типов для ликвидации как радиационных, так и других аварий [11].

После частичной ликвидации последствий аварии на Чернобыльской АЭС и сооружения объекта «Укрытие» был разработан ряд образцов РТК, привлекавшихся к работам на АЭС.

Это были, в частности, компактные РТК, разработанные совместно украинскими и российскими организациями для действий в наиболее опасных зонах внутри «Укрытия» или на его периферии. Среди них: ТР-3 (для визуального обследования внутренних помещений «Укрытия»), ТР-4 (для отбора проб в радиоактивных завалах), ТР-7 (для покрытия сильно фрагментированных РАО пылеподавляющими материалами), ТР-11 (для дробления топливосодержащих осколков), ТР-12 (для удаления труб реакторного контура), КТ (для упаковки РАО), КТ-100 (для обследования наиболее радиационно опасных помещений), «Магнитоход» (для дозиметрического обследования опасных участков на металлических конструкциях «Укрытия»), ИЛ (для извлечения наиболее активных фрагментов из недр «Укрытия») и др. $[10,13]$.

Еще одним примером использования РТК для ликвидации последствий радиационных аварий является инцидент, произошедший 17.06.1997 г. в лаборатории Всероссийского научно-исследовательского института экспериментальной физики (ВНИИЭФ). Вследствие человеческого фактора в ядерной установке возник постоянный источник тепла и нейтронов. Повышение температуры могло привести к тепловому взрыву и возгоранию радиоактивных материалов с образованием аэрозоля, который при выбросе из помещения лаборатории вызвал бы сильное радиоактивное загрязнение воздуха и местности.

Удаление контейнеров из бокса и перевод установки в подкритическое состояние «вручную» были невозможны, т.к. мощный нейтронный поток представлял собой смертельную опасность для людей. Поэтому основным средством ликвидации последствий аварии должны были стать дистанционно управляемые РТК [8].

К работам были привлечены все доступные на тот момент РТК, пригодные к действиям внутри помещения:
- МРК-25, разработанный опытным конструкторским бюро Специальной Робототехники МГТУ им. Н.Э. Баумана

- мобильные PTK «HOBO» и «RASCAL» из состава подвижной криминалистической взрывотехнической лаборатории ФСБ России;

- РТК MF-4, принадлежащий аварийно-техническому центру ВНИИЭФ.

Подготовительные работы перед ликвидацией аварии включали: изучение места аварии по схемам, фотографиям, материалам видеосъемок и с помощью перископа, установленного в пультовой; защита электронных блоков и телекамер РТК MF-4, МРК-25 и «НОBО» от нейтронного излучения радиационно-стойкими материалами с целью обеспечения их работоспособности более длительное время; размещение вспомогательных телекамер с использованием PTK «HOBO», «RASKAL» и MF-4 в аварийном и смежных помещениях с целью повышения надежности управления РТК; планирование и практическая отработка тактики движения РТК МРК-25 с целью сокращения времени его пребывания в зоне действия нейтронного потока [8].

Тактика движения РТК в аварийном боксе определялась, во-первых, необходимостью сокращения времени пребывания в зоне действия нейтронного потока и, во-вторых, требованием не подставлять под нейтронный поток слабозащищенные борта и объективы телекамер. Все движения робота выполнялись на максимально возможной скорости.

Для каждого этапа работ были определены: рабочий РТК (выполняющий основные операции); страхующий РТК (обеспечивающий эвакуацию рабочего РТК в случае выхода его из строя под воздействием радиации и продолжающий выполнение незавершенных работ); резервный РТК. Назначение РТК определялось с учетом их технических возможностей и по результатам предварительной отработки операций в помещении-аналоге.

Практически операции по ликвидации радиационной аварии были проведены в следующем порядке:

1. Эвакуация пяти контейнеров с радиоактивным источником из аварийного помещения с помощью МРК-25 с предварительной опытной отработкой операции.

2. Отработка операции по переводу аварийного объекта в подкритическое состояние с помощью мобильного РТК МF-4.

3. Ликвидация нештатной ситуации, возникшей при выполнении операции по переводу аварийного объекта в подкритическое состояние и эвакуация РТК MF-4 с помощью МРК-25. 


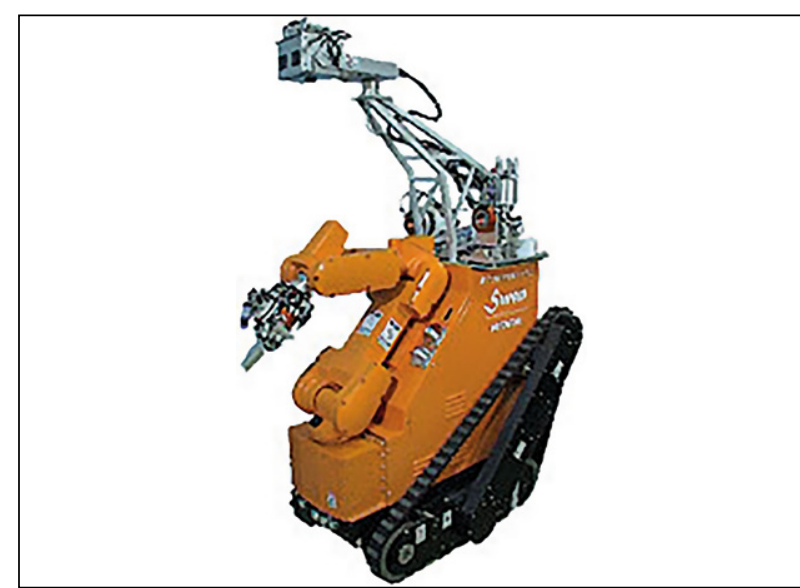

Рисунок 12 - Робототехнический комплекс SWAN (https://www.secretprojects.co.uk/proxy. php?image $=$ http\%3A\%2F\%2Fwww10.plala.or.jpg Дата обрашения: 15.02.2021)

4. Анализ, разработка и экспериментальная отработка вариантов по переводу аварийного объекта в подкритическое состояние.

5. Вывод МРК-25 из аварийного помещения, дозиметрический контроль и дезактивация МРК-25 и МF-4 [12].

Следующий толчок развития «атомная» робототехника получила в Японии. В 1999 г. на заводе по переработке урана в Токаймуре из-за нарушения технологии и техники безопасности возникла авария, сопровождающаяся спонтанной цепной реакция в урановом материале. Вскоре после этого правительство Японии выделило средства на разработку новых технологий локализации ядерных аварий, и несколько японских организаций инициировали программы создания новых РТК, предназначенных для действий при аварийных ситуациях на радиационно-опасных объектах. К проектам были привлечены компании Hitachi, MHI, Toshiba, французская Cybernetix. В результате менее чем за два года были разработаны новые PTK и их семейства: Monirobo, RESQ, RaBOT, SMERT, MARS, MENHIR и SWAN.

В частности, SWAN, созданный MSTC и Hitachi, - многоцелевой РТК на трансформируемых гусеницах, способных менять конфигурацию для преодоления препятствий. Он может проводить визуальный осмотр тремя камерами, радиационную разведку, сбор образцов (рисунок 12) [10].

У РТК имеется сложный манипулятор с собственной миниатюрной камерой на нем и сменяемыми во время миссии рабочими органами, приспособленными для разнообразных операций.

Проект RESQ (от JAERI/JAEA и Hitachi) это три разных взаимодополняющих РTK,

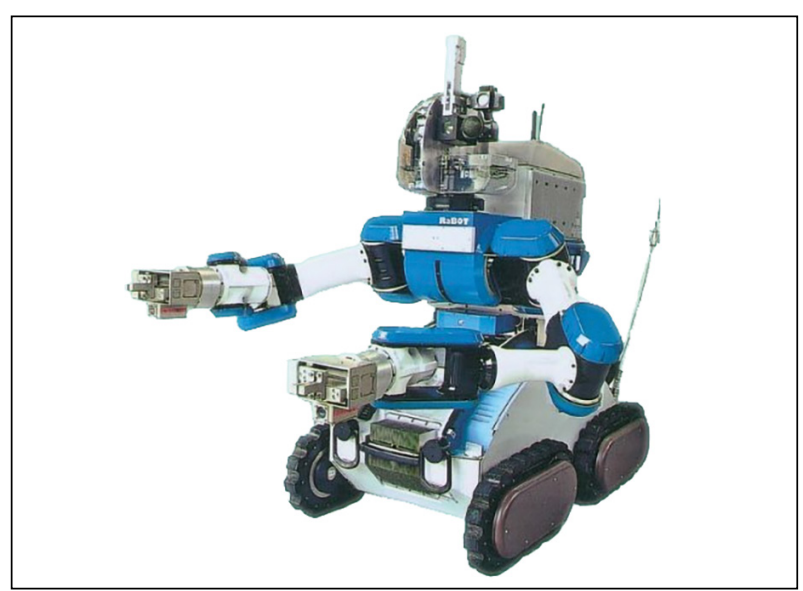

\section{Рисунок 13 - Многоцелевой робототех- нический комплекс RaBOT (https://www. secretprojects.co.uk/data/attachments/53/53306- c4e0aee406158587dd94edc10104a62e.jpg. Дama обращения: 13.02.2021)}

предназначенных, главным образом, для обследования и осмотра аварийных объектов. Самый компактный из них -RESQ-A, на полноприводном четырехколесном шасси, создан для визуального осмотра камерами, размещенными на подъемной этажерке. RESQ-B на гусеничном ходу представляет собой передвижную лабораторию для замера радиации и других параметров среды. Гусеничный RESQ-C приспособлен для сбора образцов. Два последних РТК оснащены манипуляторами для сложных активных действий [10].

RaBOT (созданный JAERI/JAEA и MHI) многоцелевой РТК с некоторыми антропоморфными чертами в дизайне, на двух совмещенных парах гусениц, с двумя способными действовать согласованно манипуляторами и камерами (рисунок 13).

SMERT-M (MSTC и Toshiba) - PTK на гусеничном шасси, несущий на себе маленькую колесную машину SMERT-K, с помощью которой обследуются труднодоступные места.

SMERT-M включает обычные и инфракрасную камеры, средства для измерения гамма- и нейтронного излучения, концентрации кислорода и водорода, температуры и влажности. Он оснащен сложным манипулятором для разнообразных действий.

Большинство из перечисленных РТК рассчитаны на работу в полях высокой радиации, могут функционировать в беспроводном режиме, но предусмотрен и кабельный вариант на случай сильных радиопомех. Все они относительно компактны и приспособлены для работы в ограниченных пространствах и в условиях затрудненного передвижения [10].

РТК, созданные японскими инженерами, остались на уровне опытных образцов и не были 
The History of the Development and Application of Robotics in the Elimination of Consequences...

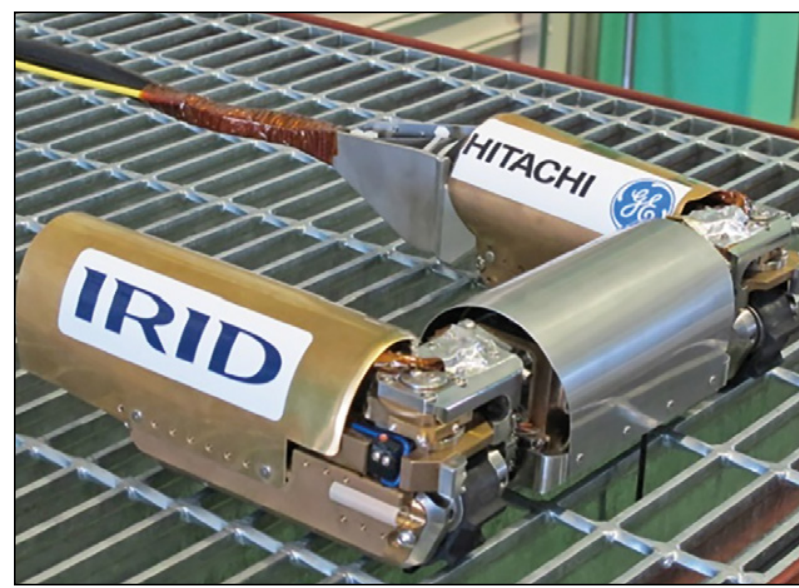

Рисунок 14 - Робототехнический комплекс PMORPH (https://social-innovation.hitachi/-/media/ project/hitachi/sib/ja-jp/case_studies/pmorph_ interview/image/hairorobot_02_01.jpg. Дата обращения: 15.02.2021)

внедрены в виде, например, мобильных роботизированных подразделений для ликвидации радиационных аварий, созданных во Франции, Германии и некоторых других странах. Это объясняется принятой государством в 2000-х гг. концепцией ядерной безопасности, в которой делалась ставка на полное исключение запроектных аварий, а не на локализацию их последствий. Финансирование проектов с новыми РТК было прекращено, большинство опытных экземпляров ржавели на складах или были разобраны (RESQ, RaBOT), нашли свое место в музеях или пожарных командах (SMERT, MENHIR и SWAN), а в отношении некоторых были утеряны ключевые особенности производства (например, RESQ) [10].

B результате Япония, известная своими достижениями в ряде других областей робототехники, к моменту аварии на АЭС «Фукусима-1» в марте 2011 г. оказалась без собственной линейки экстремальных РТК и была вынуждена привлекать многочисленные зарубежные разработки (из США, Франции, Великобритании, Швеции и т. д.) и срочно создавать заново свои. Так, для радиационной разведки и взятия проб использовались PTK PackBot и Warrior (созданные iRobot), Talon и DR-20 (от QinetiQ), T-Hawk (Honeywell), Survey Runner (Topy Industries), MEISTeR (MHI и IRID японской организацией НИОКР в сфере вывода из эксплуатации), Frigoma (MELCO), Rosemary, Sakura и Quince (разработки Технологического института Чибы в сотрудничестве с другими научными организациями), J-3 (от JAEA), HaSR (разработка японского Института передовой промышленной науки и технологий - AIST и компании Honda Motor) и т.д. [10].

В частности, для обследования контейнмента изнутри были созданы PTK PMORPH (от Hitachi и IRID), Scorpion, Mini Mola Mola

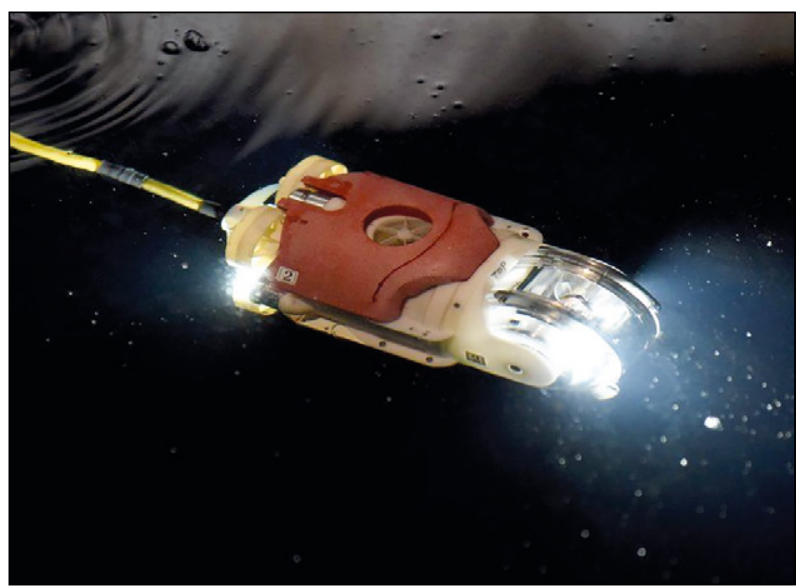

Рисунок 15 - PTK Mini Mola Mola (https://ichef.bbci.co.uk/news/976/cpsprodpb/873D/ production/_96512643_040066241-1.jpg. Дата обрашения: 15.02.2021)

и Tetrapod (Toshiba в сотрудничестве с IRID) и др. Для расчистки завалов, демонтажа конструкций на площадке применялись РТК ASTACO-SoRa (от Hitachi), Brokk 90 и Brokk 330 (одноименной шведской фирмы), Spartacus/ Bobcat (совместные изделия компаний Bobcat и QinetiQ), различные дистанционно управляемые экскаваторы, бульдозеры, грузовики, погрузчики. К уборке и дезактивации в помещениях станции привлекались РТК Raccoon (создана Atox), DX-140 (Husqvarna), Warrior (iRobot), Revi (Toshiba), MEISTeR и Super-Giraffe (разработки MHI и IRID), Arounder (IRID) и т. д. [10].

Некоторые из перечисленных РТК созданы на основе разработок, последовавших за аварией в Токаймуре, например, J-3 представляет собой доработанный вариант RESQ-A, MEISTeR создан на базе RaBOT, a Super-Giraffe является продолжением проекта MARS.

Среди образцов РТК, появившихся в результате аварии на Фукусиме, можно выделить, например, PMORPH - один из примеров современных мини-роботов, способных менять форму для проникновения в труднодоступные места (рисунок 14).

При массе менее 8 кг и диаметре около 10 см он состоит из трех звеньев, которые могут поворачиваться относительно друг друга под прямым углом. Робот предназначен для визуальной и радиационной разведки, измерения температуры в условиях высокой радиации: его камеры рассчитаны на суммарную дозу 1000 Зв. Это было первое устройство, с помощью которого провели удачную серию обследований нижней части контейнмента аварийного блока № 1 АЭС «Фукусима-1» [10].

Другой РТК схожего назначения и габаритов, получивший неформальное название Mini 


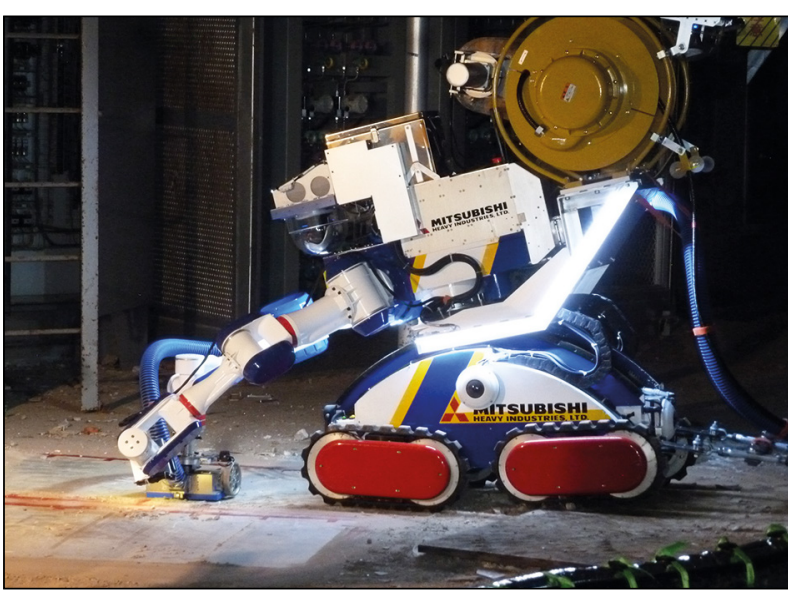

Рисунок 16 - Многофункциональный робототехнический комплекс MEISTeR (https://irid.or.jp/common/img/meister/2.jpg. Дата обращения: 15.02.2021)

Mola Mola, может проводить аналогичную разведку в затопленном контейнменте, плавая в радиоактивной воде при помощи пяти винтов. РТК весом всего 2 кг имеет диаметр 13 см и длину 27 см и несет на себе две разнонаправленные камеры (рисунок 15).

Пример многофункционального РТК MEISTeR, использование которого на АЭС «Фукусима-1» началось в 2014 г. Этот РТК весом 440 кг на четырех гусеницах может преодолевать подъемы крутизной до $40^{\circ}$ и ступени высотой до 22 см, способен осуществлять как разведку, так и механические работы посредством двух манипуляторов со сменным инструментарием, обладающих семью степенями свободы: очистку и дезактивацию горизонтальных и вертикальных поверхностей с помощью мощного пылесоса, резку и демонтаж металлических конструкций, открывание и закрывание клапанов и дверей, сверление отверстий, взятие проб из бетонных поверхностей, ремонт и т. д. (рисунок 16) [10].

Необычный РТК, разработанный для демонтажных работ и дезактивации на АЭС «Фукусима-1» - Super-Giraffe. Этот колесный радиоуправляемый РТК массой 4 т, но относительно компактных габаритов (длиной 235 см и шириной всего 80 см) может работать в помещениях на высоте до 8 м с помощью выдвижной штанги, на конце которой установлен манипулятор с семью степенями подвижности. Манипулятор имеет сменное (дистанционно устанавливаемое) приспособление для открытия и закрытия клапанов. РТК может функционировать и в режиме крана, поднимая на восьмиметровую высоту грузы до 150 кг. Литий-ионный аккумулятор рассчитан на пять часов работы [11].

\section{Заключение}

Таким образом, анализ радиационных аварий и применения роботизированной техники и робототехнических комплексов для ликвидации последствий таких аварий, позволил сделать следующие выводы. Одним из главных сдерживающих факторов развития экстремальных РТК является специфичность и конструкционная обособленность большинства из них. Недостаточная стандартизация и унификация образцов РТК и полезной нагрузки, и как следствие, колоссальная стоимость производства, трудности в эксплуатации и ремонте.

Вместе с тем, необходимо отметить, что опыт использования робототехники в атомной отрасли (как при авариях, так и при повседневной деятельности) постепенно приводит к формированию стандартных технических требований и к переходу от индивидуальных решений к типовым.

Крупнейшие аварии и катастрофы в атомной индустрии (зачастую с чудовищными последствиями) являются мощным толчком в развитии как экстремальной, так и остальной робототехники.

Авария на АЭС «Фукусима-1» в очередной раз явно показала необходимость международной консолидации в сфере разработок специализированных РТК для атомной отрасли. В виду этого также необходимо подчеркнуть потребность развития и постоянного совершенствования РТК войск РХБ защиты, а именно активного проведения НИОКР, основными целями которых должны являться создание линейки стандартизированных, недорогих и простых в управлении РТК и БЛА, предназначенных выполнения задач РХБ защиты.

\section{Вклад авторов/Author Contributions}

Оба автора участвовали в обсуждении и написании этой рукописи и одобрили окончательную версию. Оба автора прочитали и согласились с опубликованной версией рукописи.

Both authors contributed to the discussion and writing of this manuscript and approved the final version. Both authors have read and agreed to the published version of the manuscript.

Информация о конфликте интересов

Авторы заявляют, что исследования проводились при отсутствии любых коммерческих или финансовых отношений, которые могли бы быть истолкованы как потенциальный конфликт интересов. 
Сведения о рецензировании

Статья прошла открытое рецензирование двумя рецензентами, специалистами в данной области. Рецензии находятся в редакции журнала и в РИНЦе.

Литература для подготовки

1. MYC: URL: https://19.mchs.gov.ru/deyatelnost/ poleznaya-informaciya/rekomendacii-naseleniyu/chstehnogennogo-haraktera (дата обращения: 08.04.2021).

2. CYBERLESSON.RU: https://cyberlesson. $\mathrm{ru} /$ klassifikacija-radiacionnyh-avarij/\#klassifikaciaradiacionnyh-avarij (дата обращения: 08.04.2021).

3. РИА Новости: https://ria. ru/20110312/347505544.html (дата обращения: 14.04.2021). - Текст : электронный.

4. Сибирский региональный Союз «Чернобыль»: http://souzchernobylnsk.ru/articles/hronolo giyaradiacionnyhavarij\#: :text=22\%20февраля $\% 20$ $1977 \% 20$ года\%20авария,на\%20уране\%2С\%20добываемом\%20в\%20Чехословакии (дата обращения: 14.04.2021).

5. Научная Россия. https://scientificrussia. ru/articles/march1-castle-bravo (дата обращения: 28.04.2021).

6. Владыка. Безопасность и чрезвычайные ситуации: https:/vladyka23.ru/entsiklopediya/ spisok-radiacionnyh-avariy.html (дата обращения:
14.04.2021).

7. Инфоцентр AfterShock. Каким будет завтра?: https://aftershock.news/?q=node/364805\&full (дата обращения: 14.04.2021)

8. ФГБУ ВНИИПО МЧС России: http://www. vniipo.ru/departments/nicntr.html (дата обращения: 15.04.2021). -

9. Мур Т. Роботы для атомных электростанций. Бюллетень МАГАТЭ. 1985. С. 35-44.

10. ATOMICEXPERT.COM: https://atomicexpert. com/robots_in_nuclear (дата обращения: 15.04.2021).

11. Чернобыльская катастрофа (1986 г.): Катастрофы конца ХХ века. М.: 1998. 400 с.

12. Специальная техника: технология применения управляемых мобильных комплексов / А.Ф. Батанов, С.Н. Грицынин, С.В. Муркин. М., 1998-2016.

13. Аккузин К.Н. Робототехнические комплексы (средства) войск радиационной, химической и биологической защиты Вооруженных Сил Российской Федерации (лекция) // Вестник войск РХБ защиты. 2021. Т. 5. № 1. С. 71-82.

\title{
Об авторах
}

Федеральное государственное казенное военное образовательное учреждение высшего образования «Военная академия радиационной, химической и биологической защиты имени Маршала Советского Союза С.К. Тимошенко» Министерства обороны Российской Федерации, 156015, Российская Федерация, г. Кострома, ул. Горького, д.16.

Аккузин Константин Николаевич. Начальник отдела (организации научной работы и подготовки научно-педагогических кадров) ВА РХБЗ, канд. воен. наук.

Макеев Евгений Сергеевич. Начальник научно-исследовательской лаборатории (обоснования исходных данных для планирования развития системы вооружения и средств РХБ защиты) ВА РХБЗ.

Контактная информация авторов: varhbz@mil.ru Контактное лицо: Аккузин Константин Николаевич; varhbz@mil.ru

\section{The History of the Development and Application of Robotics in the Elimination of Consequences at Radiation-Hazardous Facilities}

\author{
K.N. Akkuzin, E.S Makeev
}

The Federal State Official Military Educational Establishment of Higher Education «Military Academy of Radiological, Chemical and Biological Defence named after Marshal of the Soviet Union S.K. Timoshenko", Gorky Street 16, Kostroma 156013, Russian Federation

Received 02.03.2021. Accepted for publication 20.06.2021.

The lecture is intended for training specialists in higher educational establishments according to the Federal state standard «Robotics for military and special purposes» and also for training operators of robotic complexes (facilities) for military purposes in training centers and military units. 
The lecture addresses two study questions:

1) Retrospective analysis of radiation accidents and their consequences.

2) Analysis of the use of robotic technology and robotics systems for elimination the consequences of radiation accidents.

Conclusion: The material presented in the lecture is aimed at expanding the knowledge of those who are trained in the history of radiation accidents (disasters), as well as in the use of robotic technology and robotic systems for eliminating the consequences of such accidents. The analysis of the use of robotics in conditions of an increased radiation background, given in the lecture, will make it possible to form the necessary competencies of specialists of the NBC protection troops in order to effectively perform their tasks as intended.

Keywords: radiation-hazardous facilities; radiation accidents; radiation reconnaissance and control; elimination of consequences at radiation-hazardous facilities; robotics systems.

For citation: Akkuzin K.N., Makeev E.S. The History of the Development and Application of Robotics in the Elimination of Consequences at Radiation-Hazardous Facilities (lecture) // Journal of NBC Protection Corps. 2021. V. 5. № 2. P. 149-164. https://doi.org/10.35825/2587-5728-2021-5-2-149-164

\section{Conflict of interest statement}

The authors declare that the research was conducted in the absence of any commercial or financial relationship that could be construed as a potential conflict of interest.

\section{Peer review information}

The article has been peer reviewed by two experts in the respective field. Peer reviews are available from the Editorial Board and from Russian Science Citation Index database.

\section{References}

1. Ministry of Emergency Situations: https://19. mchs.gov.ru/deyatelnost/poleznaya-informaciya/ rekomendacii-naseleniyu/chs-tehnogennogo-haraktera (date of access: 08.04.2021).

2. CYBERLESSON.RU: https://cyberlesson. ru/klassifikacija-radiacionnyh-avarij/\#klassifikaciaradiacionnyh-avarij (date of access: 08.04.2021).

3. RIA Novosti: https://ria.ru/20110312/347505544. html (date of access: 08.04.2021).

4. Siberian Regional Union "Chernobyl»: http://souzchernobylnsk.ru/articles/hronologiyaradiacionnyhavarij\#: On February 20, 1977, an accident involving uranium mined in Czechoslovakia (date of access: 04.14.2021).

5. Electronic periodical «Scientific Russia»: https:// scientificrussia.ru/articles/march1-castle-bravo (date of access: 28.04.2021).

6. Vladyka. Security and emergencies: https:// vladyka23.ru/entsiklopediya/spisok-radiacionnyhavariy.html (date of access: 14.04.2021).

7. Infocenter AfterShock. What will be tomorrow? https://aftershock.news/?q=node/364805\&full (date of access: 08.04 .2021$)$.

8. FGBU VNIIPO EMERCOM of Russia: http:// www.vniipo.ru/departments/nicntr.html (date of access: 08.04.2021).

9. Moore T. Robots for nuclear power plants. IAEA BULLETIN. 1985. P. 35-44.

10. ATOMICEXPERT/COM:https://atomicexpert. com/robots_in_nuclear (date of access: 15.04.2021).

11. The Chernobyl disaster (1986): Disasters at the end of the twentieth century / Under total, ed. Dr. tech. V.A. Vladimirov. Ministry of the Russian Federation for Civil Defense,-Emergencies and Elimination of Consequences of Natural Disasters. Moscow. 1988.

12. Special Technique: Technology of using controlled mobile complexes / A.F. Batanov, S.N. Gritsinin, S.V. Murkin. Moscow. 1998-2016.

13. Akkuzin K.N. Robotic complexes (means) of radiation, chemical and biological defense troops of the Armed Forces of the Russian Federation (lecture) // Journal of NBC Protection Corps. 2021. T. 5. No. 1. P. 71-82.

Authors

The Federal State Official Military Educational Establishment of Higher Education «Military Academy of Radiological, Chemical and Biological Defence named after Marshal of the Soviet Union S.K. Timoshenko», Gorky Street 16, Kostroma 156013, Russian Federation

Konstantin Nikolayevich Akkuzin. Chef of Department of Scientific Work Organization and ScientificPedagogical Personnel of Military Academy of NBC Defense, PhD of Military Studies.

Makeev Evgeny Sergeevich. Chief of the research laboratory (on the substantiation of the initial data for planning the development of the weapons system and means of NBC protection) of Military Academy of NBC Defense.

Contact information for all authors: varhbz@mil.ru Contact person: Konstantin Nikolayevich Akkuzin; varhbz@mil.ru 


\author{
В.В. Завьялов ${ }^{1}$, Н.В. Завьялова ${ }^{1}$, В.И. Холстов ${ }^{1}$, \\ В.А. Ковтун ${ }^{1}$, В.К. Гореленков ${ }^{2}$, Г.А. Фролов ${ }^{3}$
}

${ }^{1}$ Федеральное государственное бюджетное учреждение "27 Научный центр» Министерства обороны Российской Федерации, 105005, Российская Федерация, г. Москва, Бригадирский пер., д. 13

2000 «Научно-исследовательский институт эластомерных материалов и изделий», Российская Федерация, 111024, г. Москва, Перовский проезд, д. 2, стр. 1

${ }^{3}$ НИПУ стали и сплавов, Российская Федерация, 119049, г. Москва, Ленинский проспект, д. 4

Поступила 16.05.2021 г. Принята к публикации 20.06.2021 г.

Проведенный ранее анализ известных из научной литературы подходов к созданию и совершенствованию защитных материалов и тканей позволил предположить, что разработка средств индивидуальной защиты (СИЗ) человека от различных поражающих факторов химической, биологической и физической природы в дальнейшем может идти в направлении создания модульных металлоорганических каркасных структур (МОК-материалов) с заданными свойствами (от токсичных химикатов и патогенных микроорганизмов). Цель работы - разработка и раскрытие принципа модульности построения защитных материалов на основе МОК-структур с заданными свойствами. Предлагаемый нами принцип модульности построения защитных материалов с заданными свойствами заключается в использовании единой тканевой унифицированной платформы, на поверхность которой наносятся специальные модули или комбинации модулей, которые обеспечивают защиту человека от различных факторов химической, биологической и физической природы. Обоснована универсальная структура МОК с наиболее насыщенной по количеству модулей и вводимых в них компонентов, получившая название «МОК - универсальный». Определены - состав и свойства отдельных модулей, возможные и оптимальные комбинации модулей МОК-структур, важность и значение отдельных модулей и их комбинаций для придания МОК-материалу универсальных защитных свойств. Использование данного принципа позволит придать защитные свойства практически любой одежде, сохранив ее физиолого-гигиенические характеристики и обеспечив требуемый уровень защиты личного состава, не прибегая к использованию специализированных средств индивидуальной защиты изолирующего типа, обладающих высоким изнуряющим действием и сковывающим эффектом.

Ключевые слова: бактерицидность и вирулицидность; биомолекуль в металлорганических каркасах; защитные материалы и ткани; композиты «биомолекуль-МОК»; металлоорганические комплексы с заданными свойствами; металлоорганические комплексы; модульные МОК-материаль; принцип модульности; специфические свойства; самоочиение (самодегазация).

Библиографическое описание: Завьялов В.В., Завьялова Н.В., Холстов В.И., Ковтун В.А., Гореленков В.К., Фролов Г.А. Использование модульности как принципа построения материалов на основе металлорганических каркасных структур с заданными свойствами для создания современных средств защиты // Вестник РХБ защиты. 2021. T. 5. № 2. C. 165-172. https:// doi.org/10.35825/2587-5728-2021-5-2-162-172 
Для успешного ведения боевых действий на поле боя, где возможно применение химических и биологических поражающих агентов, военнослужащие должны иметь боевые костюмы, обеспечивающие им защиту от широкого спектра поражающих факторов, в том числе и тех, которые ранее не были известны. В США в качестве перспективного направления их разработки рассматриваются ткани со встроенными катализаторами, нанодисперсными образованиями и химическими веществами. Пятилетний контракт на разработку боевых костюмов следующего поколения на основе таких тканей получила от Агентства перспективных оборонных исследовательских проектов (DARPA) компания FLIR Systems, Inc. Сумма контракта 20,5 млн долларов [1].

Первостепенное значение при разработке новых материалов для создания средств индивидуальной защиты приобретает их самоочищение (самодегазация) и бактерицидность. Для этого в состав защитных материалов внедряют наноразмерные металлосодержащие частицы, проявляющие антибактериальные и противовирусные свойства, а также наноразмерные ферментные полиэлектролитные комплексы, катализирующие гидролиз высокотоксичных и токсичных соединений, токсинов и продуктов их деструкции [2-6]. К наиболее перспективным технологиям, позволяющим получить такие ткани, относятся технологии получения металлоорганических каркасных структур (МОК), представляющих собой соединения, состоящие из ионов металлов (например: $\mathrm{Ag}, \mathrm{Cu}, \mathrm{Zn} \mathrm{Ti}$ и др.) или кластеров, связанных между собой жесткими органическими молекулами нановолокна [7-28].

Цель работы - разработка и раскрытие принципа модульности построения защитных материалов с заданными свойствами на основе металлорганических каркасных структур.

Создание защитных костюмов следующего поколения, которые защитят военнослужащих от всех видов биологических агентов (БА) и различных токсичных химикатов (ТХ), в том числе и ОВ, предусматривают разработку совершенно новых гибридных материалов со встроенными в их состав катализаторами и химическими веществами, способными снижать химические и биологические угрозы при контакте с соответствующими поражающими агентами.

Основные подходы к созданию совершенно нового класса гибридных материалов и металлорганических каркасных структур с включенными биомолекулами, получившими название композитов «биомолекулы-МОК» с заданными свойствами, детально рассмотрены в [29]. Кроме того, в этой работе, авторами впервые была разработана Стратегия создания металлоорганических комплексов с заданными свойствами из модулей для современных средств защиты. Она основывалась на анализе существующих в литературе подходов к созданию и совершенствованию материалов и тканей, содержащих МОК, данных о свойствах МОК и характеристиках биомолекул, подходах включения биомолекул в металлорганические каркасные структуры, свойствах и характеристиках композитов «биомолекулы-МОК» и достижениях применения композитов «биомолекул-МОК» в биокатализе и доставке их к мишеням.

При выполнении работы была предложена схема создания структуры МОК с наиболее насыщенной по количеству модулей и вводимых в них компонентов, получившая название «МОК - универсальный».

Металлоорганические каркасы с включенными биомолекулами для создания защитных материалов и тканей с заданными свойствами

В таких разработках не используются готовые ткани и материалы, а создаются условия, при которых происходит их самосборка. Для прохождения самосборки подбираются наиболее приемлемые условия для создания МОК и композитов «биомолекулы-МОК», создаются соответствующие МОК и подбираются биологические и химические молекулы, обеспечивающие проявление заданных свойств, эти молекулы интегрируются в МОК и создаются композиты «биомолекулы-МОК», способные катализировать деградацию (гидролиз) ТХ (в том числе и ОВ) и инактивировать БА (бактерии и вирусы). Наиболее приемлемыми для создания материалов и тканей со специальными защитными свойствами являются способ in-situ инкапсуляции и биоМОК способ получения металлоорганических комплексов [29].

Используя способ in-situ инкапсуляции, можно создать МОК вокруг биомолекул с одновременным включением их в поры. Таким способом можно проводить инкапсуляцию аминокислот, белков и ферментов с высокой эффективностью включения их в формирующиеся МОКи. При этом инкапсулированный в наночастицы МОК белок не теряет своей активности, а полученный гибридный материал приобретает высокую чувствительность, селективность, а также стабильность при длительном хранении. Проведение такого инкапсулирования возможно только в водных растворах, поскольку большинство биомолекул необратимо конформируются и коагулируют в агрессивных синтетических средах, таких как органические растворители [29]. 
При использовании био-МОК способа получения металлорганических комплексов, биомолекулы-аминокислоты, пептиды, нуклеобазы и полисахариды, обладающие химически активными группами, хорошо координируют с различными металлами и выступают в качестве органических линкеров для синтеза МОК. Использование этих биомолекул в качестве лигандов для координации с металлами приводит к формированию совершенно новых типов МОК [29].

Бактерицидность, вирулицидность и самоочищение (самодегазация). материалы и ткани могу приобретать за счет их функциализации, при использовании наноразмерных металлосодержащих частиц - меди, кобальта, тантала, титана, цинка, серебра и др., а также наноразмерных ферментных комплексов - органофосфатгидролазы, карбоксипептидазы А и лактоназы.

В качестве необходимых для построения МОК органических лигандов будут использованы аминогруппы и пептиды. В качестве органических линкеров для построения МОК - аминокислоты, пептиды и ионы металлов: тантала, титана, меди и цинка. Металлоорганические композиты с введенными в них одновременно антимикробным компонентом и наноразмерными ферментными комплексами в дальнейшем будут наноситься на тканевую унифицированную платформу.

Порядок, количество и последовательность нанесения составных частей для формирования металлоорганических композитов «биомолекулы-МОК», на тканевую унифицированную платформу являются основой для разработки в дальнейшем технологии получения нового поколения материалов и тканей модульного типа со специальными свойствами.

Полученные при такой технологии композиты «биомолекулы-МОК» становятся новой платформой для гетерогенного биокатализа, так как имеют высокую стабильность, многократное использование и хорошую каталитическую селективность.

Раскрытие принципа модульности для создания металлоорганических комплексов с заданными свойствами для современных средств защиты

Предлагаемый нами принцип модульности построения защитных материалов с заданными свойствами, заключается в использовании единой тканевой унифицированной платформы, на поверхность которой наносятся специальные отдельные модули или комбинации модулей, которые обеспечивают защиту человека от различных факторов химической, биологической и физической природы.
Модульность, по нашему пониманию, состоит в комплектовании пакета материалов отдельными элементами защиты от различных факторов воздействия на человека. Единая тканевая унифицированная платформа, на которую наносят другие специальные модули, представляет собой защитный материал, который классифицируется как модуль «Ткань» или модуль «Броня».

Наносимые на модуль «Ткань» специальные модули сами по себе могут быть или химически нейтральными, например: «Адгезионный», «Адсорбционный» и «Абсорбционный» модули, или химически активными, как «Дезинфицирующий» («Бактерицидный» и «Вирулицидный») «Дегазирующий» («Биохимический» и «Химический»). Поэтому при нанесении на унифицированную платформу химически активных модулей будут соблюдаться определенные требования нанесения количества и последовательности, которые не позволят нейтрализовать или вывести из рабочего состояния специфические модули или мешать модулям осуществлять свои функции.

Согласно разработанному принципу модульности построения защитных материалов с заданными свойствами на модуль «Ткань» в первую очередь наносится модуль «Адгезионный», основное назначение которого состоит в обеспечении адгезии остальных модулей на тканевой унифицированной платформе.

Модули: «Противоогневой», защищающий от открытого пламени и светового излучения ядерного взрыва; «Дезинфицирующий», защищающий от бактериальных агентов и вирусов; «Дегазационный» («Биохимический» или «Химический»), защищающий от сильнодействующих ядовитых веществ; «Адсорбционный» и «Абсорбционный», размещаются в структуре ткани после использования «Адгезионного» модуля.

МОК относится к «Металлоорганическому» модулю и является модулем «Биохимический». При применении модуля «Металлоорганический» совместно с модулем «Дезинфицирующий» создается основа для получения материалов и тканей модульного типа со специальными свойствами модульно, обеспечивающих одновременную защиту от токсичных химикатов и болезнетворных патогенных микроорганизмов (бактерий и вирусов).

Для создания материалов и тканей модульного типа со специальными свойствами, обеспечивающими защиту от токсичных химикатов и патогенных микроорганизмов на основе МОК, была разработана схема модульного построения «МОК - универсальный», которая представлена на рисунке 1. 


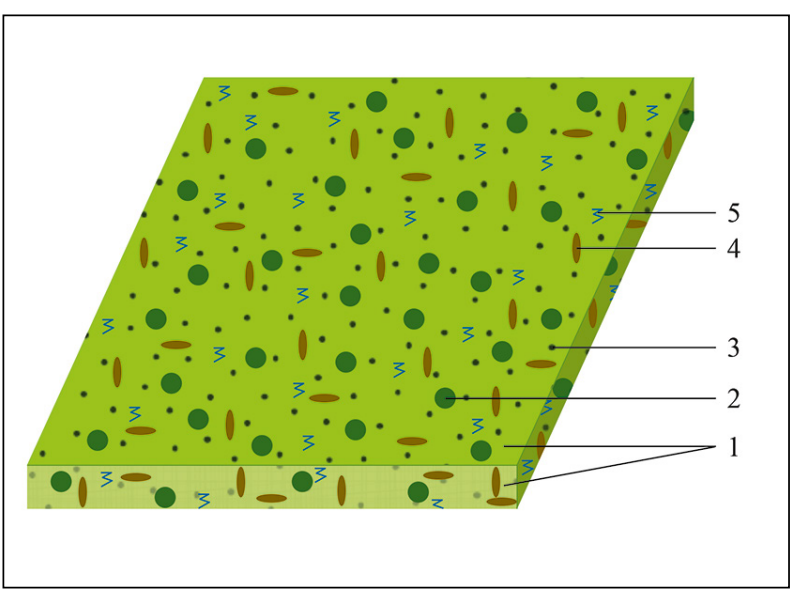

Рисунок 1 - Схема порядка модульного построения «МОК - универсальный».

1. Модуль «Адсорбчионный» - подложка, ткань параарамидная (волокно «Русар»). 2. Модуль «Адгезионный» - слой карбоксилатов металлов.

3. Модуль «Антимикробный» - слой наночастиц металлов (тантал, титан, цинк). 4. Модуль "Химический» - слой капсул алкоголятов металлов. 5. Модуль «Биохимический» - слой капсул наноразмерных ферментных комплексов. Схема авторов

Благодаря разработанной схеме структуры «МОК - универсальный» или «МОК-У», с наиболее насыщенной по количеству модулей и вводимых в них компонентов, были определены - состав и свойства отдельных модулей, возможные и оптимальные комбинации модулей МОК-структур для получения новых защитных материалов от ХА и БА, установлена важность и значение отдельных модулей и их комбинаций для придания МОК-материалу универсальных защитных свойств.

В соответствии с принципом модульного построения «МОК - универсальный» содержит следующие модули, состоящие из слоев и имеющие следующие характеристики:

- модуль «Тканъ», слой ткани параарамидной (волокно «Русар») или другие виды тканей, такие как: смесовые арамидновискозовые, арамиднохлочатобумажные, арамиднополиакрилатные, метаарамид (волокно «Номекс»), является подложкой для других модулей. Модуль выполняет функцию несущей базовой платформы для создания защитных материалов;

- модуль «Адгезионный» он же «Абсорбционный», представляет собой слой карбоксилатов металлов, в котором в качестве неполярной части молекулы используется природная карбоновая кислота с высоким гидрофобным взаимодействием, а в качестве металлов используются: алюминий, железо, стронций, барий, медь, марганец, никель, кобальт и цинк. Выбор конкретного карбоксилата металла будет обу- словлен его адгезионными и абсорбционными свойствами и задачами, которые будут выполнять эти металлы. «Адгезионный» модуль является универсальным абсорбентом для паров летучих органических веществ, он повышает адгезионное крепление на поверхности подложки других агентов, наносится (пропитывает) непосредственно на подложку. Модуль функционально отвечает за захват и удерживание частиц поражающих агентов различной природы;

- модуль "Антибактериальный», слой модифицированных наночастиц металлов (спиртозоли или гидрозоли): тантала, титана, меди и цинка, обеспечивающих бактерицидные и вирулицидные свойства материала. Модуль отвечает за нейтрализацию поражающих агентов биологического происхождения;

- модуль «Химический», слой капсул жидких химически активных компонентов, например, алкоголятов металлов, представляющих из себя раствор этилата калия и изопропилата калия в этиловом и изопропиловом спирте соответственно, который заключен в капсулы из поликапролактона или высокомолекулярного полиэтиленгликоля. Модуль обеспечивает первичную химическую нейтрализацию химических поражающих агентов;

- модуль «Биохимический» или "Самодегазирующийся» (самоочищающийся), состоящий из капсул наноразмерных ферментных комплексов (гексагистидинсодержащей органофосфатгидролазы, карбоксипептидазы А и лактоназы), в присутствии которых осуществляется каталитический гидролиз токсичных химикатов. Модуль отвечает за полную дегазацию химических поражающих агентов посредством их разложения до нетоксичных неорганических продуктов.

Таким образом разработанный нами принцип модульности для получения металлоорганических комплексов с заданными свойствами для создания современных средств защиты от токсичных химикатов и патогенных микроорганизмов, состоит в использовании единой тканевой унифицированной платформы с нанесением на её поверхность специальных модулей, которые будут обеспечивать защиту человека от различных факторов химической, биологической и физической природы.

Защитные свойства таких материалов и тканей, которые создаются с использованием принципа модульности, будут определяться наличием и компоновкой модулей, обладающих специфичными свойствами по нейтрализации поражающих факторов различной природы. При этом использование данного принципа позволит придать защитные свой- 
ства практически любой одежде, сохранив ее физиолого-гигиенические характеристики и обеспечив требуемый уровень защиты личного состава, не прибегая к использованию специализированных средств индивидуальной защиты изолирующего типа, обладающих высоким изнуряющим действием и сковывающим эффектом.

\section{Работа въполнена при финансовой поддержке РФФИ (грант № 18-29-17069).}

\section{Вклад авторов/Autor Contributions}

Все авторы внесли свой вклад в концепцию рукописи, участвовали в обсуждении и написании этой рукописи, одобрили окончательную версию. Все авторы прочитали и согласились с опубликованной версией рукописи.

All authors contributed to the conception of the manuscript, the discussion, and writing of this manuscript, approved the final version. All authors have read and agreed to the published version of the manuscript.

\section{Информация о конфликте интересов}

Авторы заявляют, что исследования проводились при отсутствии любых коммерческих или финансовых отношений, которые могли бы быть истолкованы как потенциальный конфликт интересов.

\section{Сведения о реиензировании}

Статья прошла открытое рецензирование двумя рецензентами, специалистами в данной области. Рецензии находятся в редакции журнала и в РИНЦе.

\section{Список источников/References}

1. Teiler Derden. https//www.zerohedge.com/ geopolitical/flir-darpa-contract-develop-next-gencombat-suits-biowarfare от 13 апреля 2021 г.

2. Фосфорорганические нейротоксины: монография / под ред. С.Д. Варфоломеева и Е.Н. Ефременко, РИОР, Москва, 2020 - 380 с. ISBN: 978-5-36902026-5. https://doi.org/10.29039/02026-5

Organophosphorus Neurotoxins: monograph / Eds. Professor S.D. Varfolomeev, Professor E.N. Efremenko. Moscow: RIOR, 2020. 380 p. ISBN: 978-5369-02026-5. https://doi.org/10.29039/02026-5

3. Завьялов В.В., Кужелко С.В., Завьялова Н.В., Ковтун В.А., Холстов В.И., Таранченко Ю.Ф., Сластилова Л.М., Ефременко Е.Н., Сенькилёв А.П. Современные направления создания новых защитных материалов и тканей для средств индивидуальной и коллективной защиты от токсичных химикатов и клеток патогенов // Вестник войск РХБ защиты. 2019. Т. 3. № 3. С. 117-148.

Zavialov V.V., Kujelko S.V., Zavialova N.V., Kovtun V.A., Kholstov V.I., Taranchenko Yu.F., Slastilova L.M., Efremenko E.N., Sin' keliov A.P. Modern Directions of Creating New Protective Materials and Tissues For Means of Individual and Collective Protection Against Toxic Chemicals and Pathogenic Microorganisms // Journal of NBC Protection Corps. 2019. V. 3. No 3. P. 217-254. https://doi. org/10.358.25/2587-5728-2019-3-3-217-254

4. Soldier systems technology roadmap / Capstone report and action plan / Supporting the future soldier supporting Canadian industry. Government of Canada. https://www.defenceandsecurity.ca/UserFiles/Uploads/ publication/reports/files/document-10pdf (дата обращения: 25.12.2018).
5. Sloter L. Overview of nanotechnology \& nan $\neg$ omanufacturing within the Department of defense. American Vacuum Society International Symposium and Exhibition Baltimore, Maryland. USA. 2014. URL: https://avs.org/AVS/files/d3/d388692a-70b1-472dbec6- 44df3b06126e.pdf

6. Tomar S. Nanotechnology: the emerging field for future military applications. IDSA Monograph Series No. 48. 2015. ISBN: 978-93-82169-58-1.

7. An H., Li M., Gao J., Zhenjie Z., Ma S., Chen Y. Incorporation of biomolecules in metal-organic frameworks for advanced applications // Coordination Chemistry Reviews. 2019. V. 384. P. 90-106.

8. Li M., Dan Li D., O’Keeffe M., Yaghi O.M. Topological analysis of metal-organic frameworks with polytopic linkers and/or multiple building units and the minimal transitivity principle // Chem. Rev. 2014. V. 114. P. 1343-1370.

9. Bobbitt N.S., Mendonca M.L., Howarth A.J., et al. Metal-organic frameworks for removal of toxic industrial chemicals and chemical warfare agents // Chem. Soc. Rev. 2017. V. 46. P. 3357-3385.

10. Gutov O.V., Bury W., Gomez-Gualdron D.A., et al. A highly stable zirconium-based metal-organic framework material with high surface area and gas storage capacities // Chemistry A. European J. 2014. V. 20. P. 12389-12393.

11. Furukawa H., Cordova K.E., O’Keeffe M., Yaghi O.M. The Chemistry and Applications of MetalOrganic Frameworks // Science. 2013. V. 341. № 6149. P. 12340444. https:// doi.org/10.11265/science.1230444

12. Howarth A.J., Liu Y., Li P. et al. Chemical, thermal and mechanical stabilities of metal-organic 
fameworks // Nat. Rev. Mater. 2016. V. 1. P. 15018.

13. De Coste J.B., Peterson G.W. Metal-organic fameworks for air purification of toxic chemicals // Chem. Rev. 2014. V. 114. № 11. P. 5695-5727.

14. Lopes-Maya E., Montoro C., RodriguesAlbelo L.M. et al. Textile/ metal-organic-framework composites as self-detoxifying filters for chemicalwarfare agents // Angew. Chem. Int. Ed. Engl. 2015. V. 54. № 23. P. 6790-6794.

15. Moon S-Y., Liu Y., Hupp J.T., Farha O.K. Instantaneous hydrolysis of nerve-agent smulants with a six-connected zirconium-based metal-organic famework // Angew. Chem. Int. Ed. Emgl. 2015. V. 54. № 23. P. 6795-6799.

16. Vemuri R.S., Armatis P.D., Bontha J.R., McGrail B.P., Motkuri R.K.. An overview of detection and neutralization of chemical warfare agents using metal organic frameworks // J. Bioterror. Biodef. 2015. V. 6. № 3. https://doi.org/10.4172/2157-2526.1000137

17. Alongi J.,Tata J., Carosio F., Rosace G., Alberto Frache A., Giovanni Camino G. A comparative analysis of nanoparticle adsorption as fire-potection approach for fabrics. // Polymers. 2015. V. 7. № 1. P. 47-68.

18. Bhuiyan M.A.R., Wang L., Shaid A. et al. Advances and application of chemical protective clothing system // J. Industrial Textiles. 2019. V. 49. № 1. P. 97-138. https://doi.org/10.1177/1528083718779426

19. Qi K.,Wang X., Xin J.H., Photocatalytic selfcleaning textiles based on nanocrystalline titanium dioxide // Textile Research J. 2011. V. 81. 1. P. 101-110.

20. Ugur S., Sarısık M., Aktas H. The fabrication of nanocomposite thin films with $\mathrm{TiO} 2$ nanoparticles by the layer-by-layer deposition method for multifunctional cotton fabrics // Nanotechnology. 2010. V. 21. 32. P. 32560-3. https:// doi.org/10.1088/0957$4484 / 21 / 32 / 325603$

21. Navale G.R., Thripuranthaka M, Late D.J., Shinde S.S. Antimicrobial activity of $\mathrm{ZnO}$ nanoparticles against pathogenic bacteria and fungi // JSM Nanotechnol Nanjmed. 2015. V. 3. P. 1033.

22. Jones N., Ray B., Ranjit K.T., Manna A.C. Antibacteral activity of $\mathrm{ZnO}$ nanoparticle suspensions on a broad spectrum of microorganisms // FEMS Microbial Lett. 2018. V. 279. P. 71-76. https://doi.org/10.1111/j.1574- 6968.2007.01012.x

23. Smiechowicz E., Niecraszewicz B., Kulpinski P., Dzitko K. Antibacterial composite cellulose fibers modified with silver nanoparticles and nanosilica // Cellulose. 2018. V. 25. P. 3499-3517. https://doi. org/10.1007/s10570-018-1796-1

24. Gold K., Slay B., Knachstedt M., Gaharwar A.K. Antimicrobial activity of metal and metal-oxide based nanoparticles // Adv. Therap. 2018. V. 1. P. 1100033. https://doi.org/10.1002/adtp.201700033

25. Щербаков А.Б., Жолобак Н.М., Иванов В.К., Третьяков Ю.Д., Спивак Н.Я. Наноматериалы на основе диоксида церия; свойства и перспективы использования в биологии и медицине // Биотехнология. 2011. Т. 4. № 1. С. 9-28.

Shcherbakov A.B., Zholobak N.M., Ivanov V.K., Tretyakov Yu.D., Spivak N.Ya. Nanomaterials Based on the Nanocrystalline Ceric Dioxode: Properties and Use Perspectives in Biology and Medicine // Biotechnology. 2011. V. 4. № 1. P. 9-28.

26. Ravikumar S., Gokulakrishnan R. The inhibitory effect of metal oxide nanoparticles against poultry pathogens // Int. J. Pharm. Sci. Drug Res. 2012. V. 4. P. 157-159.

27. Doskocz N., Zaleska-Radziwill M. Effects of zirconium oxide nanoparticles on bacterial growth // PhD Interdisplinary J. 2015. V. 1. P. 1-7.

28. Kim S., Ying W.B., Jung H. et al. Zirconium hydroxide-coated nanofibers mats for nerve agent decontamination // Chem. Asian J. 2017. V. 12. № 6. P. 698-705. https:// doi.org/10. 1002/asia.201601729

29. Завьялов В.В., Завьялова Н.В., Холстов В.И., Гореленков В.К., Фролов Г.А., Лягин И.В., Ефременко Е.Н., Стратегия разработки современных средств защиты на основе металлоорганических комплексов с заданными свойствами// Вестник войск РХБ защиты. 2020. Т. 4. № 3. С. 305-337.

Zavyalov V.V., Zavyalova N.V., Kholstov V.I., Gorelenkov V.K., Frolov G.A., Lyagin I.V., Efremenko E.N. Strategy for Development of Modern Protective Equipment Based on Organometallic Complexes with Desired Properties // Journal of NBC Protection Corps. 2020. V. 4. No 3. P. 305-337. https:// doi.org/10.35825/2587-5728-2020-4-3-305-337

\section{Об авторах}

Федеральное государственное бюджетное учреждение «27 Научный центр» Министерства обороны Российской Федерации - Организация, представляющая условия для реализации Проекта, 105005, Российская Федерация, г. Москва, Бригадирский пер., д. 13.

Завьялов Василий Владимирович. Старший научный сотрудник, канд. хим. наук, проф. АВН, член научного коллектива, выполняющего грант.

Завьялова Наталья Васильевна. Главный научный сотрудник, д-р. биол. наук, проф., академик АВН, руководитель научного коллектива, выполняющего грант.

Холстов Виктор Иванович. Член дис. совета на базе 27 НЦ МО РФ, д-р хим. наук, проф., почетный химик РФ, акад. РАЕН и АВН, член-корр. РАР и АН.

ООО «Научно-исследовательский институт эластомерных материалов и изделий», Российская Федерация, 111024, г. Москва, Перовский проезд, д. 2, стр. 1. 
Гореленков Валентин Константинович. Ведущий научный сотрудник, д-р хим. наук, проф., член научного коллектива, выполняющего грант.

НИПУ стали и сплавов, Российская Федерация, 119049, г. Москва, Ленинский проспект, д. 4.

Фролов Георгий Александрович. Доцент кафедры, канд. хим. наук, доцент, член научного коллектива, выполняющего грант.

\title{
Use of Modularity as a Principle of Design of Metal-organic Framework-based Materials with Specified Properties for Creating Modern Protective Equipment
}

\author{
V.V. Zavyalov' ${ }^{1}$, N.V. Zavyalova ${ }^{1}$, V.I. Kholstov ${ }^{1}$, V.K. Gorelenkov², G.A. Frolov ${ }^{3}$ \\ ${ }^{1}$ Federal State Budgetary Establishment "27 Scientific Centre» of the Ministry of Defence of \\ the Russian Federation. Brigadirskii Lane 13, Moscow 105005, Russian Federation \\ ${ }^{2}$ Limited Liability Company «Scientific Research Institute of Elastomer Materials and \\ Products». Perovsky Passage 2, Moscow 111024, Russian Federation \\ ${ }^{3}$ National University of Science and Technology MISIS. Leninsky Avenue 4, \\ Moscow 119049, Russian Federation
}

Received 16 May 2021. Accepted for publication 20 June 2021

An earlier analysis of approaches to the creation and improvement of protective materials and tissues made it possible to assume that the development of personal protective equipment (PPE) against various damaging factors of chemical, biological and physical nature can in future go towards the creation of modular organometallic frame structures (MOF-materials) with specific properties (from toxic chemicals and pathogenic microorganisms). The aim of this article is to develop and disclose the principle of modularity of construction of protective materials based on MOF-structures with specific properties. The principle of modularity of construction of protective materials with specific properties, proposed by us, is based on the use of single unified platform, on the surface of which special modules or combinations of modules are applied, which ensure the protection from various factors of chemical, biological and physical nature. The universal structure of $\mathrm{MOF}$, called «MOF-universal», has been substantiated. The composition and properties of individual modules, possible and optimal combinations of modules of MOF-structures, the importance and significance of individual modules and their combinations for imparting universal protective properties to MOF-material are determined. The use of this principle will make it possible to impart protective properties to almost any clothing, while maintaining its physiological and hygienic characteristics and providing the required level of protection for personnel, without using specialized personal protective equipment.

Keywords: bactericidal and virulicidal action; biomolecules in metal-organic frameworks; protective materials and fabrics; biomolecules/MOF composites; organometallic complexes with desired properties; organometallic complexes; modular MOF materials; modularity principle; specific properties; self-degassing.

For citation: Zavyalov V.V., ZavyalovaN.V., Kholstov V.I., Kovtun V.A., Gorelenkov V.K., Frolov G.A. Use of Modularity as a Principle of Design of Metal-organic Framework-based Materials with Specified Properties for Creating Modern Protective Equipment // Journal of NBC Protection Corps. 2021. V. 5. No 2. P. 165-172. https:// doi.org/10.35825/2587-5728-2021-5-2-165-172 
This work was carried out with the financial support of the Russian Foundation for Basic Research (RFBR) (Grant № 18-29-17069).

\section{Conflict of interest statement}

The authors declare that the research was conducted in the absence of any commercial or financial relationship that could be construed as a potential conflict of interest.

\section{Peer review information}

The article has been peer reviewed by two experts in the respective field. Peer reviews are available from the Editorial Board and from Russian Science Citation Index database.

\section{References}

See P. 169-170.

\section{Authors}

Federal State Budgetary Establishment «27 Scientific Centre» of the Ministry of Defence of the Russian Federation. Brigadirskii Lane 13, Moscow 105005, Russian Federation.

Vasily Vladimirovich Zavyalov. Senior Researcher. Candidate of Chemical Sciences. Professor of the Academy of Military Sciences.

Natalya Vasilyevna Zavyalova. Leading Researcher. Doctor of Biological Sciences, Professor. Academician of the Academy of Military Sciences.

Viktor Ivanovich Kholstov. Member of the Dissertation Council of the « 27 Scientific Centre» of the Ministry of Defence of the Russian Federation. Doctor of Chemical Sciences, Professor. Honored Chemist of the Russian Federation. Academician of the Russian Academy of Natural Sciences and the Academy of Military Sciences. Corresponding Member of the Russian Academy of Sciences and the Russian Academy of Rocket and Artillery Sciences.

Limited Liability Company «Scientific Research Institute of Elastomer Materials and Products». Perovsky Passage 2, Moscow 111024, Russian Federation.

Valentin Konstantinovich Gorelenkov. Leading Researcher. Doctor of Chemical Sciences, Professor.

National University of Science and Technology MISIS. Leninsky Avenue 4, Moscow 119049, Russian Federation.

George Alexandrovich Frolov. Candidate of Chemical Sciences, Associate Professor.

Contact information for all authors: 27nc_1@mil.ru Contact person: Natalya Vasilyevna Zavyalova; 27nc_1@mil.ru 


\author{
Федеральное государственное бюджетное учреждение \\ «27 Научный чентр» Министерства обороны Российской Федерации, 105005, \\ Российская Федерация, г. Москва, Бригадирский пер., д. 13
}

Поступила 15.05.2021 г. Принята к публикации 20.06.2021 г.

Несмотря на внимание к проблемам военных преступлений и преступлений против человечности, которые в беспрецедентных масштабах совершались в нацистских концентрационных лагерях, тема медицинских экспериментов на заключенных в современной отечественной историографии представляется одной из наименее изученных. Тем более не уделялось специального внимания испытаниям на людях химического оружия. Цель работы - рассмотреть историю разработки и испытаний на людях боевых отравляющих веществ (БОВ) в Германии в 1933-1945 гг. В годы Первой мировой войны Германия была одной из ведущих стран мира в области военно-химического дела. В результате версальских ограничений этот потенциал был в значительной степени утрачен. После прихода к власти Национал-социалистической немецкой рабочей партии (НСДАП) Германия не только восстановила, но и нарастила военную мощь, достигнув в области химического оружия над своими противниками качественного превосходства. Испытания БОВ, а также исследование эффективности средств и протоколов лечения вызванных ими поражений, проводили как военные структуры Вермахта и СС, так и гражданские научно-исследовательские и академические институты. Эксперименты на заключенных осуществлялись в концентрационных лагерях Дахау, Равенсбрюк, Аушвиц-Биркенау, Бухенвальд, Заксенхаузен, Нацвайлер-Штрутгоф, Нойенгамме и др. В основном исследовалось поражающее действие сернистого иприта и фосгена. В Аушвице-Биркенау «производилось изучение действия разных химических препаратов по заказам немецких фирм». Врачи из СС, ставившие недобровольные опыты на людях, после войны были осуждены военными трибуналами за военные преступления и преступления против человечности. Семь врачей были приговорены к смертной казни через повешение, приговор приведен в исполнение 2 июня 1948 г. в тюрьме для военных преступников в Ландсберге (Бавария). По итогам процесса 1947 г. был составлен Нюрнбергский кодекс - первый международный документ, вводивший этические нормы для ученых, занимающихся экспериментами на людях. Он включал в себя 10 принципов, главный из которых сводился к тому, что для проведения эксперимента на человеке необходимо его добровольное осознанное согласие после предоставления ему полной информации о характере, продолжительности и цели проводимого эксперимента; о методах и способах его проведения; обо всех предполагаемых неудобствах и опасностях, связанных с проведением эксперимента, и, наконец, возможных последствиях для физического или психического здоровья испытуемого, могущих возникнуть в результате его участия в эксперименте.

Ключевые слова: боевые отравляющие вещества; военные преступления; Вторая мировая война; Германия; испытания; конилагерь; Нюрнбергский трибунал; преступления против человечности.

Библиографическое описание: Шило Н.И. Разработка и испытания на людях боевых отравляющих веществ и средств лечения поражений в Германии в 1933-1945 годах// Вестник войск РХБ защитыы. 2021. Т. 5. № 2. C. 173-198. https://doi.org/10.35825/2587-5728-2021-5-2-173-198 
В годы Первой мировой войны (1914-1918) Германия была одной из ведущих стран мира в области военно-химического дела $[1,2]$. Главным центром военно-химических исследований был Институт физической химии и электрохимии кайзера Вильгельма (нем. - Kaiser Wilhelm Institut für physikalische Chemie und Elektrochemie, KWIPC) (ИФХЭ) Общества кайзера Вильгельма (нем. - Kaiser Wilhelm Gesellschaft) ${ }^{1}$ (Берлин-Далем) (рисунок 1) [3, 4].

В институте занимались поиском токсичных химикатов, пригодных к применению в качестве боевых отравляющих веществ, разработкой технологий их производства в промышленных масштабах, созданием средств доставки, вопросами хранения и утилизации, разработкой средств и способов обнаружения боевых отравляющих веществ (БОВ), а также средств индивидуальной и коллективной защиты. Там же занимались изучением токсикологических свойств БОВ и поиском средств и методов лечения поражений. Директор ИФХЭ Фриц Габер (нем. Fritz Haber, 1868-1934) (Нобелевский лауреат, 1918) был одновременно начальником военно-химической службы германской армии.

Крупнейшим токсикологическим центром, занимавшимся БОВ, был Департамент Е (фармакологический) ИФХЭ под руководством токсиколога Фердинанда Флури (нем. - Ferdinand Flury, 1877-1947).

После окончания Первой мировой войны, завершившейся поражением Германии и ее союзников, Версальский мирный договор (1919) специально оговаривал (ст. 171): «B виду воспрещения пользования удушливыми, ядовитыми или тому подобными газами, а также всякими аналогичными жидкостями, веществами или способами, производство и ввоз их в Германию строго воспреща ется. То же самое будет относиться к материалу, специально предназначенному для изготовления, сохранения или применения названных продуктов и способов...». Запрещались производство и импорт прекурсоров. Нельзя было проводить никаких секретных работ в области военной химии. В ИФХЭ департамент Е был закрыт. Германию обязали поделиться технологиями с бывшими противниками - ст. 172 Версальского мирного договора предполагала, что «в трехмесячный срок со дня вступления в силу настоящего Договора Германское Правительство доведет до сведения Правительств Главных Союзных и Объединившихся Держав о видах и способах производства всех взрывчатых веществ, ядовитых составов или других химических препаратов, употребляв-

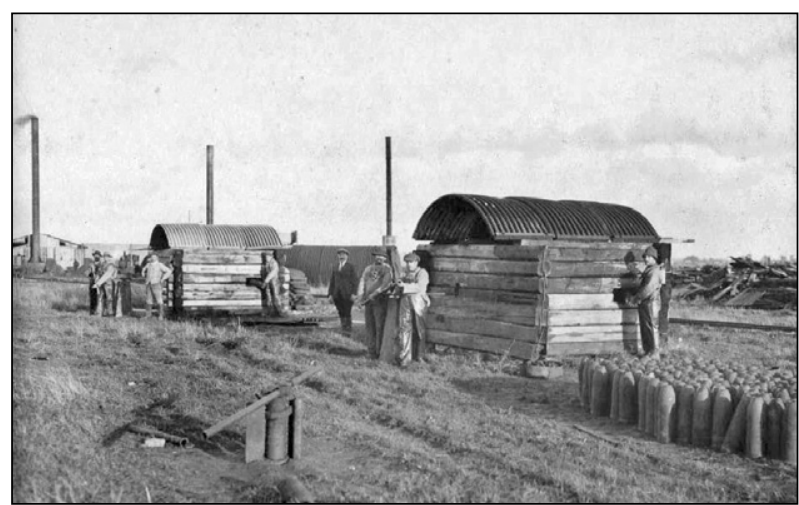

Рисунок 1 - Объект УХО образца начала ХХ века. Верден, 1919 г. Расснаряжение проводилось в деревянных бараках (в чентре). На переднем плане расснаряженные боеприпасы со снятыми взрывателями. На заднем плане - печи для сжигания uприта. Источник - GEKA [28]

шихся им в течение войны или изготовленных им с иелью употребить их таким образом» [5].

Вскоре в Германии нашли способы обхода версальских ограничений. Внутри страны научно-исследовательские работы (НИР), связанные с БОВ, велись в ограниченных масштабах группами ученых в лабораториях при университетах и научно-исследовательских центрах таких, как Биологический центр в Берлине (Biologische Reichsanstalt). Рейхсвер осуществлял взаимодействие с ними через систему контрактов. Часть работ была перенесена за пределы страны [6].

Если не принимать во внимание версальские ограничения, в этих работах не было ничего противозаконного с точки зрения международного права того времени, поскольку действовавший в то время Женевский «Протокол о запрещении применения на войне удушливых, ядовитых или других подобных газов и бактериологических средств» $(1925)^{2}$ запрещал только применение химического оружия. Готовиться к войне никакой закон не запрещал [7].

Ситуация изменилась после выборов 1933 г. с приходом к власти Национал-социалистической немецкой рабочей партии (НДСАП, нем. Nationalsozialistische Deutsche Arbeiterpartei, NSDAP) во главе с Адольфом Гитлером (нем. - Adolf Hitler, 1889-1945), ставшим рейхсканцлером. Вскоре Германия отказалась от военных статей Версальского договора, стала восстанавливать вооруженные силы и наращивать производство вооружений, в том числе химических. НИР по химическому оружию

\footnotetext{
В настоящее время - Общество научных исследований имени Макса Планка (нем. - Max Planck Gesellschaft zur Förderung der Wissenschaften e.V., MPG), сеть научно-исследовательских организаций, включающая в себя более 80 институтов и научно-исследовательских центров. Штаб-квартира находится в Мюнхене.

2 Протокол о запрещении применения на войне удушливых, ядовитых или других подобных газов и бактериологических средств. URL: https://docs.cntd.ru/document/901753260 (дата обращения: 12.06.2021)
} 


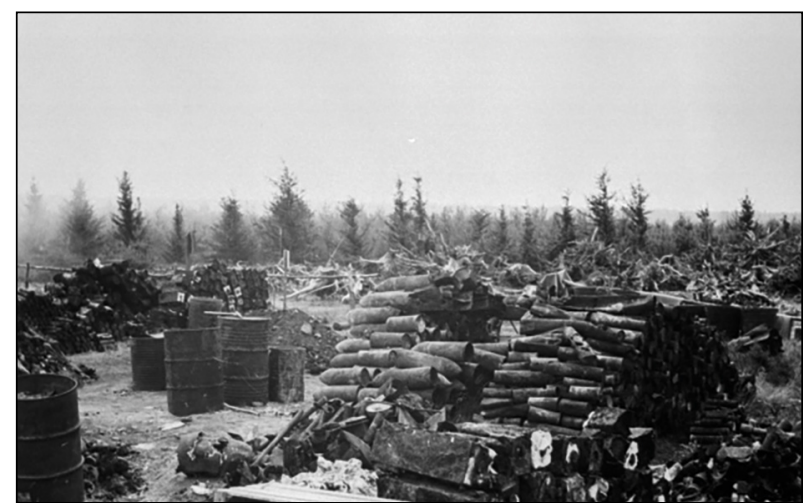

Рисунок 2 - Химические трофеи, доставшиеся союзникам после Второй мировой войны. Источник - GEKA [28]

получили дополнительное финансирование. Были созданы новые научно-исследовательские и испытательные центры, для них потребовался экспериментальный материал, война дала его в неограниченных количествах [8].

Цель работь - рассмотреть историю разработки и испытаний на людях боевых отравляющих веществ (БОВ) в Германии в 1933-1945 гг.

Основным центром научно-исследовательских и испытательных работ по химическому оружию стал учебный и испытательный полигон Вермахта и лаборатории в Раубкаммере возле Мюнстера (Heeresversuchsstelle Munster-Nord / Raubkammer) [9].

Полевые испытания, а также строительство соответствующих объектов начались в Раубкаммере в 1935 г. В 1936 г. строительство было завершено. В годы Второй мировой войны там работали около 500 человек, максимальная численность персонала достигла 800 человек (1944). Учебный полигон общей площадью $16 \times 8$ км, расположенный севернее Мюнстера, использовался как экспериментальная площадка в интересах химической службы Вермахта (в первую очередь

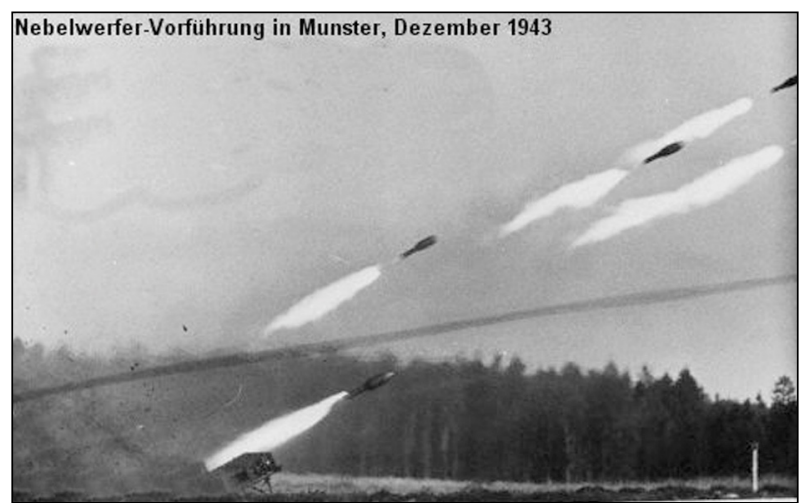

Рисунок 3 - Испытания реактивных минометов. Мюнстерский полигон. Декабрь 19432. URL: https://www.geschichtsspuren.de/artikel/ trainings-und-versuchsanlagen/108-munsterkampftstoffe.html (дата обращения: 13.06.2021)

для проведения испытаний боеприпасов с ипритом $^{3}$ (рисунок 2), а также для отработки тактических приемов ведения химической войны) и $\mathrm{BBC}$, а также как учебный полигон ${ }^{4}$ (рисунок 3). В частности, именно на испытательном полигоне в 1937 г. был построен первый пилотный объект по получению табуна, где уже к середине года наладили его маломасштабное производство 5 [10].

Вторым по величине и значимости объектом была Лаборатория противохимической защиты (Heeresgasschutzlaboratorium Spandau) в цитадели Шпандау (Берлин), созданная 9-м (химическим) отделом Управления вооружений сухопутных войск. Этот отдел осуществлял руководство и контроль над всеми НИР и испытаниями в области БОВ (боеприпасами занимался другой отдел Управления вооружений, а авиационные боеприпасы находились в ведении Люфтваффе). В цитадели Шпандау работали около 450 человек (1944). Помимо решения задач противохимической обороны, там велись работы по созданию новых БОВ, а также

\footnotetext{
В документах того времени иприт назывался Lost - сокращение от фамилий химика-технолога фирмы «Bayer» Фрица Вильгельма Ломмеля (нем. - Fritz Wilhelm Lommel, 1875-1968) и профессора Высшей технической школы в Карлсруэ (Technische Hochschule Karlsruhe) Георга Вильгельма Штайнкопфа (нем. - Georg Wilhelm Steinkopf, 1879-1949). Будучи приглашенными на работу в Институт физической химии и электрохимии Общества кайзера Вильгельма, они весной 1916 года предложили метод производства иприта в промышленных масштабах.

4 Полигон для испытаний БОВ - газовый полигон «Брелох» (Gazplatz Breloch) был организован севернее Мюнстера в 1916 г. Он функционировал почти всю войну. Однако в результате несчастного случая 24 октября 1919 г. - взрыва эшелона с химическими боеприпасами, который должен был отправляться на уничтожение (затопление в Балтийском море), почти вся инфраструктура по производству, снаряжению и хранению сотен тысяч химических боеприпасов оказалась уничтоженной (в общей сложности 42 здания), а весь район - надолго заражен. Поэтому в 1935-1938 гг. ее пришлось создавать фактически заново. Созданные в 1930-х гг. объекты, в том числе подземные снаряжательные цеха и хранилища боеприпасов, были ликвидированы в 1948 г. [11].

5 Основное производство табуна было развернуто в другом месте, с привлечением ресурсов гражданской промышленности. 7 сентября 1939 г. Совет директоров крупнейшего в стране объединения концернов химической и фармацевтической промышленности - I.G. Farbenindustrie совместно с представителями военного командования приняли решение о строительстве завода по промышленному получению табуна в Дихернфюрте-на-Одере (недалеко от Бреслау в Силезии) с проектной мощностью 1000 т/мес. Строительство началось в середине марта 1940 г. В мае 1942 г. завод был пущен в эксплуатацию.
} 
Таблица 1 - Организация научно-исследовательских работ по химическому оружию в военных структурах Германии периода Второй мировой войны [9]

\begin{tabular}{|c|c|c|c|}
\hline $\begin{array}{c}\text { Учебный и испытательный } \\
\text { полигон Вермахта } \\
\text { и лаборатории в } \\
\text { Раубқаммере (Мюнстер) }\end{array}$ & $\begin{array}{l}\text { Центр противохимической } \\
\text { защиты при 9-м отделе } \\
\text { Управления вооружений } \\
\text { сухопутных войск }\end{array}$ & \multicolumn{2}{|c|}{$\begin{array}{c}\text { Лаборатория противохимической защиты } \\
\text { (Heeresgasschutzlaboratorium), Шпандау }\end{array}$} \\
\hline & & Департамент & Научные исследования \\
\hline RI: Полигонные испытания & $\begin{array}{c}\text { 1: Организационно-плановый } \\
\text { отдел и дирекция }\end{array}$ & F1 & Химический синтез \\
\hline RII: Отдел химического анализа & 2: Отдел химической защиты & \multirow{7}{*}{$\mathrm{F} 2$} & Аналитический \\
\hline $\begin{array}{l}\text { RIII: Отдел дегазирующих } \\
\text { рецептур и средств } \\
\text { обнаружения боевых ОВ }\end{array}$ & $\begin{array}{l}\text { 3: Отдел дегазации и } \\
\text { химической защиты }\end{array}$ & & Лаборатория 1 - поляриметрия \\
\hline $\begin{array}{l}\text { RIV: Автопарк и ремонтные } \\
\text { мастерские }\end{array}$ & 4: Механический отдел & & Лаборатория 2 - зарин и табун \\
\hline $\begin{array}{c}\text { 5: Отдел вспомогательных } \\
\text { исследований }\end{array}$ & $\begin{array}{c}\text { 5: Отдел вспомогательных } \\
\text { исследований }\end{array}$ & & Лаборатория 3 - испытательная \\
\hline 6: Отдел дымовых средств & 6: Отдел дымовых средств & & Лаборатория 4 - иприт \\
\hline 7: Полигонные испытания & 7: Полигонные испытания & & Лаборатория 5 - испытания в камере \\
\hline $\begin{array}{c}\text { 8: Отдел производства боевых } \\
\text { ОВ (технологический отдел) }\end{array}$ & $\begin{array}{l}\text { 8: Производство боевых ОВ } \\
\text { (технологический отдел) }\end{array}$ & & Лаборатория 6 - исследования зарина \\
\hline 9: Финансовый отдел & 9: Финансовый отдел & \multirow{6}{*}{$\mathrm{F} 3$} & Микрохимический \\
\hline $\begin{array}{c}\text { 10: Отдел зажигательных } \\
\text { средств }\end{array}$ & $\begin{array}{c}\text { 10: Отдел зажигательных } \\
\text { средств }\end{array}$ & & Микрохимический и физико-химический \\
\hline 11: Патентный отдел & 11: Патентный отдел & & Физических измерений \\
\hline 12: Ветеринарный отдел & 12: Ветеринарный отдел & & Дымовых средств \\
\hline \multirow[t]{21}{*}{ 13: Разведывательный отдел } & 13: Разведывательный отдел & & Адсорбции и десорбции углей \\
\hline & & & Измерительный \\
\hline & & $\mathrm{F} 4$ & Измерительный \\
\hline & & F5 & Библиотека \\
\hline & & IIL & Средства индивидуальной защиты \\
\hline & & IIIL & Средства коллективной защиты \\
\hline & & IIllaL & Фильтры \\
\hline & & IIIbL & Определение боевых ОВ \\
\hline & & IIICL & Дегазация, химические боеприпасы \\
\hline & & IVL & Механический \\
\hline & & VWL & Физиологически активные вещества \\
\hline & & \multirow{5}{*}{ ViaL } & Дегазации почвы \\
\hline & & & Лаборатория 1: аэрозоль \\
\hline & & & Лаборатория 2: органической химии \\
\hline & & & Лаборатория 3: органической химии \\
\hline & & & Лаборатория 4: иприт \\
\hline & & VIbL & Дымогенераторы \\
\hline & & VicL & Разработка и испытание боеприпасов \\
\hline & & VidL & Метеорологический \\
\hline & & VIIL & $\begin{array}{c}\text { Токсикологический институт (испытания } \\
\text { на животных и на людях) }\end{array}$ \\
\hline & & VIIIL & Производство и хранение ОВ \\
\hline
\end{tabular}

по испытанию старых, главным образом кожно-нарывных. Испытывались они на лабораторных животных - кошках и мышах, реже - на собаках и обезьянах. На завершающих этапах испытаний сотрудники Лаборатории привлекали людей - добровольцев ${ }^{6}[12]$.

Кроме того, в Берлине был создан отдельный Центр противохимической защиты при

6 Испытания БОВ на людях - не чисто немецкое изобретение. В прошлом такая практика была распространена и в ряде других стран. В частности, в США к концу Второй мировой войны насчитывалось порядка 60 тыс. человек - военнослужащих, на которых испытывали БОВ, в частности, иприт и люизит [13, 14]. Об ис- 


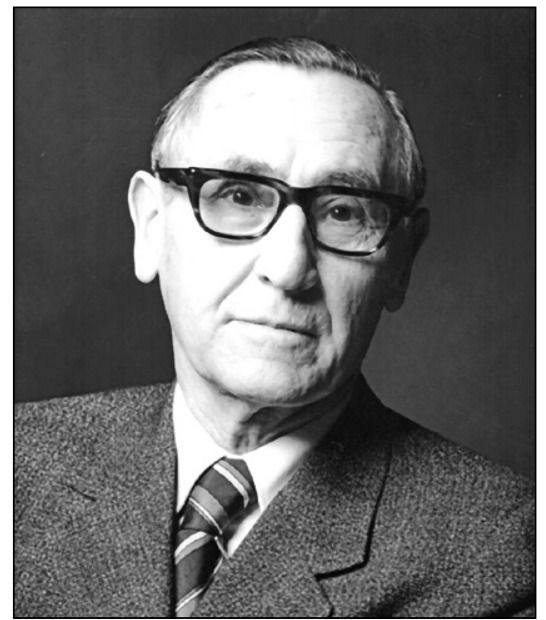

Рисунок 4 - Вольфганг Bupm (URL: https://de.wikipedia.org/ wiki/Datei:Foto_Wolfgang_Wirth_. jpg; дата обращения: 13.06.2021)

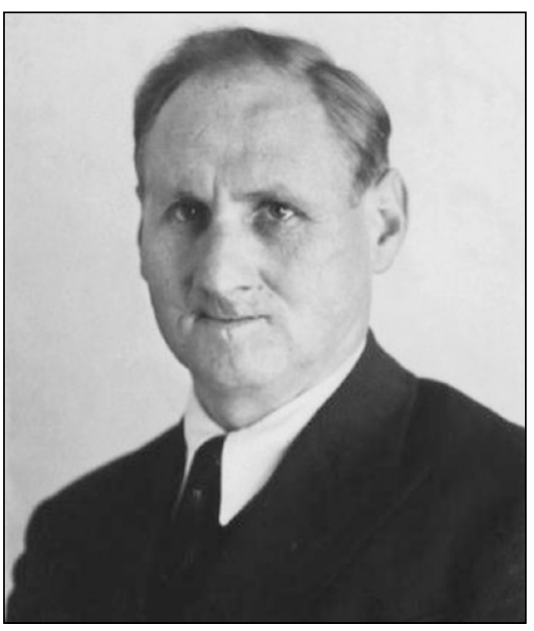

Рисунок 5 - Август Xирт (нем. - August Hirt, 1898-1945, покончил жизнь самоубийством) [19]

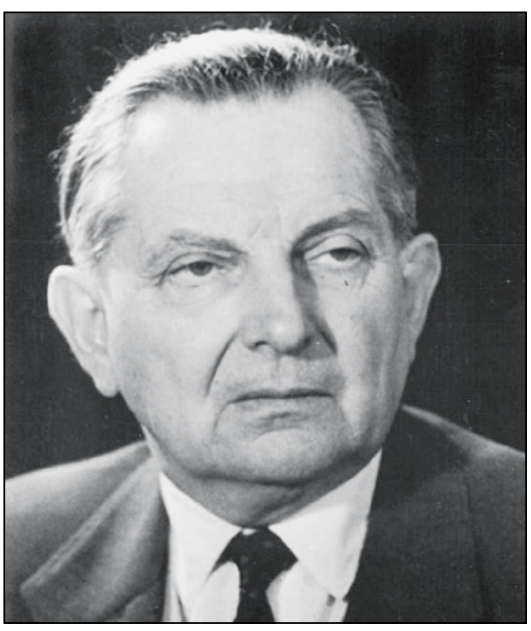

Рисунок 6 - Петер Адольф ТисceH. (URL: https://en.wikipedia.org/ wiki/Peter_Adolf_Thiessen\#/media/ File:Bundesarchiv Bild 183-832850019,_Peter_Adolf_Thiessen.jpg; дата обращения: 13.06.2021) 9-м отделе Управления вооружений сухопутных войск. Там работали 143 человека, максимум - 200 человек (1944).

Организация научно-исследовательских работ по химическому оружию в военных структурах Германии периода Второй мировой войны представлена в таблице 1.

В октябре 1934 г. в Берлине открылась Военно-медицинская академия (Militärärztliche Akademie). В интересах военно-химического дела в академии работал Институт фармакологии и военной токсикологии (Institut für Pharmakologie und Wehrtoxikologie) под руководством Вольфганга Вирта (рисунок 4)7.

Соответствующие кафедры или научно-исследовательские организации и группы усилиями Военно-медицинской академии и 9-го отдела Управления вооружений были созданы в университетах Марбурга, Мюнстера, Гессена и Вюрцбурга (Фармакологический институт при Вюрцбургском университете), а также при Медицинской академии в Данциге.

С начала 1940-х гг. к работам по химическому оружию подключилась СС. Изучением воздействия БОВ на человеческий организм занимался отдел медицинских программ Института военно-научных прикладных исследований (Institut für Wehrwissenschaftliche Zweckforschung der Waffen-SS). Этот институт был создан в июле 1942 г. организацией «Немецкое общество по изучению древней германской истории и наследия предков» (Forschungsgemeinschaft Deutsches Ahnenerbe), которая в 1937 г. вошла в состав CC (SS-Ahnenerbe) и была передана в Личный штаб рейхсфюрера СС. Отделом медицинских программ руководил антрополог, гауптштурмфюрер СС профессор Август Хирт [16, 17], с ноября 1941 по ноябрь 1944 г. возглавлявший также Анатомический институт

пытаниях на людях фосфорорганических ОВ в США и Великобритании по материалам британских архивных документов см. [15].

Вольфганг Вирт (нем. - Wolfgang Wirth, 1898-1996) - немецкий врач-токсиколог. Изучал химию в университетах Мюнхена и Вюрцбурга, а также медицину - в Берлине. Работал ассистентом Вернера Хаазе (нем. Karl Ludwig Werner Haase, 1903-1980) в лаборатории физиологической зоологии в Имперском биологическом институте сельского и лесного хозяйства (Biologische Bundesanstalt für Land- und Forstwirtschaft) в БерлинДалеме. В период Веймарской республики участвовал в работах по БОВ. В апреле 1936 - январе 1938 г. работал в 9-м отделе Управления вооружений сухопутных войск (Heereswaffenamt Wa Prüf 9), в феврале 1938 г. перешел в Военно-медицинскую академию, где возглавил Институт фармакологии и военной токсикологии. Считался крупнейшим в стране специалистом по боевым ОВ. В частности, под его руководством проводились первые испытания на людях табуна - речь шла об изучении воздействия на организм человека низких доз. В испытаниях участвовали добровольцы - военнослужащие, которым за участие в экспериментах платили. Табун В. Вирт испытывал также на себе. С июня 1941 г. - врио, с августа 1942 по август 1943 г. - начальник специальной учебно-научной группы Военно-медицинской академии. В июне 1945 г. был арестован, в декабре 1946 - августе 1947 г. допрашивался по «медицинскому делу». С 1948 г. работал в фармакологическом отделе Farbenfabriken Bayer A.G. в Вуппертале. Возглавлял отдел с 1954 г. и вплоть до своей отставки в 1963 г. 
Таблица 2 - Исследования, связанные с военно-химическим делом, в гражданских институтах Общества кайзера Вильгельма в период начионал-сочиализма [20, 21]

\begin{tabular}{|c|c|c|c|}
\hline Организация & Директор & Период & Характер исследований \\
\hline $\begin{array}{c}\text { Институт рабочей психологии } \\
\text { (нем. - KWI für Arbeitsphysiologie) } \\
\text { (филиал в Мюнстере) }\end{array}$ & $\begin{array}{c}\text { Эдгар Атцлер } \\
\text { (нем. - } \\
\text { Edgar Atzler, 1887-1938) }\end{array}$ & 1932-1934 & $\begin{array}{c}\text { - исследование пределов выносливости } \\
\text { военнослужащих при длительном ношении } \\
\text { противогазов GM } 24 \text { GM } 30 \\
\text { - эргономические недостатки конструкции } \\
\text { противогазов } \\
\text { - физиологические проблемы, связанные с длительным } \\
\text { ношением противогазов }\end{array}$ \\
\hline $\begin{array}{c}\text { Отдел генетики Института } \\
\text { изучения мозга } \\
\text { (нем. - KWI für Hirnforschung, } \\
\text { KWIHF) } \\
\text { (Берлин-Бух) }\end{array}$ & $\begin{array}{c}\text { Тимофеев- } \\
\text { Pесовский Н.B.' } \\
\text { (нем. - } \\
\text { Nikolai Timoféeff- } \\
\text { Ressovsky, 1900-1981) }\end{array}$ & 1939-1943 & $\begin{array}{c}\text { - проверка противогазовых фильтров (на } \\
\text { проницаемость) радиоактивными изотопами с } \\
\text { помощью генератора нейтронов «Philips» } \\
\text { - физиологические проблемы, связанные с длительным } \\
\text { ношением противогазов }\end{array}$ \\
\hline $\begin{array}{c}\text { Институт химии } \\
\text { (нем. - KWI für Chemie) } \\
\text { (Берлин-Далем) }\end{array}$ & $\begin{array}{c}\text { Отто Ган } \\
\text { (нем. - Otto Наhn, 1879- } \\
\text { 1968), Нобелевский } \\
\text { лауреат (1944) }\end{array}$ & 1940-1944 & $\begin{array}{c}\text { - исследование противогазовых фильтров методом } \\
\text { облучения радиоактивными изотопами }\end{array}$ \\
\hline $\begin{array}{c}\text { Институт изучения кожи } \\
\text { (нем. - KWI für Lederforschung) } \\
\text { (Дрезден) }\end{array}$ & $\begin{array}{c}\text { Вольфганг Грассман } \\
\text { (нем. - } \\
\text { Wolfgang Grassmann, } \\
\text { 1898-1978) }\end{array}$ & 1943-1944 & $\begin{array}{c}\text { - изучение воздействия противоипритных пропиток на } \\
\text { разные сорта кожи, используемые для изготовления } \\
\text { обмундирования и средств индивидуальной защиты } \\
\text { - средства дегазации, предназначенные для изделий из } \\
\text { кожи }\end{array}$ \\
\hline $\begin{array}{l}\text { Институт изучения течений } \\
\text { жидкости и газа } \\
\text { (нем. - KWI für } \\
\text { Strömungsforschung, KWIFD) } \\
\text { (Геттинген) }\end{array}$ & $\begin{array}{l}\text { Людвиг Прандтль } \\
\text { (нем. - } \\
\text { Ludwig Prandtl, 1875- } \\
\text { 1953) }\end{array}$ & $\begin{array}{c}\text { Январь - } \\
\text { сентябрь } \\
1943 \text { г. }\end{array}$ & $\begin{array}{c}\text { - изучение распространения и поведения паров ОВ на } \\
\text { море }\end{array}$ \\
\hline $\begin{array}{l}\text { Институт физической химии и } \\
\text { электрохимии (Берлин-Далем) }\end{array}$ & $\begin{array}{c}\text { Герхарт Яндер } \\
\text { (нем. - Gerhart Jander, } \\
\text { 1892-1961) } \\
\text { (временный директор } \\
\text { 1933-1934) } \\
\text { Петер Адольф Tиссен } \\
\text { (нем. - Peter Adolf } \\
\text { Thiessen, 1899-1990) } \\
\text { (1934-1945) }\end{array}$ & 1933-1945 & $\begin{array}{c}\text { - аэрозоли (дымы, туманы) } \\
\text { - фильтры для противогазов } \\
\text { - детекторы } \\
\text { - поиск новых ОВ и зажигательных средств (трифторид } \\
\text { хлора, N-Stoff) } \\
\text { - физиологическое действие OB }\end{array}$ \\
\hline $\begin{array}{c}\text { Институт химии при Институте } \\
\text { медицинских исследований } \\
\text { (нем. - Institut für Chemie des } \\
\text { KWI für medizinische Forschung, } \\
\text { KWIMR) } \\
\text { (Гейдельберг) }\end{array}$ & $\begin{array}{c}\text { Рихард Кун } \\
\text { (нем. - } \\
\text { Richard Kuhn, 1900- } \\
\text { 1967), } \\
\text { Нобелевский лауреат } \\
\text { (1939) }\end{array}$ & 1941-1945 & $\begin{array}{c}\text { - ОВ нервно-паралитического действия и антидоты } \\
\text { (а) синтез } \\
\text { (b) физиологическое действие (опыты на животных и } \\
\text { тканях мозга человека) } \\
\text { - препараты для лечения ожогов кожных покровов } \\
\text { ипритом (Lost) }\end{array}$ \\
\hline \multicolumn{4}{|c|}{$\begin{array}{l}\text { ' Советский ученый-биолог и генетик Николай Владимирович Тимофеев-Ресовский в } 1925 \text { г. официально переехал на работу } \\
\text { в Германию по приглашению Общества кайзера Вильгельма и с согласия советских властей. В конце 1930-х годов отказался } \\
\text { возвращаться в СССР, опасаясь ареста, и всю войну провел в Германии. Возвращен в } 1945 \text { г. }\end{array}$} \\
\hline
\end{tabular}

\section{(Anatomisches Institut) ${ }^{8}$ Страсбургского рейх- суниверситета (Reichsuniversität Straßburg) ${ }^{9}$}

8 В принципе, это была обычная «анатомичка», куда студентов-медиков водили изучать и сдавать анатомию в первом (зимнем) семестре. Только при А. Хирте трупы туда доставляли - из хосписов, тюрем, концентрационных лагерей - в частности, из Нацвайлера, а также из госпиталей для военнопленных. Их в Эльзасе было два - для польских, советских и итальянских военнопленных. В частности, в годы Второй мировой войны в Анатомический институт «для использования в образовательных целях» было направлено как минимум 230 тел советских военнопленных, скончавшихся в госпиталях от ранений и болезней, а также от ненадлежащего ухода. Отправляли в этот институт и погибших в результате опытов с боевыми ОВ - в частности, после опытов с ипритом, которые А. Хирт проводил в Нацвайлере с ноября 1942 г., погибли трое заключенных немцев Фридрих Трис (Friedrich Tries), Карл Кирн (Karl Kirn) и Вильгельм Мюссген (Wilhelm Müssgen). Их тела разобрали на органы и 11 января 1943 г. отправили в институт для последующего изготовления гистологических препаратов [18, 19].

9 Исследование воздействия БОВ на человеческий организм не было основной сферой деятельности А. Хирта, который после опытов с ипритом переключился на более «перспективное» по тем временам направление исследований - «расовую антропологию», которая должна была служить обоснованием нацистских 


\section{$[18,19]$ (рисунок 5).}

Кроме того, в работах по химическому оружию и средствам медицинской защиты было в той или иной степени задействовано семь из почти сорока существовавших в 1930-1940-е гг. научно-исследовательских институтов (НИИ) и организаций Общества кайзера Вильгельма крупнейшей научно-исследовательской структуры вне системы университетов [20]. Если в Первую мировую войну ИФХЭ был, по сути, головной структурой, то впоследствии исследования стали вестись децентрализованно ${ }^{10}$ [21].

Часть институтов Общества, как показано в таблице 2, работала на основе разовых программ и краткосрочных контрактов, поскольку по характеру своей основной деятельности они не были связаны ни с химией, ни с медициной. Они решали конкретно-практические задачи, которые перед ними ставили военные.

Для других организаций - ИФХЭ ${ }^{11}$ и Института химии при Институте медицинских исследований в Гейдельберге - химическое оружие и средства защиты от него были основными направлениями исследований. Там были сформированы специальные отделы. ИФХЭ до конца войны - возглавлял Петер Адольф Тиссен, после войны - активный участник программы по созданию первой советской атомной бомбы (рисунок 6).

В частности, в Институте химии при Институте медицинских исследований под руководством Рихарда Куна вели работы по изучению табуна, а затем зарина и зомана, а также по поиску антидотов к ним. Испытания физиологического действия фосфорорганических ОВ проводили на животных и тканях мозга человека (рисунок 7).

В сравнении с работами на чисто военных объектах, исследования в НИИ Общества

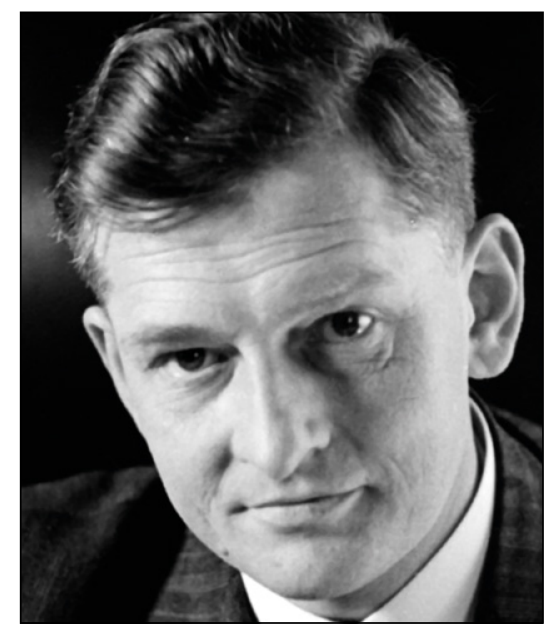

\section{Рисунок 7 - Рихард Кун \\ (URL: https://www.nobelprize.org/prizes/ chemistry/1938/kuhn/facts/; дата обращения: 13.06 .2021 )}

кайзера Вильгельма были достаточно скромными и проводились в гораздо меньших масштабах. Тем более, что начиная с 1935 г. роль главных центров военной химии постепенно перешла к лаборатории противохимической защиты в Шпандау и испытательному полигону в Мюнстере. В Шпандау перевели и часть сотрудников ИФХЭ.

Тем не менее, гражданские структуры все время работали в тесной связке с военными, а ученые, работавшие в одной и той же сфере, прекрасно знали друг друга и поддерживали тесные академические и личные контакты.

Кроме военных структур, НИИ и университетов, различные исследования велись в лабораториях при предприятиях и частных фирмах химической и фармацевтической промышленности - в частности, в концернах в составе I.G.

расовых теорий. Изначально он намеревался собрать коллекцию черепов представителей разных антропологических типов, но впоследствии переключился на «коллекционирование» именно евреев - выходцев из разных стран, в том числе из СССР. В августе 1947 г., на Нюрнбергском процессе над врачами (над медицинскими чиновниками Третьего рейха и врачами из концлагерей), обвиняемыми в медицинских преступлениях, сбор экспонатов для антропологической коллекции А. Хирта (то есть убийство военнопленных и заключенных специально для пополнения коллекции черепов) был признан военным преступлением и преступлением против человечности. Сам А. Хирт до суда не дожил - после освобождения Страсбурга союзными войсками бежал в Шварцвальд и застрелился, причем не из-за того, что испугался ответственности или его замучила совесть, а потому, что погибла «уникальная коллекция».

10 Это обстоятельство отчасти было связано с расширением круга научно-практических проблем, которые так или иначе приходилось решать, а также с усложнением задач в целом, что требовало привлечения специалистов из самых разных областей, а также применения междисциплинарных подходов. Отчасти такая децентрализованная система сложилась в годы Веймарской республики из-за необходимости обходить версальские ограничения. Рейхсвер предпочитал иметь дело с отдельными институтами, небольшими лабораториями и маленькими фирмами. Так проще было и замаскировать истинные цели той или иной работы, и обеспечить секретность.

11 Вскоре после прихода к власти НСДАП и принятия в апреле 1933 г. «Закона об ограничениях в профессиональной гражданской службе» в ИФХЭ начались кадровые перестановки. Ф. Габер, будучи евреем, в ноябре 1933 г. вынужден был покинуть пост директора института. Вместе с ним ушли еще 29 сотрудников. На руководящие посты пришли немцы и члены НСДАП, которые привели в ИФХЭ своих специалистов. 


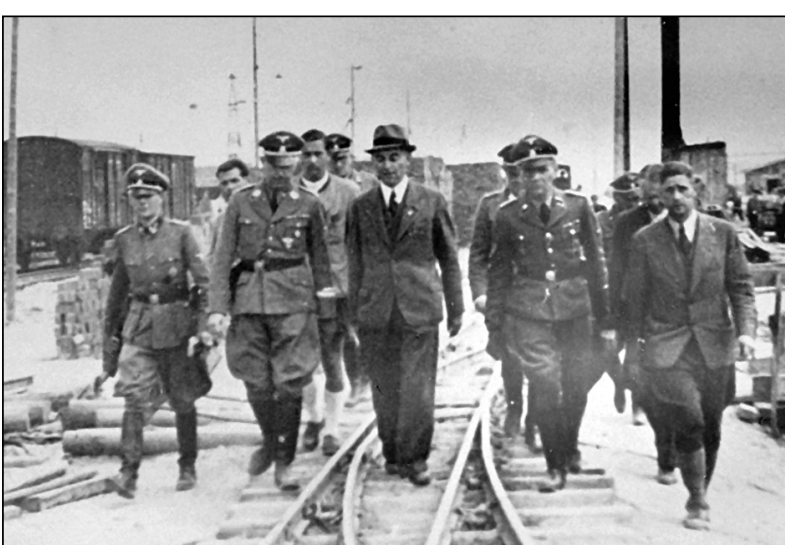

Рисунок 8 - Крупнейший в Германии конгломерат кончернов химической и фармачевтической промышленности IG Farben в годы Bmорой мировой войны размещал производство в концентрационных лагерях. Испытания отравляющих веществ и антидотов проводили на заключенных. На фотографии - рейхсфюрер СС Г. Гиммлер посещает строящийся завод IG Farben nо производству синтетического каучука. Аушвич-ІІІ Моновиц-Буна, 17-18 июля 1942 г. Слева направо - Р. Брандт, рейхсфюрер СС

Г. Гиммлер, инженер IG Farben и руководитель строительных работ объекта МоновицБуна Макс Фауст (нем. - Max Faust, 1891-1980) u комендант Аушвица Рудольф Хёсс (нем. - Rudolf

Franz Ferdinand Нӧß, 1900 - 16 апреля 1947 г., казнен за военные преступления) (URL: https:// collections.ushmm.org/search/catalog/pa1036470; дата обращения: 13.06.2021)

Farben (Interessen-Gemeinschaft Farbenindustrie $\mathrm{AG})^{12}[22]$ (рисунок 8).
Эти исследования по своим целям и задачам были сугубо гражданскими, не имевшими никакого отношения к боевым ОВ. Однако, согласно правительственному указу от 1935 г., обо всех инновациях, которые потенциально могли иметь военное значение, следовало сообщать в Военное министерство ${ }^{13}$.

Таким образом, широко проведенные исследования по БОВ, наличие научной и промышленной базы позволили Германии создать и произвести химическое оружие - БОВ в промышленных масштабах, а также средства его применения.

Так, в годы Второй мировой войны химическая промышленность Германии, переориентированная на военное производство, произвела порядка 977 тыс. 500 метрических тонн взрывчатых веществ (на 28 предприятиях), 974 тыс. метрических тонн порохов (на 43 предприятиях), а также 69 тыс. 500 метрических тонн боевых отравляющих веществ ${ }^{14}$ (на 10 предприятиях) и порядка 805 тыс. метрических тонн прекурсоров [23, 24].

Объемы производства БОВ на немецких предприятиях в годы Второй мировой войны показаны в таблице 3.

Основное количество БОВ составили сернистые и азотистые иприты, а также фосген-дифосген и арсины [23]. Одновременно были разработан новый класс БОВ - фосфорорганические.

В итоге, в годы Второй мировой войны Германия обладала полным арсеналом артиллерийских и авиационных боеприпасов [26]. На вооружении Вермахта стояли химические мины и снаряды 7,5-см, 10,5-см, 15-см и 21-см

\begin{abstract}
12 В годы войны I.G. Farben выполняла военные заказы и размещала производство в концлагерях, в частности, в Аушвице-Биркенау. После войны был даже организован специальный судебный процесс - Нюрнбергский процесс по делу I.G. Farben (официальное название - «Соединенные Штаты Америки против Карла Крауха и других», англ. - The United States of America vs. Carl Krauch, et al.) - шестой по счету процесс американского военного трибунала в Нюрнберге из 12 проведенных властями США в своей зоне оккупации Германии. Судебное разбирательство длилось с 14 августа 1947 г. по 30 июля 1948 г. 24 члена совета директоров и должностных лица I.G. Farben обвинялись в массовых убийствах, использовании принудительного труда и других преступлениях против человечности. 13 обвиняемых были осуждены на различные сроки тюремного заключения, 10 - оправданы и одному не был вынесен приговор по состоянию здоровья. Дополнительным решением суда предусматривалось разделение конгломерата I.G. Farben на BASF, Bayer и Hoechst.

13 Именно это и сделало руководство лаборатории корпорации I.G. Farbenindustrie в Леверкузене в 1937 г. Там проводили исследования фосфорорганических соединений на предмет их возможного использования в качестве сельскохозяйственных пестицидов. Однако после того, как в январе 1937 г. руководитель лаборатории Герхард Шрадер (нем. - Gerhard Schrader, 1903-1990) получил тяжелое поражение синтезированным им же новым соединением, а токсикологические исследования на животных, проведенные в лаборатории коммерческой гигиены I.G. Farbenindustrie в Эльберфельде, подтвердили его высокую токсичность для теплокровных - следовательно, и для людей, в I.G. Farbenindustrie поняли, что коммерческого интереса оно не представляет ввиду невозможности его безопасного использования, и отправили соответствующий рапорт в Управление сухопутных войск. Там, разумеется, заинтересовались, а сам Г. Шрадер вскоре перешел на работу в Шпандау. Соединение получило кодовое название «трилон» (табун).

${ }^{14}$ Строго говоря, точное количество ОВ и ХО, произведенных в Германии в годы Второй мировой войны, установлению уже, скорее всего, не подлежит. Во-первых, под конец войны немцы начали уничтожать не только само XО, но и всю документацию по нему. Во-вторых, уже после войны союзники в силу различных причин иногда жонглировали данными. Этим, в частности, объясняется периодически встречающаяся в разных источниках разница в цифрах объемов производства основных БОВ.
\end{abstract}


Таблица 3 - Объемы производства боевых отравляющих веществ на немецких предприятиях в годы Второй Мировой войны [24]

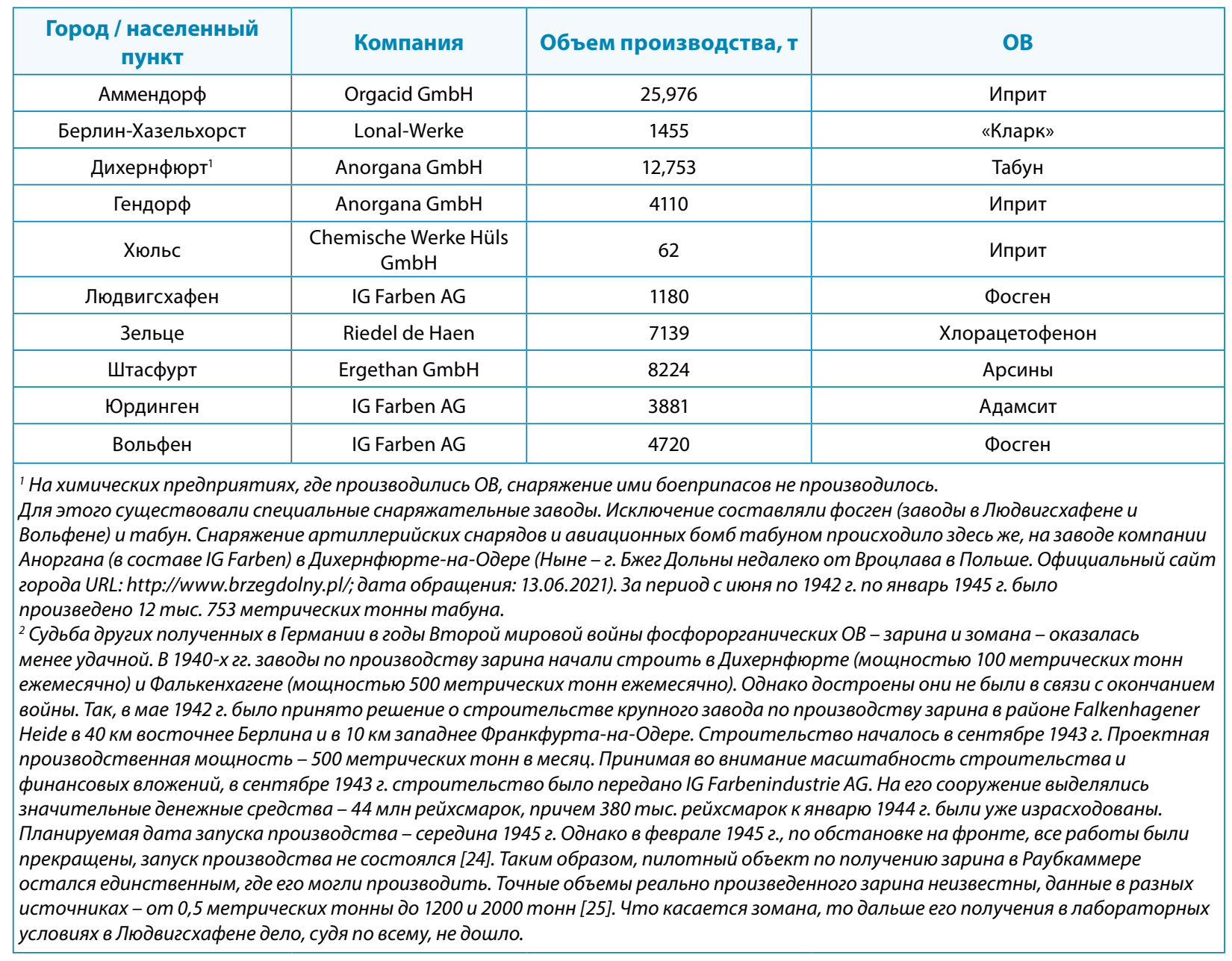

калибров, ракеты и минометные снаряды 8-см, 10-см и 15-см калибров, а также авиационные бомбы массой 50, 250 и 500 кг (в снаряженном состоянии) [27], в том числе в снаряжении табуном (рисунок 9).

Таким образом, Германия сумела не только восстановить, но и подтвердить научное и военно-промышленное превосходство над своими противниками в военно-химическом деле, а в определенном смысле и превзойти их [15]. Если бы немцы действительно масштабно применили на фронтах Второй мировой войны тяжелые 250-килограммовые авиационные бомбы с табуном, союзникам нечем было бы от них защититься и нечего им противопоставить ${ }^{15}$.
Испытания на людях в 1933-1945 г2. Испытания БОВ, изучение их физиологических и токсикологических свойств, а также средств и схем лечения поражений проводили сначала на мелких (мыши, крысы) и крупных (кролики, обезьяны) животных, а затем на людях. Для этих целей в Военно-медицинской академии и цитадели в Шпандау были сооружены газовые камеры. Участниками опытов первоначально были добровольцы сами ученые, а также военнослужащие и курсанты военно-учебных заведений, которые осознавали возможную угрозу жизни и здоровью ${ }^{16}$. Военнослужащим, кроме того, за участие в экспериментах платили от 5 до 100 рейхсмарок.

15 Военные доктрины всех ведущих европейских стран предусматривали неприменение химического ору-
жия первыми, но допускали его ответное применение - в полном соответствии с позициями этих стран при
ратификации Женевского протокола о запрещении применения на войне удушливых, ядовитых или других
подобных газов и бактериологических средств (1925). То же касалось и Германии.
${ }^{16}$ В той степени, разумеется, в какой об этой угрозе были осведомлены сами токсикологи, чтобы проинфор-
мировать о ней участников экспериментов. Это соображение было особенно актуально для табуна. Его про-
изводство в промышленных масштабах уже шло на заводе в Дихернфюрте, а ученые еще только пытались
его исследовать. В частности, в результате опытов в Шпандау и Эльберфельде были определены летальные 


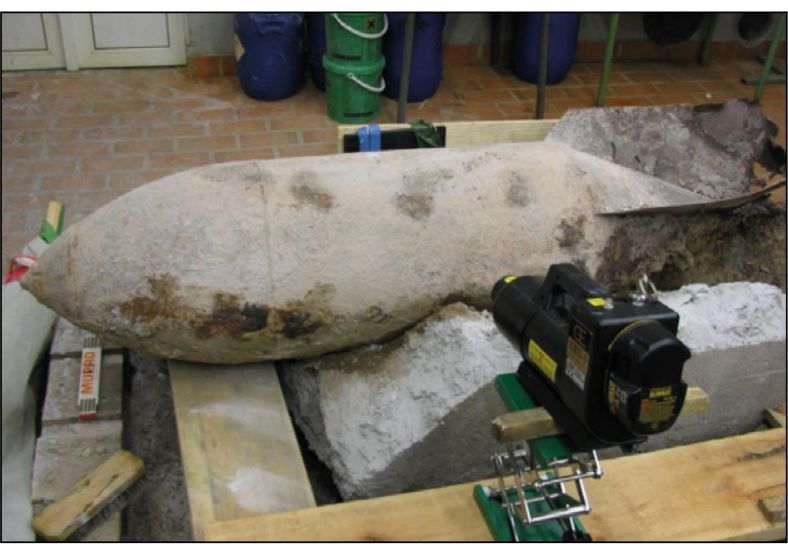

Рисунок 9 - Тяжелая авиабомба 250 кг времен Второй мировой войны на объекте УХО GEKA, Мюнстер [28]

Этическая сторона вопроса регулировалась выпущенным еще 28 февраля 1931 г. рейхсминистерством внутренних дел «Положением о новой терапии и опытах на людях», согласно которому «новая терапия может осущеесвляться только после того, как объект или его законный представитель недвусмысленно согласился на проиедуру в свете соответствующей информации, которая ему была заранее предоставлена» [29]. Поводом для появления этого документа стала гибель 77 новорожденных после прививки вакциной от туберкулеза («трагедия в Любеке») ${ }^{17}$.

Положение признавало невозможность полностью обойтись без испытаний вновь создаваемых лекарственных средств или схем лечения тех или иных заболеваний на людях. Вместе с тем оно налагало на авторов экспериментов, проводимых с чисто исследовательскими целя- ми, а не в целях профилактики и/или лечения, ответственность за жизнь и здоровье тех, кто этим экспериментам подвергался. При этом все время предлагалось учитывать как возможную пользу от эксперимента, так и возможный вред конкретным людям. В документе было указано, что опыты на людях могут быть поставлены только на завершающем этапе, после лабораторных испытаний и опытов на животных. Если опытами на животных можно было обойтись, опыты на людях запрещались. Для их проведения необходимо было заручиться недвусмысленным информированным согласием участников или их законных представителей ${ }^{18}$. Обо всех негативных последствиях следовало предупреждать заранее. Опыты с чисто исследовательскими целями на детях и на несовершеннолетних запрещались безусловно. Также признавались несовместимыми с этическими принципами и, соответственно, запрещались испытания на умирающих [30].

Это положение было действующим все годы Второй мировой войны. Формально его никто не отменял.

Однако, начиная с 1933 г. во всех научно-исследовательских структурах как военных, так и гражданских, начались проблемы с лабораторными животными. В 1933 г. в Германии был принят специальный зоозащитный закон, серьезно ограничивший возможность проведения опытов на животных. Затем весной 1939 г. военно-медицинская служба (санитарная инспекция) Вермахта запретила использовать животных для опытов везде, кроме научных лабораторий, которые постоянно подвергались проверкам. В результате к началу Второй мировой войны работы у уче-

токсодозы, но - для животных. Для людей их установить еще только предстояло. Известно, что опыты на людях (с низкими дозами) ставил В. Вирт. Кроме того, аналогичные опыты ставились в лаборатории I.G. Farbenindustrie в Эльберфельде, причем с более высокими дозами. Полученные ими результаты были в любом случае оценочными - доведение испытуемых до летального исхода не могло быть условием опытов, когда они проводились на добровольцах, а сведений об опытах с табуном в концлагерях, где с «биоматериалом» можно было не церемониться, нет, причем скорее всего, их и не было.

${ }^{17}$ В 1930 г. в Любеке (Шлезвиг-Гольштейн) началась масштабная программа вакцинации населения против туберкулеза. В программе использовалась французская вакцина BCG (Bacille Calmette-Guérin), изготовленная из штамма ослабленной живой коровьей туберкулезной палочки. Она была разработана в 1905-1921 гг. французскими бактериологами Альбером Кальметом (фр. - Albert Calmette, 1863-1933) и Камилем Гереном (фр. - Camille Guérin, 1872-1961). В 1921 г. она была одобрена парижским Институтом Пастера. Там же ее протестировали на 120 новорожденных младенцах, находившихся в группе риска по туберкулезу - их родители уже были больны. Эксперимент был признан успешным. Однако он был не совсем репрезентативным, поскольку только в 24 семьях, откуда брали детей на вакцинацию, имелись больные с открытой формой туберкулеза. В Любеке врачи сделали прививки вакциной BCG 256 10-дневным новорожденным и случилась трагедия - все привитые заболели, а 77 детей погибли. Разразился скандал. Последовал суд, на котором были обвинены трое врачей и медсестра. Расследование показало, что в трагедии виновата немецкая лаборатория, где вакцина была изготовлена - она оказалась зараженной вирулентным штаммом, который хранился в том же инкубаторе. Директор лаборатории был осужден за халатность. Однако после «трагедии в Любеке» вакцина BCG была в Германии запрещена вплоть до конца Второй мировой войны.

${ }^{18}$ Применение «новой терапии» без согласия пациента разрешалось только в том случае, когда речь шла об использовании недостаточно испытанных лекарственных средств в экстренных, жизнеугрожающих ситуациях, а также если заблаговременное согласие нельзя было получить в силу особых обстоятельств. 
ных стало больше, а лабораторных животных - меньше.

Это обстоятельство, вкупе с закрытостью всех исследований по БОВ, а также определенными идеологическими настроениями среди самих ученых способствовало переносу испытаний в концентрационные лагеря - на «биологический материал», на который соображения гуманизма в данную минуту не распространялись. Или они были направлены на другие объекты.

Испытания на людях в кониентрационных лагерях. Уже после Второй мировой войны в руки британских спецслужб попали сведения о том, что сравнительные исследования ингибирующего воздействия фосфорорганических ОВ, в частности, зарина, на холинэстеразу человека проводили в Институте медицинских исследований Общества кайзера Вильгельма. Для исследований использовались, наряду с животными (крысами, кроликами, собаками, кошками и лошадьми), ткани человеческих органов, в частности, печени. Сам Р. Кун впоследствии утверждал, что в институте имели дело исключительно с трупами утопленников, у которых органы изымались в течение 24 ч после смерти. Однако в руки британских спецслужб попал документ, датирующийся 8 апреля 1943 г., содержащий пометку секретаря Общества кайзера Вильгельма Эрнста Телшова (нем. - Ernst Telschow, 1889-1988), сделанную после посещения Гейдельберга. В ней говорилось: «Проф. Кун сейчас ставит очень интересные опыты, для которых ему нужны ткани мозга молодых и здоровых людей. Я пообещцал ему, что буду ходатайствовать по этому вопросу перед соответствуюшими властями». 22 апреля 1943 г. Э. Телшов направил Р. Куну личное письмо, в котором сообщил, что обращался по его вопросу к ряду высокопоставленных чиновни- ков в Министерстве юстиции с ходатайством о предоставлении запрошенных органов. За транспортом было предложено обращаться к военным. Никаких других документальных данных о продолжении этого сюжета не сохранилось. Можно лишь предполагать, откуда можно было в 1940-х годах взять органы «молодых, здоровых людей» в рамках пенитенциарной системы - тюрьмы и лагеря. Речь могла идти: о жертвах программ эвтаназии (этим источником иногда пользовались в других институтах Общества); о заключенных концентрационных лагерей (пока они были еще относительно здоровы); о лицах, приговоренных к смертной казни - после или вместо нее ${ }^{19}$. Точных сведений о характере предполагаемых «очень интересных опытов» тоже не сохранилось, однако, скорее всего, речь шла об исследовании нейротоксичности фосфорорганических ОВ и об изучении воздействия ФОВ на ЦНС [10].

В силу целого ряда причин, данных ${ }^{20}$ об испытаниях БОВ в концлагерях сохранилось очень мало. В частности, после войны появилась информация о якобы имевших место испытаниях табуна на заключенных лагеря Гросс-Розен возле Дихернфюрта-на-Одере. В Дихернфюрте находился завод компании "Anorgana GmbH», где с 1942 г. запустили производство табуна и снаряжение им боеприпасов. Известно, что заключенные Гросс-Розена работали там наравне с немецкими рабочими - вольнонаемными. Известно, что средства защиты были недостаточными. Известно, что на заводе периодически происходили несчастные случаи, в том числе с летальным исходом. После войны свидетели подтвердили случаи лечения пострадавших на заводе атропином ${ }^{21}$. Но были ли эти поражения вызваны несчастными случаями на опасном производ-

\footnotetext{
${ }^{19}$ Из документов по «медицинскому делу» известно, что в ряде случаев для медицинских опытов над людьми использовали лиц, приговоренных к смертной казни по тем или иным политическим или уголовным обвинениям, причем участие в опытах рассматривалось как своего рода замена. В частности, в письме А. Хирту от 3 января 1942 г. В. Зиверс, затребовав от А. Хирта более подробные сведения о характере его деятельности для последующего доклада Г. Гиммлеру, сообщил: «Что касается ваших антропологических исследований, то я уже сейчас могу проинформировать Вас, что Рейхсфюрер СС даст Вам возможность проводить любые эксперименты, которые могут помочь Вам в Ваших исследованиях, на заключенных и настоящзх преступниках, которые никогда и ни при каких условиях освобождены не будут, а также на лицах, приговоренных к смертной казни» (URL: https://nuremberg.law.harvard.edu/documents/204-letter-to-dr-hirth?q=Hirth\#p.1; дата обращения: 13.06.2021).

20 Первая причина лежит на поверхности - все работы изначально велись в режиме секретности. В конце войны документы и другие доказательства массово уничтожались самими немцами. Вторая, менее очевидная - то, что осталось, было не уничтожено, а наоборот, тщательно сохранено и засекречено победителями. В частности, материалы по «медицинскому делу» опубликованы американской стороной с заметными лакунами. Причины тоже очевидны - врачей осудили, а вот конкретные результаты их опытов победителям были и самим интересны.

21 После войны бывший заключенный Тадеуш Кароль (Tadeusz Karol), работавший на этом заводе, показал, что однажды ему приказали без средств защиты войти в снаряжательный цех, чтобы проверить наличие утечек OB и заражение цеха табуном. Он получил поражение и потерял сознание. Лечили его атропином. Очевидно, в данном случае шла речь о преднамеренном использовании человека в качестве «живого газосиг-
} 


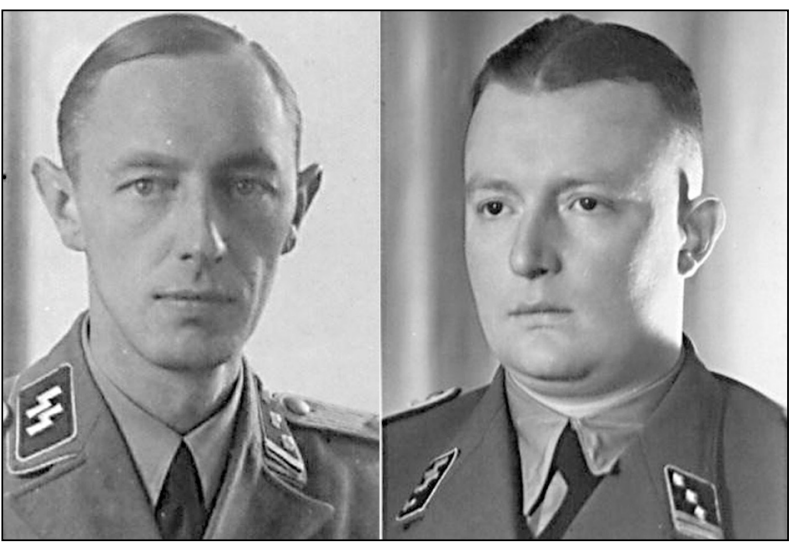

Рисунок 10 - Слева Вальтер Зоннтаг (нем. - Walter Sonntag, 1907-1948, казнен за военные преступления), справа Уго Хайни Шмик [31]

стве или преднамеренными опытами, проводившимися на регулярной основе, до сих пор точно не известно и не доказано [31].

Концентрационный лагерь Заксенхаузен. Непосредственным поводом для интенсификации работ по БОВ и средствам лечения поражений стали следующие события. 8 сентября 1939 г., через неделю после начала вторжения Вермахта в Польшу, польские войска во время отступления при попытке взорвать мост в городе Ясло (ныне - в Подкарпатском воеводстве) по ошибке использовали не обычные мины, а ипритные. В результате поражения получили 14 солдат Вермахта, двое погибли. После этого А. Гитлер издал специальное распоряжение о начале подготовки к «газовой войне».

После этого Военно-медицинская академия при участии СС организовала несколько серий испытаний протоколов и средств лечения поражений кожных покровов сернистым ипритом.

По крайней мере две серии таких испытаний были проведены в концлагере Заксенхаузен ${ }^{22}$ (Ораниенбург, земля Бранденбург) в октя- бре-декабре 1939 г. на 31 заключенном, которым наносили на кожу иприт и ждали развития поражений. Затем пораженные участки обрабатывали разными препаратами из числа общедоступных антибактериальных средств и средств лечения ожогов, в частности, фресканом (кодовое название F 1000 и F 1001 - порошок производства компании Dr. Fresenius) $)^{23}$ и тиосептом ${ }^{24}$.

Опыты ставили заведующий хирургическим отделением Заксенхаузена Уго Хайнц Шмик (нем. - Hugo-Heinz Schmick, 1909-1982) (член НСДАП с августа 1933 г., СС - с мая 1933 г.) и лагерный врач Вальтер Зоннтаг, тоже из СС (рисунок 10).

Первая серия опытов состоялась 13 октября 1939 г. В ней участвовали 23 заключенных. Им наносили на кожу рук иприт, а потом обрабатывали волдыри антибактериальными средствами. Ход эксперимента тщательно документировался и снимался на кинопленку. Во второй серии, состоявшейся в декабре 1939 г., участвовали 8 заключенных. Им нанесли иприт на кожу обеих рук, а через три дня, после того, как пораженные участки покрылись волдырями с экссудатом (в некоторых случаях их размер достигал размеров $7 \times 18$ см), волдыри вскрыли и в открытые раны занесли бактериальную инфекцию - бактерии стрептококков, стафилококков и пневмококков. Лечили антисептиками. У тех, кому занесли инфекцию, развился сепсис. Схемы лечения антисептиками не работали. В январе 1940 г. рейхсфюреру СС Генриху Гиммлеру (нем. - Heinrich Himmler, 1900-1945) было доложено о неудаче экспериментов.

В то же самое время, когда СС проводила опыты на заключенных Заксенхаузена, тот же самый фрескан испытывали на людях в Военно-медицинской академии. Авторами экспериментов были директор Института фармакологии при Университете Мюнстера Людвиг Лендле (нем. - Ludwig Lendle, 1899-1969) и директор

нализатора», причем если учесть, что речь шла о заключенном концлагеря, можно предположить, что о добровольности в данном случае речь не шла и выбора у него особо не было. Однако такой случай - едва ли не единственный, о котором стало известно [31].

22 Расположен неподалеку от Берлина. Официально открыт в сентябре 1936 г. В апреле 1938 г. была создана Немецкая компания земляных и каменоломных работ (DEST - Deutsche Erd- und Steinwerke GmbH), первоначальной целью которой было обеспечение планов А. Гитлера и Альберта Шпеера (нем. - Albert Speer, 19051981, личный архитектор Гитлера, в 1942-1945 гг. рейхсминистр вооружения и военного производства) по перестройке Берлина и других немецких городов. Именно для снабжения предприятия рабочей силой вблизи каменных карьеров были созданы Маутхаузен и Флоссенбург, Нойенгамме - филиал Заксенхаузена, а рядом с Бухенвальдом и Заксенхаузеном появились кирпичные заводы. Со 2 августа 1938 г. в Заксенхаузене располагалась главная руководящая инстанция - Инспекция концентрационных лагерей [32].

${ }^{23}$ Фрескан - антибактериальный препарат в виде порошка, использовавшийся в противоожоговой терапии, производства компании Dr.Fresenius (Бад Хомбург) (URL: https://www.fresenius.com/index, дата обращения: 13.06.2021). В настоящее время компания является одним из крупнейших в мире производителей медицинского оборудования, в первую очередь для гемодиализа почек. Работает, в том числе, в России - URL: https:// www.freseniusmedicalcare.ru/ru/glavnaja-stranica/ (дата обращения: 13.06.2021).

24 Тиосепт - сульфобитуминат аммония (ихтиол). CAS 8029-68-3.

URL: https://www.chembk.com/en/chem/thiosept (дата обращения: 13.06.2021). Мазь бактериостатического и противовоспалительного действия. 
Института фармакологии и военной токсикологии Военно-медицинской академии В. Вирт. В опытах участвовали 23 военнослужащих, которым наносили на кожу рук иприт. Результат оказался аналогичным - нулевым. Ожоги у подопытных зажили спустя 6-8 недель.

Впоследствии было доказано, что военные врачи Л. Лендле и В. Вирт не только были осведомлены об опытах своих «коллег» из СС в Заксенхаузене, но и ориентировались на их результаты. Кроме того, В. Вирт специально ездил в Заксенхаузен знакомиться с результатами опытов. Ему показали «шесть или десять человек с ожогами на руке, величиной приблизительно с ладонь». Там же ему продемонстрировали отснятый на кинопленку материал, отснятый во время этих испытаний. Разницы между теми, кого лечили антисептиками, и теми, кого не лечили вообще, он на этих кадрах не увидел.

Концентрационный тагерв Нацвайлер 25. Опыты с ипритом Августа Хирта. В период с 1942 по 1944 г. серию опытов с ипритом

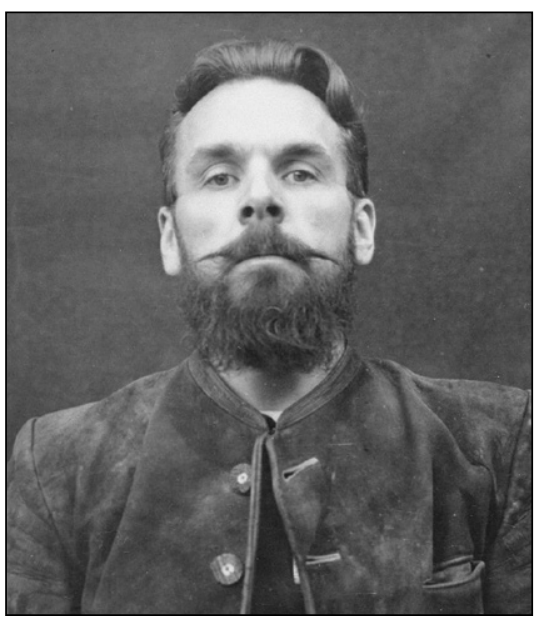

Рисунок 11 - Вольфрам Зиверс (нем. - Wolfram Sievers, 1905-1948, казнен за военные преступления и преступления против человечности) (URL: https://www.ushmm.org/information/ exhibitions/online-exhibitions/special-focus/ doctors-trial/indictment/defendants; дата обращения: 13.06.2021)

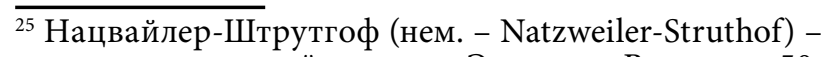

концентрационный лагерь в Эльзасе в Вогезах в 50 км юго-западнее Страсбурга. Представлял собой целую систему из порядка 50 лагерей, подчиненных главному, расположенных на границе между Францией и Германией на территории Эльзаса и Лотарингии (Франция) и Бадена и Вюртемберга (Германия). Система лагерей стала создаваться здесь вскоре после оккупации немецкими войсками Страсбурга и аннексии Эльзаса весной 1940 г. Первоначально соорудили небольшой лагерь по типу тюрьмы, рассчитанный на 150 человек и предназначенный для политических заключенных, бойцов Сопротивления и лиц, попавших под так называемый «защитный арест». Он располагался рядом с городком Шмирек в 50 км. от Страсбурга и получил название Шмирек-Форбрюк (нем. - Schirmeck-Vorbrück, фp. - Schirmeck-La Broque). Первыми заключенными в нем стали эльзасские антифашисты. Лагерь функционировал в течение всей войны как трудовой. В нем, помимо политических заключенных и членов их семей, содержались эльзасцы, пытавшиеся перейти новую границу и уйти во Францию, члены секты «Свидетели Иеговы», а также лица, обвинявшиеся в спекуляции и в уголовных преступлениях. За охрану и порядок отвечала немецкая «Полиция порядка» (нем. - Ordnungspolizei, Orpo). Через несколько месяцев после образования Шмирека неподалеку от него, возле деревни Нацвайлер, СС начала строительство другого лагеря. Приказ о его образовании издал лично рейхсфюрер СС Г. Гиммлер. Место было выбрано не случайно - неподалеку находились гранитные каменоломни, которые были экспроприированы принадлежавшей SS компанией SS-Deutsche Erd und Steinwerke GmbH (DEST) по производству строительных материалов для государственных строительных проектов, которая начала их разработку (помимо Нацвайлера, DEST имела свои производства в Заксенхаузене, Бухенвальде, Флоссенбурге, Маутхаузене, Гросс Розене и Нойенгамме). Рядом находился зимний горнолыжный курорт Штрутгоф. Официальная дата образования лагеря - 1 мая 1941 г., но работы по его строительству начались в апреле 1941 г. Для сооружения бараков использовали заключенных из Шмирека. Первая партия заключенных - 150 человек - прибыла 21 мая 1941 г. из Заксенхаузена. Заключенные, которых стали привозить партиями из других лагерей, занимались постройкой лагеря, но главным образом работали в каменоломнях. Вплоть до весны 1942 г. концлагерь Нацвайлер оставался сравнительно небольшим, в нем содержалось не более 200 человек. Однако к концу года в нем было зарегистрировано уже около 2000 человек. К 1943 г. лагерь состоял из 17 блоков в границах лагеря, и 12 - за его пределами. В него стали привозить заключенных крупными партиями из Германии, Норвегии и других европейских стран. В июне 1943 г. в Нацвайлере было зарегистрировано уже 4430 заключенных. В 1944 г. их численность колебалась в пределах 6000-7000 человек. Всего же в лагере и в бараках за его пределами было зарегистрировано 52000 человек. В лагере был достаточно высокий уровень смертности. По оценочным данным, от истощения и болезней погибли около 20000 человек. Сюда свозили заключенных со всей Европы. Женщин в лагере не было. Большинство заключенных - политические. Главному лагерю подчинялись свыше 40 вспомогательных лагерей. Их число постоянно росло, причем некоторые даже не успели достроить к осени 1944 г., когда главный лагерь был эвакуирован. Лагерь был трудовым, заключенные работали, главным образом, в гранитных каменоломнях и на дорожно-строительных работах. Осенью 1943 г. там основала производство и ремонтные мастерские авиастроительная компания «Junkers», для нее были построены два здания и 13 бараков. Заключенные, а также вольнонаемные рабочие, ремонтировали авиационные двигатели. Собственного крематория в лагере первоначально не было, тела умерших или погибших сжигали в передвижном крематории, но в октябре 1943 г. для этих целей построили собственный. Кроме того, в Нацвайлере была сооружена газовая камера - специально для медицинских экспе- 


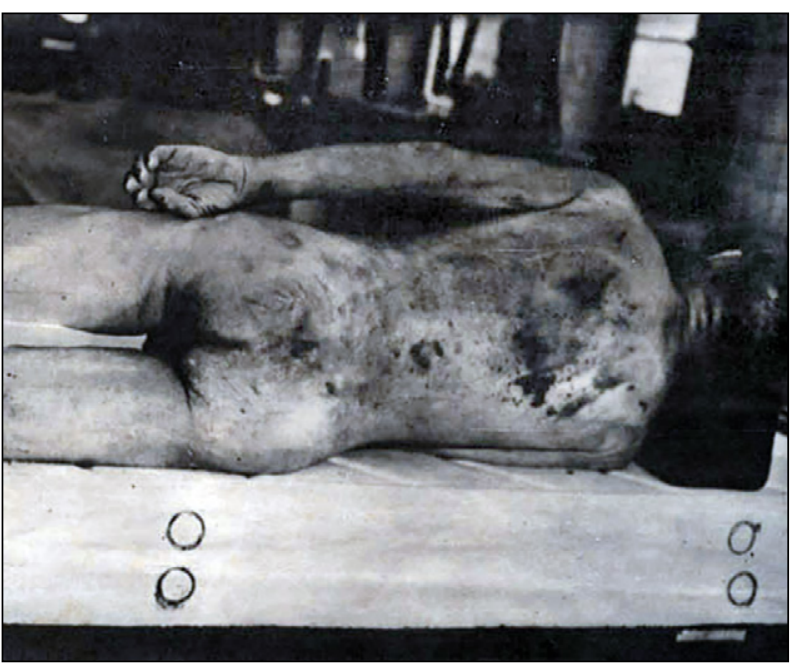

Рисунок 12 - Жертвы анатомических «исследований» А. Хирта, обнаруженные в Анатомическом институте Страсбургского университета после освобождения. Людей убили в газовой камере Начвайлера и доставили в институт на вскрытие. На теле - множественные гематомы. Из материалов «медичинского дела»

(URL: https://nuremberg.law.harvard.edu/ documents/1959-photographs-and-otherrecords?q=Natzweiler\#p.1; дата обращения: 13.06.2021)

провели на заключенных лагеря Нацвайлер (недалеко от Страсбурга).

Их инициатором стал А. Хирт - директор Анатомического института при Рейхсуниверситете Страсбурга. Опыты проходили при участии и поддержке СС-Аненербе, которая в июле 1942 года создала при Страсбургском университете специальный Институт военно-медицинских исследований с отдельным подразделением «Н» (для исследований Хирта). Ранее, зимой 1941-1942 гг., А. Хирт уже пытался изучать профилактические и терапевтические свойства витаминов, в частности, ретинола (витамин А) при поражениях ипритом [33]. При поддержке генерального секретаря СС-Аненербе Вольфрама Зиверса (рисунок 11) А. Хирт заручился согласием на проведение опытов с ипритом лично у Г. Гиммлера. В середине июля 1942 г. рейхсфюрер СС дал А. Хирту разрешение на опыты в Нацвайлере (рисунок 12). В лагере была развернута специальная экспериментальная станция, работой которой руководила СС-Аненербе. Она располагалась в нескольких помещениях, специально выделенных в уже существовавшем в лагере медицинском бараке 26,27 .

После испытаний на крысах, давших положительный результат, перешли к людям. Первый опыт был проведен 25 ноября 1942 г.

риментов. Камера, которая заработала летом 1943 г., находилась за официальной границей лагеря. «Лагерем уничтожения» (Vernichtungslager) типа АушвицаБиркенау Нацвайлер не был. После освобождения Страсбурга в ноябре 1944 г. в лагере обнаружили только 17 тел. Нацвайлер был эвакуирован 31 августа 1944 г. при наступлении союзных войск. В то время в нем находилось около 7,000 заключенных. Операция по эвакуации была завершена 4 сентября. В лагере осталось лишь несколько эсэсовцев. Тем не менее, система продолжала функционировать, поскольку вывезли только главный лагерь, во вспомогательных же по-прежнему оставались люди, которые продолжали работать. Их всех передали в распоряжение администрации концлагеря Дахау в апреле 1945 г. Суд над представителями администрации Нацвайлера состоялся в Вуппертале (Германия, Северный Рейн - Вестфалия) 29 мая 1 июня 1946 г. (Источник The United States Holocaust Memorial Museum. Encyclopedia of Camps and Ghettos, 1933-1945, Volume I: Early Camps, Youth Camps, and Concentration Camps and Subcamps under the SS-Business Administration Main Office (WVHA) Volume Editor Geoffrey P. Megargee, P. 1003-1008. URL: https://www.jstor. org/stable/j.ctt16gzb17.34?seq=1\#metadata_info_tab_contents; дата обращения: 18.04.2021).

${ }^{26}$ Letter to Richard Gluecks concerning the organization of research work at Natzweiler [poison gas]. AUTHOR Wolfram Sievers (administrator of Ahnenerbe Society; Reich Research Council). 11 September 1942. URL: http:// nuremberg.law.harvard.edu/documents/2116-letter-to-richard-gluecks?q=Natzweiler\#p.1 (дата обращения: 13.06.2021).

27 Сохранился любопытный документ - письмо В. Зиверса в секретариат Г. Гиммлера от 3 ноября 1942 г., содержащий в себе следы административно-финансовой «перебранки», связанной с опытами с ипритом в Нацвайлере. А. Хирт нажаловался своему начальству, что лагерная администрация неохотно идет навстречу его пожеланиям и чинит препятствия. Кроме того, там потребовали дополнительной оплаты за содержание заключенных, которых задействовали в опытах. Дело в том, что «для чистоты эксперимента» предполагалось, что заключенных должны были кормить не обычной лагерной пищей, а рационом охранников. В результате - расходы на дополнительное питание 10 человек, а опыты могли продолжаться до 10 месяцев, т.е. расходы должны были составить порядка 4000 рейхсмарок. В. Зиверс в докладе наверх возмущался «шкурническим» подходом лагерной администрации: «Кажется, эта публика в Нацвайлере пытается выжать из этого бизнеса как можно больше денег». Одновременно он поставил в пример администрацию Дахау, которая, по его словам, всегда «с пониманием» относилась к их изысканиям и «никогда не заикалась об оплате за заключенных». Тут же выяснился и финансовый вопрос. Работу Института военно-научных исследований финансировала Ваффен-CC. (URL: http://nuremberg.law.harvard.edu/documents/1077-memorandum-torudolf-brandt?q=Natzweiler\#p.1; дата обращения: 13.06.2021). К слову сказать, вопрос о дополнительном питании и чистоте экспериментов, очевидно, так и не был решен удовлетворительно, поскольку в своих отчетах А. Хирт оговаривал, что «подопытные» истощены. 
на 15 заключенных ${ }^{28}$. Но предоставленный Ваффен-СС иприт оказался настолько некачественным, что опыт был признан неудачным. В начале декабря 1942 г. А. Хирт продолжил эксперименты с целью проверить «защитные свойства» витаминов А, группы В и С при ипритных поражениях [34]. Результаты дали картину, обратную ожидаемой - оказалось, что, в отличие от крыс, применительно к людям витамин А не только не обеспечивал защиту, но наоборот, дал гиперчувствительность к иприту.

В конце 1943 г. В. Зиверс и А. Хирт уже рассматривали возможность расширения экспериментов с ипритом и витаминами в Нацвайлере, а также в Дахау. Сначала предполагалось поставить опыты на крысах с участием 1000 животных, а потом проверить «терапевтические свойства» витамина А на 240 заключенных.

Впоследствии бывший заключенный Нацвайлера голландец Герит Хендрик Налес (Gerit Hendrik Nales), находившийся в лагере с ноября 1942 г., рассказал на нюрнбергском трибунале по «делу врачей», что в период с апреля по май 1943 г. в лагере действительно ставили опыты над 15 заключенными немцами. Им на кожу наносили некое «вещество», вызывавшее «ужасные раны», которые потом распространялись по всему телу, которое также вызывало слепоту (очевидное описание поражения ипритом). По его словам, как минимум трое «подопытных» в течение нескольких дней скончались в ужасных мучениях.

В итоге в 1944 г. А. Хирт представил итоговый отчет о результатах своих экспериментов. В нем нигде не говорилось, что опыты ставились на заключенных. Зато там было сказано, что, возможно, результат будет лучше в случае перорального приема мультивитаминов (А, С и группы В), а также в случае инъекций витамина В1 с глюкозой.

Согласно показаниям личного секретаря-референта Г. Гиммлера Рудольфа Брандта (нем. - Rudolf («Rudi») Emil Hermann Brandt, 1909-1948) на трибунале по «медицинскому делу», опыты с ипритом в Нацвайлере и Заксенхаузене продолжались до 1944 г. включительно ${ }^{29}$.

Концентрационньй лагерь Нацвайлер. Опьты с фосгеном Отто Бикенбаха. 17 марта 1943 г. Институт военно-медицинских исследований проводил научно-практическую конференцию, куда был приглашен, в частности, доктор Отто Бикенбах (нем. - Otto
Bickenbach, 1901-1971) с медицинского факультета Страсбургского рейхсуниверситета [33]. С 1939 г. он работал над проблемой лечения легочных поражений фосгеном. В феврале 1940 г. он приступил к экспериментам, направленным на изучение профилактических и терапевтических свойств гексаметилентетрамина (уротропина). Немцам было известно, что уротропин в Первую мировую войну использовался в русской армии для пропитки противогазовых повязок для защиты от хлора и фосгена во время газобаллонных атак. Его действие хотели проверить (рисунок 13).

Программа исследований О. Бикенбаха предполагала серию испытаний на животных (кошки и обезьяны), а также эксперименты на себе. По его данным, опыты на животных показали высокую эффективность уротропина. На конференции, проводившейся под эгидой СС-Аненербе, был показан отснятый им в 1940 году документальный фильм об опытах с уротропином на кошках и обезьянах.

После конференции В. Зиверс предложил О. Бикенбаху продолжить опыты «во взаимодействии» с А. Хиртом в Нацвайлере. О. Бикенбах согласился, поскольку это означало получение доступа к «биоматериалу».

Сведения о первой серии опытов крайне противоречивы. Известно, что к началу апреля 1943 г. в Нацвайлере соорудили газовую камеру объемом $20 \mathrm{~m}^{3}$ специально для опытов О. Бикенбаха с фосгеном. Известно, что в том же апреле А. Хирт сообщил О. Бикенбаху, что он может начинать.

О дальнейшем известно лишь по послевоенным показаниям единственного свидетеля Фердинанда Холла, который был в лагере капо (полицейским). Он сообщил, что первая серия опытов состоялась в июне 1943 г. При этом он путался в показаниях относительно количества заключенных, на которых ставили опыты (от 90 до 150), а также количества погибших (50-60 человек). Поэтому этот эпизод до сих пор считается среди специалистов не до конца выясненным - вплоть до того, был ли он вообще.

Следующая серия опытов с фосгеном была проведена в Нацвайлере в июне и августе 1944 г. Соисполнителем был ассистент О. Бикенбаха Гельмут Рюль (нем. - Helmut Rühl, 1918-после 1980). Определенную техническую помощь оказал В. Вирт, хотя не известно, в какой мере он был осведомлен о проходящем в Нацвайлере, по-

\footnotetext{
${ }_{28}$ В некоторых источниках имеются обрывочные сведения об опытах А. Хирта с ипритом в октябре 1942 г. Эксперименты ставились на 150 заключенных, которым предварительно в течение двух недель давали усиленное питание. Затем им наносили иприт на кожу и заставляли дышать парами ОВ. По меньшей мере 50 человек погибли, остальные получили поражения и были убиты позднее, в газовых камерах [35].

${ }^{29}$ Rudolf Emil H. Brandt (SS Obersturmbannfuehrer (Himmler's personal staff). Affidavit concerning the poison gas experiments at Sachsenhausen and Natzweiler. 14 October 1946. URL: http://nuremberg.law.harvard.edu/ documents/1686-affidavit-concerning-the-poison?q=Natzweiler\#p.1 (дата обращения: 13.06.2021).
} 


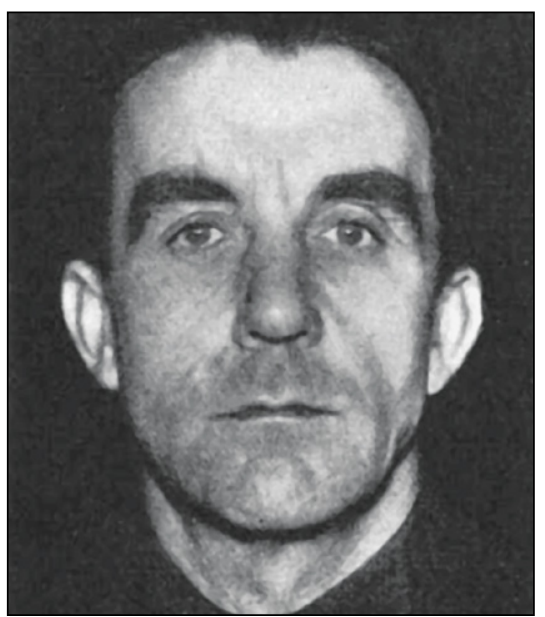

Рисунок 13 - Отто Бикенбах [31]

скольку Институт фармакологии просили всего лишь помочь откалибровать измерительную аппаратуру.

Опыты в газовой камере Нацвайлера проходили с 15 июня по 8 августа 1944 г. В них участвовали 40 заключенных. 20 давали уротропин перорально, 20 - сделали инъекции. Контрольная группа из 8 заключенных находилась в газовой камере без защиты. Большую часть заключенных (кроме нескольких немцев) составляли цыгане, которых специально доставили из «цыганского лагеря» в Аушвице-Биркенау. Заключенных заводили в камеру по четыре человека. Концентрацию фосгена постепенно увеличивали, а дозировку уротропина, наоборот, понижали. Выживший участник опыта Вилли Херцберг (Willy Herzberg) после войны давал показания о том, что О. Бикенбах лично заводил заключенных в газовую камеру, разбивал емкости с фосгеном и быстро выходил, после чего двери герметизировались.

Согласно заключительному отчету О. Бикенбаха рейхскомиссару здравоохранения и санитарии Карлу Брандту (нем. - Karl Franz Friedrich Brandt, 1904-1948), 14 человек скончались. Под конец опыта концентрация фосгена в камере значительно превышала считавшуюся летальной.

О. Бикенбах фактически подтвердил защитные свойства уротропина. Для этого ему пришлось ставить эксперименты, где смерть «подопытного» человека была частью методики - одной из задач было установить, при каких дозировках уротропина и какой концентрации фосгена смерть будет неизбежной.

Кониентрационный тагерь Нойенгамме ${ }^{30}$. Последние известные испытания на заключен- ных происходили в период между декабрем 1944 г. и мартом 1945 г. в Нойенгамме (на территории Гамбурга). Их инициатором стал профессор Карл Людвиг Вернер Хаазе (нем. - Karl Ludwig Werner Haase, 1903-1980) из рейхсинститута гигиены воды, почвы и воздуха (рисунок 14).

После разрушения плотины «Möhne Reservoir» британскими ВВС в мае 1943 г. К. Хаазе был введен в состав рабочей группы, занимавшейся ее восстановлением. Он высказал предположение, что британские ВВС могли заразить воду боевыми ОВ. Ему было поручено в лабораторных условиях разработать новый метод очистки воды от ОВ.

Весной 1944 г. К. Хаазе предложил обеззараживать отравленную люизитом воду хлорноватистой кислотой. Военные опробовали этот способ в Раубкаммере. Испытания провели также в Военно-медицинской академии, причем однозначных результатов не получилось. Тем временем К. Хаазе приступил к разработке специального аппарата для очистки воды хлорноватистой кислотой. Альтернативный способ - использование активированного угля в качестве сорбента - он отвергал на том основании, что количества угля, достаточного для обеззараживания такого количества воды, в доступе просто нет.

О его предложениях были поставлены в известность, в частности, имперский руководитель здравоохранения обергруппенфюрер СС Леонардо Конти (нем. - Leonardo Konti, 19001945) и лично Г. Гиммлер, который одобрил продолжение исследований в концлагере. Для этих целей был выбран лагерь Нойенгамме.

К. Хаазе готовил эксперименты с июня 1944 г. Аппарат планировалось установить в Нойенгамме к концу июля. 5 августа и 1 сентября 1944 г. он посетил Нойенгамме. В один из этих дней хлорноватистая кислота была залита в источник питьевой воды, откуда брали воду для приблизительно 10,000 заключенных. Целью опыта была проверка действия на человеческий организм самой кислоты. Согласно отчетам К. Хаазе, ни о каких явных проблемах со здоровьем у заключенных, которые употребляли воду с кислотой, не наблюдалось.

10 октября 1944 г. К. Хаазе продолжил испытания вместе с В. Виртом на испытательном полигоне в Раубкаммере.

В период с 3 по 15 декабря 1944 г. около 150 заключенных лагеря подверглись эксперименту с питьевой водой с люизитом, которую пропустили через изобретенные К. Хаазе очистные сооружения с хлорноватистой кисло-

\footnotetext{
${ }^{30}$ Изначально возник как филиал Заксенхаузена, в 1940 г. преобразован в отдельный лагерь. Расширение системы концлагерей обусловливалось растущими потребностями экономики Германии, а также сохранением планов А. Гитлера по перестройке немецких городов. Гросс-Розен и Нацвайлер, дополнившие Нойенгамме, Маутхаузен и Флоссенбург, должны были обеспечивать экономику строительными материалами [32].
} 
той. Начинали с минимальной концентрации люизита, потом ее постепенно увеличивали до концентраций, которые «примерно в сто раз» превышали предельно допустимые (по оценкам Военно-медицинской академии). Если верить отчетам К. Хаазе, лагерные врачи из СС никакого ухудшения состояния здоровья подопытных не зафиксировали.

К. Хаазе предполагал в январе 1945 г. продолжить эксперименты с целью изучения действия на человеческий организм длительного употребления такой «очищенной» воды, поскольку предполагалось, что в воде все равно остается определенное количество мышьяка. Г. Гиммлер разрешения не дал.

Тем не менее К. Хаазе настоял на проведении опытов с азотистыми ипритами на том основании, что их химический состав отличается от люизита. В январе - начале февраля 1945 г. в Нойенгамме провели серию опытов с азотистыми ипритами и доложили о «также положительных результатах».

Далее нацистские ученые предложили продолжить эксперименты с целью уточнения летальных токсодоз сразу нескольких ОВ. Предлагалось использовать заключенных, приговоренных к смертной казни. По предложенным им методикам опыты предполагалось продолжать до смерти участников экспериментов.

Г. Гиммлер опыты запретил. 16 февраля 1945 г. он отозвал свое разрешение на эксперименты в Нацвайлере «по соображениям текущей политической ситуации». Это был первый известный

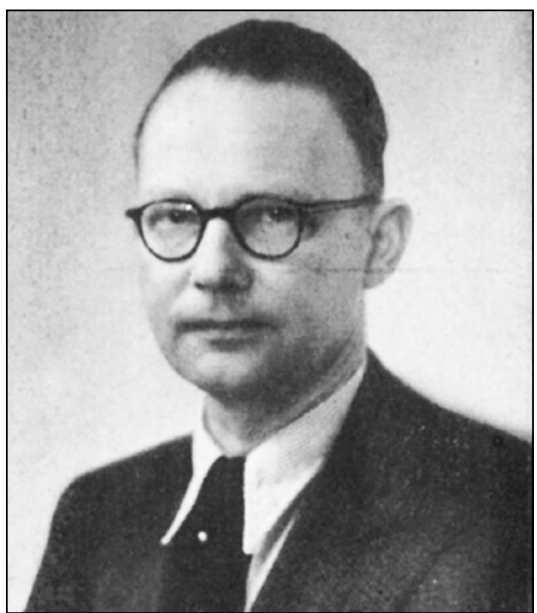

Рисунок 14 - Людвиг Вернер Хаазе [31]

случай, когда Г. Гиммлер отказался санкционировать какие бы то ни было опыты на людях в концлагере. Война подходила к концу.

Расплата. После окончания войны пришло время отвечать за содеянное [36-38]. 20 ноября 1945 г. во Дворце юстиции Нюрнберга открылся Международный военный трибунал (МВТ) - первый и главный судебный процесс по обвинению бывших руководителей Германии в преступлениях против мира, против человечности ${ }^{31}$, нарушениях законов войны и в заговоре с целью совершения данных преступных действий [39]. Трибунал завершил работу 1 октября 1946 г. и вынес обвинительные приговоры главным руководителям Третьего рейха.

\footnotetext{
31 Зарождение понятия преступления против человечности связано с деятельностью российского юриста-международника Ф.Ф. Мартенса (1845-1909), принимавшего участие в разработке Конвенций о законах и обычаях сухопутной войны 1899 г. и 1907 г. Далее его связывают с совместной декларацией стран Антанты Османской империи в 1915 г. [37]. Впоследствии они были сформулированы в Ст. 6 Устава МВТ:

«Трибунал, учрежденный Соглашением, упомянутым в статье 1 настоящего Устава для суда и наказания главных военных преступников европейских стран оси, имеет право судить и наказывать лии, которые, действуя в интересах европейских стран оси индивидуально или в качестве членов организачии, совериили любое из следующих преступлений.

Следующие действия или любые из них являются преступлениями, подлежащими юрисдикиии Трибунала и влекущими за собой индивидуальную ответственность:

а) преступления против мира, а именно: планирование, подготовка, развязывание или ведение агрессивной войны или войны в нарушение международных договоров, соглашений или заверений, или участие в общем плане или заговоре, направленных к осуществлению любого из вышеизложенных действий;

b) военные преступления, а именно: нарушения законов или обычаев войны. К этим нарушениям относятся убийства, истязания или увод в рабство или для других иелей гражданского населения оккупированной территории; убийства или истязания военнопленных или лии, находящихся в море; убийства заложников; ограбление общественной или частной собственности; бессмысленное разрушение городов или деревень; разорение, не оправданное военной необходимостью, и другие преступления;

c) преступления против человечности, а именно: убийства, истребление, порабощение, ссылка и другие жестокости, совершенные в отношении гражданского населения до или во время войны, или преследования по политическим, расовым или религиозным мотивам в иееля осуществления или в связи с любым преступлением, подлежащим юрисдикиии Трибунала, независимо от того, являлись ли эти действия нарушением внутреннего права страны, где они были совершень, или нет.

Руководители, организаторы, подстрекатели и пособники, участвовавшие в составлении или в осуществлении общего плана или заговора, направленного к совершению любых из вышеупомянутых преступлений, несут ответственность за все действия, совершенные любыми лииами в иелях осуществления такого плана» (URL; https://docs.cntd.ru/document/901737883).
} 


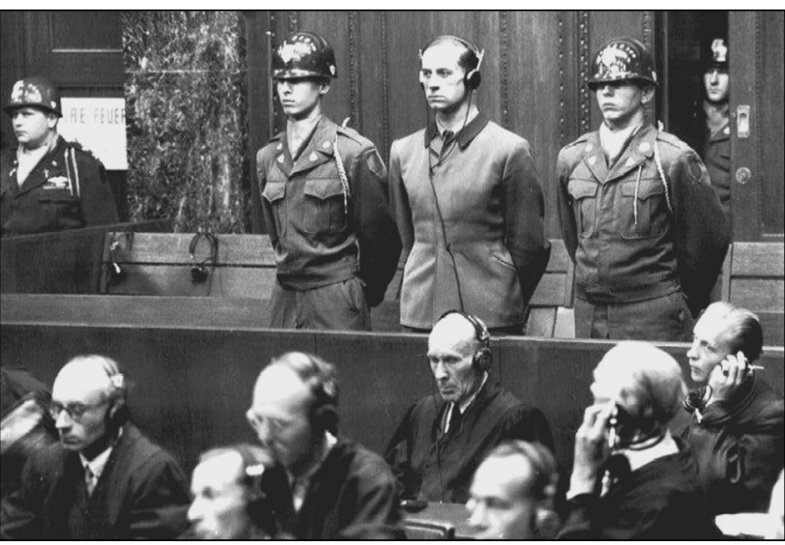

Рисунок 15 - Судебный процесс «Соединенные Штаты Америки против Карла Брандта и дp». (URL: https://commons.wikimedia.org/wiki/ File:Karl-Brandt.jpg; дата обращения: 13.06.2021)

На МВТ неоднократно звучали обвинения в адрес немецких врачей в проведении недобровольных испытаний на заключенных концентрационных лагерей тех или иных химических веществ и биологических средств [39]. В частности, было показано, что в Аушвице-Биркенау «производилось изучение действия разных химических препаратов по заказам немецких фирм... В тагере производились также опыты над мужчинами для установления действия раздражающих химических веществ на кожуголени с иелью искусственно вызывать язвы и флегмо- ны. Производился и ряд других опытов, таких, как искусственно заражение малярией, искусственное оплодотворение и т.д.». Упоминалось об опытах в Бухенвальде с искусственным заражением малярией и сыпным тифом с целью проверки эффективности различных вакцин, в том числе произведенных в лагере, об опытах с ожогами фосфором для поиска средств лечения ожогов и т.д. В. Зиверс дал показания об опытах А. Хирта с ипритом в Нацвайлере с целью поиска и апробации методов лечения поражений. Опыты проводились по личному распоряжению рейхсфюрера СС Г. Гиммлера ${ }^{32}$ как минимум до начала марта 1944 г. Однако на МВТ эти сюжеты звучали как проходные на фоне других медицинских преступлений и тем более газовых камер $[39,40]$ в «лагерях уничтожения».

«Медицинское дело». Союзным Контрольным советом 3320 декабря 1945 г. был принят Закон № 10, который уполномочил союзные державы арестовывать «военных и других подобных преступников, за исключением тии, против которых ведется преследование Международным Военным Трибуналом», и постановил учредить трибуналы для суда над ними. Задача судебного преследования таких лиц ложилась на каждую из оккупационных держав (рисунок 15).

Согласно п. 1 (b, c) ст. II Закона № 10, в качестве военных преступлений квалифицировались «жестокости или враждебные действия против лии, или имущества, представляющие

\begin{abstract}
Ныне действующее определение преступлений против человечности дано в Римском статуте Международного уголовного суда (вступил в силу 1 июля 2002 г.).

32 Очевидно, штандартенфюрер СС В. Зиверс, проходивший в данном случае как свидетель, очень не хотел перейти в разряд обвиняемых. В своих показаниях он настаивал на том, что «Пробессор Хирт разработал метод лечения ран, вызванных действием отравляющего вещества «Лост». При создании метода лечения он в порядке эксперимента проводил опыты на самом себе, которые привели к тяжельм последствиям для его здоровья... Гиммлер интересовался этими опьтами, и он очень разволновался, когда усльшил, что Хирт проводит эксперименты на самом себе. Гиммлер сослался при этом на распоряжение бюрера, чтобы для таких опьтов использовались добровольцы из числа заключенных или из числа приговоренных к смертной казни преступников. Только после требования Гиммлера Хирт провел контрольные опьты на 20 заключенных, но сделал он это только тогда, когда уже было известно на основании опьтов, проведенных на самом себе, что вредные последствия, вызываемые этими экспериментами, не носят длительного характера. Он указал далее на то, что гораздо важнее (это был первый рабочий контакт с Хиртом) получить для этих экспериментов достаточное количество животных, так как с начала войны их количество сократилось настолько, что уже невозможно было проводить необходимые научные опыты»... «после опытов на самом себе он провел эти эксперименты на 20 заключенных, которые добровольно предоставили себя в его распоряжение». Свою собственную роль в этих экспериментах он сводил к роли «лишь почтальона» и во время дачи показаний регулярно страдал забывчивостью. Эта тактика не сработала, его все равно осудили на другом трибунале и повесили в 1948 г.
\end{abstract}

${ }_{33}$ Орган верховной власти в оккупированной Германии, образованный после Второй мировой войны державами-победительницами. В соответствии с контрольным механизмом, установленным соответствующим соглашением от 14 ноября 1944 г. и подтвержденным на Потсдамской конференции летом 1945 года, верховная власть в Германии осуществляется главнокомандующими вооруженных сил четырех держав-победительниц «каждым в своей зоне оккупации, по инструкциям от своих соответствующих Правительств, а также совместно, по вопросам, затрагивающим Германию в целом». Соответственно в Контрольный совет входили маршал Г.К. Жуков, генерал Дуайт Эйзенхауэр, фельдмаршал Бернард Монтгомери и генерал Латр де Тассиньи. Учредительное заседание Контрольного совета состоялось 30 июля 1945 г. одновременно с проходившей Потсдамской конференцией. Последнее заседание состоялось 20 марта 1948 года. Формально совет был ликвидирован только с объединением Германии после обретения Германией полного суверенитета в соответствии с положениями Договора «Два плюс четыре» 1990 года. 
Разработка и испытания на людях боевых отравляющих веществ и средств лечения поражений в Германии...

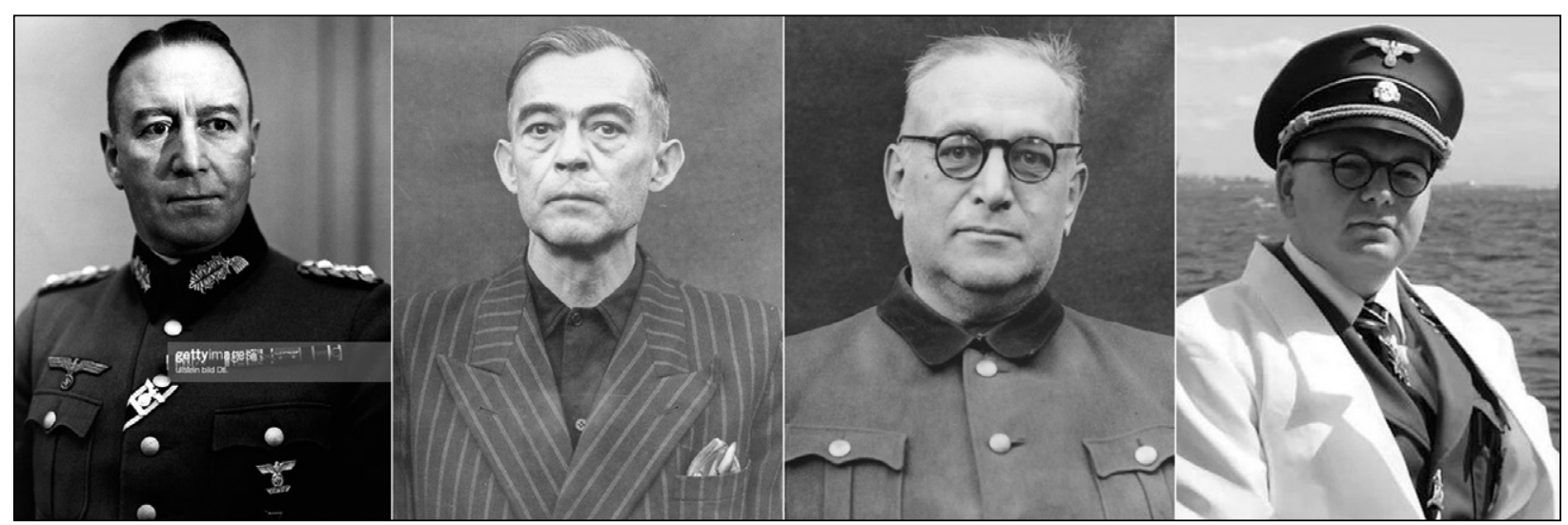

Рисунок 16 - Подсудимые на прочессе «Соединенные Штаты Америки против Карла Брандта и др.» (слева на право): Зигфрид Хандлозер - приговорен к пожизненному заключению; Курт Бломе, Пауль Росток - длительные сроки заключения. Карл Гебхардт - казнен за военные преступления и преступления против человечности)

нарушение законов или обычаев войны, включая, но не ограничиваясь: убийство, плохое обращение или увод в рабство или для каких-либо других иелей гражданского населения из оккупированной территории, убийство или плохое обращение с военнопленными или находящимися в море, убийство заложников, ограбление общественной или частной собственности, умышленное разрушение городов, населенных пунктов или деревень или опустотение, не оправданное военной необходимостью».

К преступлениям против человечности относились «жестокости и враждебнье действия, включая, но не ограничиваясь: убийство, истребление, обращение в рабство, депортация, заключение в тюрьму, пьтки, изнасилование или другие бесчеловечные действия, совериаемье против любого гражданского населения, или преследования на политической, расовой или религиозной почве, вне зависимости от того, были ли эти преступления совершены в нарушение законов страны или нет» [41].

На основании этого закона ${ }^{34}$ было проведено несколько процессов, которые союзники организовывали сами, каждый в своей оккупационной зоне. В одном только Нюрнберге с 1946 по 1949 г. состоялось 12 трибуналов.

Первым стал процесс «Соединенные Штаты Америки против Карла Брандта и др.» (Дело № 1) или «дело врачей» («медицинское дело»), который проходил в Нюрнберге с 9 декабря 1946 г. по 20 августа 1947 г. ${ }^{35}$ [42]. Нюрнберг входил в оккупационную зону США, поэтому процесс организовали США ${ }^{36}$. Все судьи были из США. Сторона обвинения была представлена американскими юристами, сторона защиты - немецкими. Суду были преданы руководители медицины Германии за организацию и проведение экспериментов на людях. В их числе - начальники медицинских служб Вермахта, Люфтваффе, Ваффен-СС и гражданской медицины, всего 23 человека, из них 20 врачей, один юрист и два чиновника.

На скамье подсудимых оказались, в частности: К. Брандт - личный врач А. Гитлера, группенфюрер СС и генерал-лейтенант Ваффен-СС, рейхскомиссар по здравоохранению и санитарии, член Совета исследований Рейха; Зигфрид Хандлозер (нем. - Siegfried Handloser, 1885-1954) - генерал-лейтенант медицинской службы, медицинский инспектор Сухопутных войск, начальник медицинской службы Вермахта; Курт Бломе (нем. - Kurt Blome, 18941969) - заместитель Имперского руководителя здравоохранения, уполномоченный по онкологическим исследованиям Совета исследований Рейха; Пауль Росток (нем. - Paul Rostock, 1892-1956) - главный хирург Хирургической клиники в Берлине, хирургический советник армии, начальник Управления медицинской науки и исследований; Карл Гебхардт (нем. - Karl Franz Gebhardt, 1897-1948) - группенфюрер CC и генерал-лейтенант Ваффен-СС, личный врач рейхсфюрера СС Г. Гиммлера, главный хирург штаба главного врача СС и полиции, президент Красного Креста Германии; Р. Брандт (нем. Rudolf («Rudi») Emil Hermann Brandt, 1909-1948) - штандартенфюрер (полковник) в общих СС,

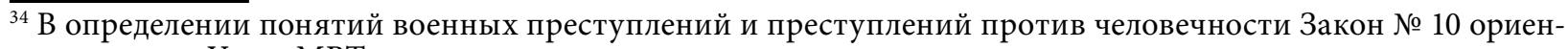
тировался на Устав МВТ.

${ }^{35}$ Большая часть материалов по процессу была сразу же засекречена. Изданный в США официальный отчет содержит многочисленные лакуны.

36 Французы проводили аналогичные военные трибуналы в Лионе и Меце. 
личный помощник (референт) рейхсфюрера СС Г. Гиммлера, министерский советник и начальник управления делами министерства внутренних дел Рейха; В. Зиверс - штандартенфюрер CC, управляющий делами общества Аненербе и директор Института военно-научных исследований, заместитель председателя управляющего совета директоров Совета исследований Рейха (рисунок 16).

Обвинения в испытаниях боевых отравляющих веществ на людях были предъявлены:

«D) Опыты с ипритом (Lost) (горчичный газ). В разное время между сентябрем 1939 и апрелем 1945 проводились опыты в концентрачионных тагерях Заксенхаузен, Нацвайлер и других концентрационных тагерях в интересах германских вооруженных сил с иелью изучения наиболее эф фективных способов течения поражений, нанесенных ипритом. Иприт - это отравляющий газ, который обычно известен как горчичный газ. Поражения ипритом наносились подопытным преднамеренно. Некоторые из подопытных погибли в результате этих экспериментов, другие испьтывали сильную боль и получили увечья. Подсудимые Карл Брандт, Хандлозер, Бломе, Росток, Гебхардт, Рудольф Брандт и Зиверс несут особую ответственность и обвиняются в участии в данных преступлениях».

Всем 23 подсудимым были предъявлены обвинения и в других медицинских преступлениях в концлагерях Дахау, Равенсбрюк, Аушвиц-Биркенау, Бухенвальд и др. Часть экспериментов (высотные, по обморожению, с морской водой, с зажигательными бомбами и т.д.) проводилась в интересах Вермахта, Люфтваффе и Кригсмарине. Часть направлена на поиск средств профилактики и лечения опасных, особо опасных, а также широко распространенных заболеваний (малярии, тифа, газовой гангрены, столбняка, туберкулеза и т.д.) и на проверку эффективности вакцин ${ }^{37}$. И наконец, часть была направлена на решение особо актуальных в то время задач расового характера (эксперименты по стерилизации с прицелом на массовость, по эвтаназии неизлечимо больных, психиатрических больных и т.д.). Отдельным пунктом обвинения фигурировала коллекция «еврейских скелетов» А. Хирта.

Приговор, не подлежавший обжалованию, был вынесен 20 августа 1947 г. Семь человек, в числе которых К. Брандт, Р. Брандт, К. Гебхардт и В. Зиверс, приговорены к смертной казни через повешение, приговор приведен в исполнение 2 июня 1948 г. в тюрьме для во- енных преступников в Ландсберге (Бавария). Пятерых, в том числе 3. Хандлозера, приговорили к пожизненному заключению. Он отсидел шесть лет. Освобожден досрочно в декабре 1953 г. в связи с резким ухудшением здоровья, умер от рака 3 июля 1954 г. в Мюнхене. Четверо получили различные сроки тюремного заключения.

В их числе был оберфюрер СС Гельмут Поппендик (нем. - Helmut Poppendick, 19021994), причастный к экспериментам в Нойенгамме. Он был приговорен к 10 годам тюрьмы, освобожден 1 февраля 1951 г., после чего продолжил врачебную деятельность в Ольденбурге, где и скончался 11 января 1994 г. Семерых подсудимых, в числе которых П. Росток и К. Бломе, оправдали. Оба продолжили заниматься медицинской практикой. П. Росток умер 17 июня 1956 г., К. Бломе - 10 октября 1969 г.

А. Хирта судил позднее и заочно французский военный трибунал во время первого из двух судебных процессов (Struthof Medical Trials) по преступлениям в Нацвайлере (1952 г. - трибунал в Меце, 1954 г. - трибунал в Лионе). Главным пунктом обвинения стала коллекция «еврейских скелетов», для комплектования которой людей убивали специально, а также опыты на людях [43].

Заключение. Еще в конце XIX - начале XX в. именно Германия (Пруссия) стала первой европейской страной, где на уровне законодательной, исполнительной и судебной ветвей власти стали запрещать медицинские опыты на людях без их согласия и требовать обязательного информированного добровольного согласия пациента на медицинское вмешательство.

Первым таким документом стало распоряжение министерства внутренних дел Пруссии от 1891 г. об использовании изобретенного в 1890 г. Робертом Кохом (нем. - Heinrich Hermann Robert Koch, 1843-1910) препарата - туберкулина при лечении заключенных. В распоряжении указывалось, что он может быть использован только в тех тюрьмах, при которых существуют больницы или другие медицинские учреждения, а также только в тех случаях, если врач, использующий туберкулин, в этой же клинике сам и живет - чтобы иметь возможность отслеживать пациентов и вмешаться в любой момент. Кроме того, этот препарат «ни при каких условиях не должен использоваться против воли пациента». Правда, это распоряжение касалось только заключенных и не распространялось на всех остальных - не в последнюю

\footnotetext{
$\overline{37}$ Такие цели исследований были бы вполне нормальными, если бы не ряд весьма существенных обстоятельств. Для этих экспериментов здоровых людей заражали специально. Кроме того, методики проведения некоторых опытов, направленных, в частности, на определение токсичности тех или иных химикатов, предполагали их продолжение вплоть до смерти «подопытных». Некоторые были признаны бессмысленными и «причиняющими излишние страдания».
} 
очередь по причине распространенности этого заболевания.

Следующим эпизодом стало так называемое «дело Нейссера» [44]. Альберт Нейссер (нем. - Albert Neisser, 1855-1916) (рис. 35), opдинарный профессор дерматологии и венерологии, директор Дерматологической клиники в Бреслау, в истории медицины известный как первооткрыватель гонококка - возбудителя гонореи, проводил исследования, направленные на поиск средств профилактики и лечения сифилиса. В 1892 г. он ввел восьми госпитализированным малолетним девицам изобретенную им сыворотку, полученную от больных пациентов, чтобы проверить ее способность «убивать сифилитический яд». Четверо из них были проститутками, госпитализированными с венерическими заболеваниями (но не сифилисом), еще четверо - с различными кожными заболеваниями. О том, что на них ставятся опыты, девицы в известность поставлены не были. В течение ближайших четырех лет некоторые из них заболели. А. Нейссер пришел к выводу, что вакцинация «не сработала», однако объяснял это обстоятельство не неэффективностью сыворотки, а «естественными обстоятельствами», т.е. нахождением в группе риска по сифилису в силу занятий проституцией.

Результаты своих исследований А. Нейссер в 1898 г. опубликовал в специализированном научном журнале. Однако в 1900 г. мюнхенская либеральная газета «Freie Presse» («Свободная пресса») опубликовала пространную статью «Arme Leute in Krankenhausen» («Бедные люди в больницах»), в которой ее автор, в частности, обвинил А. Нейссера в опытах на несовершеннолетних, да еще и без их согласия.

Последовали разбирательство, суд и дисциплинарное расследование. «Камнем преткновения» стал вопрос о том, давали ли испытуемые/пациенты согласие на лечение, носившее, по сути, экспериментальный характер. А. Нейссер вины не признавал и упирал на то, что в данном случае оно и не требовалось, поскольку, во-первых, этого требовали интересы науки, а во-вторых, пациентки в силу низкого образовательного и культурного уровня все равно ничего бы не поняли. Медицинское сообщество А. Нейссера поддержало ${ }^{38}$. Позиция юристов того времени сводилась к тому, что «нетерапевтические», то есть экспериментальные исследования, без согласия испытуемых соответствуют критериям понятия причинения физического ущерба в уголовном праве. Научные цели экспериментов смягчающими обстоятельствами считаться были не должны.

В итоге А. Нейссер был признан виновным «в нарушении долга врача» $[44,45]$. Королевский дисциплинарный суд (Königlicher Disciplinarhof für nichtrichterliche Beamte) приговорил его к штрафу в размере 300 рейхсмарок. Также он должен был возместить судебные издержки в сумме 1245 марок (в то время годовой доход А. Нейссера составлял 2400 марок) [46].

Общественный резонанс, который вызвало «дело Нейссера», привел к тому, что оно несколько раз обсуждалось в парламенте Пруссии, который обратился к правительству с предложением принять меры.

После собственного разбирательства 29 декабря 1900 г. министерство по делам религии, образования и медицины обнародовало положение, которое распространялось на все лечебные учреждения Пруссии. Оно обязывало врачей при любых экспериментах («нетерапевтическом вмешательстве») обязательно получать информированное добровольное согласие пациентов и ставить их в известность относительно возможных негативных последствий ${ }^{39}$.

Таким образом, в годы Второй мировой войны врачи из СС действовали вопреки законам, научным и гуманистическим традициям в первую очередь своей собственной страны. И, несмотря на законность и естественность целей и задач этих опытов, именно бесчеловечность

\footnotetext{
${ }_{38}$ В конце XIX в. экспериментальные исследования, в первую очередь в только что зарождающейся области бактериологии, иммунологии и физиологии, проводились главным образом в больницах на пациентах, причем, как правило, действительно без их согласия, поскольку «интересы науки и прогресса» представлялись более важными.

${ }^{39}$ Полный текст документа:

«Рейхсминистр Пруссии по делам религии, образования и медицины

Указ всем медицинским начальникам (директорам) университетских больнии, поликлиник и других лечебных учреждений

І. Приказываю медицинским начальникам (директорам) университетских больнии, поликлиник и всех остальных лечебных учреждений - любое медицинское вмешательство с иелями, отличными от диагностических, лечебных, а также иммунизации, вне зависимости от других правовых или моральных обоснований, исключается при любых обстоятельствах, если:

(1) Испьтуемый человек несовершеннолетний или недееспособный в силу иных причин;

(2) Испытуемый человек не давал своего недвусмысленного согласия;

(3) Согласию не предшествовало разбяснение должным образом возможных негативных последствий вмешательства.

II. В то же время постановляю, что:
} 
их методов являлась грубейшим нарушением научной и медицинской этики, а также носила преступный характер, что и было подтверждено соответствующими обвинительными заключениями.

По итогам процесса 1947 г. был составлен Нюрнбергский кодекс - первый международный документ, вводивший этические нормы для ученых, занимающихся экспериментами на людях [47-50]. Он включал в себя 10 принципов, главный из которых сводился к тому, что для проведения эксперимента на человеке необходимо его добровольное осознанное согласие после предоставления ему полной информации о характере, продолжительности и цели проводимого эксперимента; о методах и способах его проведения; обо всех предполагаемых неудобствах и опасностях, связанных с проведением эксперимента, и, наконец, возможных последствиях для физического или психического здоровья испытуемого, могущих возникнуть в результате его участия в эксперименте.

Кроме того, Нюрнбергским кодексом предписывалось избегать всех излишних физических и психических страданий и повреждений. Также предполагалось, что ни один эксперимент не должен проводиться в случае, если есть основания предполагать возможность смерти или инвалидизирующего ранения испытуемого. Эксперимент должен быть прекращен в случае, если его продолжение может привести к ранению, инвалидности или смерти испытуемого.

Принципы, сформулированные в Нюрнбергском кодексе, стали основой для многих международных ${ }^{40}$ и национальных, в том числе российских, законодательных актов в области проведения медицинских исследований на человеке.

(1) Такого рода вмешательство может проводиться только медицинским начальником (директором) лично или по его специальному разрешению;

(2) Во всех случаях таких вмешательств выполнение требований I (1-3) и II (1), а также прочие обстоятельства документируются в медииинской карте.

III. Существующие инструкиии относительно медицинского вмещательства с диагностическими и лечебными целями, а также иелями иммунизации, настоящим указом не затрагиваются.

Берлин, 29 декабря 1900

Министр по делам религии и т.д.

Umyдm»*

* Генрих Конрад фон Штудт (нем. - Heinrich Conrad von Studt, 1838-1921) - прусский юрист и политический деятель, с 1899 г. - министр по делам религии, образования и медицины (Ministerium der Geistlichen, Unterrichts und Medizinal-Angelegenheiten)

${ }^{40}$ Нюрнбергский кодекс послужил фундаментом принятых в течение XX века важнейших международных этических и правовых актов в области биомедицинских исследований с участием человека в качестве субъекта. Следующим шагом в области проведения экспериментов на людях явилась Хельсинкская декларация, которая была принята на восемнадцатой Генеральной Ассамблее Всемирной Медицинской Ассоциации в Хельсинки (Финляндия) в июне 1964 года. Текст Декларации см. [51].

\section{БЛАГОДАРНОСТИ}

Автор выражает свою глубочайшую признательность главному специилисту ФГБУ «27 Научный центр» Министерства обороны Российской Федерации, кандидату биологических наук, старшему научному сотруднику М.В. Супотницкому и старшему научному сотруднику этого же Центра, доктору технических наук, кандидату медицинских наук, Заслуженному химику Российской Федерачии А.И. Банникову за чрезвычайно полезные советы и ценные замечания, высказанные в ходе обсуждения настоящей статьи.

\section{Вклад автора/ Autor Contribution}

Идея и концепция статьи, поиск и анализ литературы, написание статьи цифровая обработка изображений / Idea and concept of an article, search and analysis of literature, writing an article, digital image processing.

\section{Информация о конфликте интересов}

Автор заявляет, что исследования проводились при отсутствии любых коммерческих или финансовых отношений, которые могли бы быть истолкованы как потенциальный конфликт интересов.

Сведения о рецензировании

Статья прошла открытое рецензирование двумя рецензентами, специалистами в данной области. Рецензии находятся в редакции журнала и в РИНЦе. 
Список источников / References

1. Супотницкий М.В., Петров С.В., Ковтун В.А. Влияние химического оружия на тактику и оперативное искусство Первой мировой войны (исторический очерк) // Вестник войск РХБ защиты. 2017. T. 1; № 1. C. 53-68; № 2. С. 39-63; № 3. С. 51-78.

Supotnitskiy M.V., Petrov S.V., Kovtun V.A. The Influence of Chemical Weapons on Tactics and Operational Art in World War 1 (Essays in the History of Chemical Weapons), Part 3 // Journal of NBC Protection Corps. 2017. V. 1; № 1. P. 53-68; № 2. P. 39-63; № 3. P. 51-78 (in Russian).

2. Супотницкий М.В., Петров С.В., Ковтун В.А. Химическое оружие в Первой Мировой войне. М.: Русская панорама, 2020. 446 c.

Supotnitskiy M.V., Petrov S.V., Kovtun V.A. Chemical Weapons in World War I. M.: Russian Panorama, 2020. 446 p. (in Russian).

3. Bretislav Friedrich. From Berlin-Dahlem to the Fronts of World War I: The Role of Fritz Haber and His Kaiser Wilhelm Institute in German Chemical Warfare // One Hundred Years of Chemical Warfare: Research, Deployment, Consequences (pp.25-44) https://doi.org/10.1007/978-3-319-51664-6_3

4. Henning E., Kazemi M. Dahlem - Domain of Science. A walking tour of the Berlin institutes of the Kaiser Wilhelm / Max Planck Society in the "German Oxford». 4th ed., expanded and updated. Berlin. 2009. P. 97.

5. Версальский мирный договор / Полный перевод с французского подлинника под ред. Ключникова Ю.В., Сабанина А. М.: Литиздат НКИД, 1925. С. 67.

Treaty of peace with Germany (treaty of Versailles). Transl. from French orig. Moscow, 1925. 197 p. (in Russian).

6. Войска радиационной, химической и биологической защиты. 100 лет. М., 2018.

Troops of radiation, chemical and biological protection. 100 years. M., 2018.

7. Шило Н.И. Первые попытки запрещения химического оружия // Вестник войск РХБ защиты. 2018. T. 2. № 1. C. $48-69$.

Shilo N.I. First Attempts to Ban Chemical Weapons // Journal of NBC Protection Corps. 2018. V. 2. № 1. P. 48-69 (in Russian).

8. The Problem of Chemical and Biological Warfare. Vol. I. The Rise of CB Weapons. SIPRI, 1971.

9. Mills, A.K. Investigations of Chemical Warfare Installations in the Munsterlager area, including Raubkammer. CIOS File No. XXXI-86, ed. SHAEF Combined Intelligence Objectives Sub-Committee-G-2 Division, London. 1945.

10. Schmaltz F. Neurosciences and Research on Chemical Weapons of Mass Destruction in Nazi Germany // J. History Neurosci.: Basic and Clin. Perspectives. 2006. V. 15. № 3. P. 186-209. http://doi. org/10.1080/09647040600658229

11. Bunnett J.F., Mikolajczyk M. Arsenic and Old Mustard: Chemical Problems in the Destruction of Old Arsenical and «Mustard» Munitions. NATO ASI Series. Disarmament Technologies. V. 19. 1998.
12. Baader G., Lederer S.E., Low M., et al. Pathways to Human Experimentation, 1933-1945: Germany, Japan, and the United States. Osiris. 2005; 20:205-31. https://doi.org/10.1086/649419

13. Brown M. Military Chemical Warfare Agent Human Subjects Testing: Part 1 - History of Six-Decades of Military Experiments with Chemical Warfare Agents // Military Medicine. 2009. V. 174. № 10. P.1041.

14. National Academy of Sciences, Institute of Medicine: Committee to Survey the Health Effects of Mustard Gas and Lewisite: Veterans at Risk: Health Effects of Mustard Gas and Lewisite. Washington, DC, National Academy Press, 1993.

15. Нельга И.А., Медвецкий И.В., Злобин А.В. и др. Химическое оружие: история исследования фосфорорганических отравляющих веществ за рубежом // Вестник войск РХБ защиты. 2019. Т. 3. № 2. C. 175-193.

Nelga I.A., Medvetsky I.V., Zlobin A.V., Tretyakov S.V., Sherstyuk A.V., Kostyuchenko I.V. Chemical Weapons: History of the Study of Organophosphorus Toxic Agents Abroad // Journal of NBC Protection Corps. 2019. V. 3. № 2. P. 175-193 (in Russian).

16. Reitzenstein J. Himmlers Forscher. Wehrwissenschaft und Medizinverbrechen im «Ahnenerbe» des SS. Paderborn: Ferdinand Schöning Verlag, 2014.

17. Рецензия на: Reitzenstein J. Himmlers Forscher. Wehrwissenschaft und Medizinverbrechen im "Ahnenerbe» des SS. Paderborn; Ferdinand Schöning Verlag, 2014. cM. URL: https://www.recensio.net/ rezensionen/zeitschriften/recensio-moskau/2018-9/ ReviewMonograph154519422, https://perspectivia. net/receive/pnet_mods_00000890? (дата обращения: 13.06.2021).

18. Toledano R. Anatomy in the Third Reich - The Anatomical Institute of the Reichsuniversität Strassburg and the deliveries of dead bodies // Ann. Anatomy Anatomischer Anzeiger. 2016. V. 205. P. 128-144. http:// dx.doi.org/10.1016/j.aanat.2016.03.006

19. Lang H.-J. August Hirt and «extraordinary opportunities for cadaver delivery» to anatomical institutes in National Socialism: A murderous change in paradigm // Ann. Anatomy - Anatomischer Anzeiger. 2013. V. 195. № 5. P. 373-380. http://dx.doi.org/10.1016/j. aanat.2013.03.013

20. Schmaltz F. Chemical weapons research in National Socialism: The collaboration of the Kaiser Wilhelm institutes with the military and industry // In: The Kaiser Wilhelm Society under National Socialism / Ed. Heim S., Sachse C., Walker M. Cambridge: Cambridge University Press, 2009. P. 312-338.

21. Ash M.G. Die Kaiser-Wilhelm Gesellschaft im Nationalsozialismus. Published online: 20 April 2010. http://doi.org/10.1007/s00048-009-0011-8

22. F. Lo'pez-Mun oz. The pharmaceutical industry and the German National Socialist Regime: 
I.G. Farben and pharmacological Research. // J. Clin. Pharm. Therapeutics. 2009. V. 34. P. 67-77.

23. Stephen L. McFarland. Preparing for What Never Came: Chemical and Biological Warfare in World War II // Defense Analysis. V. 2. No. 2. 1986. P. 108.

24. Preuss J. The Reconstruction of Production and Storage Sites for Chemical Warfare Agents and Weapons from Both World Wars in the Context of Assessing Former Munitions Sites / Eds. Friedrich B. et al. One Hundred Years of Chemical Warfare: Research, Deployment, Consequences. 2017. P. 291.

25. Пака В.Т. Затопленное химическое оружие: состояние проблемы // Рос. хим. ж. (Ж. Рос. хим. обва им. Д.И. Менделеева). 2004. Т. XLVIII. № 2. С. 106.

Paka V.T. Dumped chemical weapons: the state of the problem // Ross. Chim. Zh. (J. of the Russian Chemical Society named after D.I.Mendeleev). 2004. T. XLVIII. № 2. P. 106 (in Russian).

26. Old Chemical Weapons Reference Guide. May 1998. Section 4-3.

27. U.S. Army Chemical Materiel Destruction Agency. Old Chemical Weapons: Munitions Specification Report. September 1994.

28. Entsorgung von kampfmittelbelasteten Böden am Beispiel der GEKA.

29. Weindling P. The Origins of Informed Consent: The International Scientific Commission on Medical War Crimes, and the Nuremberg Code // Bull. History Med. 2001. V. 75. № 1. P. 37-71.

30. Sass H.-M. Reichsrundschrefben 1931: PreNuremberg German Regulations Concerning New Therapy and Human Experimentation // J. Med. Philosophy. 1983. V. 99. P. 111.

31. Schmaltz F. Chemical Weapons Research on Soldiers and Concentration Camp Inmates in Nazi Germany // In: One Hundred Years of Chemical Warfare: Research, Deployment, Consequences / Eds. Friedrich B. et al. http://doi.org/10.1007/978-3-319-51664-6_13

32. Аристов С.В. Повседневная жизнь нацистских концентрационных лагерей. М.: Молодая гвардия, 2017.

Aristov S.V. Daily life of Nazi concentration camps. Moscow: Young Guard, 2017 (in Russian).

33. Schmaltz F. Otto Bickenbach's Human Experiments with Chemical Warfare Agents and the Concentration Camp Natzweiler // In: Man, Medicine, and the State: the Human Body as an Object of Government Sponsored Medical Research in the 20th Century / Ed. Eckart W.U. Stuttgart: Steiner, 2006. P. 139-156.

34. Schmaltz F. Kampfstoff-Forschung im Nationalsozialismus. Zur Kooperation von KaiserWilhelm-Instituten, Militär und Industrie. Göttingen: Wallstein Verlag, 2005.

35. Daan de Leeuw. In the Name of Humanity. Nazi Doctors and Human Experiments in German Concentration Camps, 1939-1945. University of Amsterdam, Department of History Master's Thesis in History. 2013.

36. Глотова С.В. Преступления против человеч- ности: генезис и современное понимание концепции // Журнал зарубежного законодательства и сравнительного правоведения. № 3. 2016. С. 101-108.

Glotova S.V. Crimes against humanity: genesis and modern understanding of the concept // Journal of Foreign Legislation and Comparative Law. № 3. 2016. P. 101-108 (in Russian).

37. Барсегов Ю.А. Декларация 1915 года - этап формирования международной ответственности за геноцид // Турецкая доктрина международного права на службе политики геноцида (о концепции члена «Комиссии примирения» Гюндюз Актана). М., 2002. URL: http://www.armenianhouse.org/barsegov/ genocide-ru/doctrine/doctrine.html\#6

Barsegov Yu.A. Declaration of 1915 - the stage of formation of international responsibility for genocide // Turkish doctrine of international law in the service of the policy of genocide (on the concept of a member of the "Reconciliation Commission» Gündüz Aktan) M., 2002. URL: http://www.armenianhouse.org/barsegov/ genocide-ru/doctrine/doctrine.html\#6 (in Russian).

38. Валеев Р.М. Кодификация преступлений против человечности (к 70-летию Нюрнбергского процесса) // Юридическая наука. 2015. № 3. С. 69-74.

Valeev R.M. Codification of Crimes Against Humanity (to the 70th Anniversary of the Nuremberg Trials) // Legal Science. 2015. № 3. P. 69-74 (in Russian).

39. Нюрнбергский процесс: Сборник материалов. В 8-ми т. Т. 5. М.: Юрид. лит., 1991. 672 с.

The Nuremberg Trials: Collection of Materials. In 8 volumes.V. 5. M.: Jurid. Lit., 1991.672 p (in Russian).

40. СС в действии. Документы о преступлениях

СС. Перевод с немецкого. М.: СВЕТОТОН, 2000. 624 с.

SS in Action. Documents About SS Crimes. Translated from German. Moscow: SVETOTON, 2000. 624 p. (in Russian).

41. Enactments and Approved Papers of the Control Council and Coordinating Committee. Allied Control Authority. Germany. 1945. Volume I. Legal Division. Office of Military Government for Germany (US). P. 306-307.

42. Trials of war criminals before the Nuernberg military tribunals under Control Council Law No. 10. Volume I. Nuernberg. October 1946-April 1947. (The Medical Case) Washington, D.C.: U.S. Government Printing Office, 1949-1953.

43. Weindling P. From Clinic to Concentration Camp. Reassessing Nazi Medical and Racial Research, 1933-1945. 2017.

44. Benedek T.G. Case Neisser: Experimental Design, the Beginnings of Immunology, and Informed Consent // Perspectives in Biology and Medicine. V. 57. № 2. 2014. P. 249-267.

45. Vollmann J., Winau R. Informed consent in human experimentation before the Nuremberg code. // British Med. J. 1996. V. 313. P. 1445-1447.

46. Vollmann J., Winau R. The Prussian Regulation of 1900: Early Ethical Standards for Human Experimentation in Germany // Ethics and Human 
Research. 1996.V. 18. № 4. P. 9-11.

47. Силуянова И.В. «Нюрнбергский кодекс» и его значение для современной науки // Медицинская этика. 2014. Т. 2. № 1. С. 85-88.

Siluyanova I.V. «Nuremberg Code» and its significance for modern science // Medical Ethics. 2014. V. 2. № 1. P. 85-88 (in Russian).

48. Чучалин А.Г. Добровольное информированное согласие // Пульмонология. 2021. Т. 31. № 1. C. $116-120$.

Chuchalin A.G. Voluntary informed consent // Pulmonology. 2021. V. 31. № 1. P. 116-120 (in Russian).

49. Петрова Т.Н. Античеловечная медицина: запреты Нюрнберга // В сб.: Итоги Нюрнбергского процесса и вызовы современности. Материалы Международной научно-практической конференции / Под общ. ред. Бастрыкина А.И. 2016. С. 157-162.

Petrova T.N. Unhuman medicine: prohibitions of Nuremberg // In: Results of the Nuremberg trial and modern challenges. Materials of the International Scientific and Practical Conference / Ed. A.I. Bastrykin.
2016. P. 157-162 (in Russian).

50. Трубецкова Е.Г. «Записки врача» В. Вересаева в контексте этических проблем современной медицины // Изв. Сарат. ун-та. Нов. сер. Сер. Филология. Журналистика. 2020. Т. 20. № 2. С. 207-211. https://doi.org/10.18500/1817-7115-2020-20-2-207-211

Trubetskova E.G. Notes of a Doctor by V. Veresaev in the Context of Ethical Problems of Contemporary Medicine // Izv. Saratov Univ. (N.S.), Ser. Philology. Journalism. 2020. V. 20. № 2. P. 207-211 (in Russian).

51. Хельсинкская Декларация Всемирной Ассамблеи Врачей. Рекомендации для врачей, осуществляющихбиомедицинскиеисследования//Радиация и риск (Бюллетень Национального радиационноэпидемиологического регистра). 1997. № 10. C. $16-18$.

Helsinki Declaration of the World Assembly of Physicians. Recommendations for Physicians Carrying Out Biomedical Research // Radiation and Risk (Bulletin of the National Radiation Epidemiological Register). 1997. №. 10. P. 16-18 (in Russian).

Об авторе

Федеральное государственное бюджетное учреждение «27 Научный центр» Министерства обороны Российской Федерации, 105005, Российская Федерация, Москва, Бригадирский пер., д. 13.

Шило Наталья Игоревна. Научный сотрудник отдела.

\title{
Development and Human Testing of Chemical Warfare Agents and Means of Treatment of Lesions in Germany in 1933-1945
}

\author{
N.I. Shilo \\ Federal State Budgetary Establishment "27 Scientific Centre» of the Ministry of Defence \\ of the Russian Federation, Brigadirskii Lane 13, Moscow 105005, Russian Federation
}

Received 15 May 2021. Accepted for publication 20 June 2021

Despite serious attention to the issues of war crimes and crimes against humanity, committed on an unprecedented scale in concentration camps in Nazi Germany, the problem of medical experiments on prisoners appears to be one of the least-studied in modern Russian historiography. Moreover, no special attention was paid to testing chemical weapons on humans. The aim of this work is to review the history of the development and testing of chemical warfare agents (CWA) in Germany in 1933-1945. During the First World War, Germany was one of the leading countries in the sphere of military chemistry in the world. After the Versailles treaty this potential was largely lost as a result of the restrictions. After the National Socialist German Workers' Party (NSDAP) came to power, Germany not only restored, but also increased its military power and achieved a qualitative superiority over its opponents in the field of chemical weapons. The tests of CWA, as well as the study of the effectiveness of the means and protocols for the treatment of the lesions caused by CWA, were carried out both by the military structures of the Wehrmacht and the SS, and by civilian research and academic institutions. Experiments on prisoners were carried out in the concentration camps of Dachau, Ravensbrück, Auschwitz-Birkenau, Buchenwald, Sachsenhausen, Natzweiler-Struthof, Neuengamme, etc. Basically, the damaging effects of sulfur mustard and phosgene was investigated. In Auschwitz-Birkenau «a study of the action of 
various chemical preparations was carried out on the orders of German firms». After the war several SS doctors, who performed involuntary experiments on humans, were convicted by military tribunals for war crimes and crimes against humanity. Seven doctors were sentenced to death and executed on June 2, 1948, at the prison for war criminals in Landsberg, Bavaria. As a result of the Nuremberg trials, the Nuremberg Code was drawn up. It was the first international document that introduced ethical standards for scientists engaged in experiments on humans. It consisted of 10 principles, including the necessity of voluntary informed consent of the patient for the participation in medical experiments after providing him with full information about the nature, duration and purpose of the experiment; on the methods of its implementation; about all the perceived inconveniences and dangers associated with the experiment, and, finally, the possible consequences for the physical or mental health of the subject, which may arise as a result of his participation in the experiment.

Keywords: chemical warfare agents; war crimes; Second World War; Germany; testing; concentration camp; Nuremberg trial; crimes against humanity.

For citation: Shilo N.I. Development and Human Testing of Chemical Warfare Agents and Means of Treatment of Lesions in Germany in 1933-1945 // Journal of NBC Protection Corps. 2021. V. 5. № 2.

P. 173-198. https://doi.org/10.35825/2587-5728-2021-5-2-173-198

Conflict of interest statement

The author declares that the research was conducted in the absence of any commercial or financial relationship that could be construed as a potential conflict of interest.

Peer review information

The article has been peer reviewed by two experts in the respective field. Peer reviews are available from the Editorial Board and from Russian Science Citation Index database.

\section{References}

See P. 195-197.

Author

Federal State Budgetary Establishment «27 Scientific Centre» of the Ministry of Defence of the Russian Federation. Brigadirskii Lane 13, Moscow 105005, Russian Federation.

Natalya Igorevna Shilo. Researcher of the Centre.

Contact information:27nc_1@mil.ru 


\section{Анатолий Васильевич Шатохин (к 70-летию со дня рождения)}

22 августа 2021 г. исполняется 70 лет ветерану Вооруженных Сил, заместителю начальника войск радиационной, химической и биологической защиты ВС РФ генерал-лейтенанту в отставке Анатолию $\mathrm{Ba}$ сильевичу Шатохину.

Анатолий Васильевич родился в 1951 г. в г. Орджоникидзе (ныне г. Владикавказ) Республики Северная Осетия - Алания в семье рабочего. В 1968 г. окончил среднюю школу и в течение одного года работал наладчиком на электроламповом заводе. В 1969 г. поступил в Костромское высшее военное командное училище химической защиты, которое успешно окончил в 1972 г., в 1984 г. -

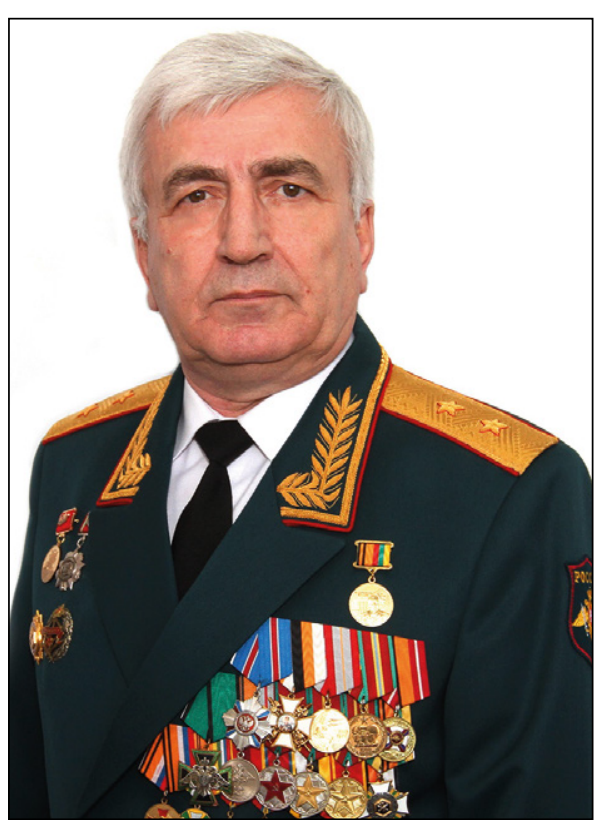

Генерал-лейтенант Анатолий Васильевич Шатохин ки и разведки Белорусского военного округа (19871989 гг.), начальника 282 учебного центра войск РХБ защиты (1989-1996 гг.), где осуществлялась подготовка прапорщиков, младших командиров и специалистов для комплектования войск РХБ защиты. Во время начального периода контртеррористической операции на Северном Кавказе Анатолий Васильевич в короткие сроки организовал подготовку огнеметных подразделений по типу маршевых рот, которые в дальнейшем умело и с честью выполняли возложенные на них задачи в условиях сложной боевой обстановки.

В 1996 г. Анатолий Васильевич возглавил Саракомандный факультет Военной академии химической защиты имени Маршала Советского Союза С.К. Тимошенко, высшие курсы Военной академии ГШ ВС РФ - в 2001 г.

Анатолий Васильевич имеет богатый войсковой опыт, который получил при прохождении военной службы в должностях: командира взвода, командира роты и начальника штаба батальона в составе бригады химической защиты Московского военного округа, г. Кинешма (1972-1980 гг.), командира отдельного огнеметного батальона Группы советских войск в Германии (1984-1987 гг.). Анатолий Васильевич стал одним из первых командиров отдельных огнеметных батальонов, вооруженных новыми реактивными пехотными огнеметами. В это время отрабатывались вопросы боевого применения перспективного огнеметно-зажигательного вооружения в огневом поражении противника, тактики огнеметных подразделений при ведении боевых действий в составе общевойсковых формирований и взаимодействия с ними в различных условиях обстановки. Накопленный боевой опыт нашел реализацию в руководящих боевых документах не только химических войск, но и документах видов и родов войск ВС СССР.

Дальнейший ратный труд А.В. Шатохина проходил в должностях командира полка засеч- товское высшее военное инженерное училище химической защиты, которое в 1998 г. было преобразовано в военный институт РХБ защиты (1996-1999 гг.), где успешно руководил деятельностью коллектива, на высоком уровне организовывал подготовку офицерских кадров для комплектования штатов воинских частей на объектах по хранению и уничтожению химического оружия.

В 1999 г. генерал-майор А.В. Шатохин был назначен заместителем начальника Военного университета РХБ защиты, в котором успешно проходил службу до 2004 г. (1999-2004 гг.), а с 2004 г. - заместителем начальника войск РХБ защиты ВС РФ (2004-2006 гг.).

Таким образом, за время своей службы Анатолий Васильевич прошел в войсках РХБ защиты практически все командные должности.

Управляя большими воинскими коллективами, Анатолий Васильевич зарекомендовал себя как умелый организатор, воспитатель и профессионал своего дела.

С 2006 г., после увольнения в запас, в течение 10 лет работал советником Начальника Федерального управления по безопасному хранению и уничтожению химического оружия и исполнял обязанности представителя заказчика при строительстве объектов по уничтожению химического оружия, расположенных в 


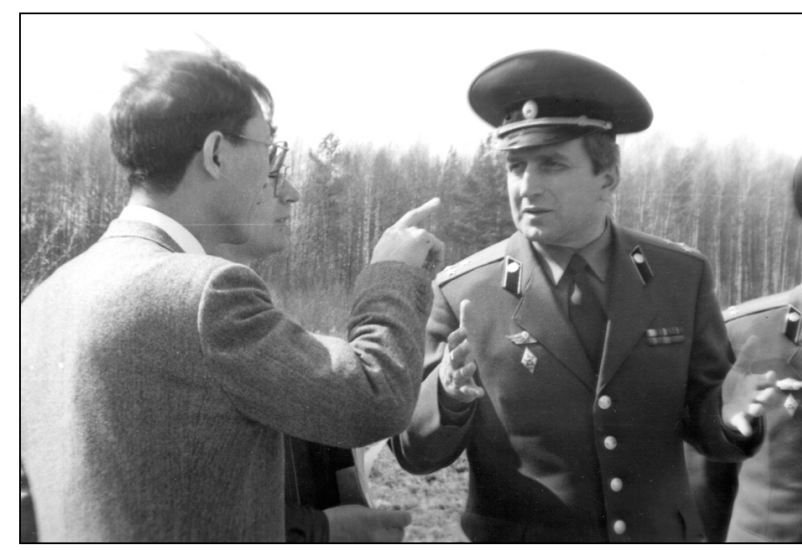

Полковник А.В. Шатохин работает с делегачией японских военных

г. Почеп Брянской области и пос. Кизнер Удмуртской Республики, где в полном объеме использовал накопленный богатый опыт службы в рядах Вооруженных Сил.

Кандидат технических наук, доцент. Направление научных исследований кандидатской диссертации связано с разработкой методики подготовки международных инспекторов по контролю за уничтожением химического оружия.

С 2018 г. является сотрудником «27 Научного центра» МО РФ. В составе группы научных сотрудников Анатолий Васильевич продолжает активную работу по обоснованию направлений развития огнеметно-зажигательного вооружения и военно-научному сопровождению ОКР, выполняемых предприятиями оборонно-промышленного комплекса в интересах войск РХБ защиты ВС РФ.

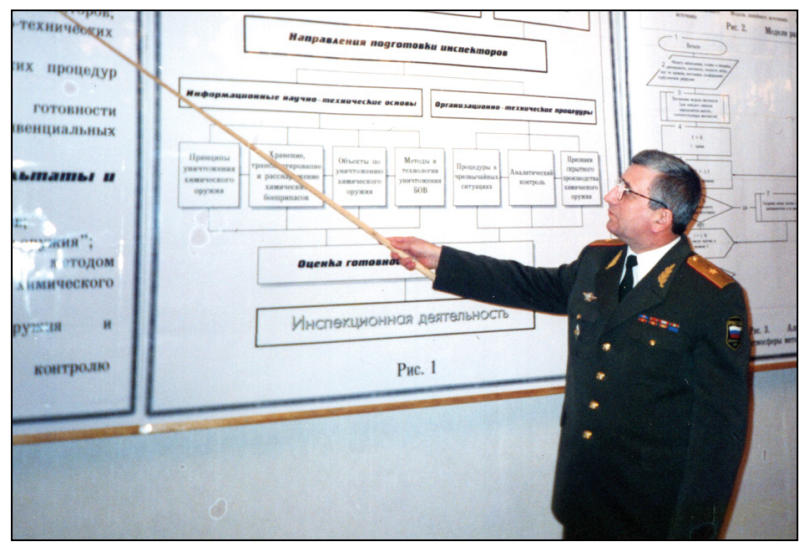

\section{Генерал-майор А.В. Шатохин защищает кандидатскую диссертацию}

Награжден орденом «За военные заслуги», медалью «За отличие в воинской службе» I степени; именным оружием и медалями различных министерств и ведомств. Занесен в Книгу Славы войск РХБ защиты.

Анатолия Васильевича характеризует доброжелательность, отзывчивость, порядочность, личная скромность, тактичность и доступность, открытость, глубокая вдумчивость при принятии решений, высокая работоспособность.

Командование войск РХБ защичты, коллектив "27 Научного иентра» $и$ «Федерального управления по безопасному хранению $и$ уничтожению химического оружия», друзья, товарищи и коллеги поздравляют Анатолия Васильевича Шатохина с 70-летием со дня рождения ижелают емудоброго здоровья, счастья и успехов. 


\section{Наша замeyatenbhag Россня}

\section{Соловецкая обитель в Белом море}
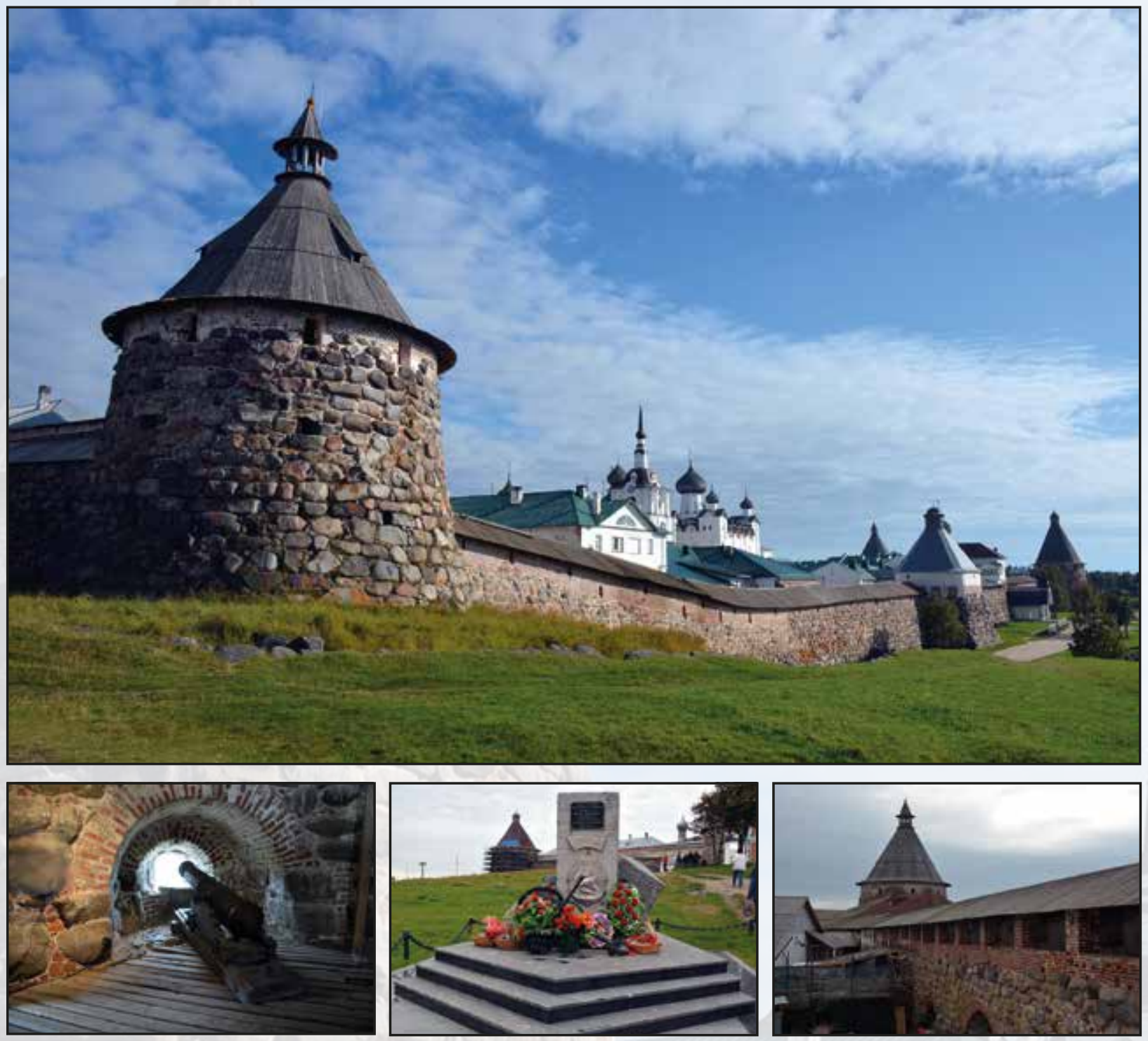

Спасо-Преображенский Соловецкий монастырь - ставропигиальный мужской монастырь Русской православной церкви, расположен в посёлке Соловецком Приморского района Архангельской области на Большом Соловецком острове в Белом море. Здесь, в 1436 г., отшельники Герман и Зрсима возвели первую деревянную церковь, положив начало Соловецкий обители. Через полтора столетия монастырь окружили стеной в виде неправильного пятиугольника, построенной из гранитных глыб и дикого булыжника. В стене было 7 ворот, в амбразурах восьми громадных башен стояли пушки. Оценить масштаб этой работы можно только побывав на Соловках. К концу XVI в. монастырь был не только мощной крепостью на Севере, венчавшей систему укреплений нашей Родины, но также кормильцем и просветителем северных земель русского государства. В монастыре процветали ремёсла: он владел солеварнями, кузницами; монахи и послушники ловили и разводили рыбу, добывали зверя, выращивали овощи, печатали духовные книги, имелась обширная библиотека, а к XX в. появилась и собственная гидроэлектростанция. В XVI-XVII в. монастырь выдержал несколько нападений шведов (в 1571, 1582 и 1611). В 1854 г. монастырь в течение 9 часов обстреливался английскими фрегатами «Бриск» И «Миранда». Когда рассеялся пушечный дым, британцы с удивлением обнаружили, что монастырь не пострадал. Монастырь и его братия много пережили за свою историю. В 1920 г. монастырь был ликвидирован. Монашеская жизнь возобновлена 25.10.1990 г.

На верхней фотографии вид монастыря со стороны Корожной башни, далее идут Успенская и Прядильная башни. На левой фотографии нижнего ряда - амбразура одной из башен, обратите внимание на толщину стен; в центре - памятник воспитанникам Соловецкого отряд и школы юнгов, погибших в годы ВОВ; справа двухярусная галерея крепостной стены, примыкающая к Прядильной башне. 


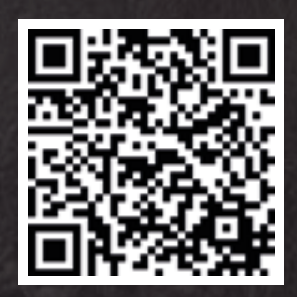

Сайт журнала
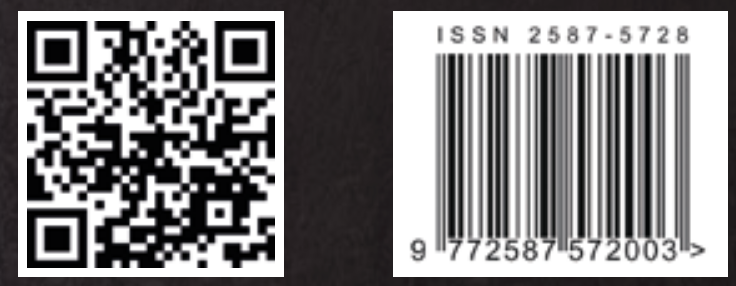

РИНЦ 